NATIONAL LABORATORY

MANAGED BY UT-BATTELLE

FOR THE DEPARTMENT OF ENERGY

\title{
Application of the SCALE TSUNAMI Tools for the Validation of Criticality Safety Calculations Involving ${ }^{233} \mathrm{U}$
}

\author{
January 2009
}

Prepared by

D. E. Mueller

B. T. Rearden

D. F. Hollenbach

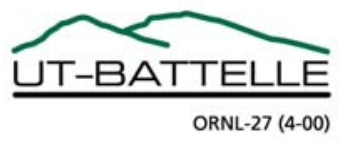




\title{
DOCUMENT AVAILABILITY
}

Reports produced after January 1, 1996, are generally available free via the U.S. Department of Energy (DOE) Information Bridge.

Web site http://www.osti.gov/bridge

Reports produced before January 1, 1996, may be purchased by members of the public from the following source.

\author{
National Technical Information Service \\ 5285 Port Royal Road \\ Springfield, VA 22161 \\ Telephone 703-605-6000 (1-800-553-6847) \\ TDD 703-487-4639 \\ Fax 703-605-6900 \\ E-mail info@ntis.gov \\ Web site http://www.ntis.gov/support/ordernowabout.htm
}

Reports are available to DOE employees, DOE contractors, Energy Technology Data Exchange (ETDE) representatives, and International Nuclear Information System (INIS) representatives from the following source.

Office of Scientific and Technical Information

P.O. Box 62

Oak Ridge, TN 37831

Telephone 865-576-8401

Fax 865-576-5728

E-mail reports@osti.gov

Web site http://www.osti.gov/contact.html

This report was prepared as an account of work sponsored by an agency of the United States Government. Neither the United States Government nor any agency thereof, nor any of their employees, makes any warranty, express or implied, or assumes any legal liability or responsibility for the accuracy, completeness, or usefulness of any information, apparatus, product, or process disclosed, or represents that its use would not infringe privately owned rights. Reference herein to any specific commercial product, process, or service by trade name, trademark, manufacturer, or otherwise, does not necessarily constitute or imply its endorsement, recommendation, or favoring by the United States Government or any agency thereof. The views and opinions of authors expressed herein do not necessarily state or reflect those of the United States Government or any agency thereof. 
Nuclear Science and Technology Division

\title{
APPLICATION OF THE SCALE TSUNAMI TOOLS FOR THE VALIDATION OF CRITICALITY SAFETY CALCULATIONS INVOLVING ${ }^{233} \mathrm{U}$
}

\author{
D. E. Mueller \\ B. T. Rearden \\ D. F. Hollenbach
}

Date Published: January 2009

\author{
Prepared by \\ OAK RIDGE NATIONAL LABORATORY \\ P.O. Box 2008 \\ Oak Ridge, Tennessee 37831-6285 \\ managed by \\ UT-BATTELLE, LLC \\ for the \\ U.S. DEPARTMENT OF ENERGY \\ under contract DE-AC05-00OR22725
}





\section{CONTENTS}

Page

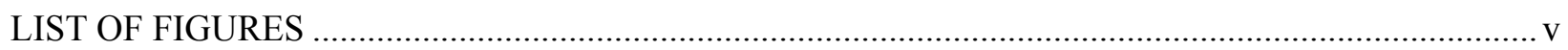

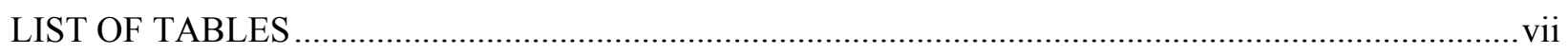

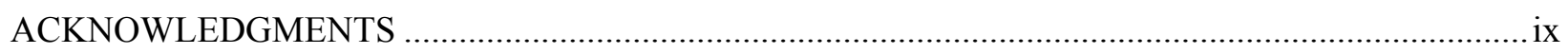

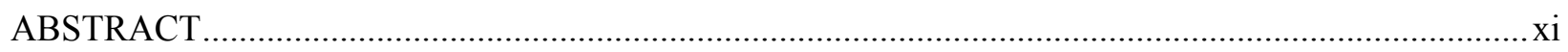

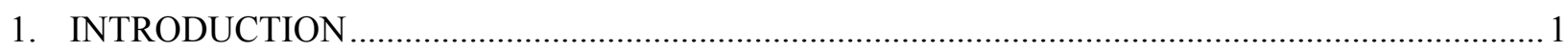

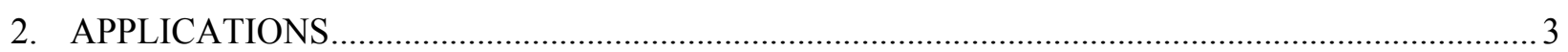

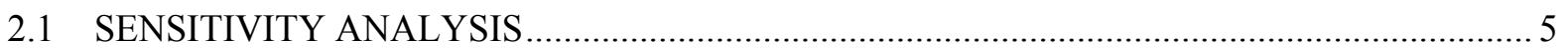

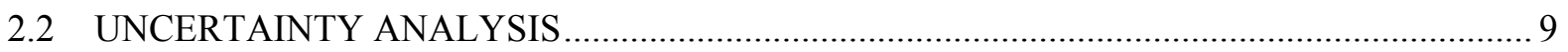

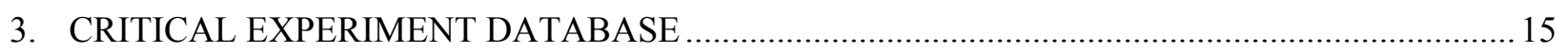

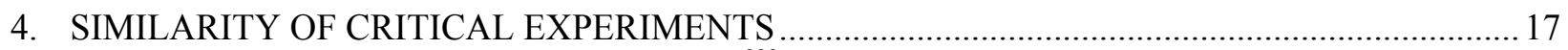

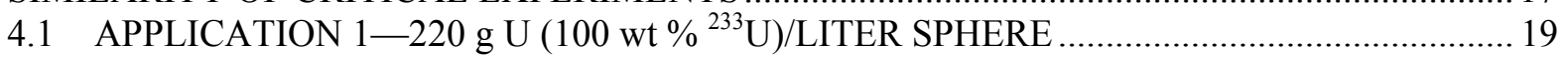

4.2 APPLICATION 2-300 g U (WITH CEUSP U ISOTOPICS)/LITER SPHERE ...................... 25

4.3 APPLICATION 3-600 g U (DOWNBLENDED U ISOTOPICS)/LITER SPHERE ................ 30

4.4 APPLICATION 4-STORAGE ARRAY, CEUSP CONTAINERS ........................................ 34

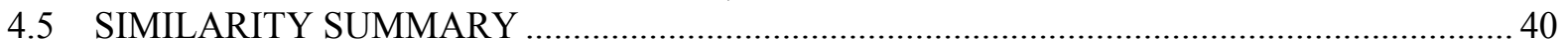

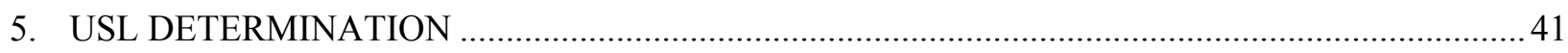

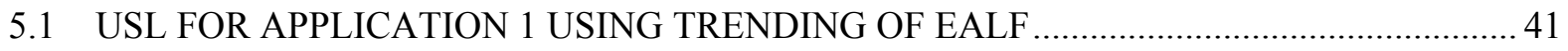

5.2 USL FOR APPLICATION 1 USING TRENDING OF THE $\mathrm{c}_{\mathrm{r}}$ SIMILARITY

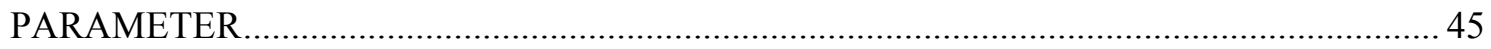

5.3 USL FOR APPLICATIONS 1-4 USING TSURFER DATA ADJUSTMENT

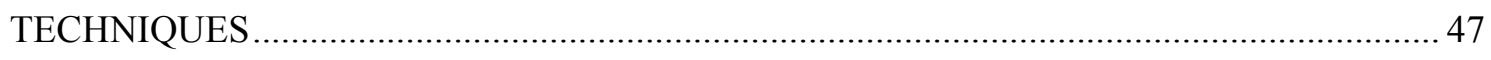

6. ADDRESSING VALIDATION WEAKNESSES AND GAPS …................................................. 53

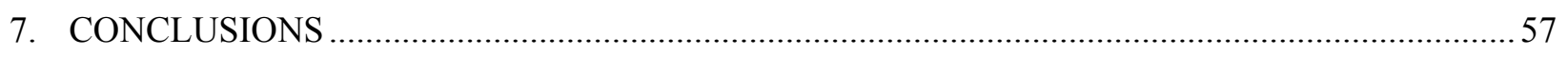

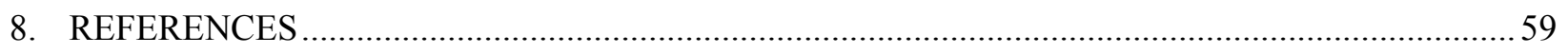

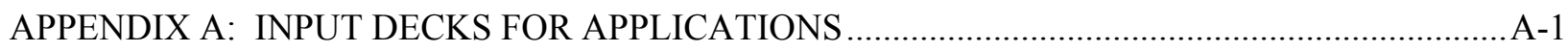

APPENDIX B: LIST OF CRITICAL EXPERIMENTS .................................................................. B-1

APPENDIX C: INPUT FILE FOR TSUNAMI-IP CALCULATION FOR APPLICATION 1 .............. C-1

APPENDIX D: SIMILARITY LISTING FOR APPLICATIONS 1 THROUGH 4 ..............................D-1

APPENDIX E: EXAMPLE USLSTATS INPUT FILE FOR APPLICATION 1, CASE 4.................... E-1 



\section{LIST OF FIGURES}

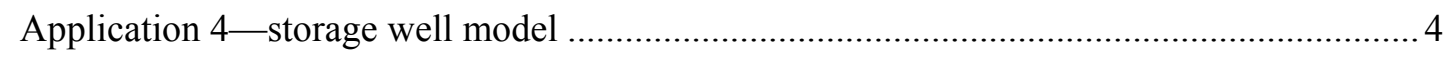

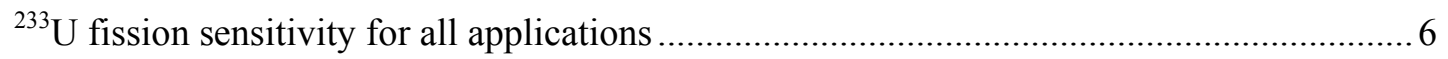

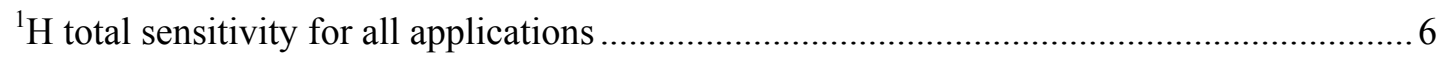

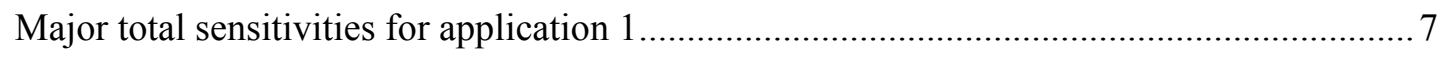

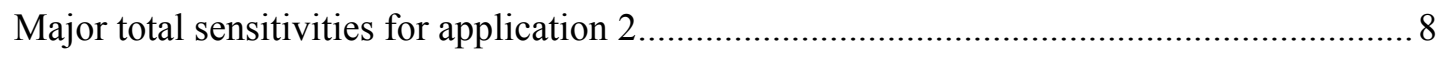

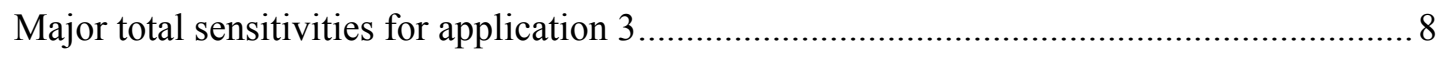

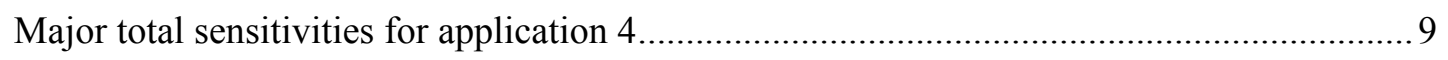

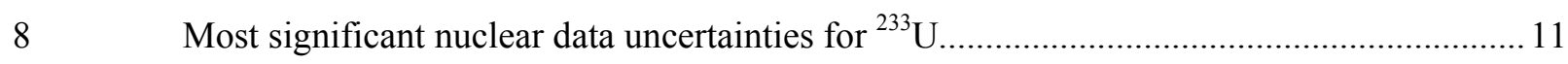

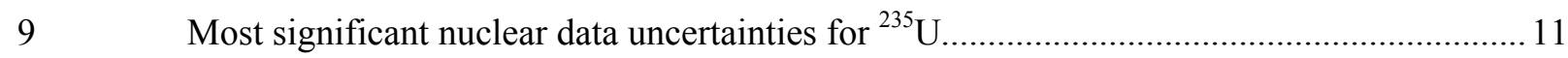

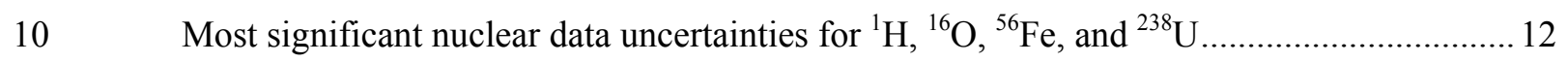

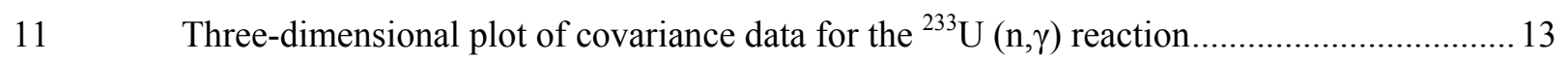

12 Application 1 similarity index values $\left(\mathrm{c}_{\mathrm{r}}\right)$ for 672 critical experiments .............................20

$13 \quad{ }^{1} \mathrm{H}$ elastic scattering sensitivity profiles for application 1 and experiments

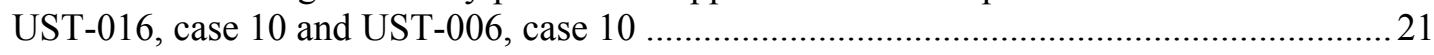

$14{ }^{16} \mathrm{O}$ elastic scattering sensitivity profiles for application 1 and experiments

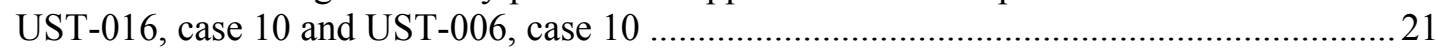

$15 \quad{ }^{233} \mathrm{U}(\mathrm{n}, \gamma)$ reaction sensitivity profiles for application 1 and experiments

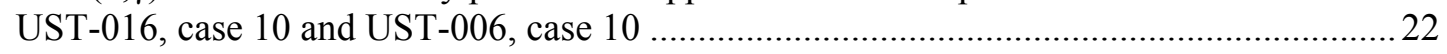

$16 \quad{ }^{233} \mathrm{U}$ Nu-bar sensitivity profiles for application 1 and experiments UST-016, case 10 and UST-006, case 10

$17 \quad{ }^{233} \mathrm{U}$ fission reaction sensitivity profiles for application 1 and experiments

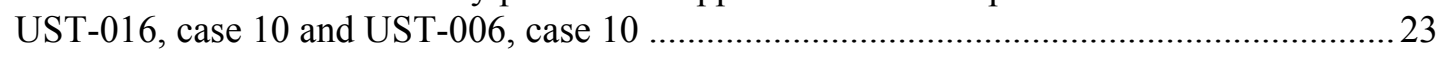

18 Application 2 similarity index values $\left(\mathrm{c}_{\mathrm{r}}\right)$ for 672 critical experiments ............................225

$19 \quad{ }^{1} \mathrm{H}$ elastic scattering reaction sensitivity profiles for application 2 and

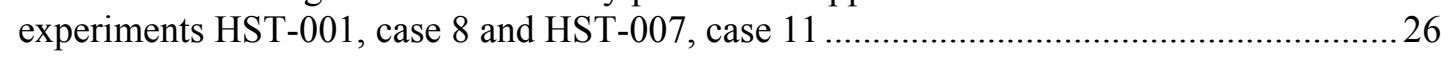

$20 \quad{ }^{235} \mathrm{U}$ Nu-bar sensitivity profiles for application 2 and experiments HST-001, case 8 and HST-007, case 11

$21 \quad{ }^{235} \mathrm{U}(\mathrm{n}, \gamma)$ reaction sensitivity profiles for application 2 and experiments HST-001, case 8 and HST-007, case 11

$22 \quad{ }^{16} \mathrm{O}$ elastic scattering reaction sensitivity profiles for application 2 and experiments HST-001, case 8 and HST-007, case 11

$23 \quad{ }^{235} \mathrm{U}$ fission reaction sensitivity profiles for application 2 and experiments

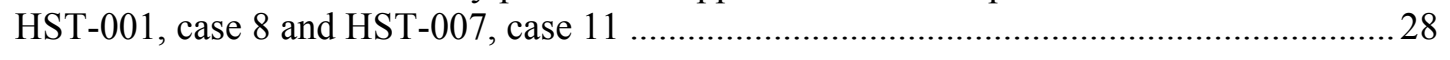

24. Application 3 similarity index values $\left(\mathrm{c}_{\mathrm{r}}\right)$ for 672 critical experiments .............................30

$25{ }^{14} \mathrm{~N}(\mathrm{n}, \mathrm{p})$ reaction sensitivity profiles for application 3 and experiment LST-005, case $1 \ldots . .31$ 


\section{LIST OF FIGURES (continued)}

Figure

Page

$26 \quad{ }^{238} \mathrm{U}(\mathrm{n}, \gamma)$ reaction sensitivity profiles for application 3 and experiment LST-005, case $1 \ldots . .32$

${ }^{233} \mathrm{U}$ fission reaction sensitivity profile for application 3

${ }^{1} \mathrm{H}(\mathrm{n}, \gamma)$ reaction sensitivity profiles for application 3 and experiment LST-005, case $1 \ldots . . .33$

${ }^{233} \mathrm{U}$ Nu-bar sensitivity profile for application 3

${ }^{56} \mathrm{Fe}(\mathrm{n}, \gamma)$ and ${ }^{56} \mathrm{Fe}$ elastic scattering reaction sensitivity profiles for application 4

$\mathrm{Ca}(\mathrm{n}, \gamma)$ reaction sensitivity profile for application 4 and experiment HST-007, case 13

$33 \quad{ }^{235} \mathrm{U}(\mathrm{n}, \gamma)$ reaction sensitivity profile for application 4 and experiment HST-007, case 13

${ }^{235} \mathrm{U}$ fission reaction sensitivity profile for application 4 and experiment HST-007, case 13

${ }^{235} \mathrm{U}$ Nu-bar sensitivity profile for application 4 and experiment HST-007, case 13

USLSTATS plot for EALF trending of all experiments

USLSTATS plot for EALF trending of experiments with $\mathrm{c}_{\mathrm{r}} \geq 0.8$

USLSTATS plot for EALF trending of experiments with $c_{r} \geq 0.9$

USLSTATS plot for EALF trending of experiments with $c_{r} \geq 0.95$ 


\section{LIST OF TABLES}

Table

Page

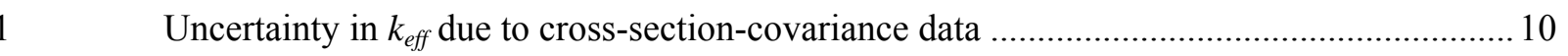

2 Summary of IHECSBE critical configurations considered in initial screening ................... 16

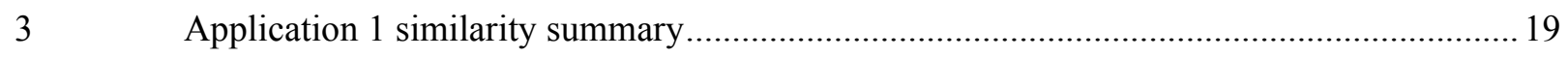

4 Top contributors to similarity $\left(\mathrm{c}_{\mathrm{r}}\right)$ for application 1 compared to itself .............................23

5 Top contributors to similarity $\left(c_{r}\right)$ for application 1 compared to UST-016, case $10 \ldots \ldots \ldots . . .24$

6 Top contributors to similarity $\left(c_{r}\right)$ for application 1 compared to UST-006, case $10 \ldots \ldots \ldots . . .24$

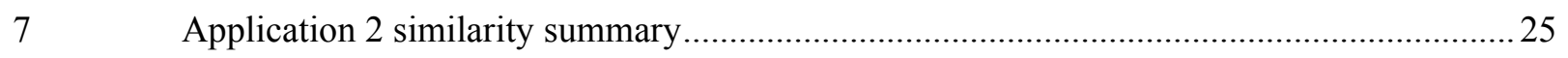

8 Top contributors to similarity $\left(\mathrm{c}_{\mathrm{r}}\right)$ for application 2 compared to itself .............................29

9 Top contributors to similarity $\left(c_{r}\right)$ for application 2 compared to experiment

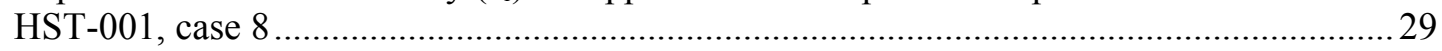

10 Top contributors to similarity $\left(\mathrm{c}_{\mathrm{r}}\right)$ for application 2 compared to experiment

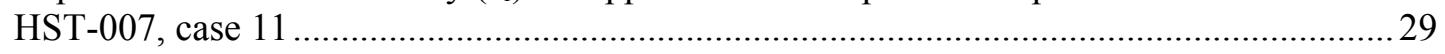

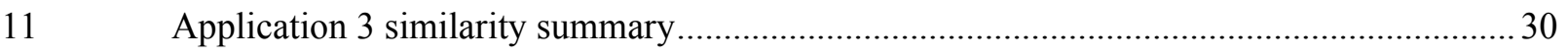

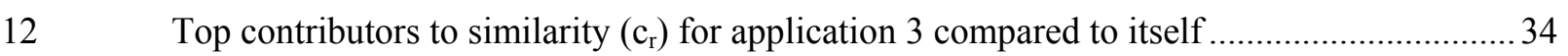

13 Top contributors to similarity $\left(\mathrm{c}_{\mathrm{r}}\right)$ for application 3 compared to experiment

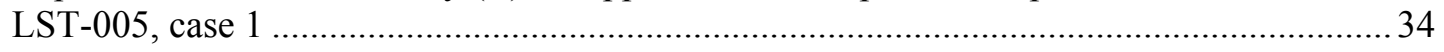

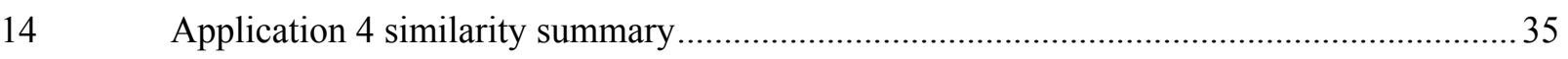

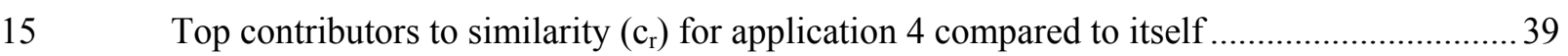

16 Top contributors to similarity $\left(\mathrm{c}_{\mathrm{r}}\right)$ for application 4 compared to experiment

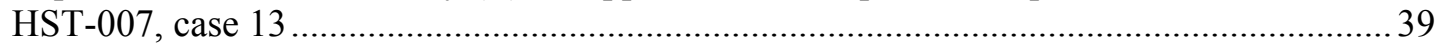

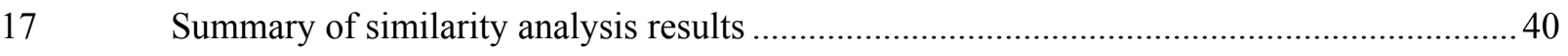

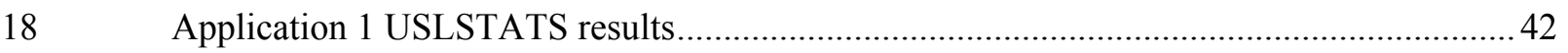

19 Bias, bias uncertainty, and USL values computed with TSURFER ................................... 48

20 Top contributors to TSURFER-determined bias for application 1 ..................................... 49

21 TSURFER bias uncertainty due to cross-section-covariance data ......................................51 



\section{ACKNOWLEDGMENTS}

The authors wish to acknowledge the assistance provided by Kevin Kimball of NYSIS and Karla Elam of ISOTEK in the preparation of this report. Their contributions of the application models and feedback on the report content were greatly appreciated. The authors also wish to acknowledge the assistance provided by Debbie Weaver in the preparation of the report and for the careful reviews of Matt Jessee and Davis Reed. 



\begin{abstract}
The Radiochemical Development Facility at Oak Ridge National Laboratory has been storing solid materials containing ${ }^{233} \mathrm{U}$ for decades. Preparations are under way to process these materials into a form that is inherently safe from a nuclear criticality safety perspective. This will be accomplished by downblending the ${ }^{233} \mathrm{U}$ materials with depleted or natural uranium. At the request of the U.S. Department of Energy, a study has been performed using the SCALE sensitivity and uncertainty analysis tools to demonstrate how these tools could be used to validate nuclear criticality safety calculations of selected process and storage configurations. ISOTEK nuclear criticality safety staff provided four models that are representative of the criticality safety calculations for which validation will be needed. The SCALE TSUNAMI-1D and TSUNAMI-3D sequences were used to generate energy-dependent $k_{\text {eff }}$ sensitivity profiles for each nuclide and reaction present in the four safety analysis models, also referred to as the applications, and in a large set of critical experiments. The SCALE TSUNAMI-IP module was used together with the sensitivity profiles and the cross-section uncertainty data contained in the SCALE covariance data files to propagate the cross-section uncertainties $(\Delta \sigma / \sigma)$ to $k_{\text {eff }}$ uncertainties $(\Delta k / k)$ for each application model. The SCALE TSUNAMI-IP module was also used to evaluate the similarity of each of the 672 critical experiments with each application. Results of the uncertainty analysis and similarity assessment are presented in this report. A total of 142 experiments were judged to be similar to application 1, and 68 experiments were judged to be similar to application 2. None of the 672 experiments were judged to be adequately similar to applications 3 and 4 . Discussion of the uncertainty analysis and similarity assessment is provided for each of the four applications. Example upper subcritical limits (USLs) were generated for application 1 based on trending of the energy of average lethargy of neutrons causing fission, trending of the TSUNAMI similarity parameters, and use of data adjustment techniques.
\end{abstract}





\section{INTRODUCTION}

Sensitivity/uncertainty analyses have been performed using the SCALE 5.1 TSUNAMI tools on a set of four typical safety analysis models provided by ISOTEK Nuclear Criticality Safety (NCS) staff. Where appropriate, upper subcritical limits (USLs) have been produced. The goal of this report is to describe the analysis performed and to provide guidance that ISOTEK NCS staff could use in validation studies to support criticality safety analyses.

Validation is performed to establish the relationship between calculated $k_{\text {eff }}$ values and the actual system neutron multiplication factors. Validation analysis typically involves modeling of critical experiments that are similar to one or more safety analysis cases, referred to in this report as applications. Statistical analysis of the results is performed to generate bias and bias uncertainty values that can be used in developing safety limits.

It is important that the critical experiments used for validation are similar to the applications. A significant part of the computational bias is attributed to errors in nuclear data or in how the nuclear data are used. In a conventional bias determination analysis, the true bias of an application can be produced from critical experiments only if the experiments and application use the same nuclear data and the critical experiment and application $k_{\text {eff }}$ values are affected by the nuclear data errors in the same way. Of course, perfect matches between applications and experiments are rarely achieved.

Historically, the determination of similarity has been largely qualitative in nature; criteria such as the presence of the same fissionable nuclides, moderating, and absorbing materials were frequently used. In some cases, similarity determination has relied upon comparison of one or more system characteristic parameters, such as the hydrogen-to-fissile atom ratio $(\mathrm{H} / \mathrm{X})$ or the Energy of Average Lethargy of neutrons causing Fission (EALF). The level of similarity of critical experiments with the safety applications has varied significantly, depending on who performed the determination and on the availability of suitable critical experiments.

The SCALE TSUNAMI sensitivity/uncertainty analysis tools permit detailed energy-, nuclide-, and reaction-dependent comparison of critical experiments with safety applications. The TSUNAMI-1D ${ }^{1}$ and TSUNAMI-3D ${ }^{2}$ sensitivity analysis tools are described in the SCALE manual Sections C8 and C9, respectively. The TSUNAMI-IP module, described in SCALE manual Section M18, uses the sensitivity data to quantify the similarity of experiments to safety applications based on sensitivity/uncertainty criteria. The sensitivity data were coupled with the uncertainty in the cross-section data to produce an uncertainty in $k_{\text {eff }}$ due to uncertainties in the basic nuclear data. As cross-section data are believed to be the primary cause of computational biases, a benchmark experiment with uncertainties in $k_{\text {eff }}$ that are highly correlated to the uncertainties in the design system will provide a good indication of the expected computational bias. TSUNAMI-IP ${ }^{3}$ processes the sensitivity data and cross-section-covariance data and produces a correlation coefficient, denoted $c_{k}$, that provides an indication of the similarity of a given benchmark experiment to a design system in terms of the correlations in the uncertainties between the two systems. This correlation coefficient is normalized such that a $c_{k}$ value of 1.0 indicates that the two systems are identical. The $c_{k}$ correlation coefficient is a global integral index in that it produces a single value from information about all nuclides and all reactions of both systems on an energy-dependent basis. Thus, the computed value of $c_{k}$ provides an indication of the overall similarity of two systems.

In general, a critical experiment is considered to be adequately similar to an application if the $c_{k}$ value is 0.90 or higher. Such experiments are said to be "applicable" to the validation of the 
safety basis model calculation. Experiments with a $c_{k}$ value of 0.8 or higher are said to be "marginally similar" or are "marginally applicable." A $c_{k}$ value of 0.8 means that the application and experiment share about $80 \%$ of the reactivity uncertainties associated with nuclear data uncertainties. Experiments with $c_{k}$ values below 0.8 are considered "not applicable" to the validation of the application. A low $c_{k}$ value means that there are many differences between the application and the compared experiment.

Calculations for the application models and the ${ }^{233} \mathrm{U}$ critical experiments used in this study were performed using SCALE 5.1 and a 238-neutron-energy-group ENDV/B-VI nuclear data library augmented with updated ${ }^{233} \mathrm{U}$ data $(\mathrm{ENDF} / \mathrm{B}-\mathrm{VII})$. Updated ${ }^{233} \mathrm{U}$ pointwise data was also used for the CENTRM/CENTRMST unit cell calculations. The analysis also utilized some additional sensitivity data files generated for non ${ }^{233} \mathrm{U}$ critical experiments. These sensitivity data files had been previously generated using either the 238-neutron-energy-group ENDF/B-V or ENDF/B-VI nuclear data library and either NITAWLST or CENTRMST for unit cell calculations. In general, the use of differing codes and nuclear data libraries is not acceptable for bias determination purposes. Such data was included in this analysis to assist in identifying additional critical experiments that are similar to the applications and for use in illustrative analysis examples. Sensitivity calculations were performed using TSUNAMI-1D or TSUNAMI-3D. The similarity assessment was performed using the TSUNAMI-IP module and the 44-group ENDF/B-VI recommended covariance data set augmented with pre-release ENDF/B-VII covariance data for the ${ }^{233} \mathrm{U}$ reactions.

The work discussed in this report involved identifying critical experiments that may be similar to the applications, performing sensitivity analysis of the applications and critical experiments using TSUNAMI-1D or TSUNAMI-3D, comparing the critical experiments with the applications using TSUNAMI-IP, using the comparison results to identify which critical experiments are similar to each application, and calculation of upper subcritical limits. The sections following this one describe the applications, the selection of the candidate critical configurations, the quantitative similarity assessment, USL determination, and some suggestions for handling applications that do not have an adequate set of similar critical experiments. Appendix A includes the TSUNAMI-3D input listings for the four application models. Appendix B contains a listing of the critical experiments considered. Appendix $\mathrm{C}$ is the TSUNAMI-IP input file for application 1.

Appendix D is a list of critical experiments sorted by decreasing similarity for each application. Appendix E contains the USLSTATS input deck used to calculate one of the USLs for application 1 . 


\section{APPLICATIONS}

Similarity was assessed for four applications provided by ISOTEK staff. Input decks are provided in Appendix A for each application. The remainder of this section is a summary of each application.

Application 1 is a 12.2 -cm-radius sphere of $220 \mathrm{~g} \mathrm{U}$ per liter uranyl nitrate solution with no excess acid. The uranium is $100 \mathrm{wt} \%{ }^{233} \mathrm{U}$. The solution sphere is reflected by $0.25 \mathrm{~cm}$ of Type 304 stainless steel (ss-304) and $2 \mathrm{~cm}$ of water. The EALF calculated for this application was $0.282 \mathrm{eV}$. The $k_{\text {eff }}$ calculated for this system is $1.0028 \pm 0.0002$.

Application 2 is a 14.0-cm-radius sphere of $220 \mathrm{~g} \mathrm{U}$ per liter uranyl nitrate solution with no excess acid. The uranium is from the Consolidated Edison Uranium Solidification Project (CEUSP). ${ }^{4}$ This project converted liquid waste containing uranium enriched in ${ }^{233} \mathrm{U}$ and ${ }^{235} \mathrm{U}$ into a solid form. The CEUSP isotopics are $9.7 \mathrm{wt} \%{ }^{233} \mathrm{U}, 1.4 \mathrm{wt} \%{ }^{234} \mathrm{U}, 76.5 \mathrm{wt} \%{ }^{235} \mathrm{U}, 5.6 \mathrm{wt} \%$

${ }^{236} \mathrm{U}$, and $6.8 \mathrm{wt} \%{ }^{238} \mathrm{U}$. The solution sphere is reflected by $0.25 \mathrm{~cm}$ of ss-304 and $2 \mathrm{~cm}$ of water. The EALF calculated for this application was $0.121 \mathrm{eV}$. The $k_{\text {eff }}$ calculated for this system is $0.9889 \pm 0.0002$.

Application 3 is a 53.0-cm-radius sphere of $600 \mathrm{~g} \mathrm{U}$ per liter uranyl nitrate solution with no excess acid. The solution temperature is $80{ }^{\circ} \mathrm{C}(353 \mathrm{~K})$. The uranium is $3 \mathrm{wt} \%{ }^{233} \mathrm{U}, 0.2 \mathrm{wt} \%$ ${ }^{235} \mathrm{U}$, and $96.8 \mathrm{wt} \%{ }^{238} \mathrm{U}$. The fissile solution sphere is reflected by $0.25 \mathrm{~cm}$ of ss-304 and $2.0 \mathrm{~cm}$ of water. The EALF calculated for this application was $0.0631 \mathrm{eV}$. The $k_{\text {eff }}$ calculated for this system is $0.9690 \pm 0.0002$.

Application 4 is a storage array loaded with uranium mixed with hydrogen ( $\mathrm{H} / \mathrm{U} 0.21)$, oxygen $(\mathrm{O} / \mathrm{U} 3.1)$, and carbon $(\mathrm{C} / \mathrm{U} 4.7)$. The uranium is $9.7 \mathrm{wt} \%{ }^{233} \mathrm{U}, 1.4 \mathrm{wt} \%{ }^{234} \mathrm{U}, 76.5 \mathrm{wt} \%{ }^{235} \mathrm{U}$, $5.6 \mathrm{wt} \%{ }^{236} \mathrm{U}$, and $6.8 \mathrm{wt} \%{ }^{238} \mathrm{U}$. The array is moderated by concrete and steel and reflected by concrete. Figure 1 shows some of the detail from the application 4 model. The EALF calculated for this application was $2.63 \mathrm{eV}$. The $k_{\text {eff }}$ calculated for this system is $0.751 \pm 0.0001$. 


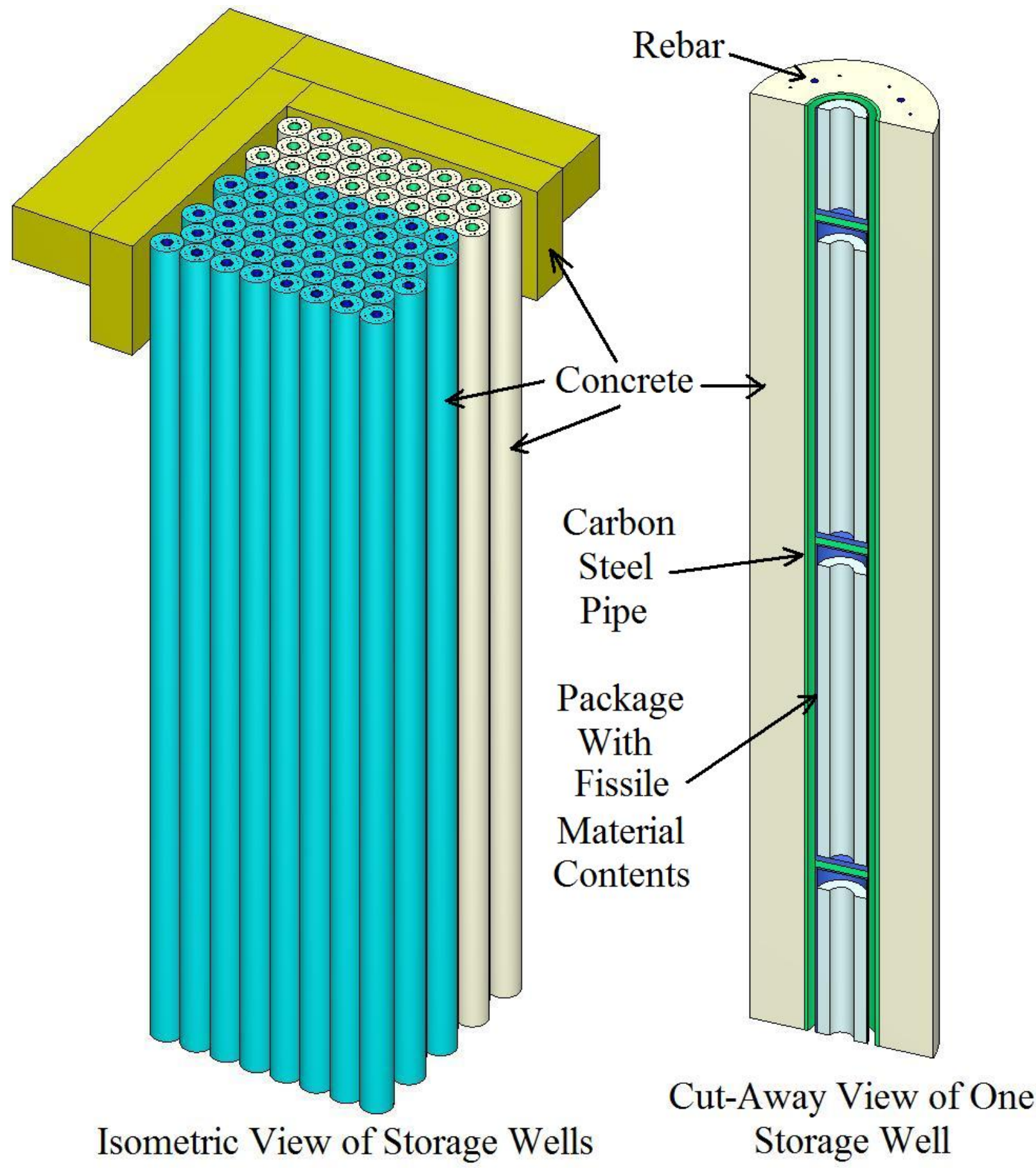

Fig. 1. Application 4-storage well model. 


\subsection{SENSITIVITY ANALYSIS}

As used in this report, sensitivity is a prediction of how a change in nuclear data would affect the system multiplication factor, $k_{\text {eff. }}$ The particular implementation in the TSUNAMI tools is that sensitivity is the fractional change in $k_{\text {eff }}$ caused by a fractional change in the nuclear data. A sensitivity of -0.1 means that a $1 \%$ increase in the nuclear data will cause a $0.1 \%$ reduction in $k_{\text {eff }}$.

Sensitivity is calculated by the TSUNAMI-1D and TSUNAMI-3D sequences using the first-order linear perturbation theory method as described in the SCALE manual sections for these sequences. The results are energy-, nuclide-, and reaction-dependent sensitivity profiles. The data are saved in sensitivity data files that usually end with a ".sdf" suffix.

Correct use of the TSUNAMI-3D sequence to obtain sensitivity data can be difficult. Thus it is very important to verify the results by checking that the forward and adjoint $k_{\text {eff }}$ values are close, ideally only a few tenths of a percent $\Delta k$ apart, and by performing direct perturbation calculations.

Direct perturbation calculations involve performing additional criticality calculations in which the number density of a key nuclide is changed some small amount. The resulting $k_{\text {eff }}$ values are then used to manually calculate a total sensitivity coefficient to be compared with the total sensitivity coefficient generated by TSUNAMI-1D or TSUNAMI-3D. The TSUNAMI and direct perturbation results should be within 1 or 2 standard deviations of each other. Direct perturbation calculations were performed for the applications and for representative critical experiment models to ensure that the TSUNAMI calculation approach was appropriate for the applications and experiments.

The names of the sensitivity data files for the critical experiments are listed in the TSUNAMI-IP input file in Appendix C.

Figures 2-7 provide sensitivity profiles for the four applications in the SCALE 238-group energy

structure. Figure 2 shows the sensitivity of $k_{\text {eff }}$ to changes in the ${ }^{233} \mathrm{U}$ fission cross-section data for each application. Figure 3 shows the sensitivity of $k_{\text {eff }}$ to the ${ }^{1} \mathrm{H}$ total cross section for each application. Note that the total cross section includes contributions from capture and scattering reactions. 


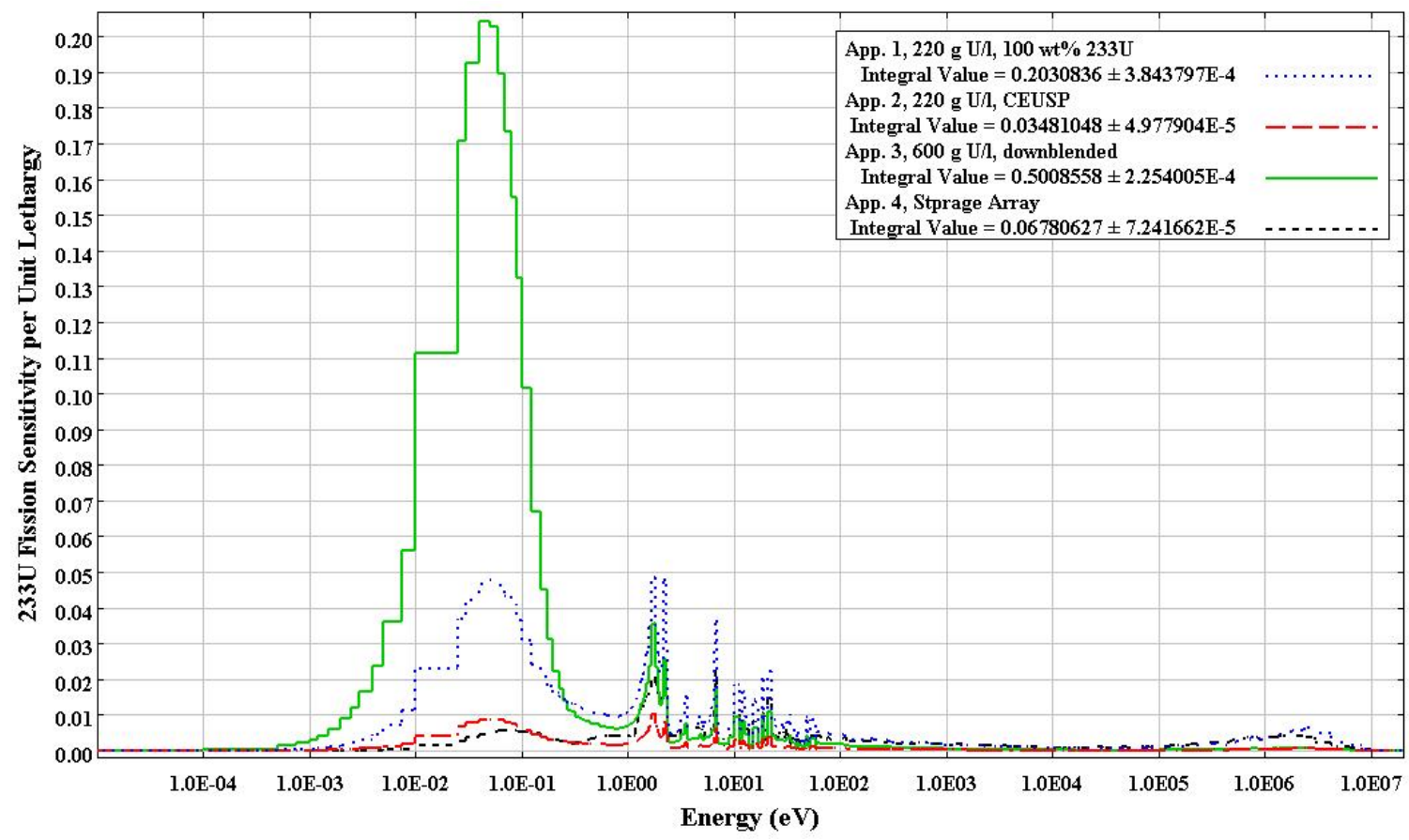

Fig. 2. ${ }^{233} \mathrm{U}$ fission sensitivity for all applications.

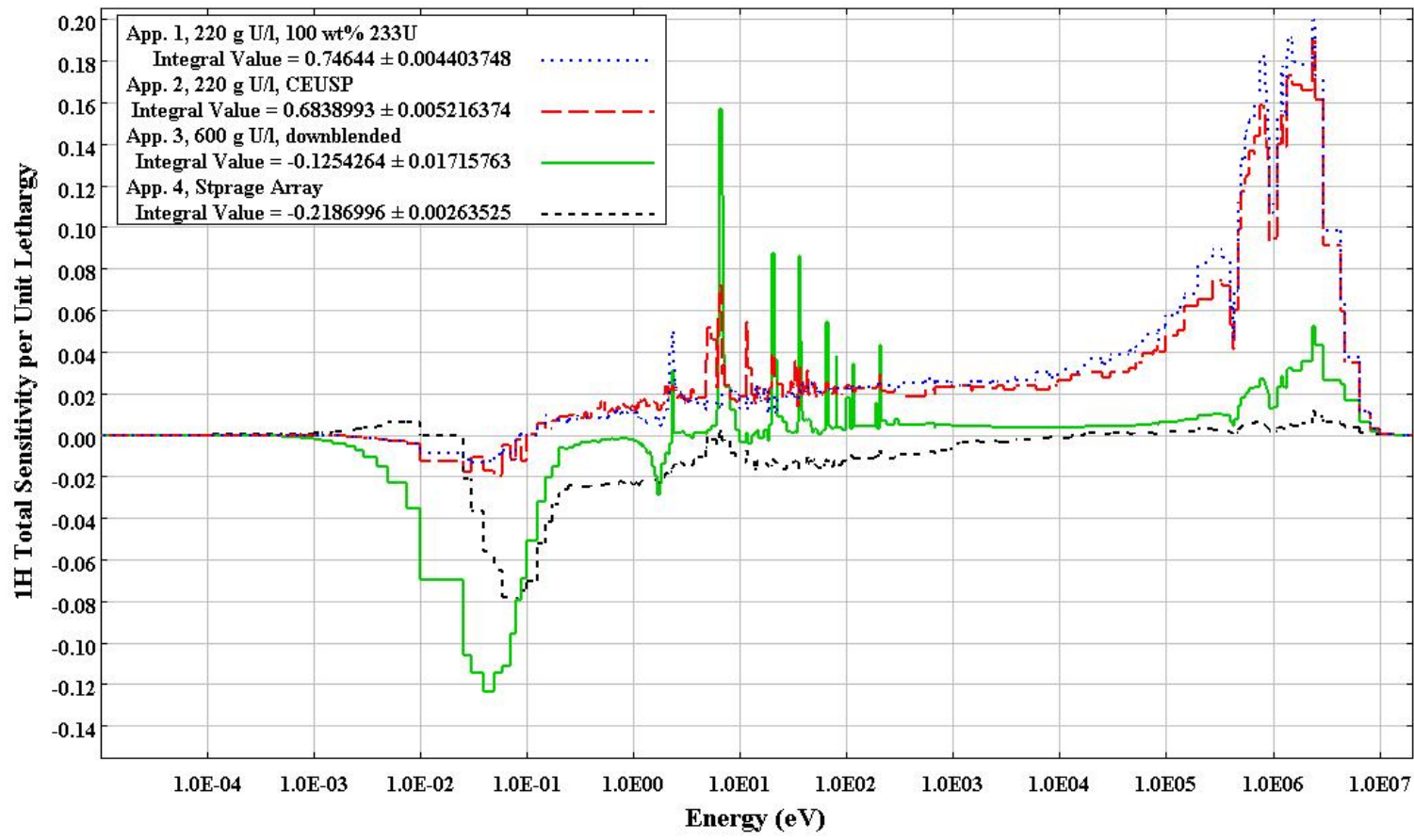

Fig. 3. ${ }^{1} \mathrm{H}$ total sensitivity for all applications.

Figures 4-7 show the sensitivity of $k_{\text {eff }}$ to changes in the cross sections for the most important nuclides or mixtures for each of the four applications. From Fig. 7, note the relative importance of the carbon steel and concrete used to model the concrete logs. Keep in mind that similarity, as 
implemented in the TSUNAMI $c_{k}$ parameter, also considers the uncertainty in the cross-section data associated with each data point. While the nuclides shown are those that have the largest effect on the application systems, the uncertainty in the nuclear data for some of these nuclides is relatively small. Other nuclides to which $k_{\text {eff }}$ is less sensitive may have much larger uncertainties and, hence, are more likely candidates for contributing to the overall bias. Detailed evaluations of similarity and nonsimilarity relative to benchmark experiments are provided in Section 5.

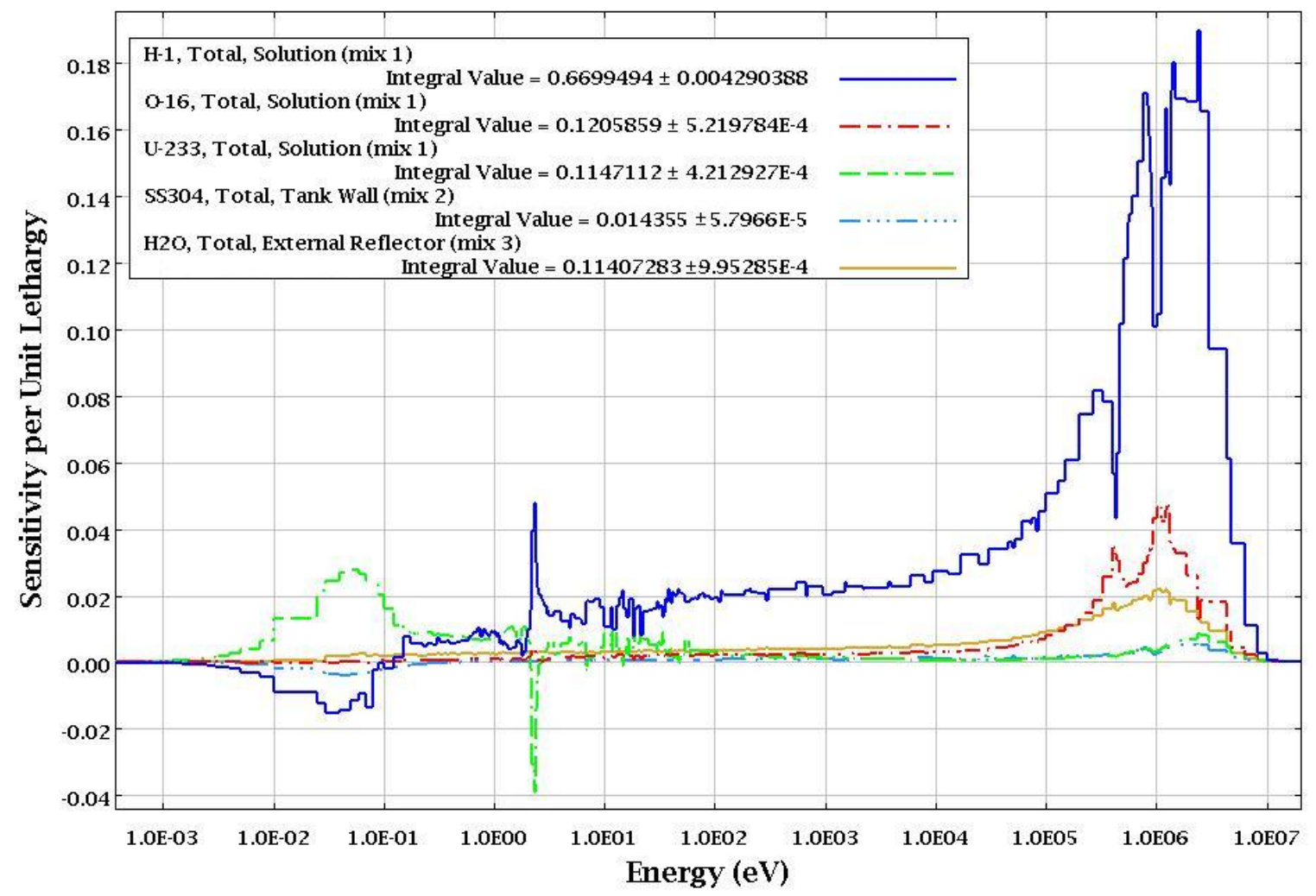

Fig. 4. Major total sensitivities for application 1. 


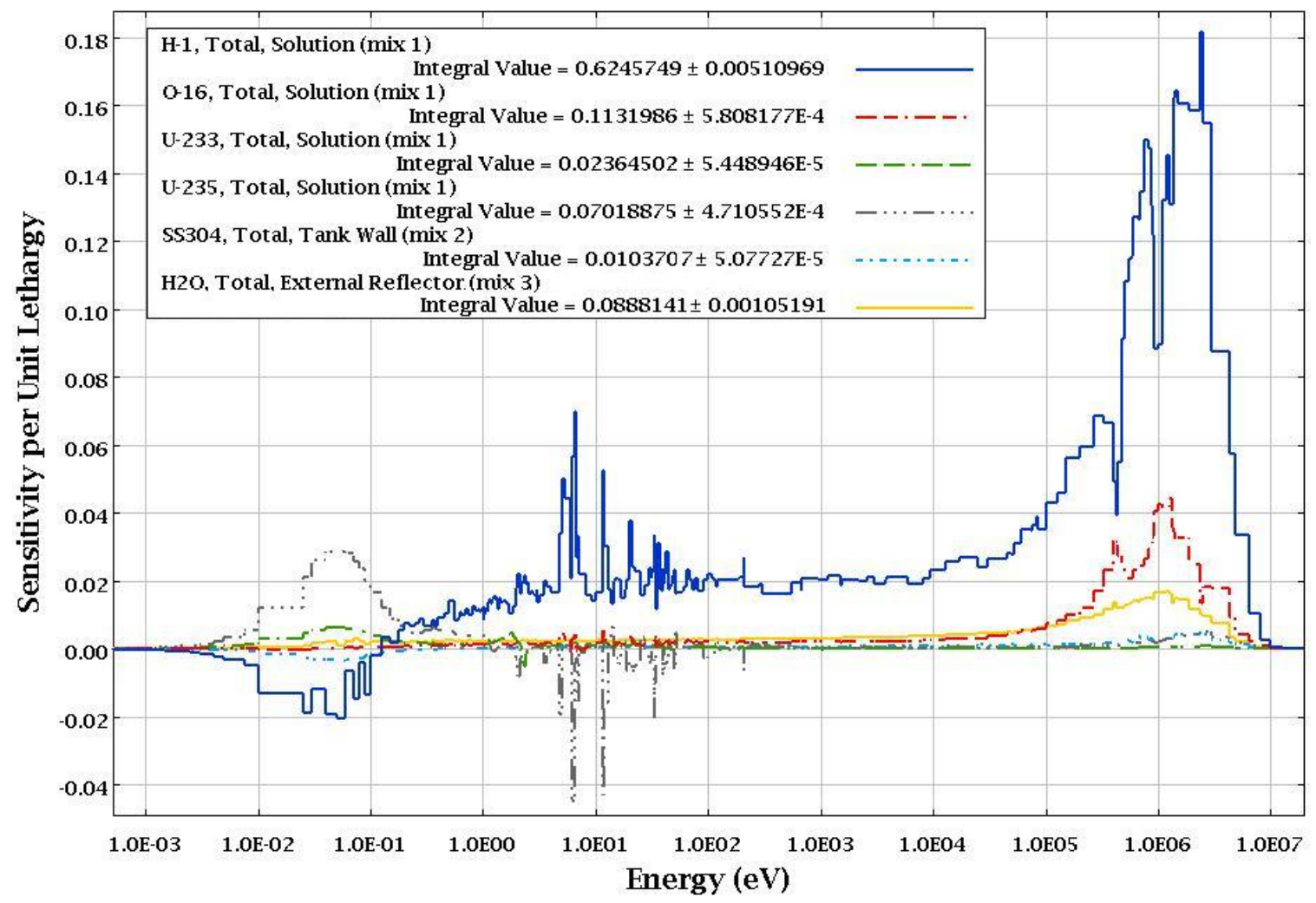

Fig. 5. Major total sensitivities for application 2.

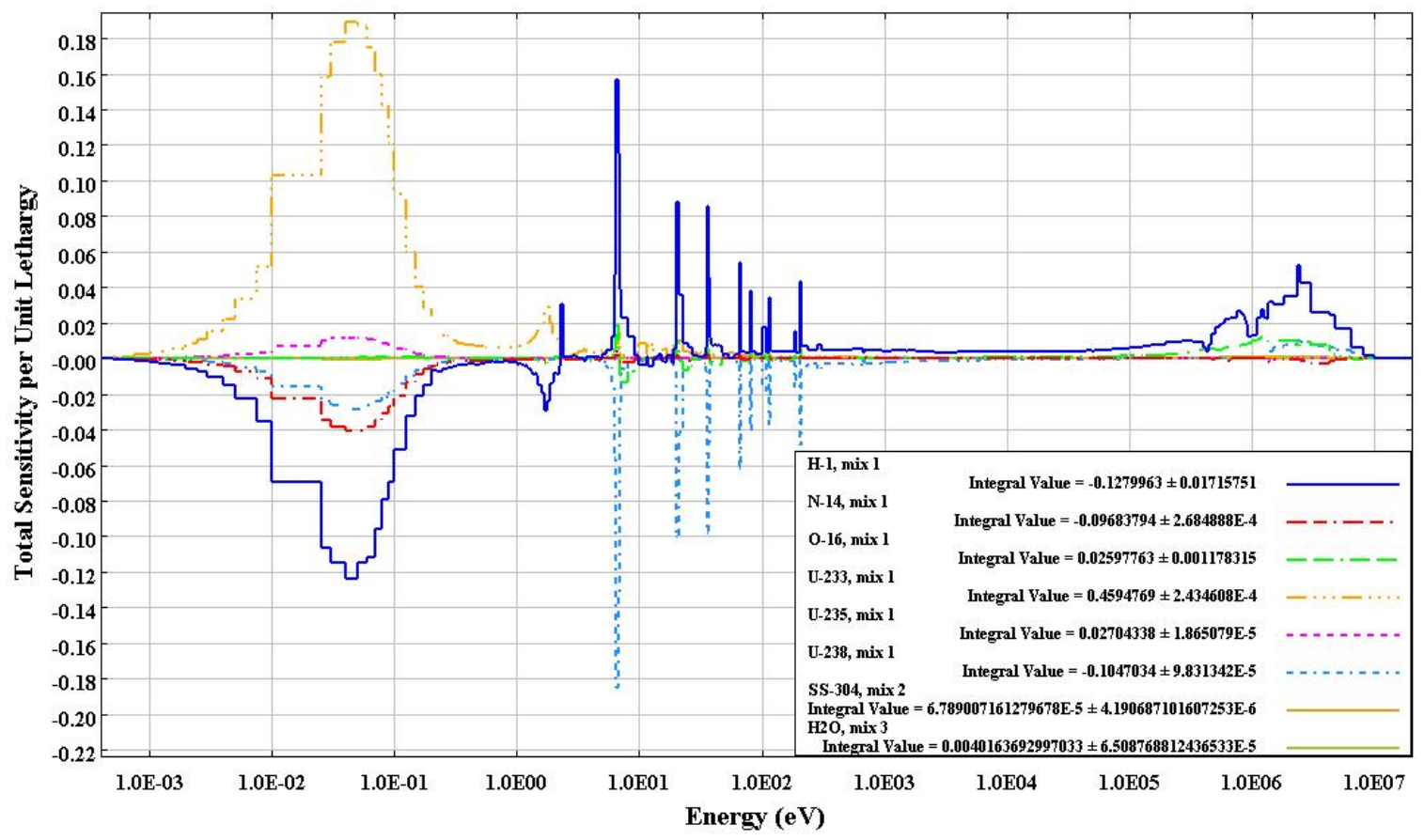

Fig. 6. Major total sensitivities for application 3. 


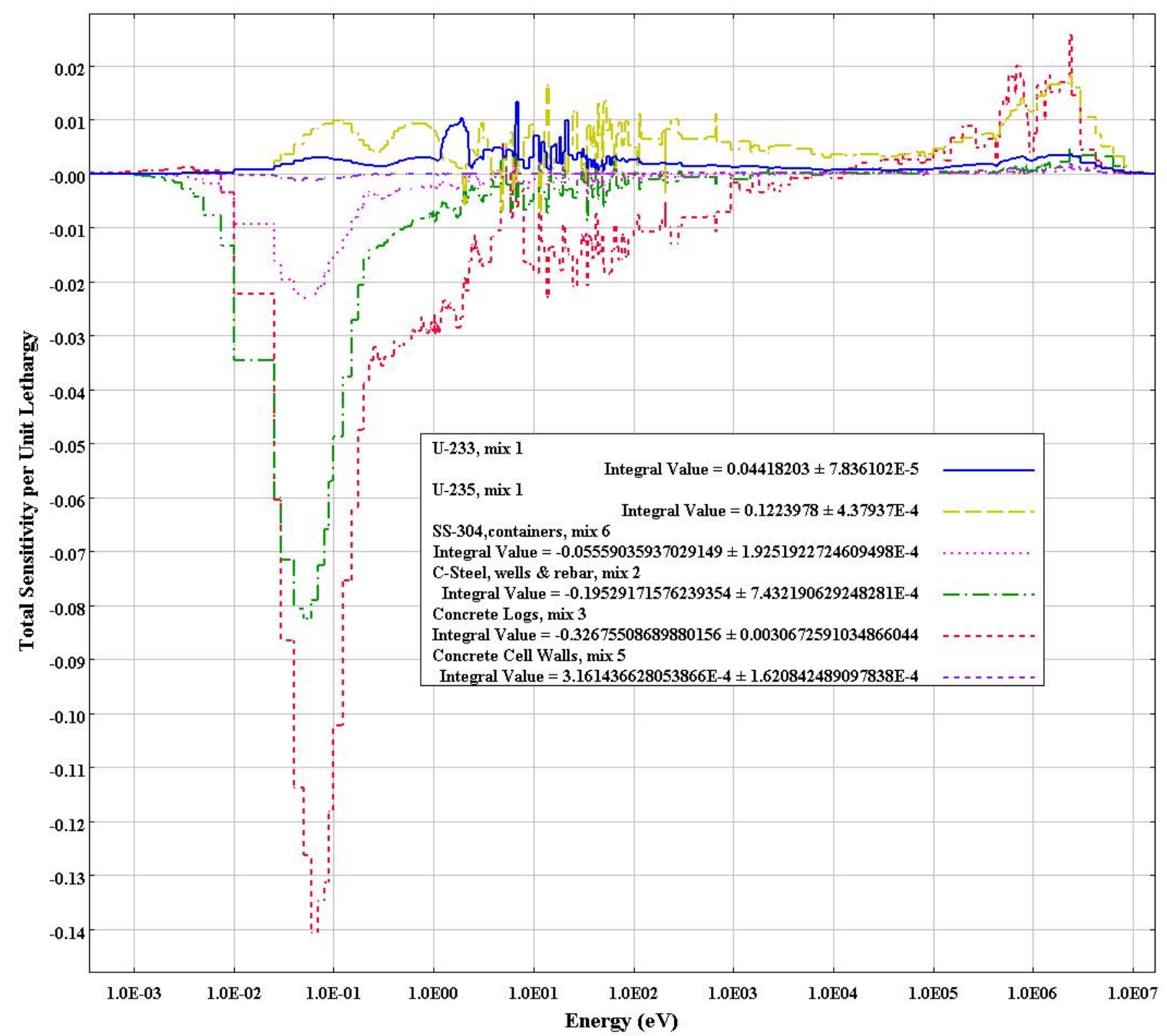

Fig. 7. Major total sensitivities for application 4.

\subsection{UNCERTAINTY ANALYSIS}

The uncertainty in the computed $k_{\text {eff }}$ due to the cross-section-covariance data from the ENDF/B-VI-recommended covariance data set from SCALE 5.1 was determined for each application system considered in this study. The relative standard deviations in $k_{\text {eff }}\left(\Delta k_{\text {eff }} / k_{\text {eff }}\right)$, in percent, for each of the four systems considered in the analysis are shown in Table 1 along with the relative standard deviations for the top six nuclide-reaction pairs that contribute to the $k_{\text {eff }}$ uncertainty. The combined relative uncertainty is calculated by subtracting the sum of the squares of the negative values from the sum of the squares of the positive values and taking the square root of the result. Negative values result from negative correlations in uncertainty data that can exist between reactions for a nuclide or between different nuclides. Negative correlations can be generated due to cross-nuclide calibration practices or when nuclear data from one reaction is used to infer nuclear data for another reaction. In these cases, some of the uncertainty is shared. Thus the combined uncertainty associated with both reactions needs to be reduced to account for this shared uncertainty. In the evaluated application systems, the top six nuclide-reaction pairs produce $\sim 98 \%$ of the total cross-section uncertainty. Thus, because these nuclides are the largest contributors to the uncertainty, they are the most likely source of 
computational biases. Note that applications 1 and 2 exhibit high $k_{\text {eff }}$ uncertainties due to uncertainties in the fission spectrum, chi. The use of chi data will be addressed in a subsequent discussion on system similarity.

Table 1. Uncertainty in $\boldsymbol{k}_{\text {eff }}$ due to cross-section-covariance data

\begin{tabular}{|c|c|c|c|}
\hline System & $\begin{array}{l}\text { Standard } \\
\text { deviation } \\
(\%)\end{array}$ & $\begin{array}{l}\text { Top six contributor } \\
\text { standard deviati } \\
(\%)\end{array}$ & \\
\hline \multirow{6}{*}{ Application 1} & \multirow{6}{*}{0.937} & ${ }^{233} \mathrm{U}$ chi to ${ }^{233} \mathrm{U}$ chi & 0.819 \\
\hline & & ${ }^{1} \mathrm{H}$ elastic to ${ }^{1} \mathrm{H}$ elastic & 0.320 \\
\hline & & ${ }^{16} \mathrm{O}$ elastic to ${ }^{16} \mathrm{O}$ elastic & 0.194 \\
\hline & & ${ }^{233} \mathrm{U} n, \gamma$ to ${ }^{233} \mathrm{Un}, \gamma$ & 0.174 \\
\hline & & ${ }^{233} \mathrm{U}$ nubar to ${ }^{233} \mathrm{U}$ nubar & 0.145 \\
\hline & & ${ }^{233} \mathrm{U}$ fission to ${ }^{233} \mathrm{U}$ fission & 0.117 \\
\hline \multirow{6}{*}{ Application 2} & \multirow{6}{*}{0.752} & ${ }^{235} \mathrm{U}$ chi to ${ }^{235} \mathrm{U}$ chi & 0.578 \\
\hline & & ${ }^{1} \mathrm{H}$ elastic to ${ }^{1} \mathrm{H}$ elastic & 0.286 \\
\hline & & ${ }^{235} \mathrm{U}$ nubar to ${ }^{235} \mathrm{U}$ nubar & 0.253 \\
\hline & & ${ }^{235} \mathrm{U} n, \gamma$ to ${ }^{235} \mathrm{Un}, \gamma$ & 0.180 \\
\hline & & ${ }^{16} \mathrm{O}$ elastic to ${ }^{16} \mathrm{O}$ elastic & 0.180 \\
\hline & & ${ }^{233} \mathrm{U}$ chi to ${ }^{233} \mathrm{U}$ chi & 0.098 \\
\hline \multirow{6}{*}{ Application 3} & \multirow{6}{*}{0.515} & ${ }^{14} \mathrm{~N} n, p$ to ${ }^{14} \mathrm{~N} n, p$ & 0.346 \\
\hline & & ${ }^{238} \mathrm{U} n, \gamma$ to ${ }^{238} \mathrm{U} n, \gamma$ & 0.233 \\
\hline & & ${ }^{233} \mathrm{U}$ fission to ${ }^{233} \mathrm{U}$ fission & 0.173 \\
\hline & & ${ }^{1} \mathrm{H} \mathrm{n}, \gamma$ to ${ }^{1} \mathrm{H} \mathrm{n, \gamma}$ & 0.145 \\
\hline & & ${ }^{233} \mathrm{U}$ chi to ${ }^{233} \mathrm{U}$ chi & 0.136 \\
\hline & & ${ }^{233} \mathrm{U}$ nubar to ${ }^{233} \mathrm{U}$ nubar & 0.135 \\
\hline \multirow{6}{*}{ Application 4} & \multirow{6}{*}{1.354} & ${ }^{56} \mathrm{Fe} n, \gamma$ to ${ }^{56} \mathrm{Fe} n, \gamma$ & 1.151 \\
\hline & & $\mathrm{Ca} \mathrm{n}, \gamma$ to $\mathrm{Ca} n, \gamma$ & 0.485 \\
\hline & & ${ }^{56} \mathrm{Fe}$ elastic to ${ }^{56} \mathrm{Fe}$ elastic & 0.266 \\
\hline & & ${ }^{235} \mathrm{Un}, \gamma$ to ${ }^{235} \mathrm{Un}, \gamma$ & 0.234 \\
\hline & & ${ }^{235} \mathrm{U}$ fission to ${ }^{235} \mathrm{U}$ fission & 0.222 \\
\hline & & ${ }^{235} \mathrm{U}$ nubar to ${ }^{235} \mathrm{U}$ nubar & 0.196 \\
\hline
\end{tabular}

It is important to note that the top contributor to uncertainty is not necessarily the nuclide to which $k_{\text {eff }}$ is most sensitive. The uncertainty calculation considers the sensitivity of the system, on an energy-dependent basis as well as the uncertainty in the cross section, also on an energy-dependent basis. The uncertainty calculations consider not only the uncertainty at specific energies, but also the covariance, or shared uncertainty, in ranges of energies for the same nuclide and reaction, between reactions of the same nuclide, and between different nuclides.

Uncertainty data for some of the more significant nuclide-reaction pairs are shown in Figs. 8-10 in the SCALE 44-group energy structure. Note that uncertainty calculations are performed within 
the TSUNAMI codes by first collapsing the 238-group sensitivity to the 44-group structure, then performing the necessary mathematical operations. The reader may also use the SCALE Javapeño program ${ }^{5}$ to view three-dimensional plots of the covariance data for a specific nuclidereaction pair. Figure 11 shows the covariance data for the ${ }^{233} \mathrm{U}(\mathrm{n}, \gamma)$ reaction.

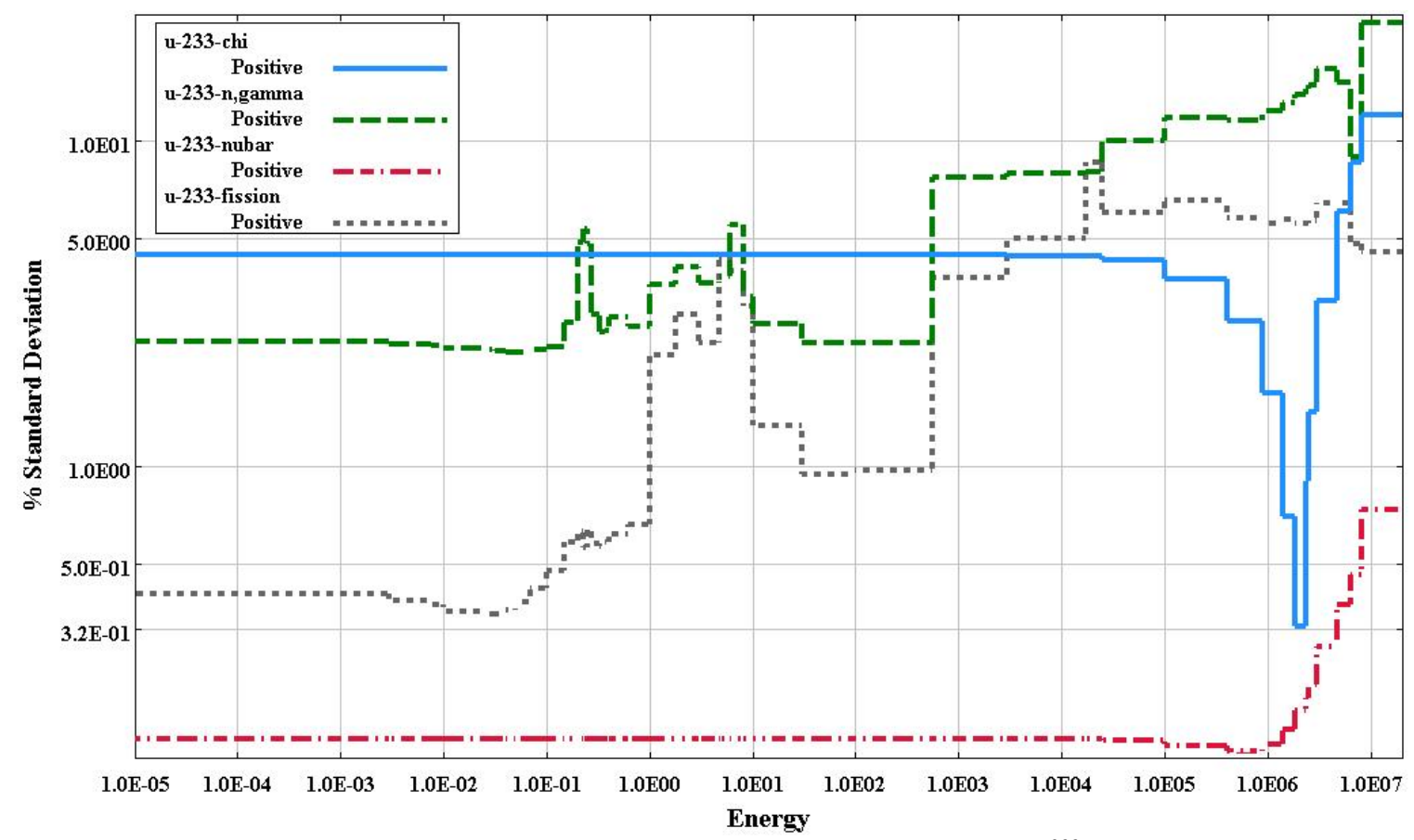

Fig. 8. Most significant nuclear data uncertainties for ${ }^{233} \mathrm{U}$.

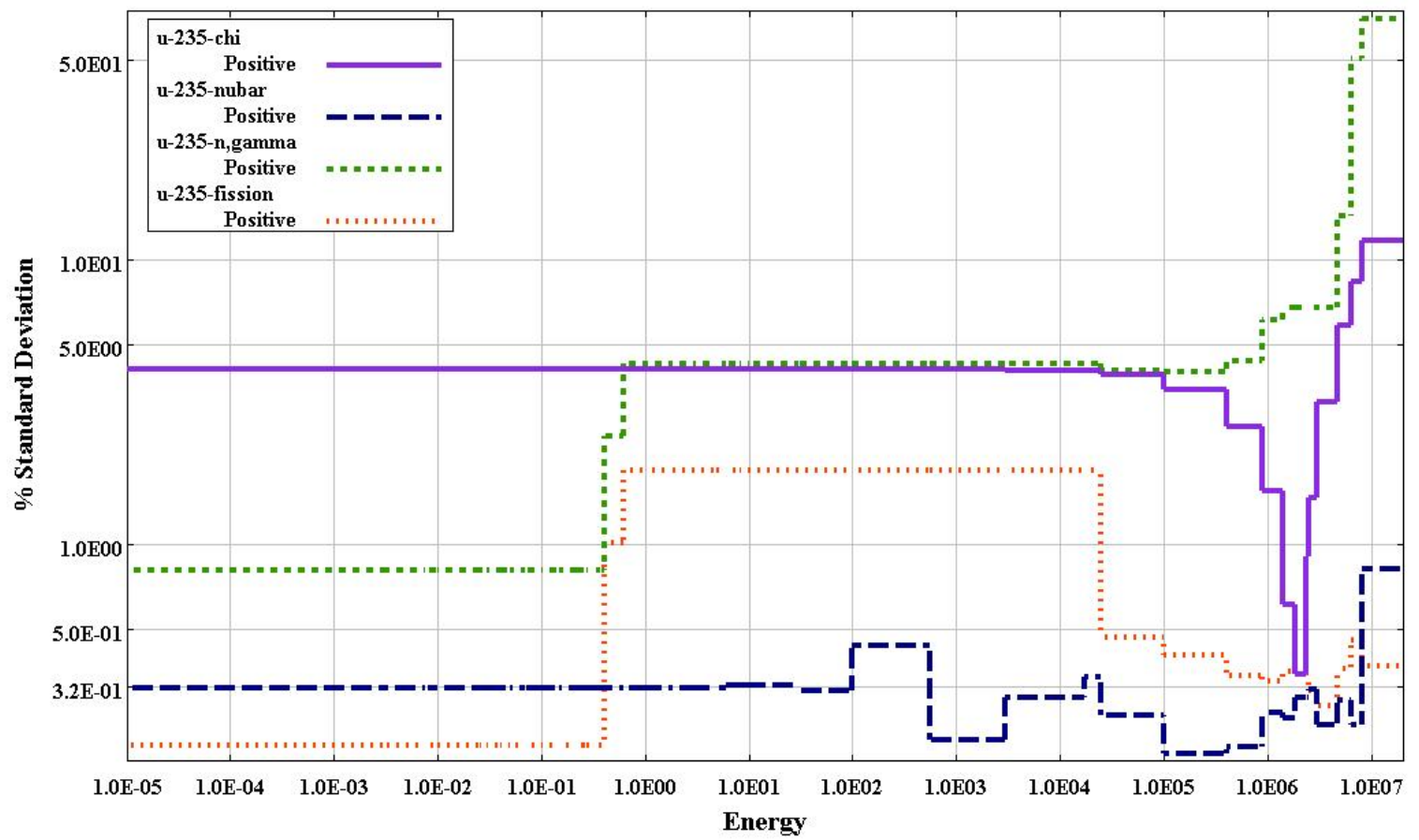

Fig. 9. Most significant nuclear data uncertainties for ${ }^{235} \mathrm{U}$. 


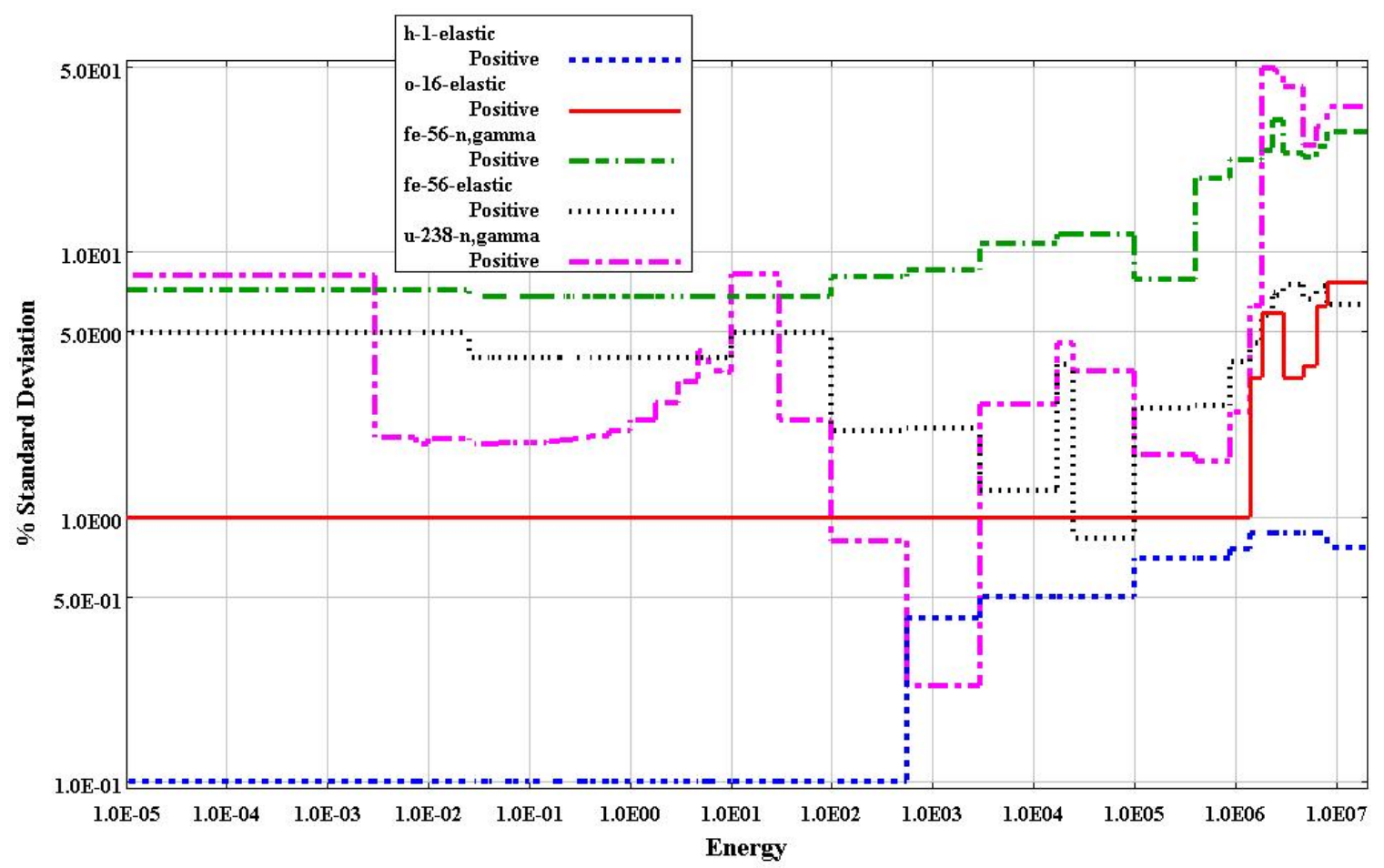

Fig. 10. Most significant nuclear data uncertainties for ${ }^{1} \mathrm{H},{ }^{16} \mathrm{O},{ }^{56} \mathrm{Fe}$, and ${ }^{238} \mathrm{U}$. 

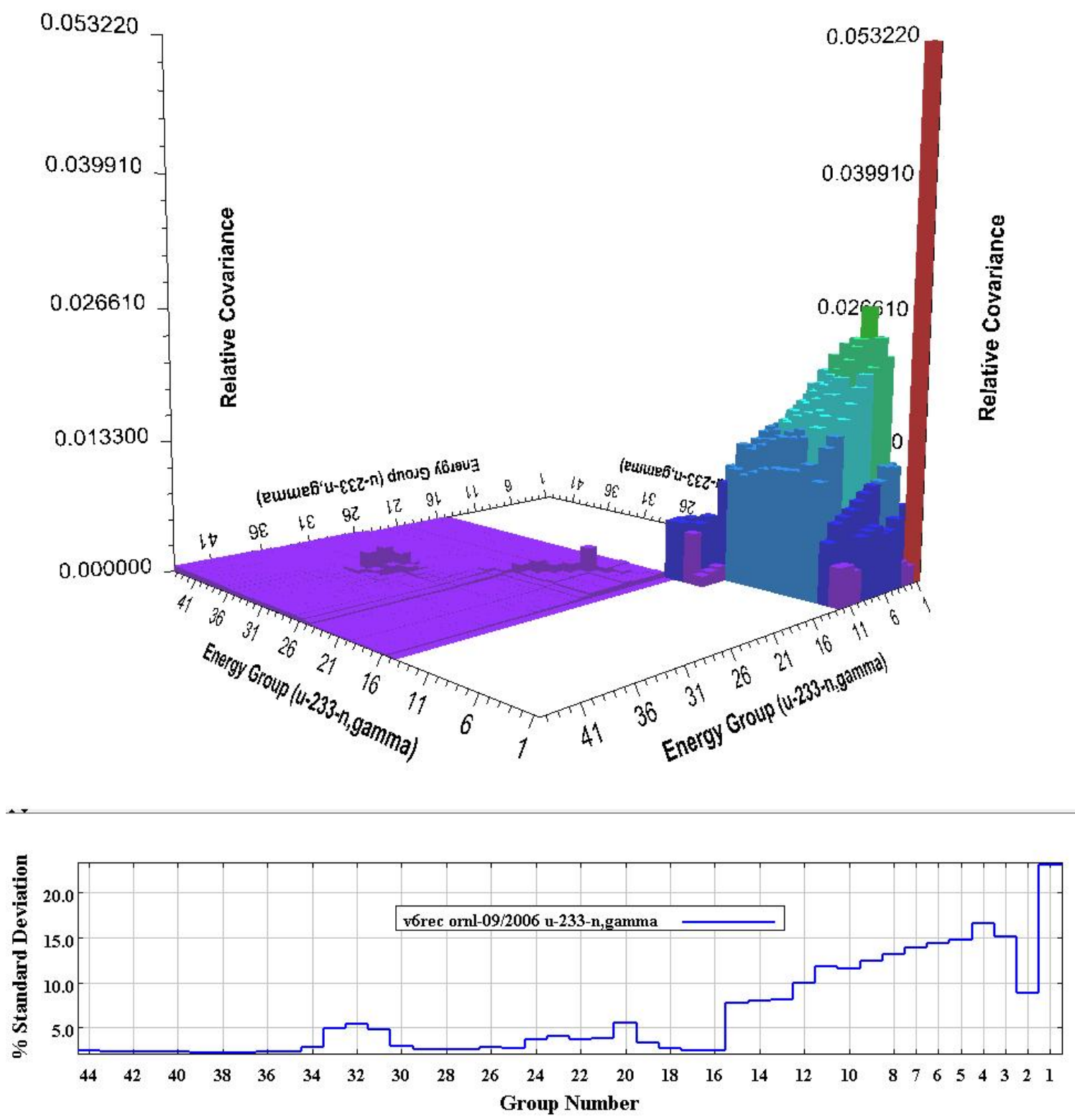

Fig. 11. Three-dimensional plot of covariance data for the ${ }^{233} U(n, \gamma)$ reaction. 


\section{CRITICAL EXPERIMENT DATABASE}

Criticality safety validation requires a range of valid critical benchmark experiments that span the important parameters of the systems and operations of interest. The benchmark descriptions for all the experiments used in this validation study are provided in the International Handbook of Evaluated Criticality Safety Benchmark Experiments (IHECSBE),${ }^{6}$ which is published yearly as part of the International Criticality Safety Benchmark Evaluation Program. The initial experimental database used in this work was derived from 101 individual evaluations from the IHECSBE, containing a total of 672 critical configurations. The initial prescreening validation set included $232{ }^{233} \mathrm{U}, 28$ mixed U+Pu, 4 intermediate-enrichment-uranium (IEU), 153 high-enrichment-uranium (HEU), and 255 low-enrichment-uranium (LEU) critical configurations. This wide range of critical benchmarks was included in the initial screening to maximize the identification of critical configurations that are similar to the four applications described in Section 2. of this report. Each of the four applications was compared to all 672 critical configurations.

The primary fissile components represented in the applications are ${ }^{233} \mathrm{U}$ and ${ }^{235} \mathrm{U}$. The IHECSBE evaluations documenting the critical benchmark configurations and the number of configurations modeled are listed in Table 2. During processing, the material will be dissolved prior to down blending, which involves the addition of significant quantities of hydrogen to the fissile material. This area of applicability (AOA) should be covered by the ${ }^{233} \mathrm{U}$ solution thermal set of benchmarks. The ${ }^{233} \mathrm{U}$ is stored in many forms: ${ }^{233} \mathrm{U}$ metal, uranium oxides, uranium fluorides, different combinations of ${ }^{233} \mathrm{U}$ and ${ }^{235} \mathrm{U}$, and as CEUSP material. To cover the range of other materials, including enriched ${ }^{235} \mathrm{U}$ mixed with ${ }^{233} \mathrm{U}, 440$ critical configurations were included that contain no ${ }^{233} \mathrm{U}$.

The IHECSBE should be consulted for detailed descriptions of the critical configurations considered for use in this validation study.

The following list shows the relationship between the IHECSBE identifiers used in this report and the full identifiers used in the handbook.

$$
\begin{array}{ll}
\mathrm{hct} & =\text { HEU-COMP-THERM } \\
\mathrm{hmf} & =\text { HEU-MET-FAST } \\
\mathrm{hmt} & =\text { HEU-MET-THERM } \\
\mathrm{hst} & =\text { HEU-SOL-THERM } \\
\mathrm{imf} & =\text { IEU-MET-FAST } \\
\mathrm{mci} & =\text { MIX-COMP-INTER } \\
\mathrm{mcf} & =\text { MIX-COMP-FAST } \\
\mathrm{mcm} & =\text { MIX-COMP-MIXED }
\end{array}
$$

$$
\begin{array}{ll}
\operatorname{mmf} & =\text { MIX-MET-FAST } \\
\text { lct } & =\text { LEU-COMP-THERM } \\
\text { lst } & =\text { LEU SOL-THERM } \\
\text { uct } & =\mathrm{U} 233-\text { COMP-THERM } \\
\text { umf } & =\text { U233-MET-FAST } \\
\text { usi } & =\mathrm{U} 233-\text { SOL-INTER } \\
\text { ust } & =\mathrm{U} 233-\text { SOL-THERM }
\end{array}
$$

TSUNAMI-1D or TSUNAMI-3D was used to generate 238-group sensitivity data for each of the experiments identified in the section. 
Table 2. Summary of IHECSBE critical configurations considered in initial screening

\begin{tabular}{|c|c|c|c|c|c|}
\hline IHECSBE eval. ID & Exps. & IHECSBE eval. ID & Exps. & IHECSBE eval. ID & Exps. \\
\hline uct001 & 3 & hct010 & 15 & lct009 & 26 \\
\hline umf001 & 1 & het011 & 3 & lct010 & 30 \\
\hline umf002 & 2 & het012 & 2 & lct012 & 10 \\
\hline umf003 & 2 & het013 & 2 & lct017 & 29 \\
\hline umf004 & 2 & hct014 & 2 & lct018 & 1 \\
\hline umf005 & 2 & hmf030 & 1 & lct019 & 3 \\
\hline umf006 & 1 & hmt006 & 23 & lct020 & 7 \\
\hline usi001 & 33 & hmt025 & 2 & $\operatorname{lct} 021$ & 6 \\
\hline ust001 & 5 & hst001 & 10 & $1 \mathrm{ct} 022$ & 7 \\
\hline ust002 & 17 & hst005 & 5 & lct023 & 6 \\
\hline ust003 & 10 & hst006 & 4 & lct024 & 2 \\
\hline ust004 & 8 & hst007 & 17 & $1 \mathrm{ct} 025$ & 4 \\
\hline ust005 & 2 & hst009 & 4 & lct026 & 4 \\
\hline ust006 & 25 & hst010 & 4 & $1 \mathrm{ct} 032$ & 9 \\
\hline ust008 & 1 & hst011 & 2 & lct040 & 3 \\
\hline ust009 & 4 & hst012 & 1 & lct042 & 7 \\
\hline ust012 & 8 & hst013 & 1 & lct049 & 18 \\
\hline ust013 & 21 & hst014 & 1 & lct079 & 10 \\
\hline ust014 & 16 & hst 015 & 2 & lst001 & 1 \\
\hline ust015 & 31 & hst016 & 1 & 1st003 & 9 \\
\hline ust016 & 31 & hst017 & 3 & lst004 & 7 \\
\hline ust017 & 7 & hst018 & 3 & 1 st005 & 3 \\
\hline \multirow[t]{2}{*}{${ }^{233} \mathrm{U}$ total } & 232 & hst019 & 1 & 1st006 & 5 \\
\hline & & hst025 & 4 & $1 s t 007$ & 5 \\
\hline mcf001 & 1 & hst027 & 1 & $1 \mathrm{st} 008$ & 4 \\
\hline mci005 & 1 & hst028 & 9 & lst009 & 3 \\
\hline $\mathrm{mcm} 001$ & 19 & hst029 & 1 & $1 \mathrm{st} 010$ & 4 \\
\hline $\mathrm{mmf008}$ & 7 & hst030 & 2 & $1 \mathrm{st} 016$ & 7 \\
\hline \multirow[t]{2}{*}{ Pu \& U mixed total } & 28 & hst032 & 1 & $1 \mathrm{st} 017$ & 6 \\
\hline & & hst033 & 9 & lst018 & 5 \\
\hline imf003 & 1 & hst035 & 3 & 1st019 & 6 \\
\hline imf004 & 1 & hst 037 & 3 & $1 \mathrm{st} 020$ & 4 \\
\hline imf005 & 1 & hst042 & 8 & lst021 & 4 \\
\hline imf006 & 1 & hst043 & 3 & LEU total & 255 \\
\hline IEU total & 4 & HEU total & 153 & & \\
\hline & & Total evaluations & 101 & & \\
\hline \multicolumn{3}{|c|}{ Total critical configurations } & 672 & & \\
\hline
\end{tabular}




\section{SIMILARITY OF CRITICAL EXPERIMENTS}

Effectively all nuclear data, whether pointwise or multigroup, has errors. The errors result from uncertainties in the experimental setup used to measure the nuclear data; the conduct of the experiment; collection, interpretation, adjustment, and reporting of the measurements; evaluation of the measurement results to produce neutron-energy-dependent nuclear data libraries; and, for multigroup libraries, the techniques used to collapse the data to the desired group structure and to incorporate the unresolved and resolved resonances. When using robust three-dimensional neutron transport techniques to predict the criticality of a system, the most likely sources of computational bias are errors in the nuclear data. In order to quantify the effect of these errors on computed results, efforts have been made by the experimentalists measuring the data and the nuclear data evaluators to quantify the uncertainty on the nuclear data values. Where it exists, this uncertainty information is contained in the evaluated nuclear data files. Nuclear data uncertainties have been processed into a 44-energy-group format ${ }^{7}$ and are contained in the cross-section covariance data files distributed with SCALE. Given that nuclear data errors do exist, each error contributes toward an overall computational bias. The individual biases may be positive, resulting in a high calculated $k_{\text {eff }}$ value, or negative, resulting in a low calculated $k_{\text {eff }}$ value. The overall bias is the simple sum of the many biases. Providing a quantified estimate of this overall bias is the primary goal of validation.

If the experiments and the safety application have the same $k_{\text {eff }}$ sensitivity to the same nuclear data, the experiments and the application will have the same $k_{\text {eff }}$ bias. However, where materials are present in the application and not in the experiment, no bias can be determined for the materials not present in the experiments. Where materials are present in the experiments and not in the application, the bias calculated from the experiments includes some contribution from the extra materials. If the bias contribution of the extra materials is positive, the calculated overall bias will be nonconservative. Thus, care must be taken to account for differences in material compositions as dissimilarities that increase the uncertainty in the bias to ensure that the upper subcritical limits are sufficient to ensure safety.

It is not enough to simply have the same materials in both the experiments and the application. For example, if an experiment is ten times more sensitive to the boron capture cross sections than is the application, the overall bias calculated from the experiments will have ten times too much contribution from the boron capture cross section errors. This is not necessarily conservative. If the boron capture cross section is too low, the calculated $k_{\text {eff }}$ value would be too high, and the bias associated with the boron capture would be positive and ten times too large. Furthermore, this nonconservative contribution may be obscured by other compensating biases. The correct overall bias is then obtained if the experiments and the application contain the same materials and have similar $k_{\text {eff }}$ sensitivities to these materials. The TSUNAMI-IP module can provide applicationspecific estimates of the impact of nuclear data uncertainties on the $k_{\text {eff }}$ value calculated for the application. Examples of such data are provided in Section 2.

Identification of critical experiments that are sufficiently similar to a nuclear criticality safety application can be problematic. Fortunately, some nuclear data is well known (i.e., has a low uncertainty) and criticality safety calculations frequently have low sensitivity to some of the materials present in the calculation. The TSUNAMI-IP $c_{k}$ parameter is an integral similarity parameter that considers both of these effects. Similarity is affected very little by nuclides that have very low uncertainties and by nuclides to which the system $k_{\text {eff }}$ value has little sensitivity. If the system is not sensitive to the presence of a nuclide, then a small error in the cross-section data for that nuclide will not contribute appreciably to the system bias. If the nuclear data have relatively low uncertainties, then the bias associated with those nuclear data is likely small. 
A modified form of the $c_{k}$ parameter was used in the work presented in this report. This parameter, referred to as $c_{r}$, excludes consideration of the fission spectrum (chi) sensitivities/uncertainties when determining similarity. Based on recent examinations by ORNL staff, as bolstered by the findings of the OECD/NEA Working Party on International Data Evaluation Co-operation (WPEC) Subgroup 26, the fission spectrum sensitivities computed using the classical approach implemented in TSUNAMI do not consider the normalization of the fission spectrum to unity when computing group-wise chi sensitivities. Fission spectrum data are different from the other nuclear data because, by definition, the fission spectrum for a given nuclide must integrate to one. The classical approach to calculate chi sensitivity coefficients ignores this normalization such that the sensitivity to each group is computed independent of the offsetting effects that would be observed in preserving the normalization. In uncertainty calculations, the chi covariance data generated for SCALE does account for the anti-correlations in the data; if one value is increased, others must be decreased. However, it has not been proven that this covariance treatment is always equivalent to preserving the normalization with the sensitivity data. Increasing chi in one energy group without adjusting the others is equivalent to adjusting nu-bar, which is already considered separately in the calculation of the nu-bar sensitivities. Errors in the shape of the chi distribution could contribute toward the system bias, but the current treatment in TSUNAMI-IP exaggerates the importance of chi, especially for the application systems considered in this study. Due to compensating adjustments, small variations in the shape of the chi distribution should have little effect on $k_{\text {eff }}$. Differences in the uncertainty in $k_{\text {eff }}$ for a single system based on constrained or unconstrained chi are small due to the anticorrelations present in the cross-section-covariance data for chi. The TSUNAMI techniques for fission spectrum sensitivities will be modified to implement the preferred constrained calculation in SCALE 6.

The $\mathrm{c}_{\mathrm{r}}$ parameter is calculated by TSUNAMI-IP by including the keywords " $c r$ " and "cr_long" in the parameter block and by including "chi" in the exclusions block.

The input file for the TSUNAMI-IP calculation for application 1 is shown in Appendix C. The covariance input block, which begins with read covariance and terminates with end covariance, in the application 1 input file includes nuclide-reaction pair default values to use for correcting the cross-section covariance data. The format for the data is described in the TSUNAMI-IP documentation. ${ }^{3}$ The nuclide-reaction pairs that needed individual corrections were identified by reviewing the warning messages in the output generated using an earlier version of the input file. The values specified in the application 1 input file were selected by using the Javapeño graphical data display program to examine energy-dependent trends in uncertainty data. Reasonable values were selected based on energy-dependent trends near the energy group or groups that were being modified by TSUNAMI-IP. For example, energy group 10 of the ${ }^{62} \mathrm{Ni}(\mathrm{n}, \alpha)$ reaction had an uncertainty value of $1800 \%$ in the cross-section covariance data file. This large uncertainty appears to be caused by cross sections for this "threshold" reaction dropping off to near zero within energy group 10 . Energy group 9 has an uncertainty value that is nearly $600 \%$, and energy group 11 has an uncertainty of zero. It was decided to use the $600 \%$ value for group 10 . This was accomplished by specifying a 6.0 fractional uncertainty value for the ${ }^{62} \mathrm{Ni}(\mathrm{n}, \alpha)$ reaction in the covariance data block.

The input file also includes input to correct a code discrepancy related to removing excessively large values in threshold reaction uncertainties from the covariance data. The cov_fix parameter of TSUNAMI-IP triggers the use of user-specified uncertainties whenever actual covariance data is excessively large or is not provided in the covariance data file. During this work, it was discovered that TSUNAMI-IP was not properly correcting large values in the ${ }^{238} \mathrm{U}$ fission covariance data. The warning messages provided by TSUNAMI-IP indicated that all of the ${ }^{238} \mathrm{U}$ 
fission covariance data were replaced with the default value specified by parameter udcov. The proper corrections should have been to replace the data for one energy group, which had a large uncertainty value, and to use the user-specified data for 2 energy groups, in which no covariance data were provided, leaving the remaining 41 energy groups unmodified. The work-around for this problem was to specify the parameter "use_icov" and then to provide covariance data for ${ }^{238} \mathrm{U}$ fission in the read covariance data block. This work-around is shown in the TSUNAMI-IP input file in Appendix C. The SCALE 6 version of TSUNAMI-IP will correct this discrepancy.

TSUNAMI-IP calculations compared each of the 672 critical experiments to each application. Sections 4.1 through 4.4 discuss the similarity results for each of the four applications.

\subsection{APPLICATION $1-220 \mathrm{~g} \mathrm{U}\left(100 \mathrm{wt} \%{ }^{233} \mathrm{U}\right) /$ LITER SPHERE}

Table 3 and Fig. 12 show the distribution of $\mathrm{c}_{\mathrm{r}}$ values calculated for the 672 critical configurations examined. Analysis of the similarity results follows Fig. 12. The analysis was initially performed using only experiments through experiment number 282 . HEU, IEU, and LEU experiments were added in an attempt to identify additional critical experiments that could be used for validation of the applications. Descriptions of each of the critical experiments and their experiment numbers are provided in Appendix B. Experiment numbers 283 and higher include the additional HEU, IEU, and LEU critical experiments.

Table 3. Application 1 similarity summary

\begin{tabular}{ccc}
\hline $\begin{array}{c}\text { Similarity } \\
\text { index } \\
\text { range }\end{array}$ & $\begin{array}{c}\text { Number } \\
\text { of } \\
\text { experiments }\end{array}$ & Applicability \\
\hline $\mathrm{c}_{\mathrm{r}}<0.1$ & 43 & Low \\
$0.1 \leq \mathrm{c}_{\mathrm{r}}<0.2$ & 80 & Low \\
$0.2 \leq \mathrm{c}_{\mathrm{r}}<0.3$ & 136 & Low \\
$0.3 \leq \mathrm{c}_{\mathrm{r}}<0.4$ & 140 & Low \\
$0.4 \leq \mathrm{c}_{\mathrm{r}}<0.5$ & 63 & Low \\
$0.5 \leq \mathrm{c}_{\mathrm{r}}<0.6$ & 30 & Low \\
$0.6 \leq \mathrm{c}_{\mathrm{r}}<0.7$ & 14 & Low \\
$0.7 \leq \mathrm{c}_{\mathrm{r}}<0.8$ & 7 & Low \\
$0.8 \leq \mathrm{c}_{\mathrm{r}}<0.9$ & 17 & Marginal \\
$0.9 \leq \mathrm{c}_{\mathrm{r}}<0.95$ & 60 & Applicable \\
$0.95 \leq \mathrm{c}_{\mathrm{r}}<1.0$ & 82 & High \\
All & 672 & \\
\hline
\end{tabular}




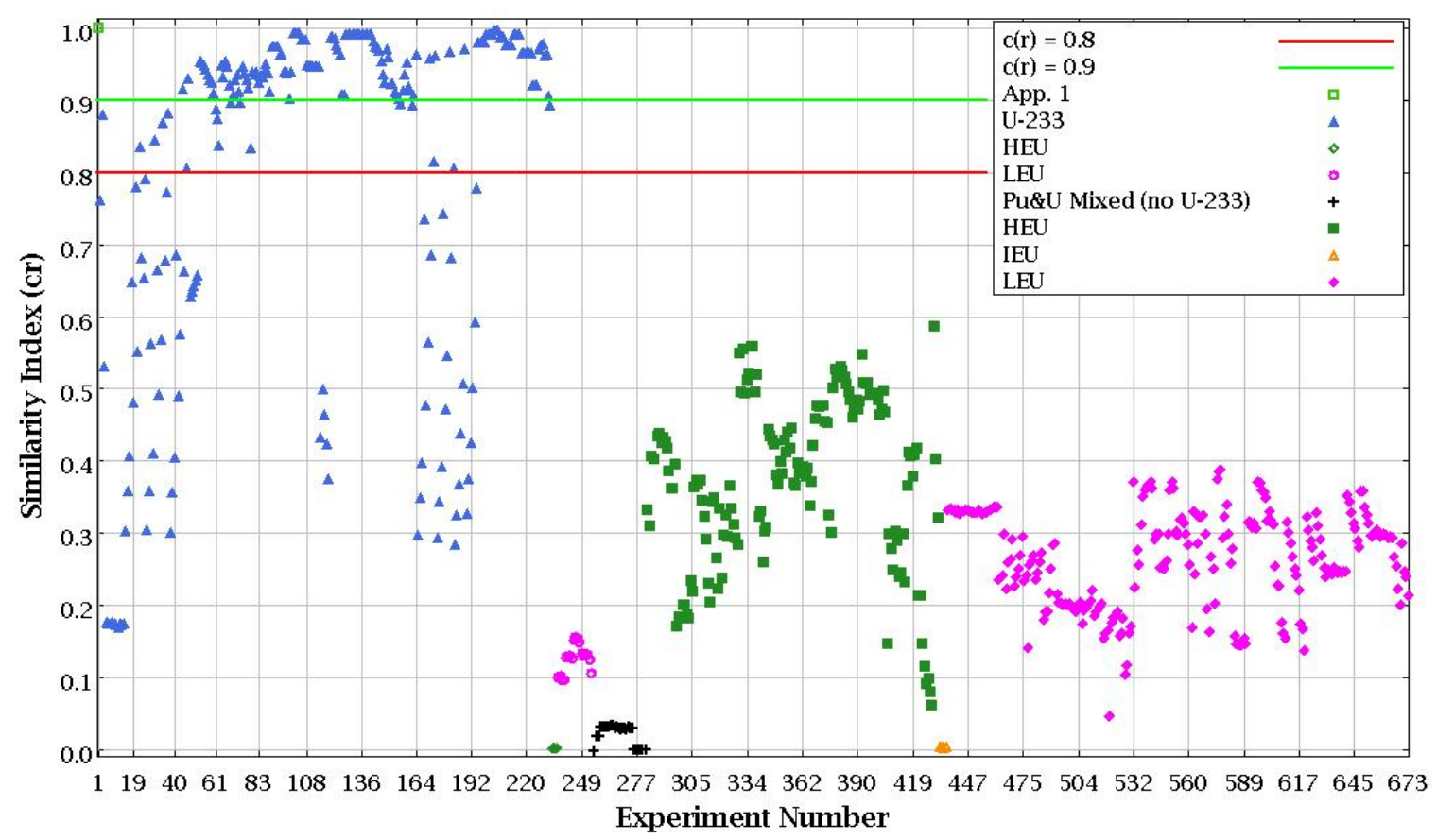

Fig. 12. Application 1 similarity index values $\left(c_{r}\right)$ for 672 critical experiments.

The similarity results for application 1 demonstrate that 82 of the experiments, those yielding $\mathrm{c}_{\mathrm{r}}$ values above 0.95 , are considered highly similar and 60 additional experiments yielded $\mathrm{c}_{\mathrm{r}}$ values between 0.9 and 0.95 and are considered similar. All 142 of the similar and highly similar experiments are ${ }^{233} \mathrm{U}$ experiments and are recommended for use in validation for application 1. An additional 17 critical configurations are considered to be only marginally similar $\left(0.9>c_{\mathrm{r}}>\right.$ 0.8 ) to application 1 . Considering that there are 144 configurations that are highly or adequately similar to application 1, use of the marginally similar configurations is not recommended. A list of critical experiments ordered by decreasing similarity is provided for each application in Appendix D.

The TSUNAMI-IP output for this application includes results from a detailed calculation of the $\mathrm{c}_{\mathrm{r}}$ value of the application compared with itself. This edit indicates that the most important contributors to $\mathrm{c}_{\mathrm{r}}$ for this application are the ${ }^{1} \mathrm{H}$ elastic scattering, ${ }^{16} \mathrm{O}$ elastic scattering, ${ }^{233} \mathrm{U}$ $\mathrm{n}$,gamma capture, ${ }^{233} \mathrm{U}$ nu-bar, and ${ }^{233} \mathrm{U}$ fission reactions.

The highest $\mathrm{c}_{\mathrm{r}}$ value, 0.995, was for experiment U233-SOL-THERM-016, case 10. Figures 13-17 show the sensitivity profiles for the four reactions identified above for both the application and the experiment. Results from U233-SOL-THERM-006, case 10 are also provided. This experiment yielded the lowest $\mathrm{c}_{\mathrm{r}}$ value that was greater than 0.9 . 


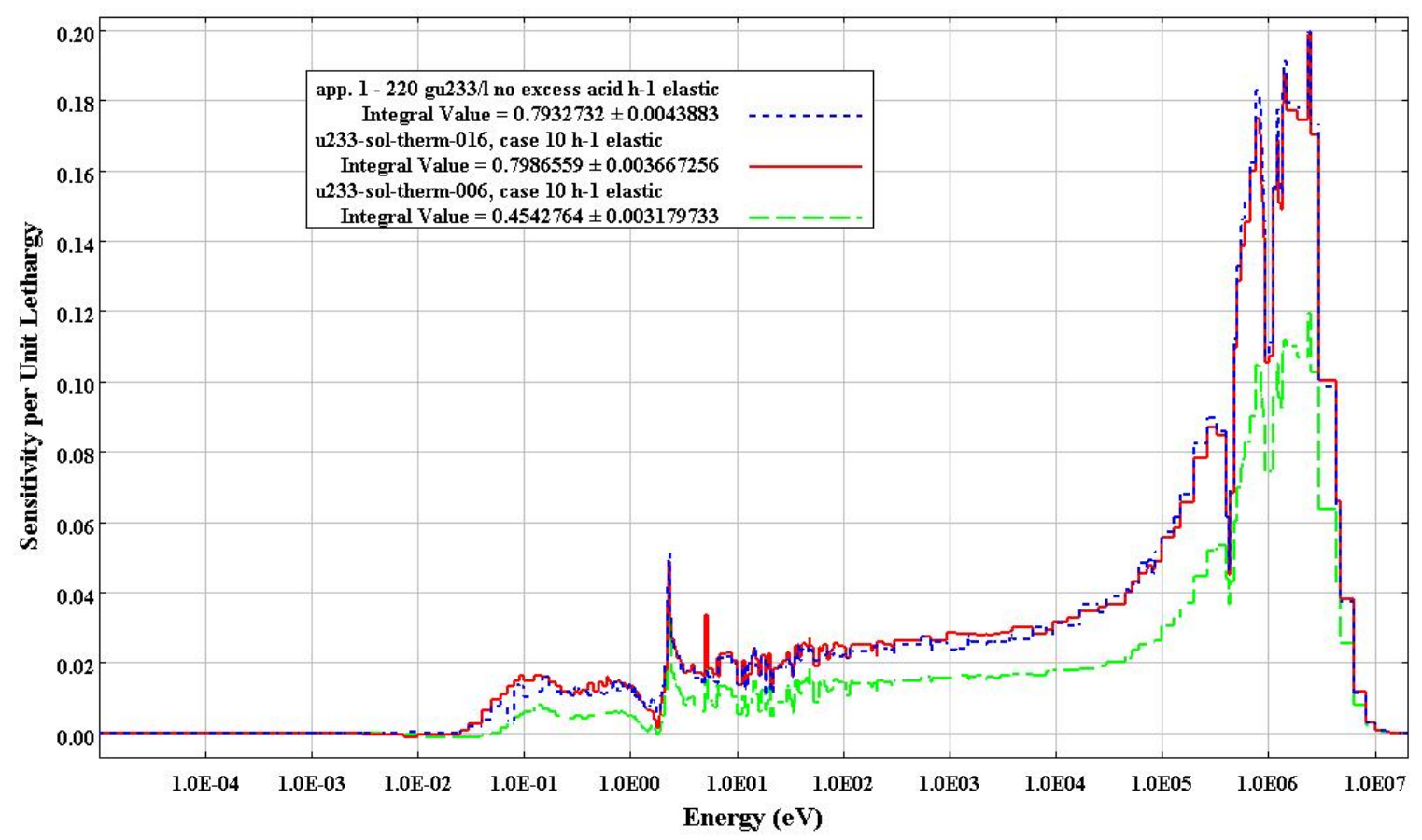

Fig. 13. ${ }^{1} \mathrm{H}$ elastic scattering sensitivity profiles for application 1 and experiments UST-016, case 10 and UST-006, case 10.

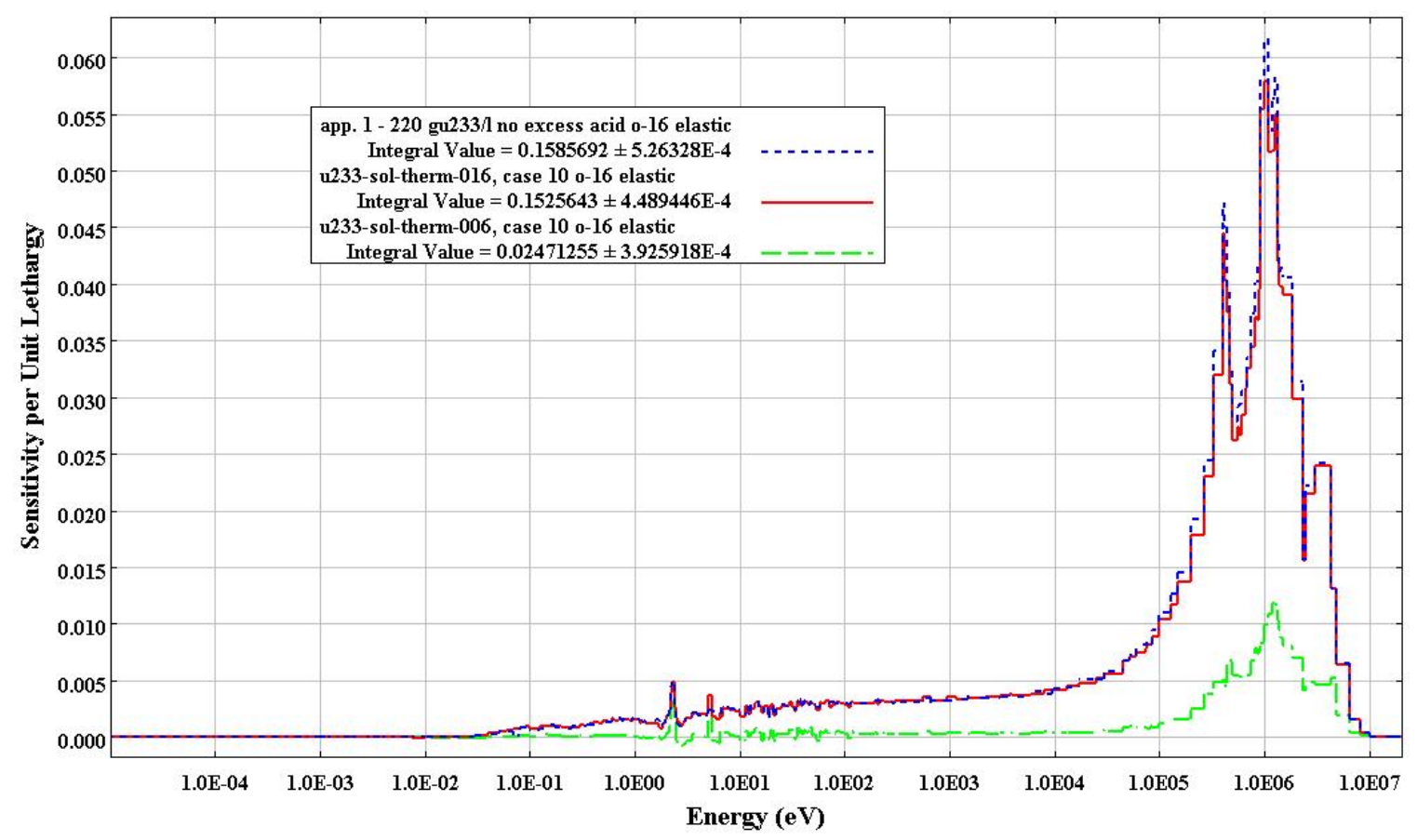

Fig. 14. ${ }^{16} \mathrm{O}$ elastic scattering sensitivity profiles for application 1 and experiments UST-016, case 10 and UST-006, case 10. 


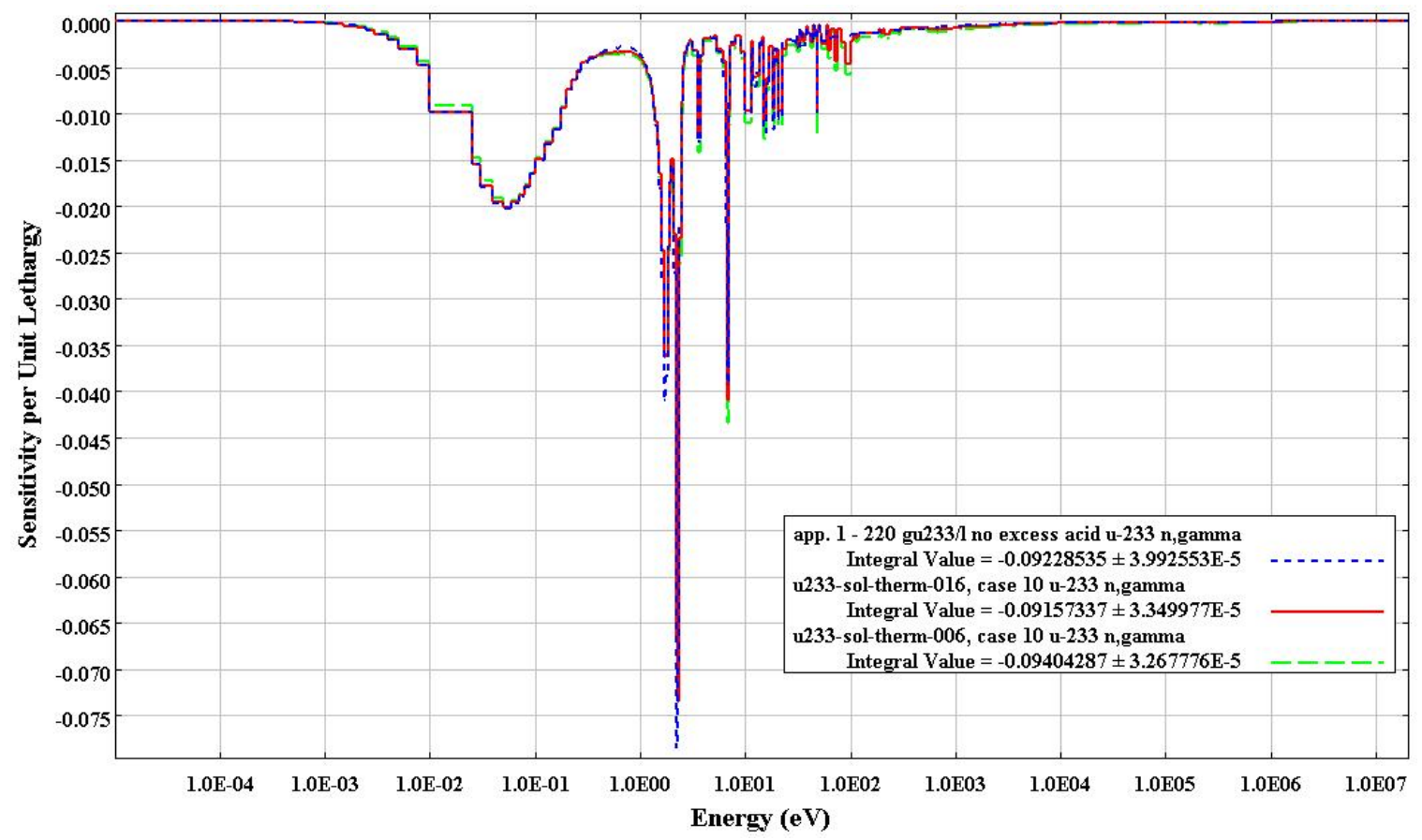

Fig. 15. ${ }^{233} \mathrm{U}(\mathrm{n}, \gamma)$ reaction sensitivity profiles for application 1 and experiments UST-016, case 10 and UST-006, case 10.

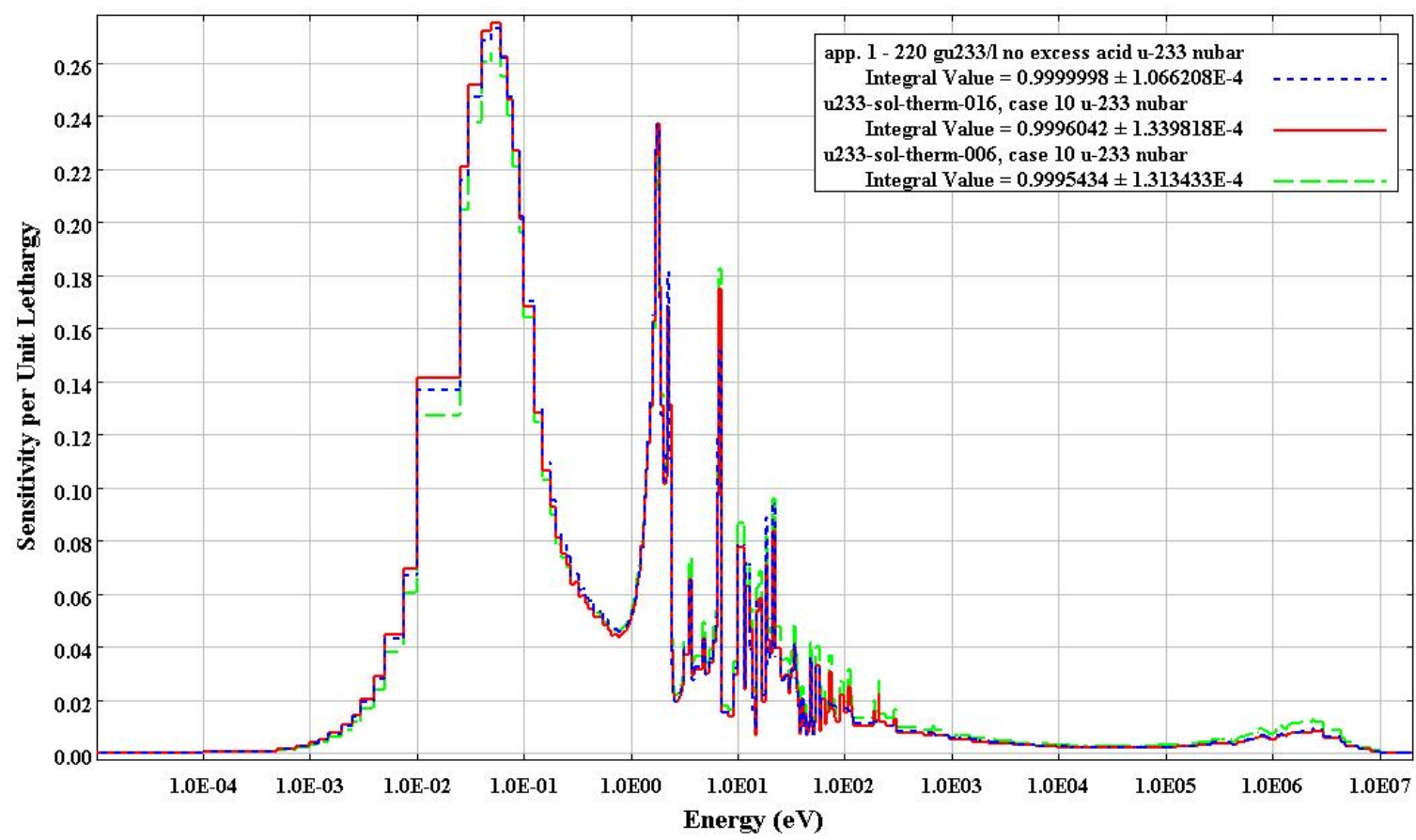

Fig. 16. ${ }^{233} \mathrm{U}$ Nu-bar sensitivity profiles for application 1 and experiments UST-016, case 10 and UST-006, case 10. 


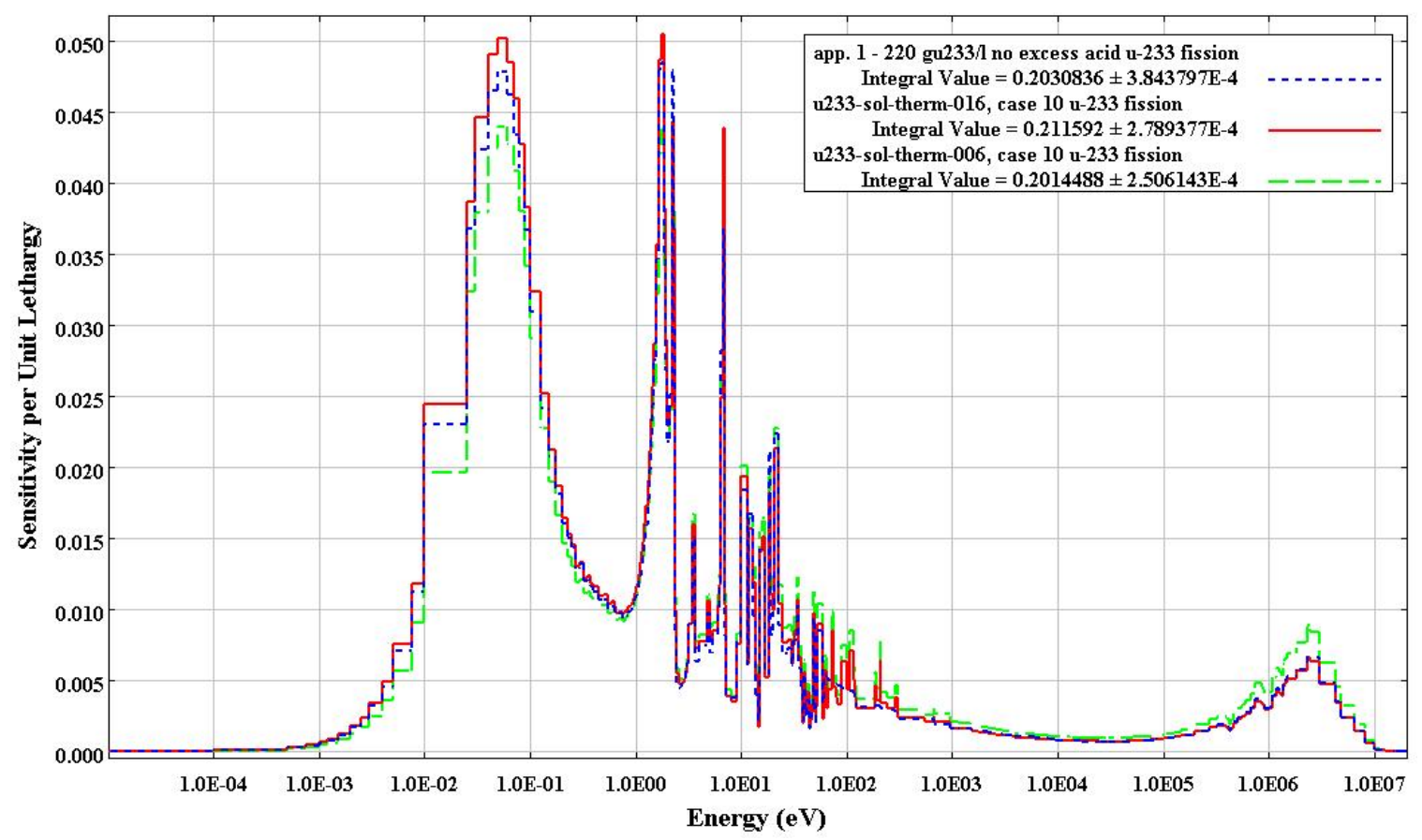

Fig. 17. ${ }^{233} \mathrm{U}$ fission reaction sensitivity profiles for application 1 and experiments UST-016, case 10 and UST-006, case 10.

One method of quantifying the contribution of each nuclide reaction towards applicability is to examine the extended $\mathrm{c}_{\mathrm{r}}$ edit generated when the application is compared to itself. By definition, the $c_{r}$ value of a system compared to itself is 1.0 since every energy-dependent sensitivity coefficient exactly matches between the application and the "experiment," which is the application itself. The extended $c_{r}$ edit shows the contributions of each nuclide and reaction to this perfect similarity, ranked in descending order. This edit provides a guide to which nuclides and reactions are important to validate the application in terms of the uncertainty-weighted sensitivities. Table 4 shows the top contributors toward similarity for application 1 compared to itself. The data show some of the characteristics of the ideal critical experiment for validation of application 1 .

Table 4. Top contributors to similarity $\left(c_{r}\right)$ for application 1 compared to itself

\begin{tabular}{|c|c|c|}
\hline \multicolumn{2}{|c|}{ Covariance matrix } & \multirow{2}{*}{$\begin{array}{c}\text { Contribution to } \\
\text { similarity }\left(c_{r}\right)\end{array}$} \\
\hline \multicolumn{2}{|c|}{ Nuclide reaction with nuclide reaction } & \\
\hline Elastic & ${ }^{1} \mathrm{H}$ elastic & 0.494 \\
\hline${ }^{16} \mathrm{O} \quad$ Elastic & ${ }^{16} \mathrm{O}$ elastic & 0.181 \\
\hline${ }^{233} \mathrm{U} \quad \mathrm{n}, \gamma$ & ${ }^{233} \mathrm{U} \quad \mathrm{n}, \gamma$ & 0.145 \\
\hline${ }^{233} \mathrm{U} \quad$ nu-bar & ${ }^{233} \mathrm{U} \quad$ nu-bar & 0.101 \\
\hline${ }^{233} \mathrm{U} \quad$ Fission & ${ }^{233} \mathrm{U}$ fission & 0.066 \\
\hline
\end{tabular}

Tables 5 and 6 show the top contributors to similarity for the application compared to the experiments with the highest $c_{r}$ value and the lowest "similar" $c_{r}$ value. Differences between the partial $\mathrm{c}_{\mathrm{r}}$ values shown in Table 4 for the application compared to itself and in Tables 5 and 6 for 
the application compared to each of these experiments are quantified with the $\Delta c_{r}$ values in Tables 5 and 6 . Any non-zero $\Delta c_{r}$ indicates differences in the sensitivities between the application and the experiment, which will lead to decreased $c_{r}$ values. A negative $\Delta c_{r}$ value indicates that the sensitivity of the experiment is generally lower than that of the application, especially in energy regions where the uncertainty in the cross section is higher. A negative $\Delta c_{r}$ value leads directly to reduced values of $c_{r}$. A positive $\Delta c_{r}$ value indicates that the sensitivity of the experiment is generally greater than that of the application, especially in energy regions where the cross section uncertainty is greater (see Figs. 8-11). These values also lead to a reduction in $\mathrm{c}_{\mathrm{r}}$ by increasing the overall uncertainty in $k_{\text {eff }}$ for the experiment, which increases the denominator of the $c_{r}$ equation, resulting in a smaller value of $c_{r}$. The $\Delta c_{r}$ values identify the nuclide-reaction pairs that are limiting similarity for the two experiments. Note that for experiment UST-006 case 10 the $\Delta \mathrm{c}_{\mathrm{r}}$ values with the largest magnitude are for ${ }^{1} \mathrm{H}$ elastic scattering and ${ }^{16} \mathrm{O}$ elastic scattering. Both of these values are negative, and the sensitivities of the experiments are much lower than those of the application, as shown in Figs. 13 and 14, respectively. The $\Delta c_{\mathrm{r}}$ for the ${ }^{233} \mathrm{U}(\mathrm{n}, \gamma)$ reaction has a small positive value, due to the experiment sensitivity slightly exceeding that of the application at intermediate energies where the cross-section uncertainties are higher, as shown in Fig. 11.

Table 5. Top contributors to similarity $\left(c_{r}\right)$ for application 1 compared to UST-016, case 10

\begin{tabular}{|c|c|c|c|c|c|}
\hline \multicolumn{4}{|c|}{ Covariance matrix } & \multirow{2}{*}{$\begin{array}{l}\text { Contribution to } \\
\text { similarity }\left(c_{\mathbf{r}}\right)\end{array}$} & \multirow{2}{*}{$\begin{array}{c}\text { Change from } \\
\text { optimum similarity } \\
\left(\Delta c_{r}{ }^{a}\right)\end{array}$} \\
\hline \multicolumn{4}{|c|}{ Nuclide reaction with nuclide reaction } & & \\
\hline${ }^{1} \mathrm{H}$ & elastic & ${ }^{1} \mathrm{H}$ & elastic & 0.495 & 0.001 \\
\hline${ }^{16} \mathrm{O}$ & elastic & ${ }^{16} \mathrm{O}$ & elastic & 0.177 & -0.004 \\
\hline${ }^{233} \mathrm{U}$ & $\mathrm{n}, \gamma$ & ${ }^{233} \mathrm{U}$ & $\mathrm{n}, \gamma$ & 0.146 & 0.000 \\
\hline${ }^{233} \mathrm{U}$ & nu-bar & ${ }^{233} \mathrm{U}$ & nu-bar & 0.102 & 0.002 \\
\hline${ }^{233} \mathrm{U}$ & fission & ${ }^{233} \mathrm{U}$ & fission & 0.069 & 0.002 \\
\hline
\end{tabular}

Table 6. Top contributors to similarity $\left(c_{r}\right)$ for application 1 compared to UST-006, case 10

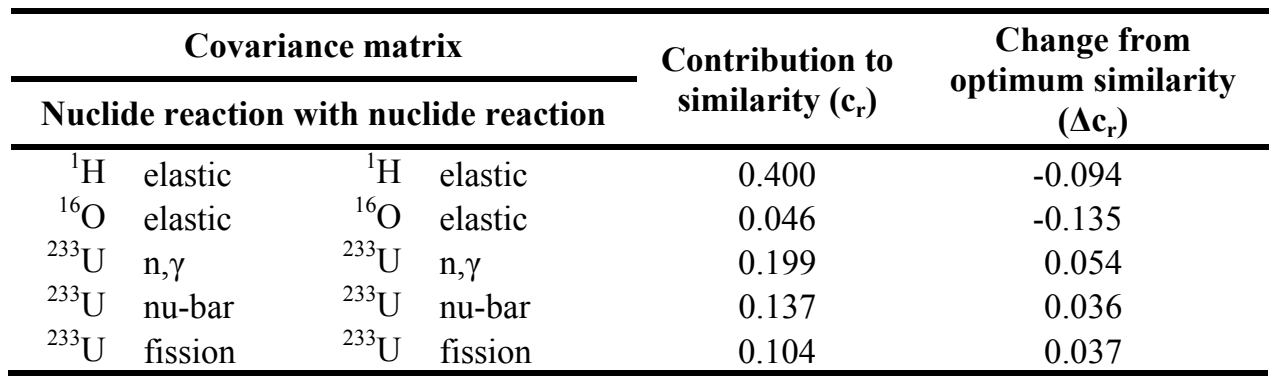

The TSUNAMI-IP output may be used in this way to identify why an experiment is not similar to an application and what variations to the experiment might identify experiments that are more similar to the target application. 


\subsection{APPLICATION $2-300 \mathrm{~g} \mathrm{U}$ (WITH CEUSP U ISOTOPICS)/LITER SPHERE}

Table 7 and Fig. 18 show the distribution of $\mathrm{c}_{\mathrm{r}}$ values calculated for the 672 critical configurations examined. Analysis of the similarity results follows Fig. 18.

Table 7. Application 2 similarity summary

\begin{tabular}{ccc}
\hline $\begin{array}{c}\text { Similarity } \\
\text { index } \\
\text { range }\end{array}$ & $\begin{array}{c}\text { Number } \\
\text { of } \\
\text { experiments }\end{array}$ & Applicability \\
\hline $\mathrm{c}_{\mathrm{r}}<0.1$ & 43 & Low \\
$0.1 \leq \mathrm{c}_{\mathrm{r}}<0.2$ & 18 & Low \\
$0.2 \leq \mathrm{c}_{\mathrm{r}}<0.3$ & 21 & Low \\
$0.3 \leq \mathrm{c}_{\mathrm{r}}<0.4$ & 19 & Low \\
$0.4 \leq \mathrm{c}_{\mathrm{r}}<0.5$ & 32 & Low \\
$0.5 \leq \mathrm{c}_{\mathrm{r}}<0.6$ & 115 & Low \\
$0.6 \leq \mathrm{c}_{\mathrm{r}}<0.7$ & 158 & Low \\
$0.7 \leq \mathrm{c}_{\mathrm{r}}<0.8$ & 150 & Low \\
$0.8 \leq \mathrm{c}_{\mathrm{r}}<0.9$ & 48 & Marginal \\
$0.9 \leq \mathrm{c}_{\mathrm{r}}<0.95$ & 42 & Applicable \\
$0.95 \leq \mathrm{c}_{\mathrm{r}}<1.0$ & 26 & High \\
All & 672 & \\
\hline
\end{tabular}

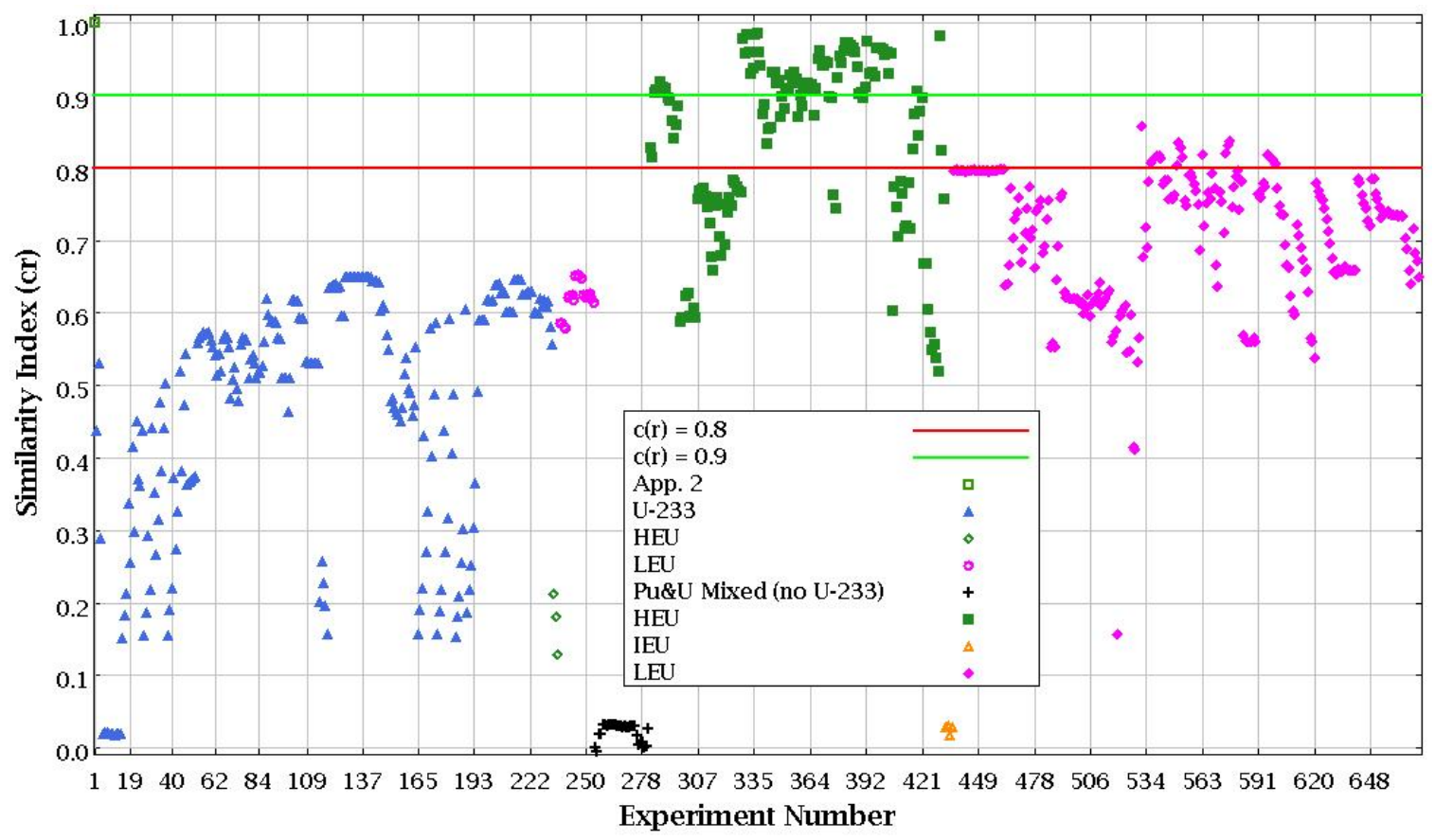

Fig. 18. Application 2 similarity index values $\left(c_{r}\right)$ for 672 critical experiments. 
The similarity results for application 2 demonstrate that 26 of the evaluated critical configurations are considered to be highly similar $\left(\mathrm{c}_{\mathrm{r}}>0.95\right)$ to application 2 . An additional 42 critical configurations are considered to be adequately similar $\left(0.95>c_{r}>0.90\right)$ to application 2 . An additional 48 critical configurations are considered to be only marginally similar $\left(0.9>\mathrm{c}_{\mathrm{r}}>0.8\right)$ to application 2. Considering that there are 68 configurations that are highly or adequately similar to application 2 , use of the marginally similar configurations is not recommended. A list of critical experiments ordered by decreasing similarity is provided in Appendix D.

The TSUNAMI-IP output for this application includes a detailed calculation of the $\mathrm{c}_{\mathrm{r}}$ value of the application compared with itself. This edit indicates that the most important contributors to $\mathrm{c}_{\mathrm{r}}$ for this application are ${ }^{1} \mathrm{H}$ elastic scattering, ${ }^{235} \mathrm{U}$ nu-bar, ${ }^{235} \mathrm{U}(\mathrm{n}, \gamma),{ }^{16} \mathrm{O}$ elastic scattering, and ${ }^{235} \mathrm{U}$ fission reactions.

The highest $\mathrm{c}_{\mathrm{r}}$ value, 0.985 , was generated by comparing experiment HST-001, case 8 to application 2 . Of the $c_{r}$ values above 0.9 , the lowest value, 0.901 , was generated by comparing experiment HST-007, case 11 to the application. Figures 19-23 show the sensitivity profiles for the five reactions identified above for application 2 and for HST-001, case 8 and HST-007, case 11 .

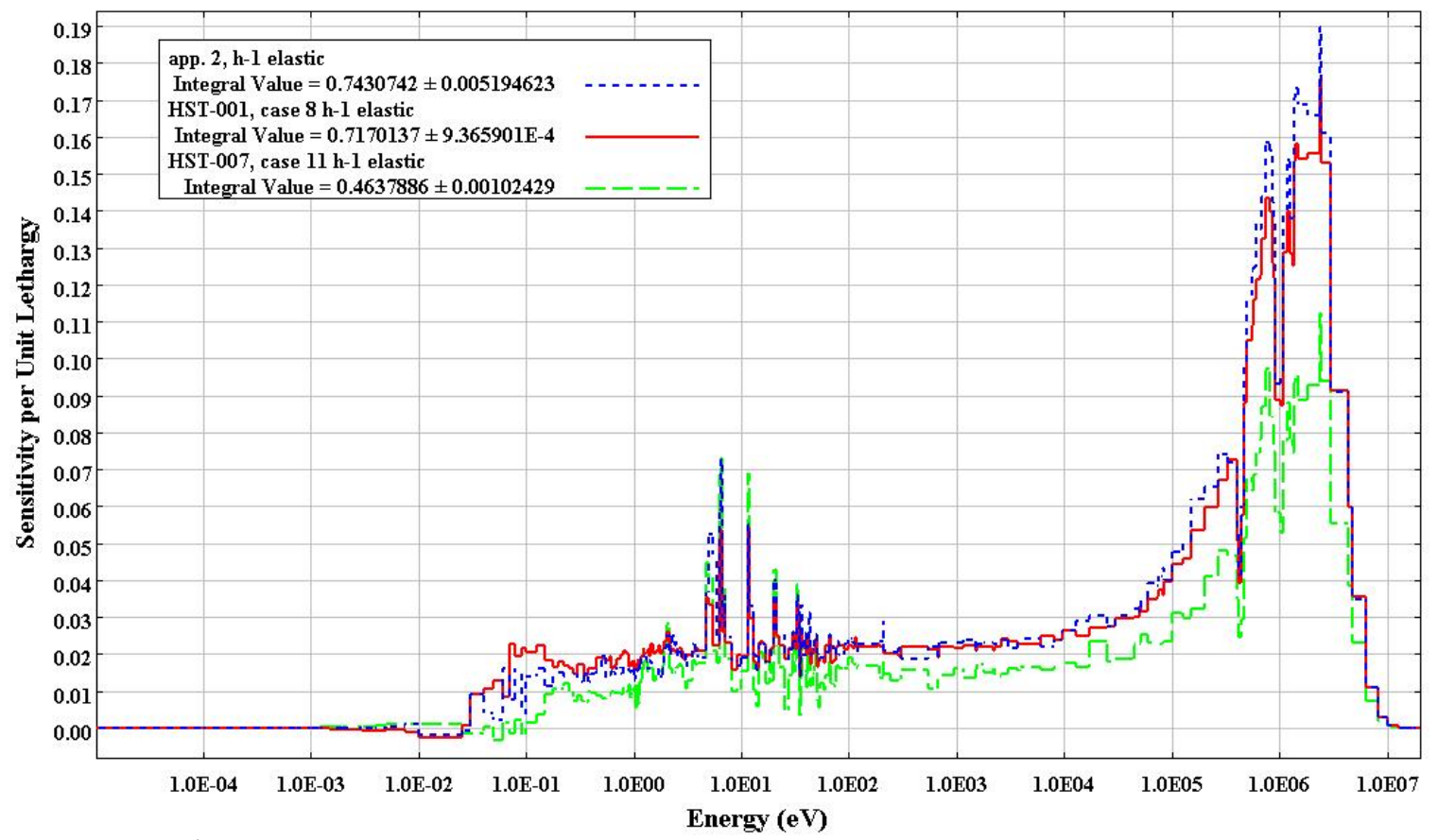

Fig. 19. ${ }^{1} \mathrm{H}$ elastic scattering reaction sensitivity profiles for application 2 and experiments HST-001, case 8 and HST-007, case 11. 


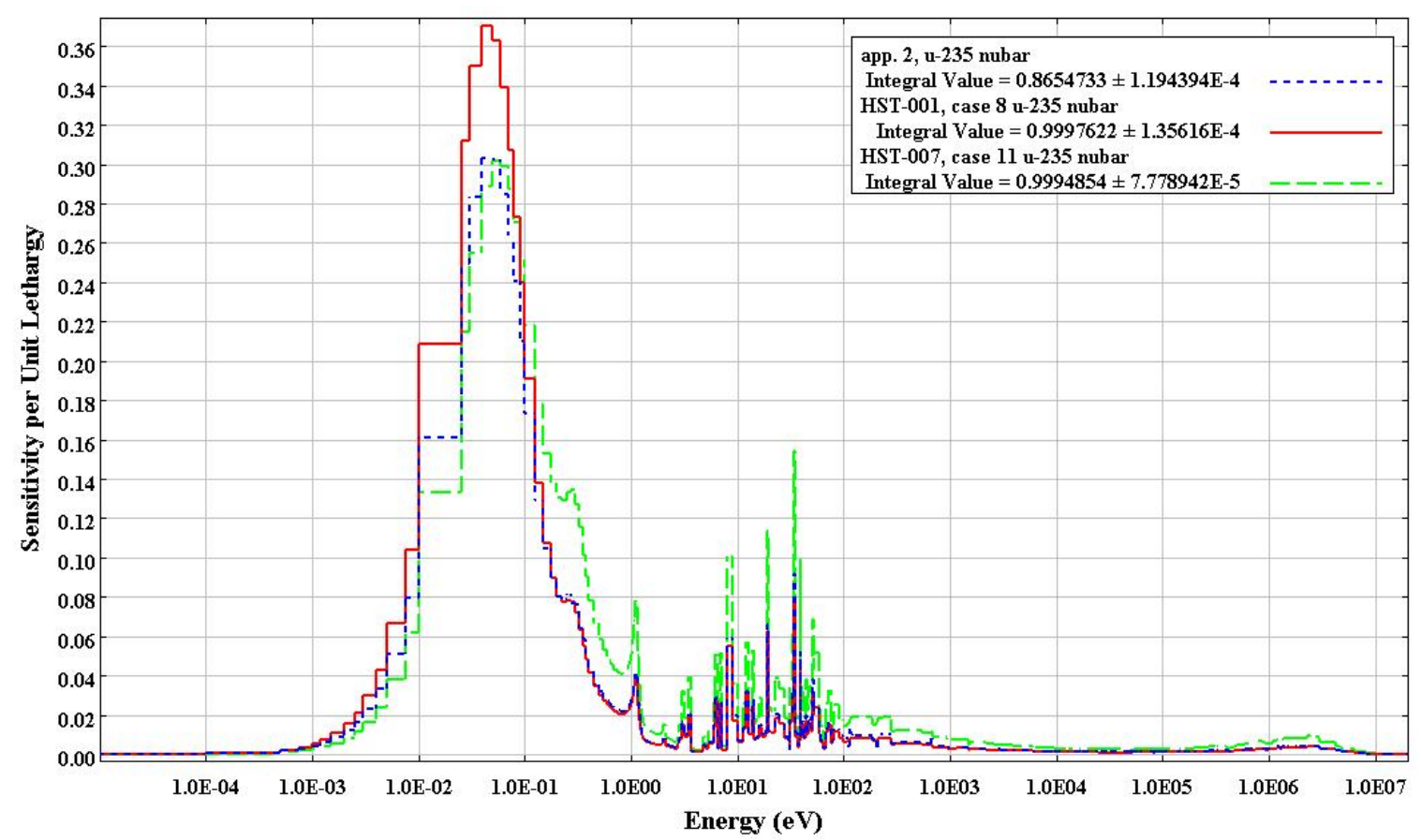

Fig. 20. ${ }^{235} \mathrm{U}$ Nu-bar sensitivity profiles for application 2 and experiments HST-001, case 8 and HST-007, case 11.

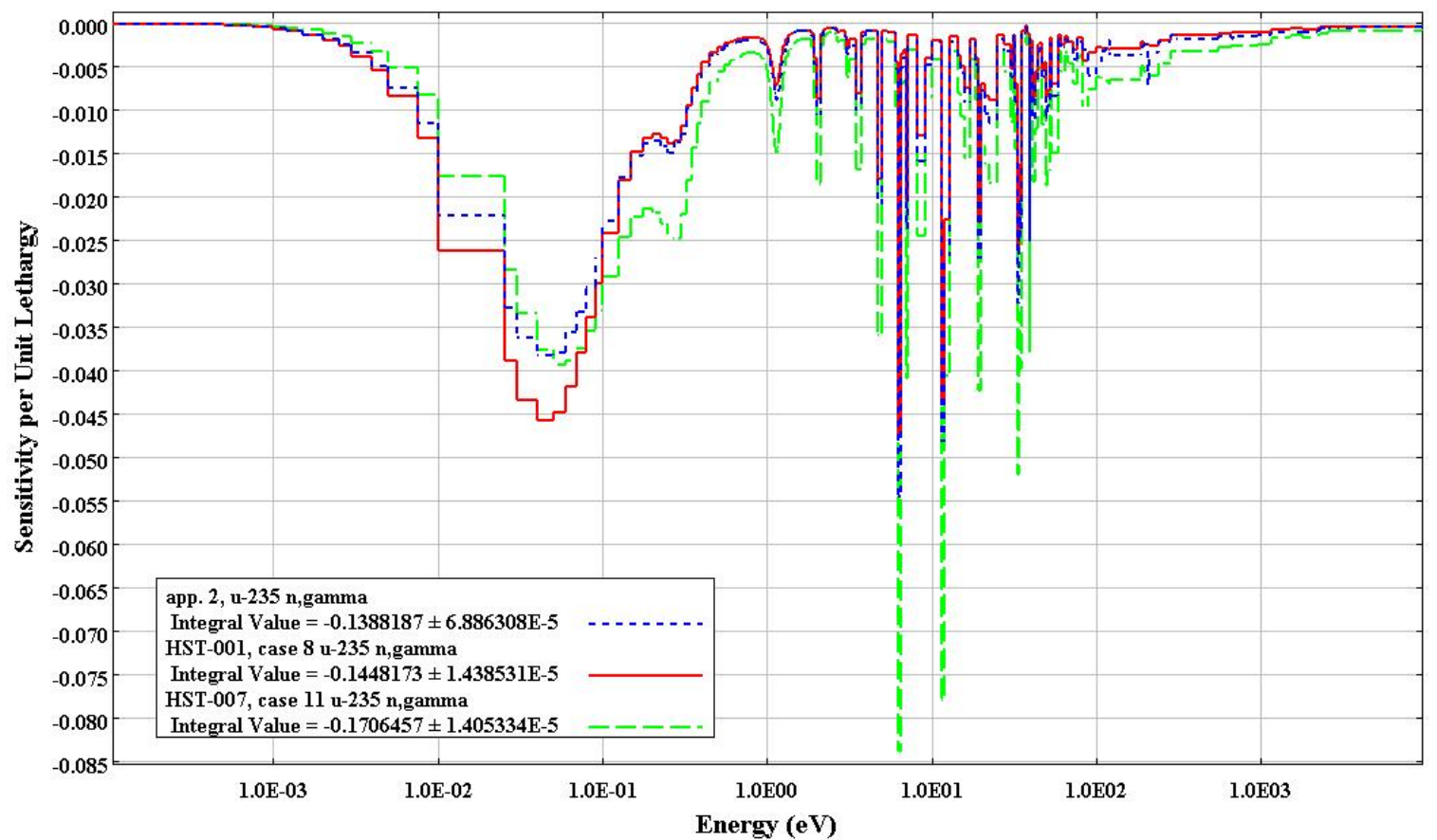

Fig. 21. ${ }^{235} U(n, \gamma)$ reaction sensitivity profiles for application 2 and experiments HST-001, case 8 and HST-007, case 11. 


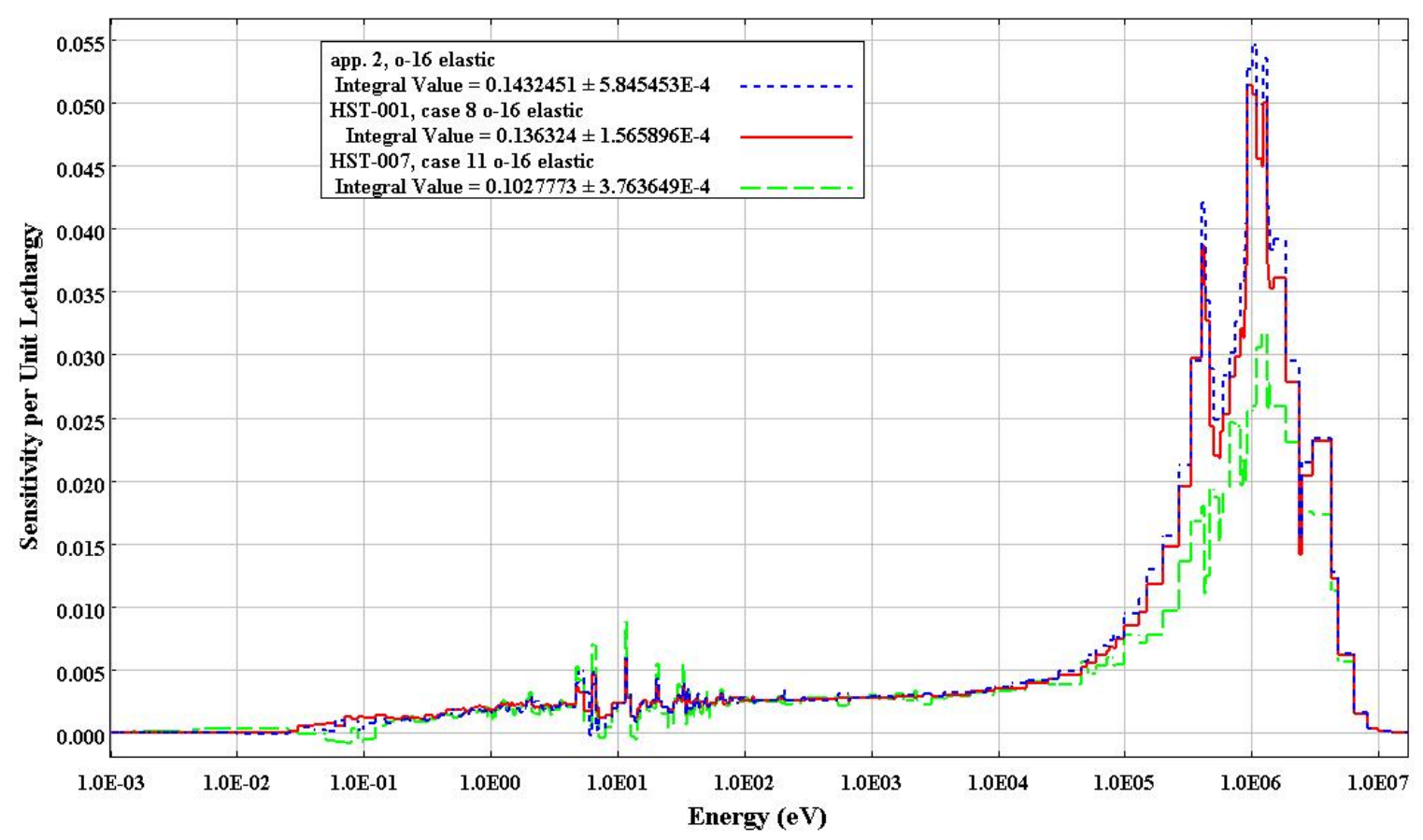

Fig. 22. ${ }^{16} \mathrm{O}$ elastic scattering reaction sensitivity profiles for application 2 and experiments HST-001, case 8 and HST-007, case 11.

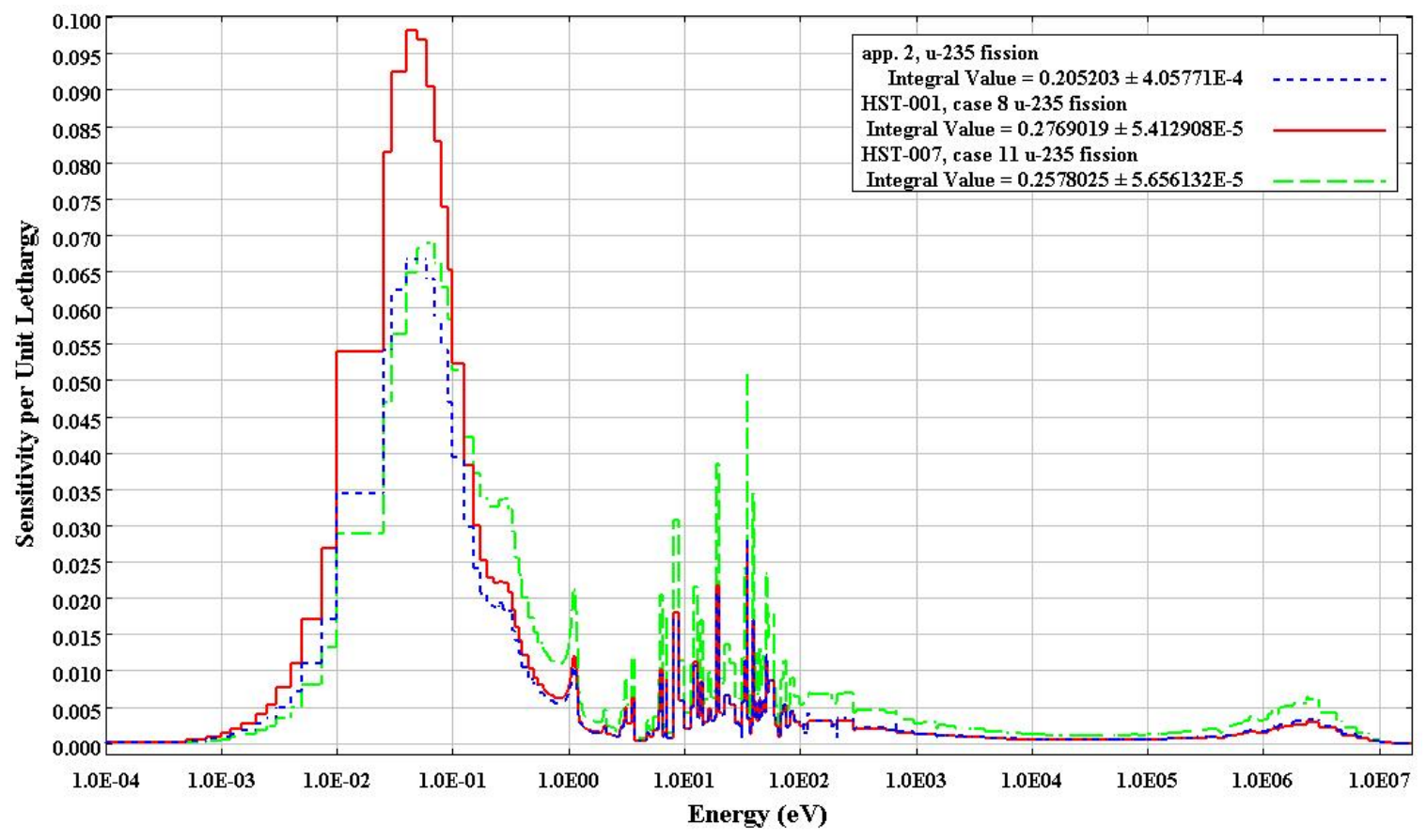

Fig. 23. ${ }^{235} \mathrm{U}$ fission reaction sensitivity profiles for application 2 and experiments HST-001, case 8 and HST-007, case 11. 
Table 8 shows the top contributors toward similarity for application 2 compared to itself. The data show some of the characteristics of the ideal critical experiment for validation of application 2 .

Table 8. Top contributors to similarity $\left(c_{r}\right)$ for application 2 compared to itself

\begin{tabular}{ccccc}
\hline \multicolumn{3}{c}{ Covariance matrix } & $\begin{array}{c}\text { Contribution to } \\
\text { similarity }\left(\mathbf{c}_{\mathbf{r}}\right)\end{array}$ \\
\hline \multicolumn{2}{c}{ Nuclide reaction with nuclide reaction } & ${ }^{1} \mathrm{H}$ & elastic & 0.369 \\
\hline${ }^{1} \mathrm{H}$ & elastic & ${ }^{235} \mathrm{U}$ & nu-bar & 0.290 \\
${ }^{235} \mathrm{U}$ & nu-bar & ${ }^{235} \mathrm{U}$ & $\mathrm{n}, \gamma$ & 0.147 \\
${ }^{235} \mathrm{U}$ & $\mathrm{n}, \gamma$ & ${ }^{16} \mathrm{O}$ & elastic & 0.146 \\
${ }^{16} \mathrm{O}$ & elastic & ${ }^{235} \mathrm{U}$ & fission & 0.021 \\
\hline${ }^{235} \mathrm{U}$ & fission &
\end{tabular}

Tables 9 and 10 show the top contributors toward similarity for the application compared to the experiments with the highest $c_{r}$ value and the lowest $c_{r}$ value that is greater than 0.9. Differences between the partial $c_{\mathrm{r}}$ values shown in Table 8 for the application compared to itself and Tables 9 and 10 for the application compared to each of these experiments are quantified with the $\Delta \mathrm{c}_{\mathrm{r}}$ values shown in Tables 9 and 10. For an explanation of these values, see Section 4.1. Note that for experiment HST-007 case 11, the $\Delta \mathrm{c}_{\mathrm{r}}$ values with the largest negative magnitude are for ${ }^{1} \mathrm{H}$ elastic scattering and ${ }^{16} \mathrm{O}$ elastic scattering, reflecting their reduced sensitivity relative to the application, as shown in Figs. 19 and 22. The largest positive $\Delta c_{r}$ is for ${ }^{235} U n, \gamma$, where the sensitivity of the experiment exceeds that of the application, especially at intermediate energies, where the cross-section uncertainties are higher, as shown in Fig. 21.

Table 9. Top contributors to similarity $\left(c_{r}\right)$ for application 2 compared to experiment HST-001, case 8

\begin{tabular}{|c|c|c|c|c|}
\hline \multicolumn{3}{|c|}{ Covariance matrix } & \multirow{2}{*}{$\begin{array}{l}\text { Contribution to } \\
\text { similarity }\left(c_{\mathbf{r}}\right)\end{array}$} & \multirow{2}{*}{$\begin{array}{c}\text { Change from } \\
\text { optimum similarity } \\
\left(\Delta c_{r}\right)\end{array}$} \\
\hline \multicolumn{3}{|c|}{ Nuclide reaction with nuclide reaction } & & \\
\hline${ }^{1} \mathrm{H}$ & Elastic & ${ }^{1} \mathrm{H}$ elastic & 0.344 & -0.026 \\
\hline${ }^{235} \mathrm{U}$ & nu-bar & ${ }^{235} \mathrm{U} \quad$ nu-bar & 0.338 & 0.048 \\
\hline${ }^{235} \mathrm{U}$ & $\mathrm{n}, \gamma$ & ${ }^{235} \mathrm{U} \quad \mathrm{n}, \gamma$ & 0.129 & -0.018 \\
\hline${ }^{16} \mathrm{O}$ & elastic & ${ }^{16} \mathrm{O}$ elastic & 0.138 & -0.008 \\
\hline${ }^{235} \mathrm{U}$ & fission & ${ }^{235} \mathrm{U}$ fission & 0.023 & 0.002 \\
\hline
\end{tabular}

Table 10. Top contributors to similarity $\left(c_{r}\right)$ for application 2 compared to experiment HST-007, case 11

\begin{tabular}{|c|c|c|c|c|}
\hline \multicolumn{3}{|c|}{ Covariance matrix } & \multirow{2}{*}{$\begin{array}{l}\text { Contribution to } \\
\text { similarity }\left(c_{\mathbf{r}}\right)\end{array}$} & \multirow{2}{*}{$\begin{array}{c}\text { Change from } \\
\text { optimum similarity } \\
\left(\Delta c_{r}\right)\end{array}$} \\
\hline \multicolumn{3}{|c|}{ Nuclide reaction with nuclide reaction } & & \\
\hline${ }^{1} \mathrm{H}$ & elastic & ${ }^{1} \mathrm{H}$ elastic & 0.210 & -0.159 \\
\hline${ }^{235} \mathrm{U}$ & nu-bar & ${ }^{235} \mathrm{U} \quad$ nu-bar & 0.311 & 0.021 \\
\hline${ }^{235} \mathrm{U}$ & $\mathrm{n}, \gamma$ & ${ }^{235} \mathrm{U}$ & 0.224 & 0.077 \\
\hline${ }^{16} \mathrm{O}$ & elastic & ${ }^{16} \mathrm{O}$ elastic & 0.104 & -0.042 \\
\hline${ }^{235} \mathrm{U}$ & fission & ${ }^{235} \mathrm{U}$ fission & 0.037 & 0.016 \\
\hline
\end{tabular}




\subsection{APPLICATION 3-600 g U (DOWNBLENDED U ISOTOPICS)/LITER SPHERE}

Table 11 and Fig. 24 show the distribution of $\mathrm{c}_{\mathrm{r}}$ values calculated for the 672 critical configurations examined. Analysis of the similarity results follows Fig. 24.

Table 11. Application 3 similarity summary

\begin{tabular}{ccc}
\hline $\begin{array}{c}\text { Similarity } \\
\text { index } \\
\text { range }\end{array}$ & $\begin{array}{c}\text { Number } \\
\text { of } \\
\text { experiments }\end{array}$ & Applicability \\
\hline $\mathrm{c}_{\mathrm{r}}<0.1$ & 54 & Low \\
$0.1 \leq \mathrm{c}_{\mathrm{r}}<0.2$ & 124 & Low \\
$0.2 \leq \mathrm{c}_{\mathrm{r}}<0.3$ & 141 & Low \\
$0.3 \leq \mathrm{c}_{\mathrm{r}}<0.4$ & 176 & Low \\
$0.4 \leq \mathrm{c}_{\mathrm{r}}<0.5$ & 79 & Low \\
$0.5 \leq \mathrm{c}_{\mathrm{r}}<0.6$ & 68 & Low \\
$0.6 \leq \mathrm{c}_{\mathrm{r}}<0.7$ & 30 & Low \\
$0.7 \leq \mathrm{c}_{\mathrm{r}}<0.8$ & 0 & Low \\
$0.8 \leq \mathrm{c}_{\mathrm{r}}<0.9$ & 0 & Marginal \\
$0.9 \leq \mathrm{c}_{\mathrm{r}}<0.95$ & 0 & Applicable \\
$0.95 \leq \mathrm{c}_{\mathrm{r}}<1.0$ & 0 & High \\
All & 672 & \\
\hline
\end{tabular}

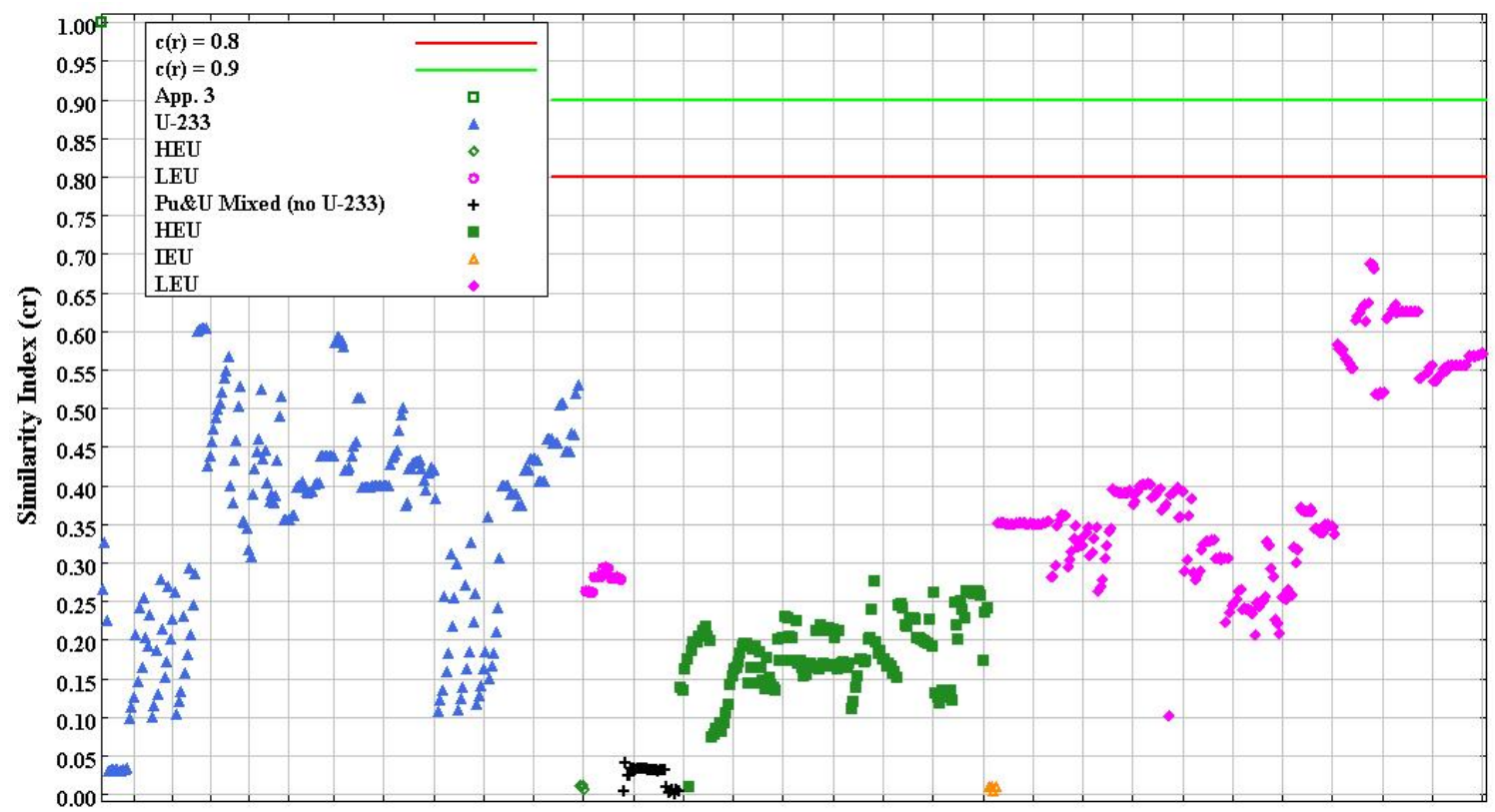

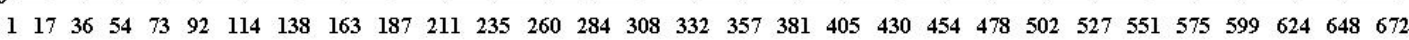
Experiment Number

Fig. 24. Application 3 similarity index values $\left(c_{r}\right)$ for 672 critical experiments. 
The similarity results for application 3 demonstrate that none of the 672 critical experiments are even marginally similar $\left(c_{r} \geq 0.8\right)$. This should not be particularly surprising because none of the experiments involve low enrichment of ${ }^{233} \mathrm{U}$ as the principal fissionable nuclide. The neutronic interaction between the $96.8 \mathrm{wt} \%{ }^{238} \mathrm{U}$ and the $3 \mathrm{wt} \%{ }^{233} \mathrm{U}$ is not exemplified by any available critical experiments. This lack of applicable critical experiments will be addressed in the discussion addressing validation gaps presented in Section 6. Experiment LST-005, case 1 yielded the highest $c_{r}$ value, which is 0.687 .

The TSUNAMI-IP output for this application includes a detailed calculation of the $c_{r}$ value of the application compared with itself. This edit indicates that the five most important contributors to $\mathrm{c}_{\mathrm{r}}$ for this application are ${ }^{14} \mathrm{~N}(\mathrm{n}, \mathrm{p}),{ }^{238} \mathrm{U}(\mathrm{n}, \gamma),{ }^{233} \mathrm{U}$ fission, ${ }^{1} \mathrm{H}(\mathrm{n}, \gamma)$, and ${ }^{233} \mathrm{U}$ nu-bar.

Figures 25-29 show the sensitivity profiles for application 3 and for the most similar experiment, LST-005, case 1 , for each of these reactions. Note that LST-005 contains no ${ }^{233} \mathrm{U}$ and, therefore, is not shown in Figs. 27 or 29.

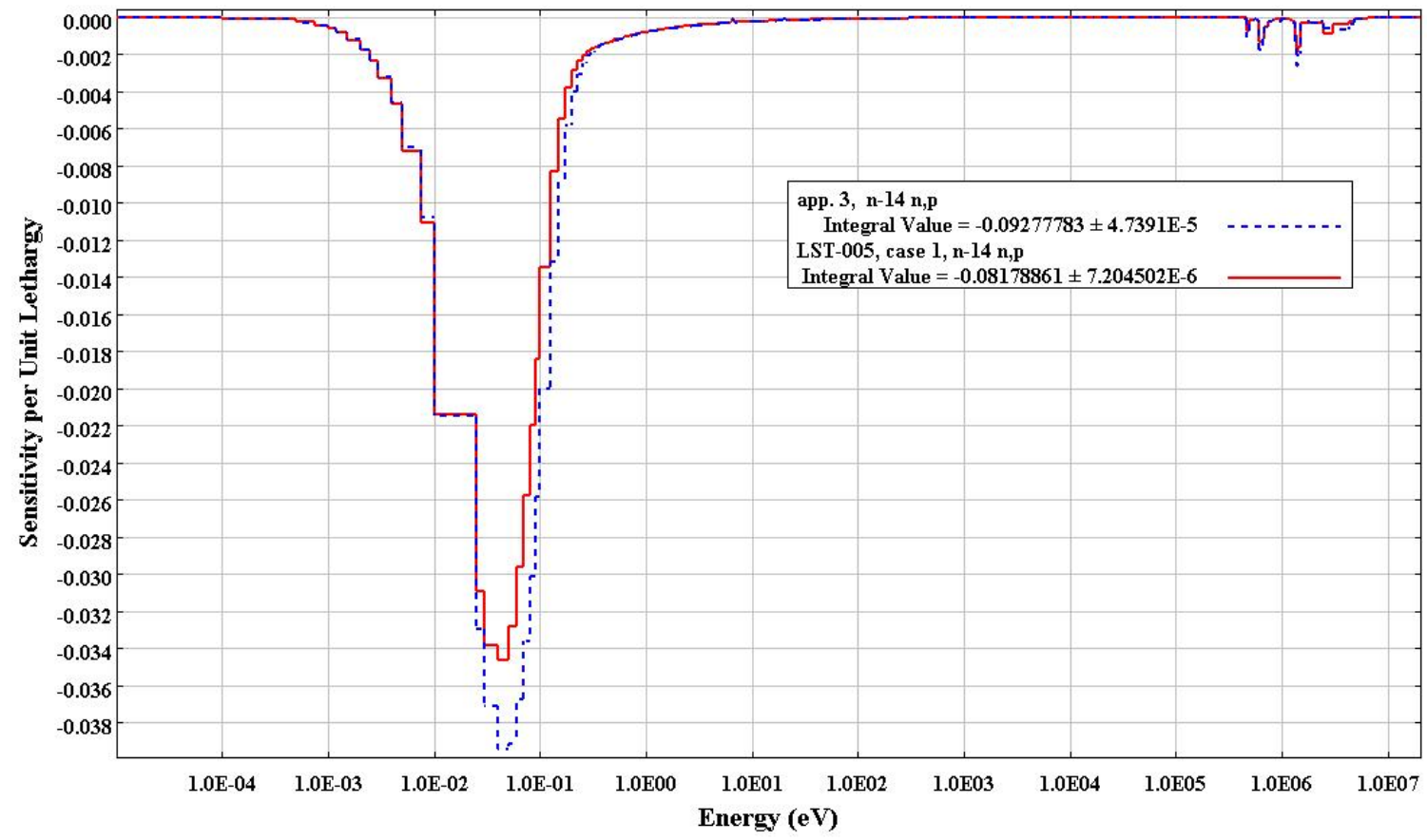

Fig. $25 .{ }^{14} \mathrm{~N}(\mathrm{n}, \mathrm{p})$ reaction sensitivity profiles for application 3 and experiment LST-005, case 1. 


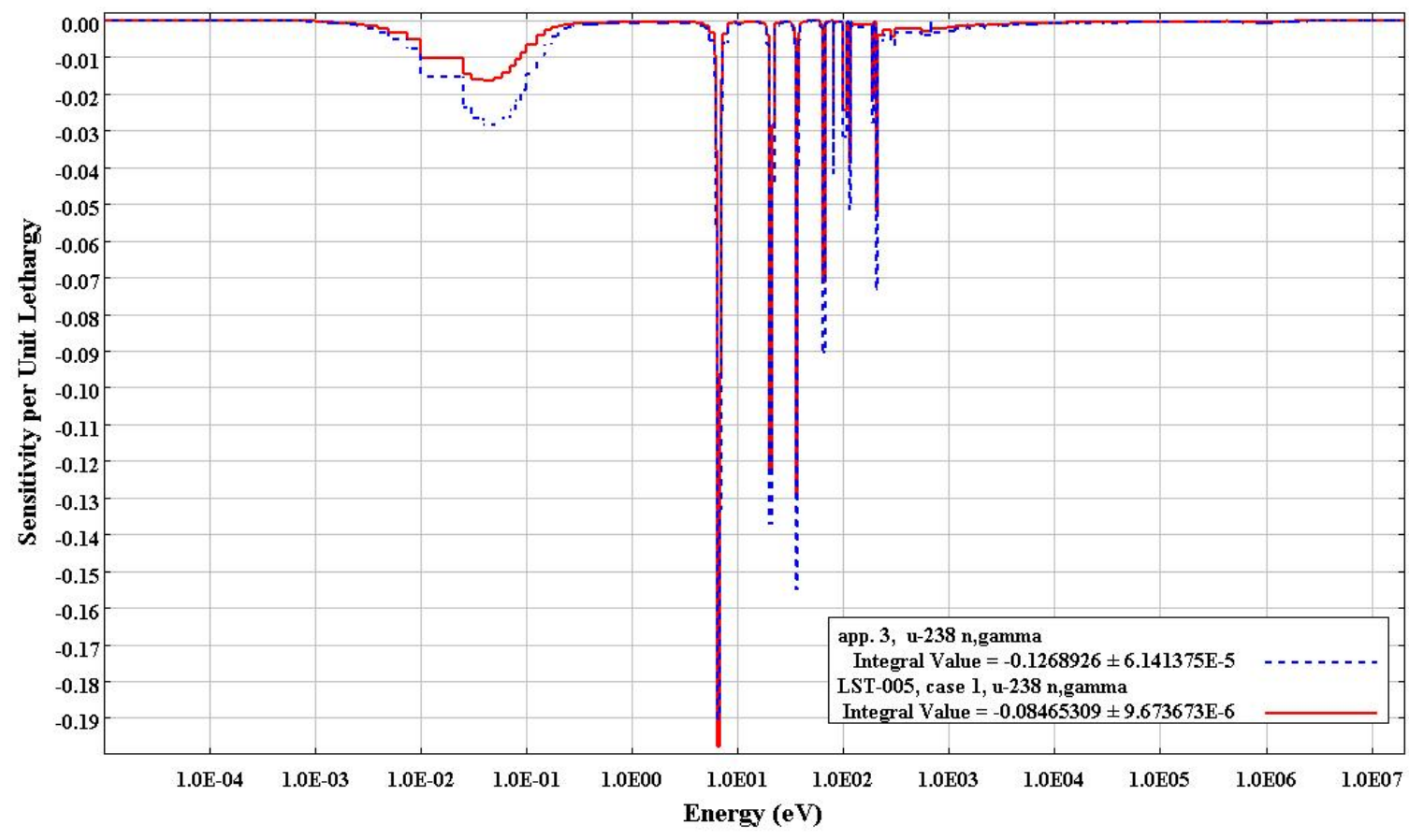

Fig. 26. ${ }^{238} \mathrm{U}(\mathrm{n}, \gamma)$ reaction sensitivity profiles for application 3 and experiment LST-005, case 1.

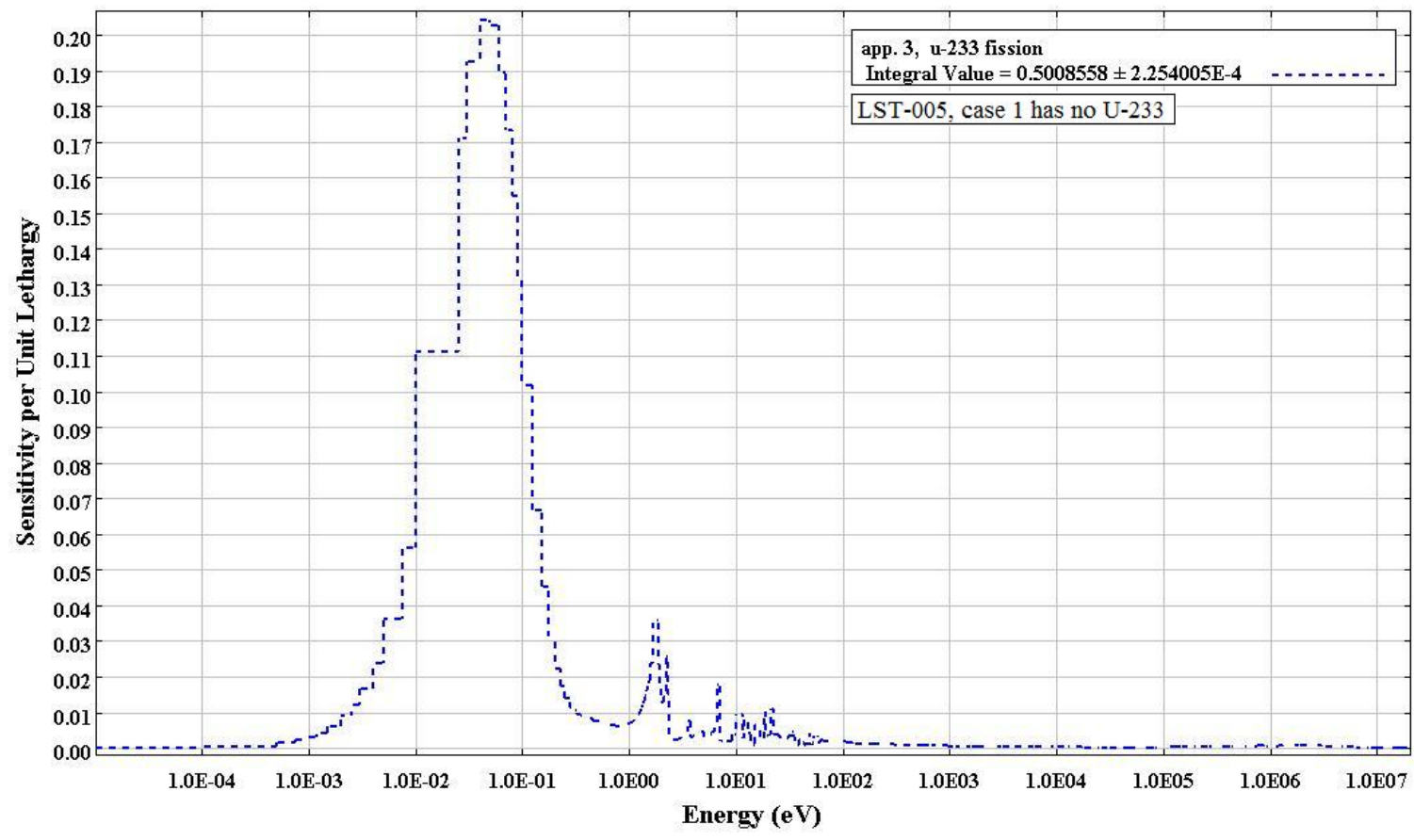

Fig. 27. ${ }^{233} \mathrm{U}$ fission reaction sensitivity profile for application 3 . 


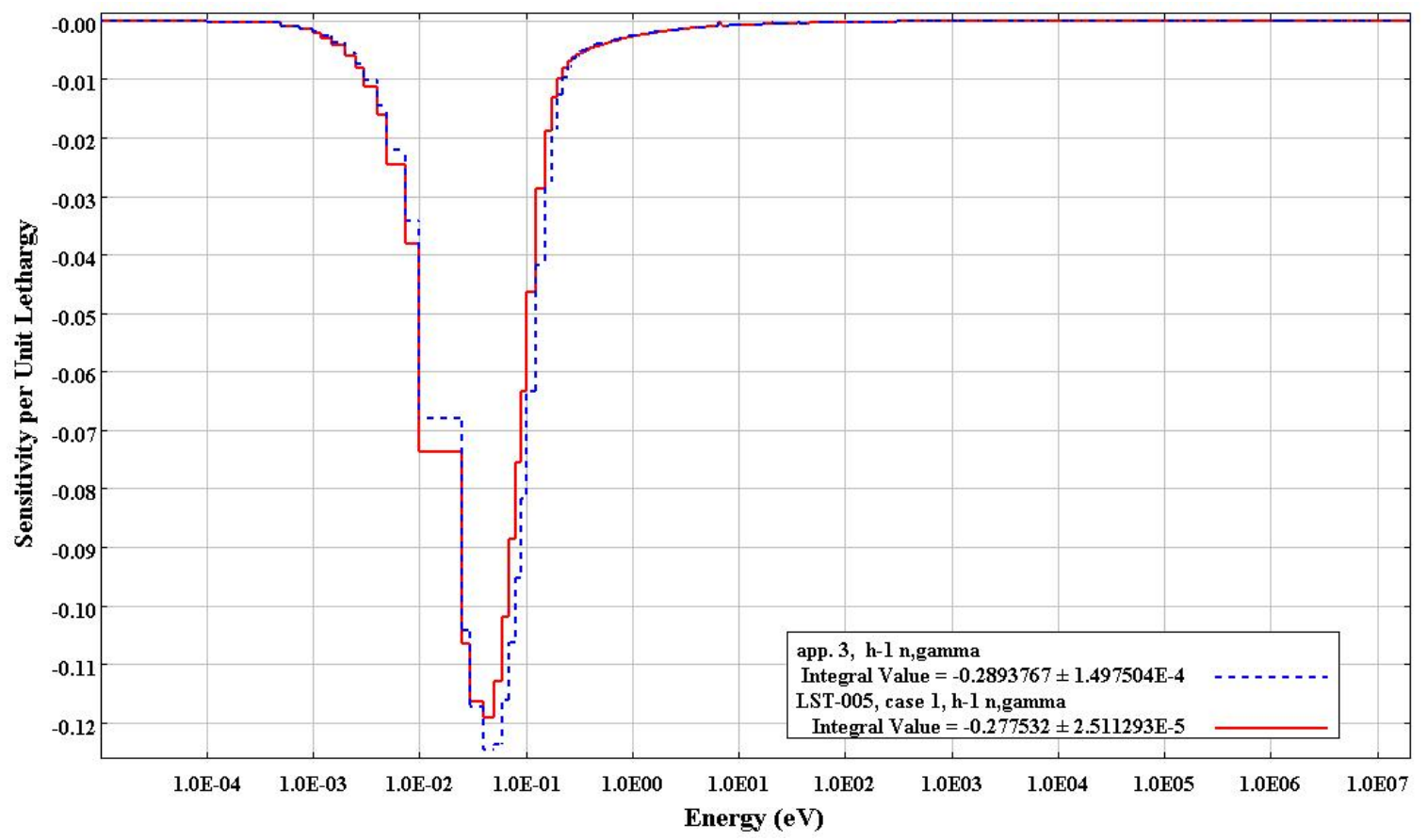

Fig. 28. ${ }^{1} \mathrm{H}(\mathrm{n}, \gamma)$ reaction sensitivity profiles for application 3 and experiment LST-005, case 1.

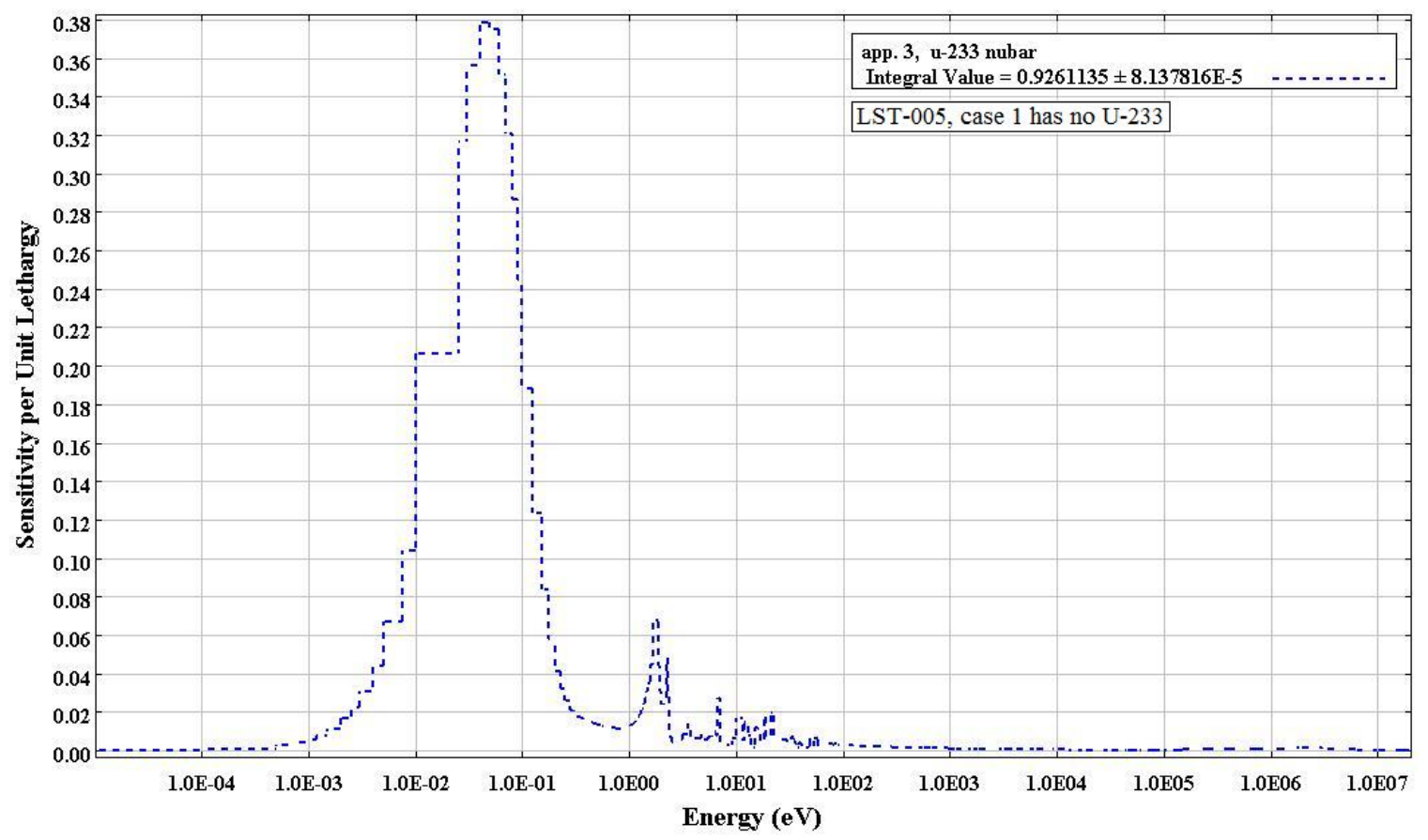

Fig. 29. ${ }^{233} \mathrm{U}$ Nu-bar sensitivity profile for application 3.

A review of the detailed $c_{r}$ information from TSUNAMI-IP shows that the biggest differences between application 3 and the most similar critical experiment, LST-005, case 1 , are for ${ }^{14} \mathrm{~N}(\mathrm{n}, \mathrm{p})$, 
${ }^{238} \mathrm{U}(\mathrm{n}, \gamma),{ }^{233} \mathrm{U}$ fission, ${ }^{1} \mathrm{H}(\mathrm{n}, \gamma)$, and ${ }^{233} \mathrm{U}$ nu-bar. Note that LST-005, case 1 has no ${ }^{233} \mathrm{U}$, which is the primary fissionable nuclide in the application.

Table 12 shows the top contributors toward similarity for application 3 compared to itself. The data show some of the characteristics of the ideal critical experiment for validation of application 3 .

Table 12. Top contributors to similarity $\left(c_{r}\right)$ for application 3 compared to itself

\begin{tabular}{|c|c|c|c|c|}
\hline \multicolumn{4}{|c|}{ Covariance matrix } & \multirow{2}{*}{$\begin{array}{c}\text { Contribution to } \\
\text { similarity }\left(c_{r}\right)\end{array}$} \\
\hline \multicolumn{4}{|c|}{ Nuclide reaction with nuclide reaction } & \\
\hline${ }^{14} \mathrm{~N}$ & $\mathrm{n}, \mathrm{p}$ & ${ }^{14} \mathrm{~N}$ & $\mathrm{n}, \mathrm{p}$ & 0.486 \\
\hline${ }^{238} \mathrm{U}$ & $\mathrm{n}, \gamma$ & ${ }^{238} \mathrm{U}$ & $\mathrm{n}, \gamma$ & 0.219 \\
\hline${ }^{233} \mathrm{U}$ & fission & ${ }^{233} \mathrm{U}$ & fission & 0.122 \\
\hline${ }^{1} \mathrm{H}$ & $\mathrm{n}, \gamma$ & ${ }^{1} \mathrm{H}$ & $\mathrm{n}, \gamma$ & 0.085 \\
\hline${ }^{233} \mathrm{U}$ & nu-bar & ${ }^{233} \mathrm{U}$ & nu-bar & 0.074 \\
\hline
\end{tabular}

Table 13 shows the top contributors toward similarity for the application compared to the experiment with the highest similarity (LST-005, case 1, $c_{r}=0.687$ ). Differences between the $c_{r}$ values shown in Tables 12 and 13, presented as $\Delta \mathrm{c}_{\mathrm{r}}$ in Table 13, indicate which nuclide reactions contribute toward similarity reduction. These values identify the nuclide reactions that are limiting similarity. Note that the $\Delta \mathrm{c}_{\mathrm{r}}$ values with the largest magnitude are for ${ }^{233} \mathrm{U}$ fission and nu-bar.

Table 13. Top contributors to similarity $\left(c_{r}\right)$ for application 3 compared to experiment LST-005, case 1

\begin{tabular}{|c|c|c|c|c|c|}
\hline \multicolumn{4}{|c|}{ Covariance matrix } & \multirow{2}{*}{$\begin{array}{l}\text { Contribution } \\
\text { to similarity } \\
\left(c_{r}\right)\end{array}$} & \multirow{2}{*}{$\begin{array}{c}\text { Change from } \\
\text { optimum similarity } \\
\left(\Delta c_{r}\right)\end{array}$} \\
\hline \multicolumn{4}{|c|}{ Nuclide reaction with nuclide reaction } & & \\
\hline${ }^{14} \mathrm{~N}$ & $\mathrm{n}, \mathrm{p}$ & ${ }^{14} \mathrm{~N}$ & $\mathrm{n}, \mathrm{p}$ & 0.427 & -0.059 \\
\hline${ }^{238} \mathrm{U}$ & $\mathrm{n}, \gamma$ & ${ }^{238} \mathrm{U}$ & $\mathrm{n}, \gamma$ & 0.150 & -0.068 \\
\hline${ }^{233} \mathrm{U}$ & fission & ${ }^{233} \mathrm{U}$ & fission & 0 & -0.122 \\
\hline${ }^{1} \mathrm{H}$ & $\mathrm{n}, \gamma$ & ${ }^{1} \mathrm{H}$ & $\mathrm{n}, \gamma$ & 0.081 & -0.004 \\
\hline${ }^{233} \mathrm{U}$ & nu-bar & ${ }^{233} \mathrm{U}$ & nu-bar & 0 & -0.074 \\
\hline
\end{tabular}

\subsection{APPLICATION 4-STORAGE ARRAY, CEUSP CONTAINERS}

Table 14 and Fig. 30 show the distribution of $\mathrm{c}_{\mathrm{r}}$ values calculated for the 672 critical configurations examined. Analysis of the similarity results follows Fig. 30. 
Table 14. Application 4 similarity summary

\begin{tabular}{ccc}
\hline $\begin{array}{c}\text { Similarity } \\
\text { index } \\
\text { range }\end{array}$ & $\begin{array}{c}\text { Number } \\
\text { of } \\
\text { experiments }\end{array}$ & Applicability \\
\hline $\mathrm{c}_{\mathrm{r}}<0.1$ & 253 & Low \\
$0.1 \leq \mathrm{c}_{\mathrm{r}}<0.2$ & 315 & Low \\
$0.2 \leq \mathrm{c}_{\mathrm{r}}<0.3$ & 103 & Low \\
$0.3 \leq \mathrm{c}_{\mathrm{r}}<0.4$ & 1 & Low \\
$0.4 \leq \mathrm{c}_{\mathrm{r}}<0.5$ & 0 & Low \\
$0.5 \leq \mathrm{c}_{\mathrm{r}}<0.6$ & 0 & Low \\
$0.6 \leq \mathrm{c}_{\mathrm{r}}<0.7$ & 0 & Low \\
$0.7 \leq \mathrm{c}_{\mathrm{r}}<0.8$ & 0 & Low \\
$0.8 \leq \mathrm{c}_{\mathrm{r}}<0.9$ & 0 & Marginal \\
$0.9 \leq \mathrm{c}_{\mathrm{r}}<0.95$ & 0 & Applicable \\
$0.95 \leq \mathrm{c}_{\mathrm{r}}<1.0$ & 0 & High \\
All & 672 & \\
\hline
\end{tabular}

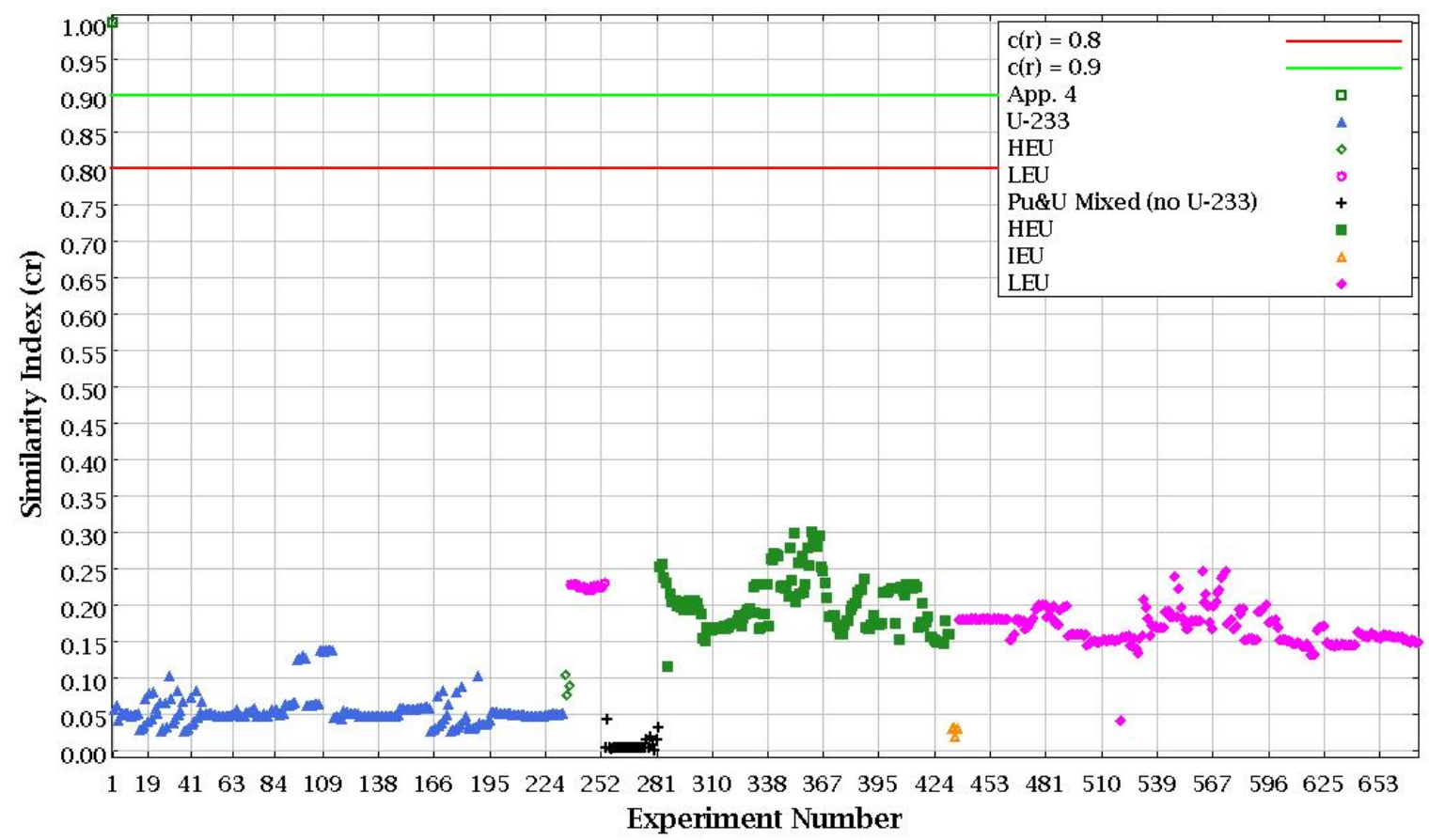

Fig. 30. Application 4 similarity index values $\left(c_{r}\right)$ for 672 critical experiments.

The similarity results for application 4 demonstrate that none of the 672 critical experiments would be considered even marginally applicable. The highest similarity index $\left(\mathrm{c}_{\mathrm{r}}\right)$ value was 0.301 for experiment HST-007, case 13.

The TSUNAMI-IP output for this application includes a detailed calculation of the $\mathrm{c}_{\mathrm{r}}$ value of the application compared with itself. This edit indicates that the most important contributors to $c_{r}$ for 
this application are ${ }^{56} \mathrm{Fe}(\mathrm{n}, \gamma), \mathrm{Ca}(\mathrm{n}, \gamma),{ }^{56} \mathrm{Fe}$ elastic scattering, ${ }^{235} \mathrm{U}(\mathrm{n}, \gamma),{ }^{235} \mathrm{U}$ fission, and ${ }^{235} \mathrm{U}$ nu-bar.

The highest $\mathrm{c}_{\mathrm{r}}$ value, 0.301 , generated by comparing the experiments to the application was experiment HEU-SOL-THERM-007, case 13. Figures 31-35 show the sensitivity profiles for these reactions for both the application and the experiment. In order to achieve an acceptable level of similarity when compared to application 4, it looks like a critical experiment would need to have fissile units with thick layers of steel and concrete, similar to the concrete surrounding the storage tubes, between the units.

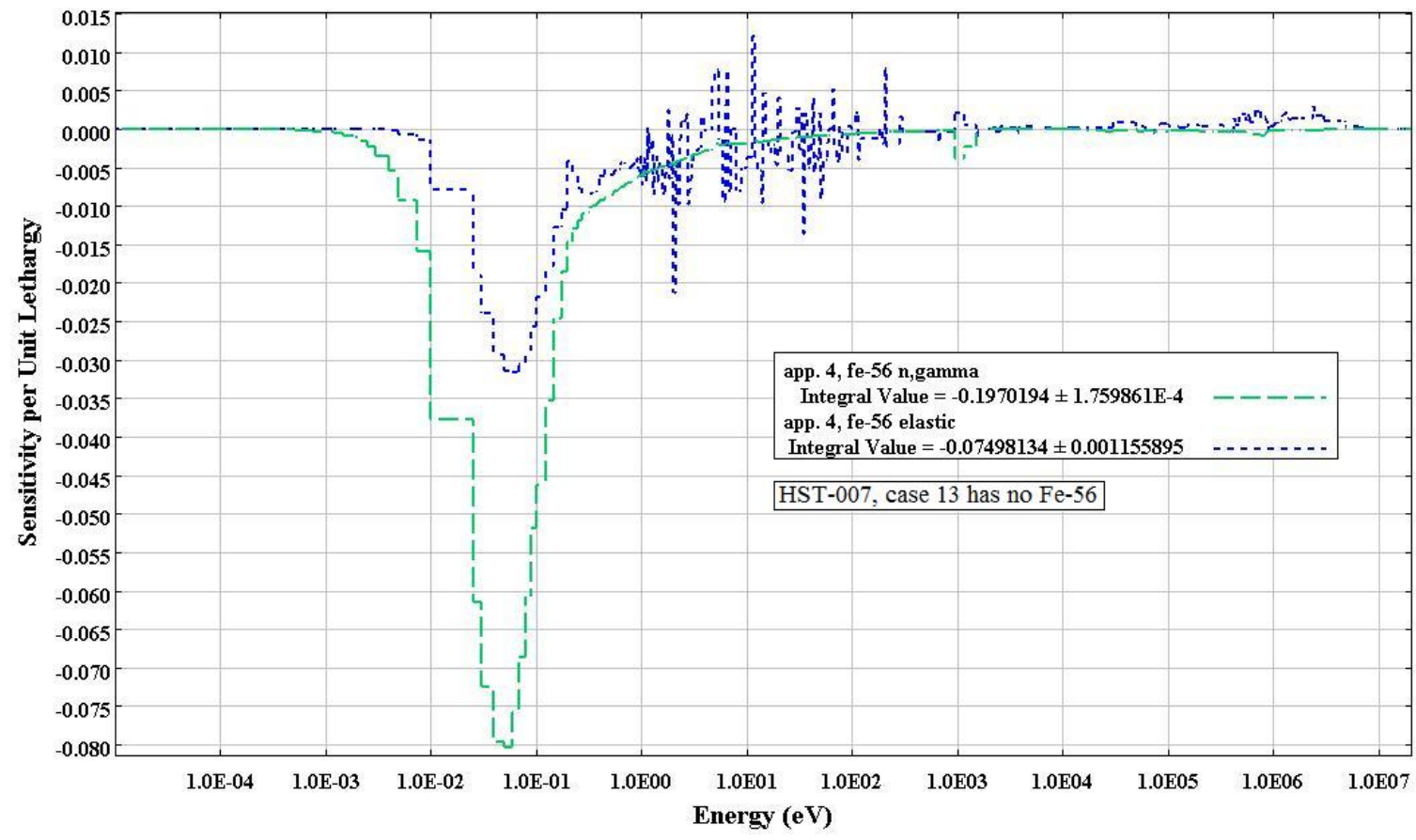

Fig. 31. ${ }^{56} \mathrm{Fe}(\mathrm{n}, \gamma)$ and ${ }^{56} \mathrm{Fe}$ elastic scattering reaction sensitivity profiles for application 4. Experiment HST-007, case 13 has no ${ }^{56} \mathrm{Fe}$. 


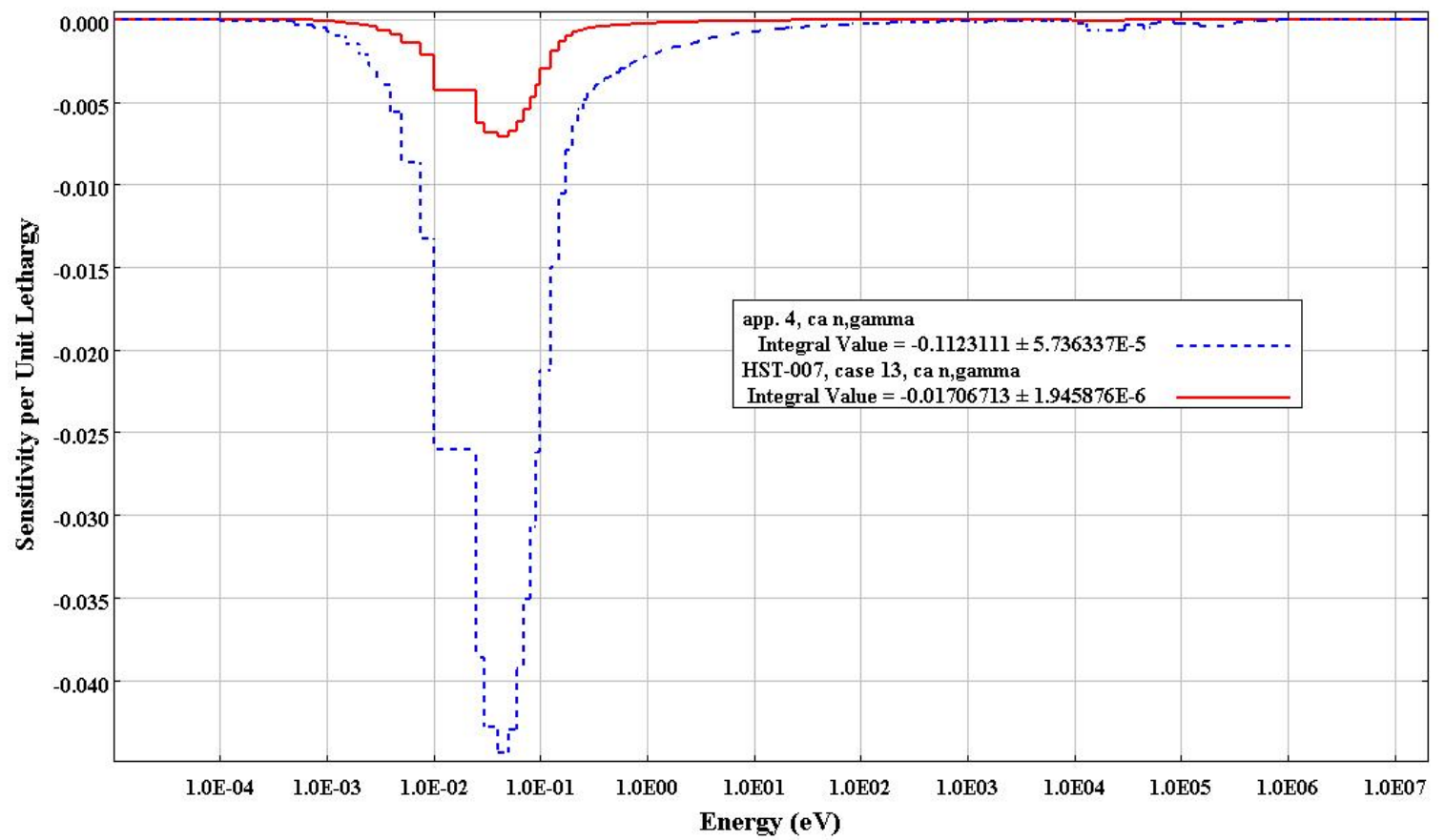

Fig. 32. Ca (n, $\gamma)$ reaction sensitivity profile for application 4 and experiment HST-007, case 13.

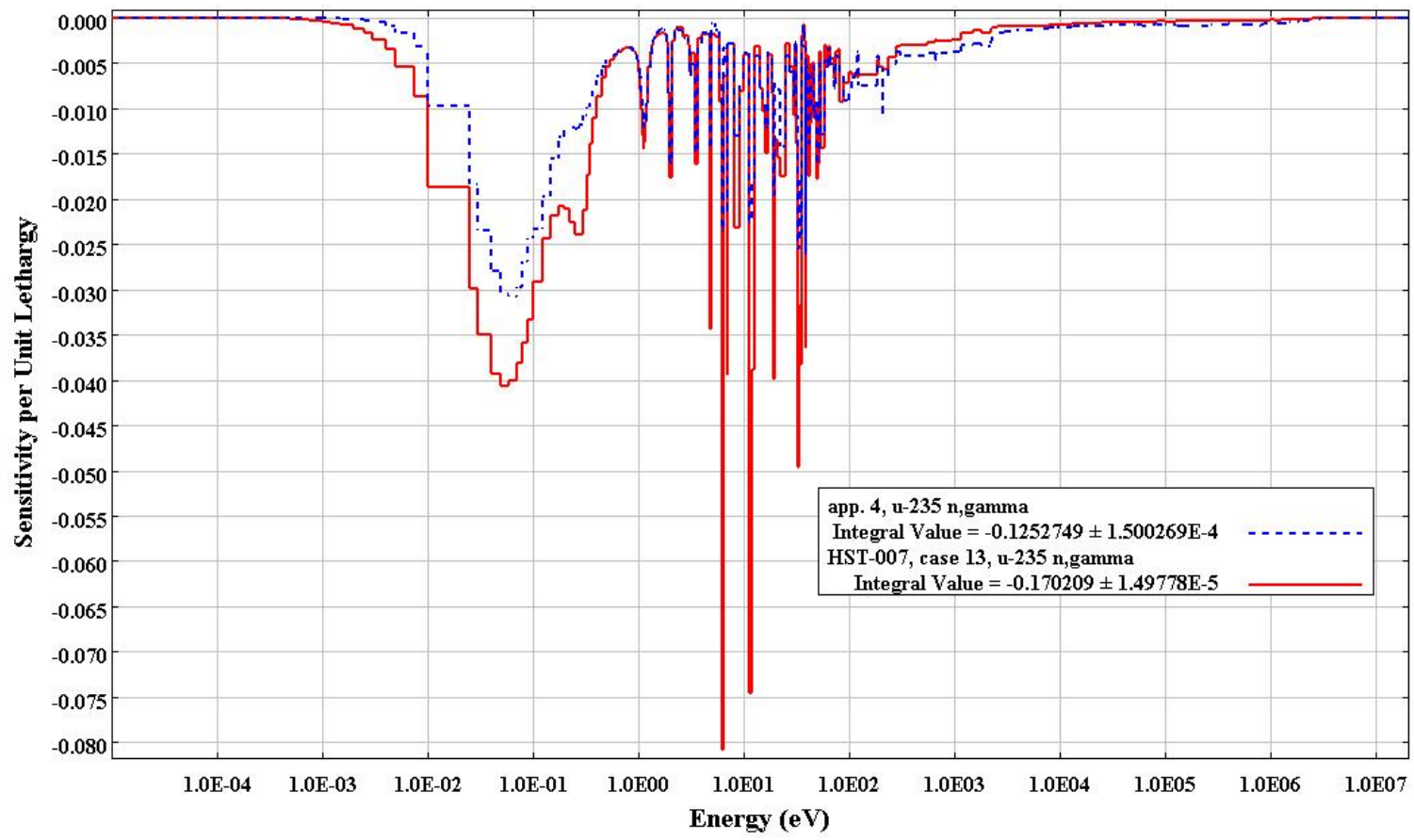

Fig. 33. ${ }^{235} \mathbf{U}(\mathrm{n}, \gamma)$ reaction sensitivity profile for application 4 and experiment HST-007, case 13. 


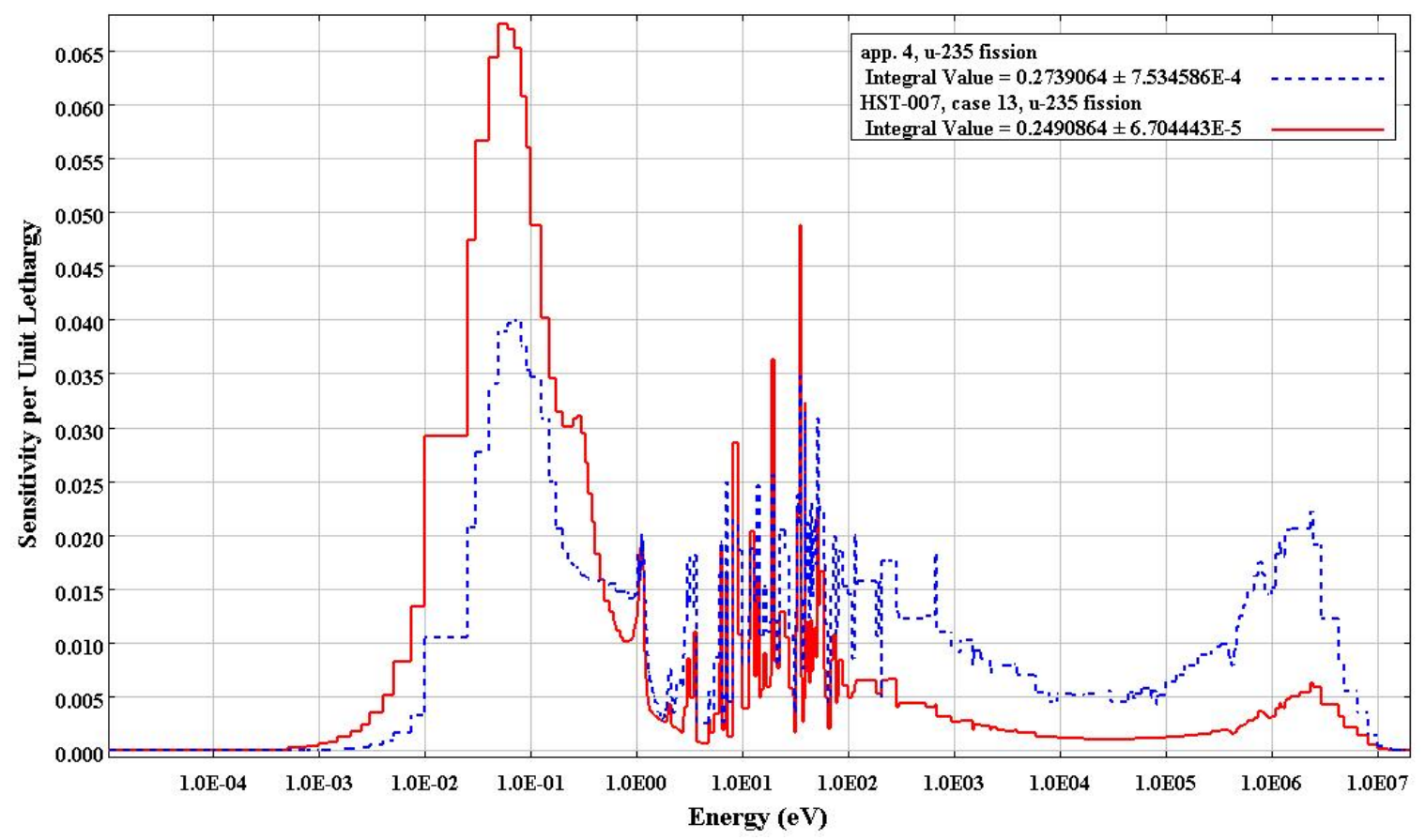

Fig. 34. ${ }^{235} \mathrm{U}$ fission reaction sensitivity profile for application 4 and experiment HST-007, case 13.

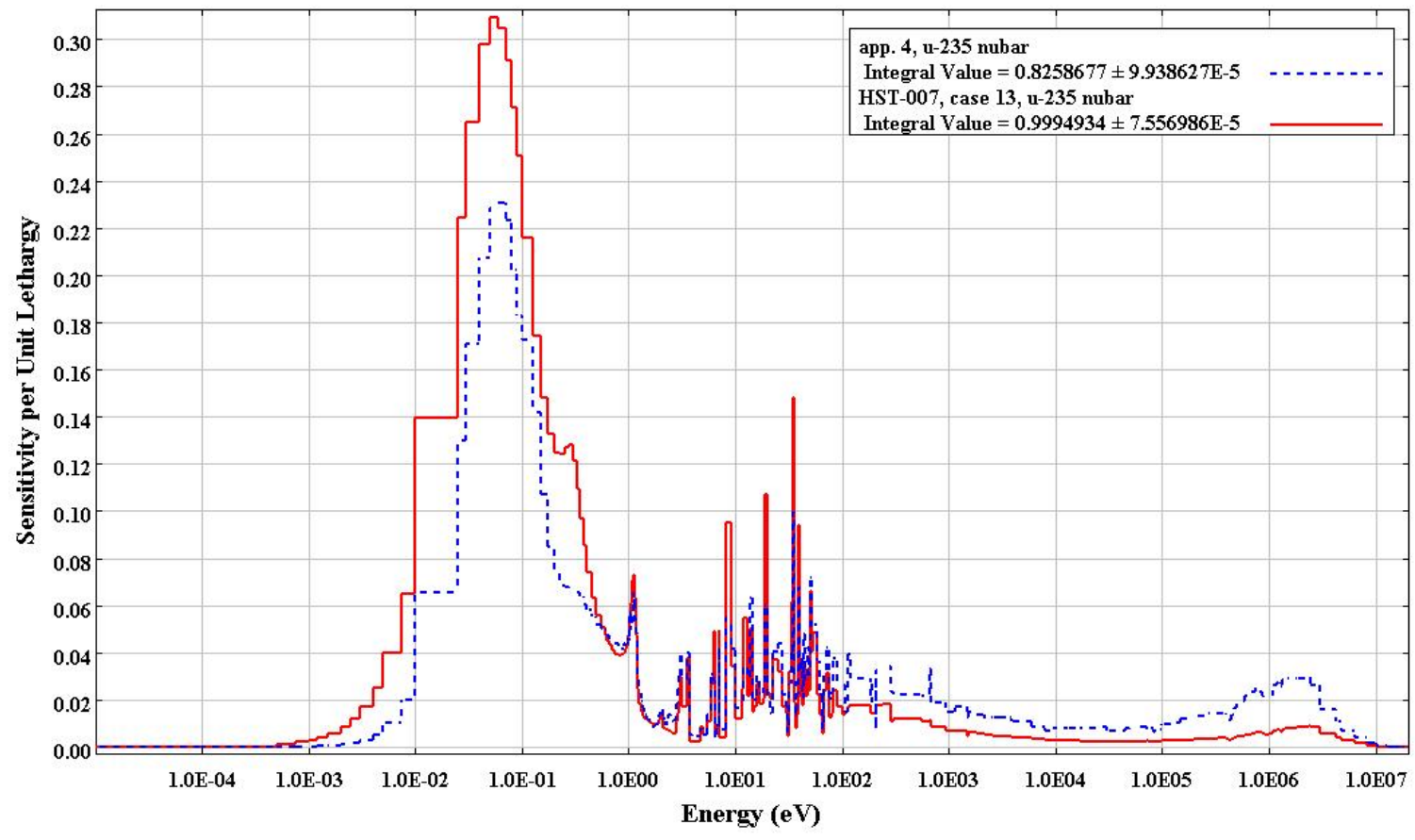

Fig. 35. ${ }^{235} \mathrm{U}$ Nu-bar sensitivity profile for application 4 and experiment HST-007, case 13. 
A review of the $\mathrm{c}_{\mathrm{r}}$ information from TSUNAMI-IP shows that the biggest differences between application 4 and the most similar critical experiment are in the ${ }^{56} \mathrm{Fe}(\mathrm{n}, \gamma)$ and $\mathrm{Ca}(\mathrm{n}, \gamma)$ reaction sensitivities. The experiment has no iron and, as can be seen in Fig. 32, application 4 is much more sensitive to the $\mathrm{Ca}(\mathrm{n}, \gamma)$ than the experiment.

Table 15 shows the top contributors toward similarity for application 4 compared to itself. The data show some of the characteristics of the ideal critical experiment for validation of application 4 .

Table 15. Top contributors to similarity $\left(c_{r}\right)$ for application 4 compared to itself

\begin{tabular}{clllc}
\hline \multicolumn{3}{c}{ Covariance matrix } & $\begin{array}{c}\text { Contribution } \\
\text { to similarity } \\
\left(\mathbf{c}_{\mathbf{r}}\right)\end{array}$ \\
\hline \multicolumn{2}{c}{ Nuclide reaction with nuclide reaction } & 0.730 \\
\hline${ }^{56} \mathrm{Fe}$ & $\mathrm{n}, \gamma$ & ${ }^{56} \mathrm{Fe}$ & $\mathrm{n}, \gamma$ & 0.129 \\
$\mathrm{Ca}$ & $\mathrm{n}, \gamma$ & $\mathrm{Ca}$ & $\mathrm{n}, \gamma$ & 0.039 \\
${ }^{56} \mathrm{Fe}$ & elastic & ${ }^{56} \mathrm{Fe}$ & elastic & 0.030 \\
${ }^{235} \mathrm{U}$ & $\mathrm{n}, \gamma$ & ${ }^{235} \mathrm{U}$ & $\mathrm{n}, \gamma$ & 0.027 \\
${ }^{235} \mathrm{U}$ & fission & ${ }^{235} \mathrm{U}$ & fission & 0.021 \\
${ }^{235} \mathrm{U}$ & nu-bar & ${ }^{235} \mathrm{U}$ & nu-bar & \\
\hline
\end{tabular}

The high importance of iron and calcium is due to the design of the storage array, which involves thick steel pipes with thick concrete between the pipes.

Table 16 shows the top contributors toward similarity for the application compared to the experiment with the highest $c_{r}$ value, 0.301. Differences between the $c_{r}$ values shown in Tables 15 and $16, \Delta c_{r}$ in Table 16, indicate which nuclide reactions contribute toward similarity reduction (negative $\Delta c_{r}$ ). The smaller positive values are generated due to differences in normalization of the correlation coefficients for the application compared to itself versus the application compared to the experiment. The non-zero $\Delta \mathrm{c}_{\mathrm{r}}$ values identify the nuclide-reaction pairs that are limiting similarity for the two experiments. Note that the $\Delta \mathrm{c}_{\mathrm{r}}$ values with the largest magnitude are for ${ }^{56} \mathrm{Fe}(\mathrm{n}, \gamma)$ and $\mathrm{Ca}(\mathrm{n}, \gamma)$ reactions.

Table 16. Top contributors to similarity $\left(c_{r}\right)$ for application 4 compared to experiment HST-007, case 13

\begin{tabular}{|c|c|c|c|c|c|}
\hline \multicolumn{4}{|c|}{ Covariance matrix } & \multirow{2}{*}{$\begin{array}{l}\text { Contribution } \\
\text { to similarity } \\
\left(c_{r}\right)\end{array}$} & \multirow{2}{*}{$\begin{array}{c}\text { Change from } \\
\text { optimum } \\
\text { similarity } \\
\left(\Delta c_{r}\right)\end{array}$} \\
\hline \multicolumn{4}{|c|}{ Nuclide reaction with nuclide reaction } & & \\
\hline${ }^{56} \mathrm{Fe}$ & $\mathrm{n}, \gamma$ & ${ }^{56} \mathrm{Fe}$ & $\overline{\mathrm{n}, \gamma}$ & $\overline{0}$ & -0.730 \\
\hline $\mathrm{Ca}$ & $\mathrm{n}, \gamma$ & $\mathrm{Ca}$ & $\mathrm{n}, \gamma$ & 0.056 & -0.073 \\
\hline${ }^{56} \mathrm{Fe}$ & elastic & ${ }^{56} \mathrm{Fe}$ & elastic & 0 & -0.039 \\
\hline${ }^{235} \mathrm{U}$ & $\mathrm{n}, \gamma$ & ${ }^{235} \mathrm{U}$ & $\mathrm{n}, \gamma$ & 0.099 & 0.069 \\
\hline${ }^{235} \mathrm{U}$ & fission & ${ }^{235} \mathrm{U}$ & fission & 0.040 & 0.013 \\
\hline${ }^{235} \mathrm{U}$ & nu-bar & ${ }^{235} \mathrm{U}$ & nu-bar & 0.084 & 0.063 \\
\hline
\end{tabular}

Examination of application 4 and HST-007, case 13 models reveals that the difference in the ${ }^{56} \mathrm{Fe}$ sensitivity is due to the importance of the carbon steel in the application and the lack of any iron 
in the experiment. If one were trying to quantify the bias due to errors in the iron and calcium data, using this experiment would not be appropriate.

\subsection{SIMILARITY SUMMARY}

Table 17 is a summary of the similarity analysis results for a pool of 672 candidate critical configurations. Similarity analyses presented in Sections 4.1-4.4 indicate that the candidate set of critical experiments did not include any experiments that are considered adequately similar to applications 3 and 4 . There are a significant number of applicable experiments for applications 1 and 2 .

Table 17. Summary of similarity analysis results

\begin{tabular}{|c|c|c|c|c|c|}
\hline \multirow{3}{*}{$\begin{array}{c}\text { Similarity } \\
\text { index } \\
\text { range }\end{array}$} & \multirow{3}{*}{ Applicability } & \multicolumn{4}{|c|}{ Application } \\
\hline & & 1 & 2 & 3 & 4 \\
\hline & & \multicolumn{4}{|c|}{$\begin{array}{c}\text { Number of experiments in } \\
\text { each category }\end{array}$} \\
\hline $\mathrm{c}_{\mathrm{r}}<0.1$ & Low & 43 & 43 & 54 & 253 \\
\hline $0.1 \leq \mathrm{c}_{\mathrm{r}}<0.2$ & Low & 80 & 18 & 124 & 315 \\
\hline $0.2 \leq \mathrm{c}_{\mathrm{r}}<0.3$ & Low & 136 & 21 & 141 & 103 \\
\hline $0.3 \leq \mathrm{c}_{\mathrm{r}}<0.4$ & Low & 140 & 19 & 176 & 1 \\
\hline $0.4 \leq \mathrm{c}_{\mathrm{r}}<0.5$ & Low & 63 & 32 & 79 & 0 \\
\hline $0.5 \leq \mathrm{c}_{\mathrm{r}}<0.6$ & Low & 30 & 115 & 68 & 0 \\
\hline $0.6 \leq \mathrm{c}_{\mathrm{r}}<0.7$ & Low & 14 & 158 & 30 & 0 \\
\hline $0.7 \leq \mathrm{c}_{\mathrm{r}}<0.8$ & Low & 7 & 150 & 0 & 0 \\
\hline $0.8 \leq \mathrm{c}_{\mathrm{r}}<0.9$ & Marginal & 17 & 48 & 0 & 0 \\
\hline $0.9 \leq \mathrm{c}_{\mathrm{r}}<0.95$ & Applicable & 60 & 42 & 0 & 0 \\
\hline $0.95 \leq \mathrm{c}_{\mathrm{r}}<1.0$ & High & 82 & 26 & 0 & 0 \\
\hline
\end{tabular}

Section 6. provides some discussion as to how to address a lack of applicable critical experiments to perform validation of critical calculations. 


\section{USL DETERMINATION}

Typically, the purpose of validation is to support determination of an upper subcritical limit (USL) to which a safety analysis case or "application" may be compared. ANSI/ANS-8.24 (Ref. 8) provides the following definition for a USL:

Upper subcritical limit: A limit on the calculated k-effective value established to ensure that conditions calculated to be subcritical will actually be subcritical.

The work presented in this report to this point has been directed toward identifying critical experiments that are similar to the applications, to support determination of USL values. The USL examples provided below focus on determination of calculational margins to account for nuclear data uncertainties and the consequent biases in computed results. The USL examples do not include any additional margin to account for process condition uncertainties, which could lead to process conditions that differ from the application models.

Of the four applications evaluated, only for applications 1 and 2 were good sets of critical experiments identified as applicable for validation. USLs may be determined for applications 1 and 2 using standard statistical techniques such as those documented in NUREG/CR-6698, Guide for Validation of Nuclear Criticality Safety Calculational Methodology ${ }^{9}$ and computer codes such as USLSTATS. ${ }^{10}$ Many statistical methods, including those implemented in USLSTATS, require that the population of $k_{\text {eff }}$ values have a normal distribution. For these methods, if the distribution is not approximately normal, the conclusions related to the "confidence level" of the limit are not valid. The normality test implemented in USLSTATS is a rather crude 5-bin chi-squared normality test. If a normality test is failed, the evaluator may also examine the normality of the data using other, more sophisticated tests.

No critical experiments similar to applications 3 and 4 were identified. For applications such as these, the evaluator needs to supplement the margin of subcriticality with some additional margin to be applied to USLs determined with the best data available. Section 7 of the report discusses some options and data available from the TSUNAMI tools to help identify and defend the selected additional margin.

The rest of this section will document calculation of USLs for application 1 using the USLSTATS code. Section 5.1 is a standard USL determination based on trending of the EALF parameter. Section 5.2 documents another way in which the TSUNAMI tools may be used for validation analysis. Use of the same procedure for application 2 is not included here but would be appropriate.

\subsection{USL FOR APPLICATION 1 USING TRENDING OF EALF}

The similarity determination documented in Section 4.1 identified 142 critical experiments that were identified as applicable $\left(0.95>c_{r}>0.9\right)$ or highly applicable $\left(c_{r}>0.95\right)$ to the validation of application 1. An additional 17 critical experiments were identified as marginally applicable $\left(0.9>c_{r}>0.8\right)$.

Four USLSTATS calculations were performed with trending as a function of critical experiment energy of average lethargy of neutrons causing fission (EALF). These calculations used results from (1) all 672 critical experiments without regard for similarity, (2) all 159 critical experiments with $c_{r} \geq 0.8,(3)$ the 142 critical configurations with $c_{r} \geq 0.9$, and (4) the 82 critical experiments 
with $\mathrm{c}_{\mathrm{r}} \geq 0.95$. The EALF for application 1 is $0.282 \mathrm{eV}$. The USLSTATS calculations all used the following input parameters:

- $\quad$ Proportion of population $=0.999$

- $\quad$ Confidence of fit $=0.950$

- $\quad$ Confidence on proportion $=0.950$

- Average standard deviation of all input $k_{\text {eff }}$ values $=-1$ (directing USLSTATS to use values input for each experiment)

- Additional margin (sometimes referred to as administrative margin) $=0.02$

The EALF and $k_{\text {eff }}$ values were taken from a set of TSUNAMI-3D or TSUNAMI-1D forward calculations performed for each of the experiments. The uncertainty provided for each experiment is the experimental uncertainty, taken from the IHECSBE, combined with the Monte Carlo uncertainty from the forward KENO calculations.

Table 18 provides the results from these calculations. Case 1 includes 513 cases with $\mathrm{c}_{\mathrm{r}}$ values less than 0.8. The application 1 EALF is $0.282 \mathrm{eV}$, and the experiment EALF values range from $0.03 \mathrm{eV}$ to $1.1 \mathrm{MeV}$. The use of experiments with significantly higher EALF values is clearly not appropriate. The impact of including only increasingly similar experiments is seen by comparing the results from the various cases. Note that with increasely high $\mathrm{c}_{\mathrm{r}}$ criteria, the range of EALF of the best matching experiments narrows to more closely match that of the application. Table 18 also includes the results for cases 5 through 8, which are discussed in Section 5.2.

Table 18. Application 1 USLSTATS results

\begin{tabular}{ccccl}
\hline $\begin{array}{c}\text { USL } \\
\text { case }\end{array}$ & $\begin{array}{c}\text { Number of } \\
\text { experiments }\end{array}$ & Normality test & USL-1 $^{\boldsymbol{a}}$ & \multicolumn{1}{c}{ Description } \\
\hline 1 & 672 & Failed & 0.9626 & EALF trending, all experiments \\
2 & 159 & Passed & 0.9608 & EALF trending, $\mathrm{c}_{\mathrm{r}}>0.8$ \\
3 & 142 & Passed & 0.9619 & EALF trending, $\mathrm{c}_{\mathrm{r}}>0.9$ \\
4 & 82 & Passed & 0.9652 & EALF trending, $\mathrm{c}_{\mathrm{r}}>0.95$ \\
& & & & \\
5 & 666 & Failed & 0.9649 & $\mathrm{c}_{\mathrm{r}}$ trending, all experiments with $\mathrm{c}_{\mathrm{r}} \geq 0$ \\
6 & 159 & Passed & 0.9619 & $\mathrm{c}_{\mathrm{r}}$ trending, $\mathrm{c}_{\mathrm{r}}>0.8$ \\
7 & 142 & Passed & 0.9559 & $\mathrm{c}_{\mathrm{r}}$ trending, $\mathrm{c}_{\mathrm{r}}>0.9$ \\
8 & 82 & Passed & 0.9649 & $\mathrm{c}_{\mathrm{r}}$ trending, $\mathrm{c}_{\mathrm{r}}>0.95$ \\
\hline
\end{tabular}

${ }^{a}$ Application $1 \mathrm{EALF}=0.282 \mathrm{eV}$ and $\mathrm{c}_{\mathrm{r}}=1.0$

Figures 36-39 show the trending analysis for each of the first 4 cases. The USLSTATS input deck for USL case 4 is provided in Appendix E. 


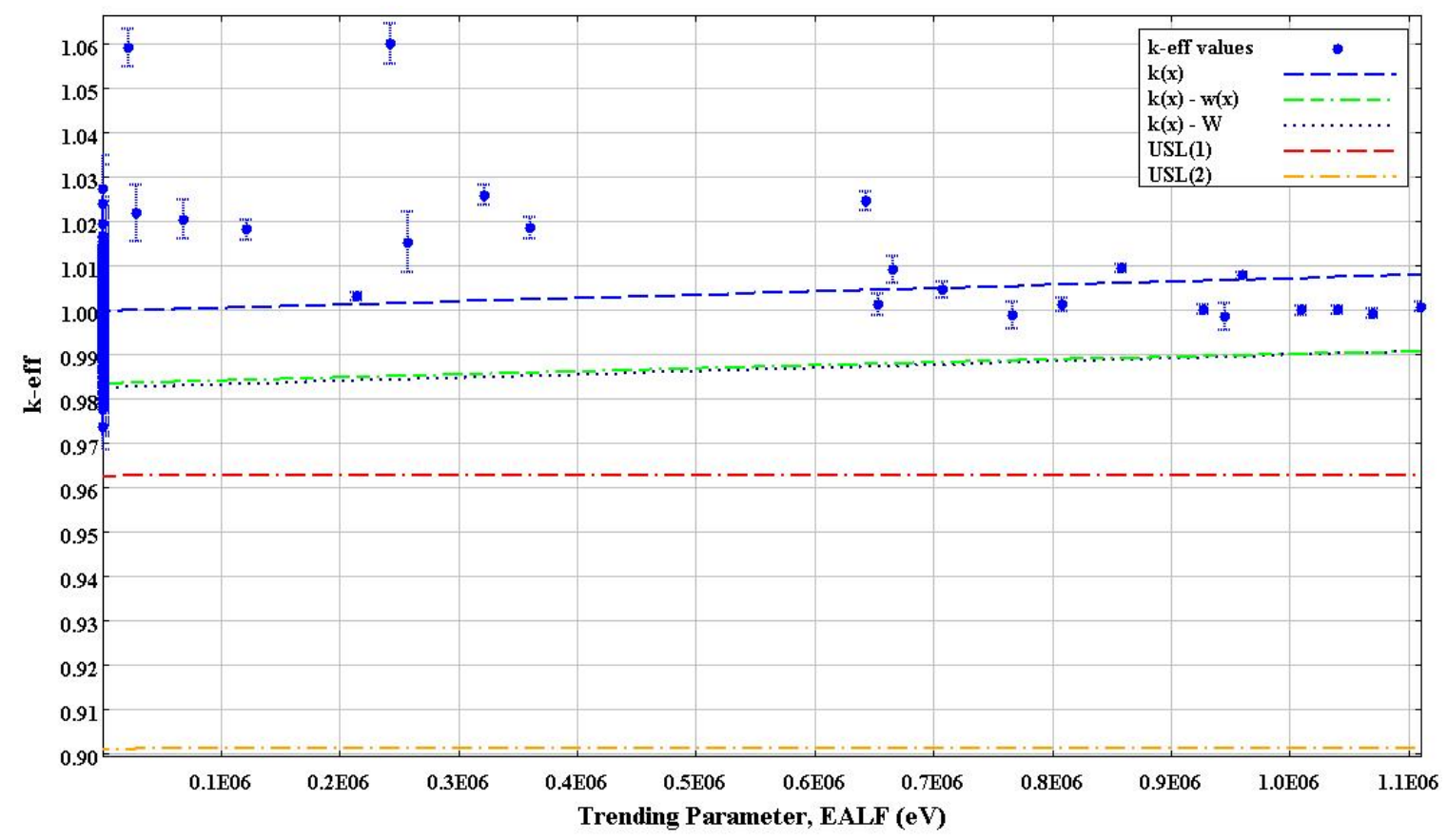

Fig. 36. USLSTATS plot for EALF trending of all experiments.

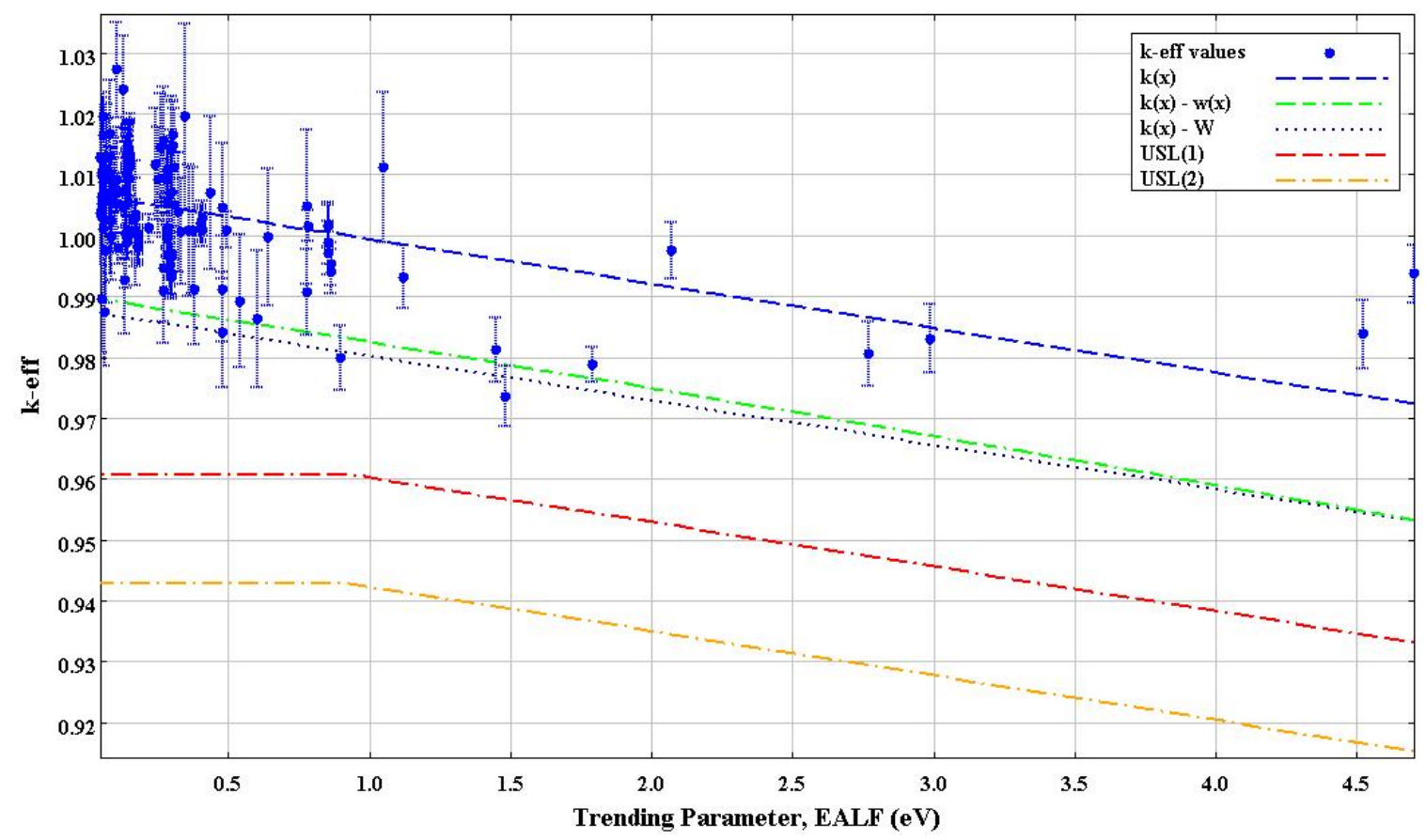

Fig. 37. USLSTATS plot for EALF trending of experiments with $c_{r} \geq 0.8$. 


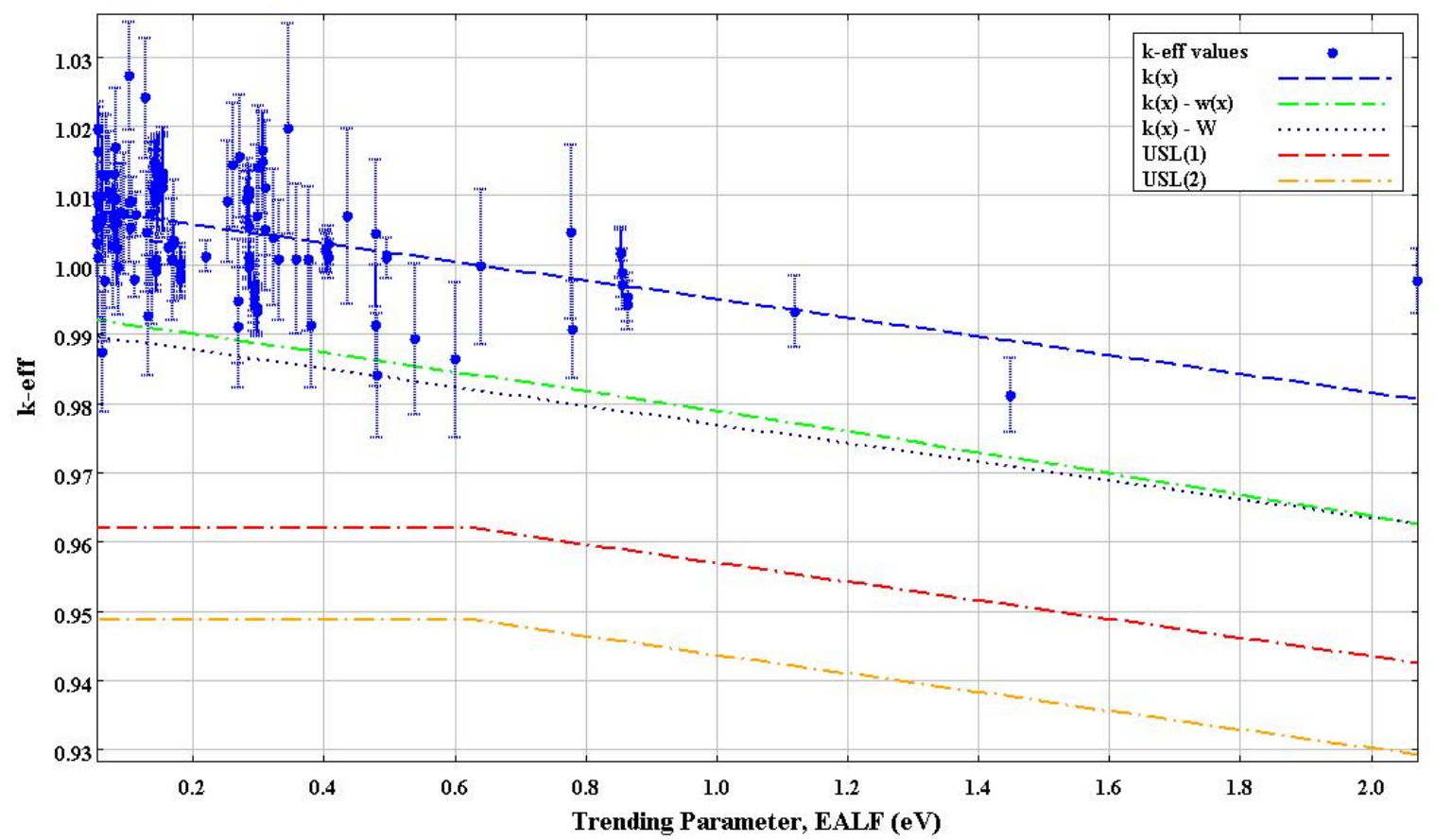

Fig. 38. USLSTATS plot for EALF trending of experiments with $c_{r} \geq 0.9$.

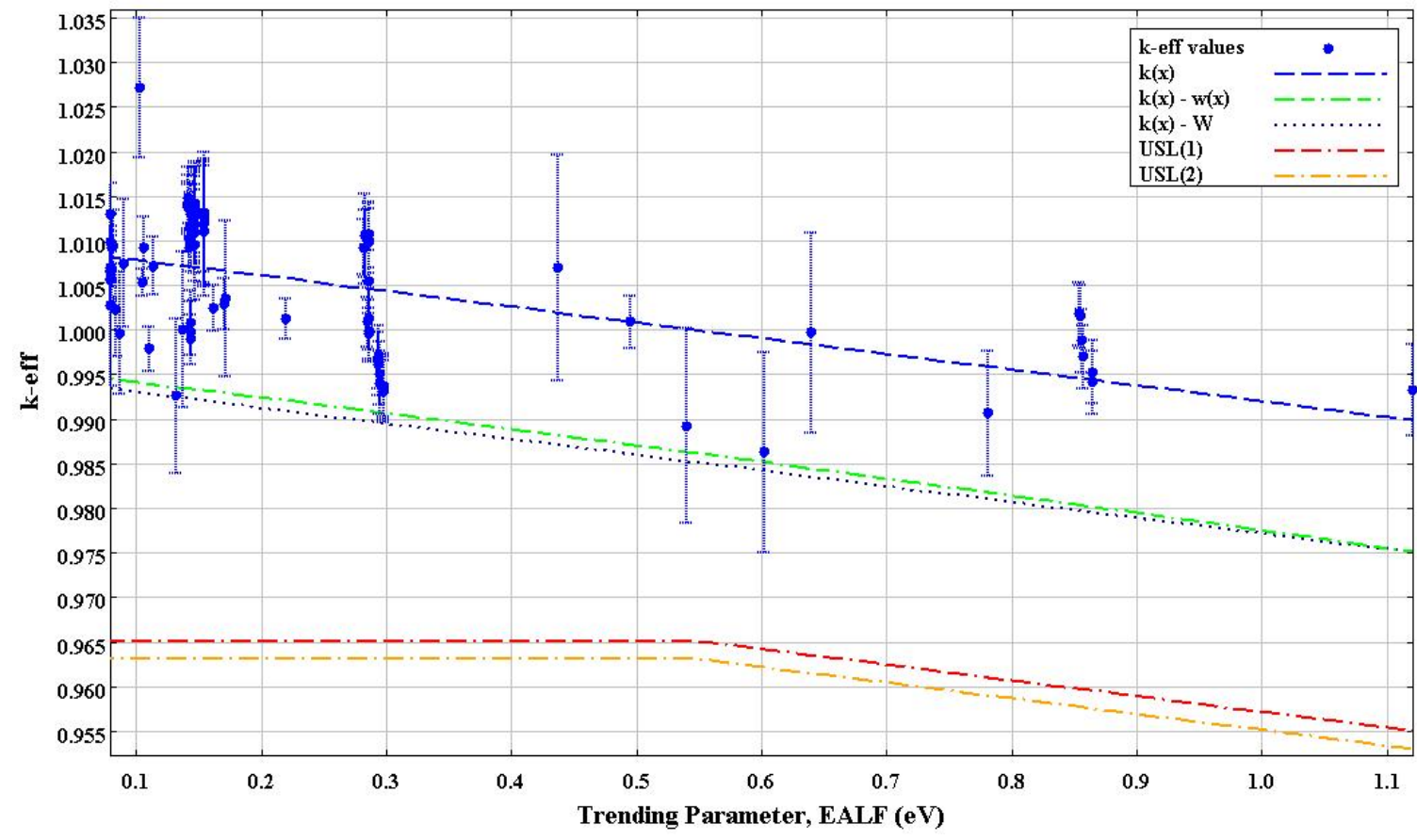

Fig. 39. USLSTATS plot for EALF trending of experiments with $c_{r} \geq 0.95$. 


\subsection{USL FOR APPLICATION 1 USING TRENDING OF THE $\mathrm{c}_{\mathrm{r}}$ SIMILARITY PARAMETER}

Table 18 also includes the results for four cases in which the trending parameter was the modified similarity index $\left(c_{r}\right)$. The unmodified similarity index $\left(c_{k}\right)$ could also have been used as the trending parameter. In the work presented in this report, the difference between the two is in the handling of the sensitivity of $k_{\text {eff }}$ to the variations in the fission spectrum (chi). As was discussed in Section 4., the chi sensitivity calculated using SCALE 5.1 ignores the fact that the chi data is constrained by definition to sum to one. Due to normalization, any chi data errors must be accompanied by one or more offsetting errors so that the distribution still sums to one. For critical experiments that are very similar to the application, $\mathrm{c}_{\mathrm{k}}$ and $\mathrm{c}_{\mathrm{r}}$ are nearly identical. Inclusion of the chi sensitivity tends to emphasize differences in the sensitivity of the fissionable nuclides. Thus trending of results, using many similar experiments, to perfect similarity (i.e., $\mathrm{c}_{\mathrm{k}}$ or $\mathrm{c}_{\mathrm{r}}$ equal to one) should have negligible impact on the calculated USL.

For these cases, trending is performed as a function of similarity with the results extrapolated to complete similarity (i.e., $\mathrm{c}_{\mathrm{r}}=1.0$ ). USLSTATS accounts for the extrapolation with a quadratic confidence band, where the width of the confidence band increases as the extrapolation distance from the highest $c_{r}$ value to unity increases. Note that USL(2) is a closed interval approach that is not valid outside the range of the experimental data. Thus, extrapolation to $c_{r}=1$ for USL(2) is not valid. Figures $40-43$ show the USLSTATS plots for the $c_{r}$ trending cases.

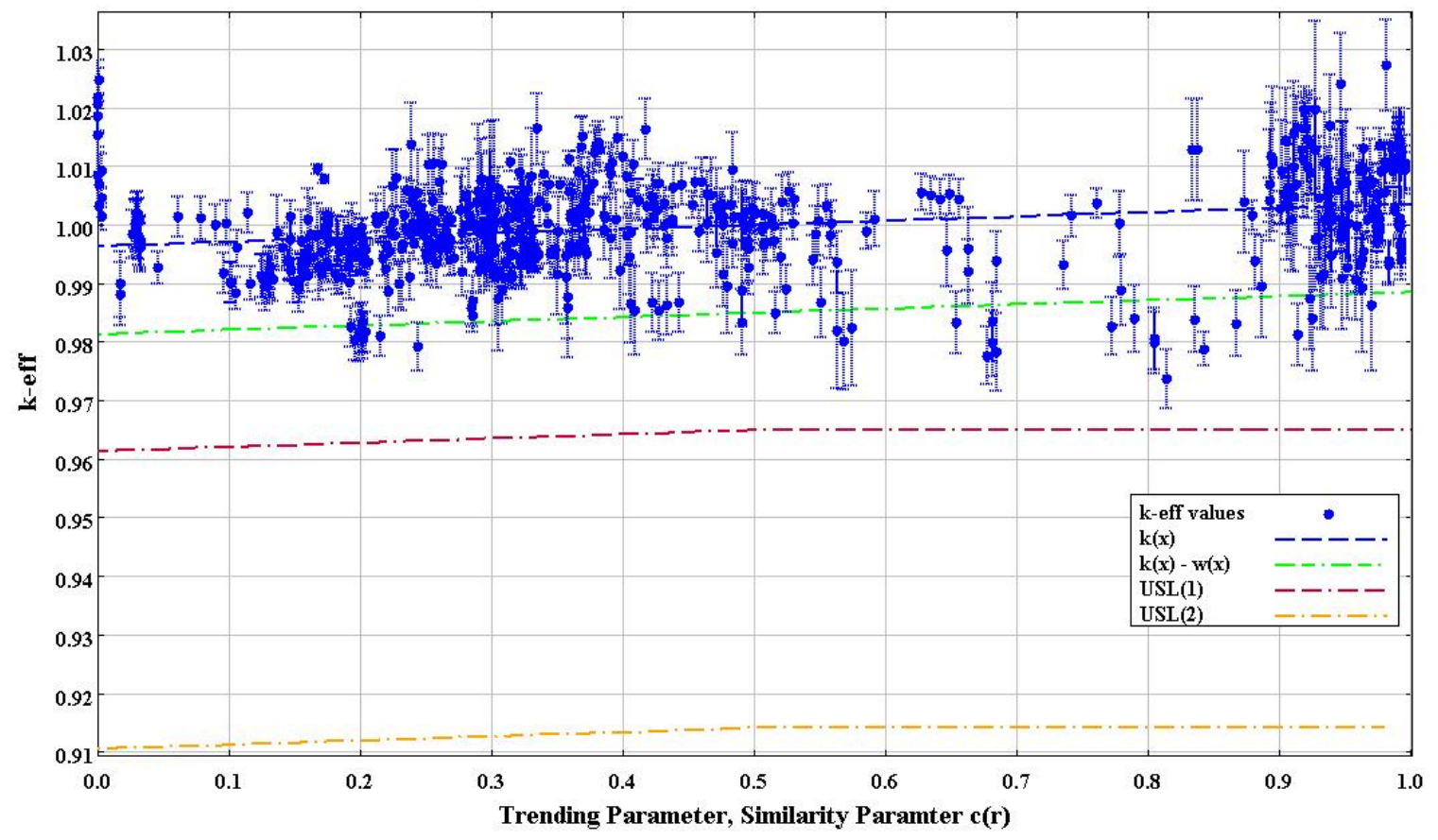

Fig. 40. USLSTATS plot for $c_{\mathrm{r}}$ trending of all experiments. 


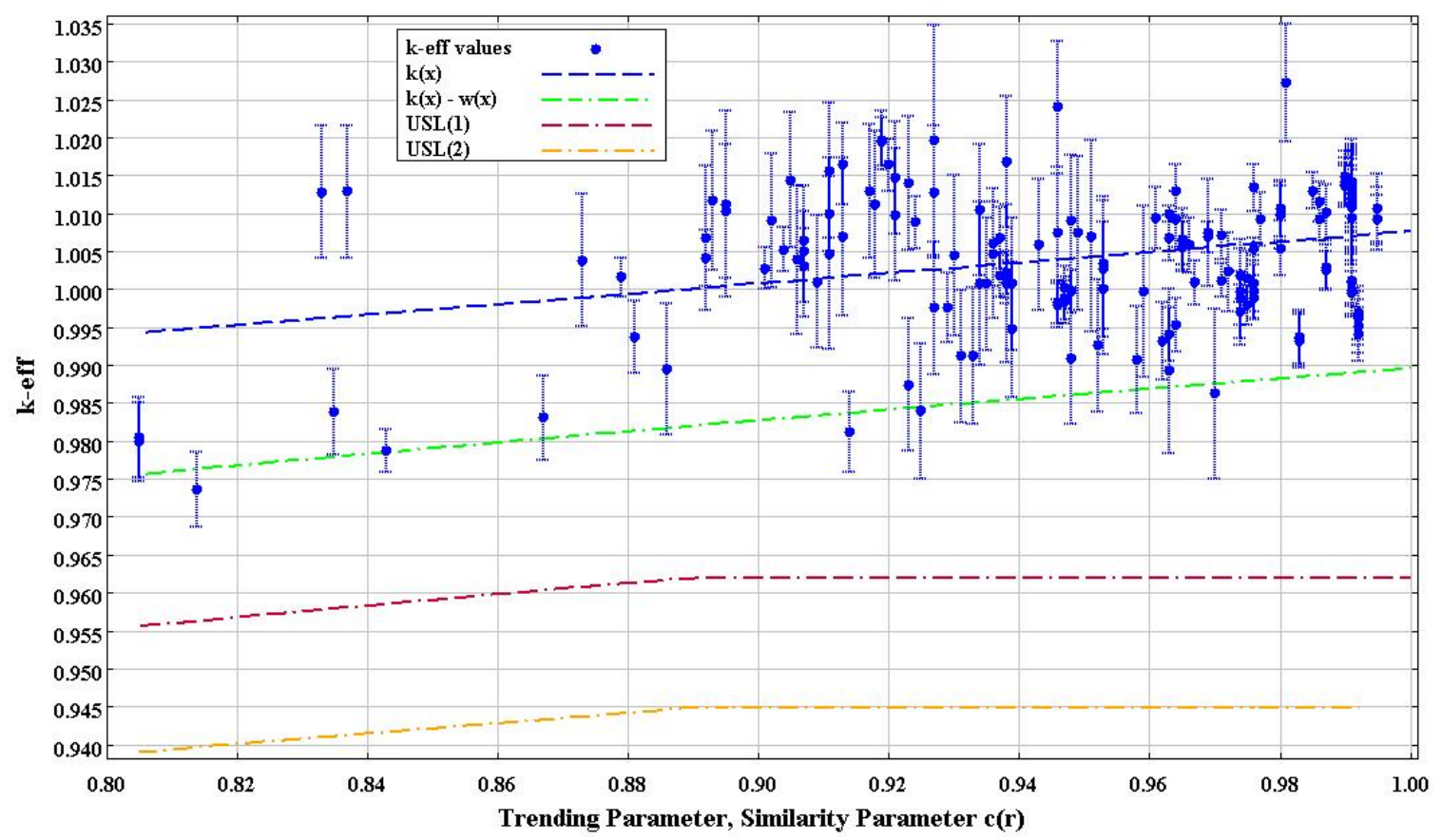

Fig. 41. USLSTATS plot for $c_{r}$ trending of experiments with $c_{r} \geq 0.8$.

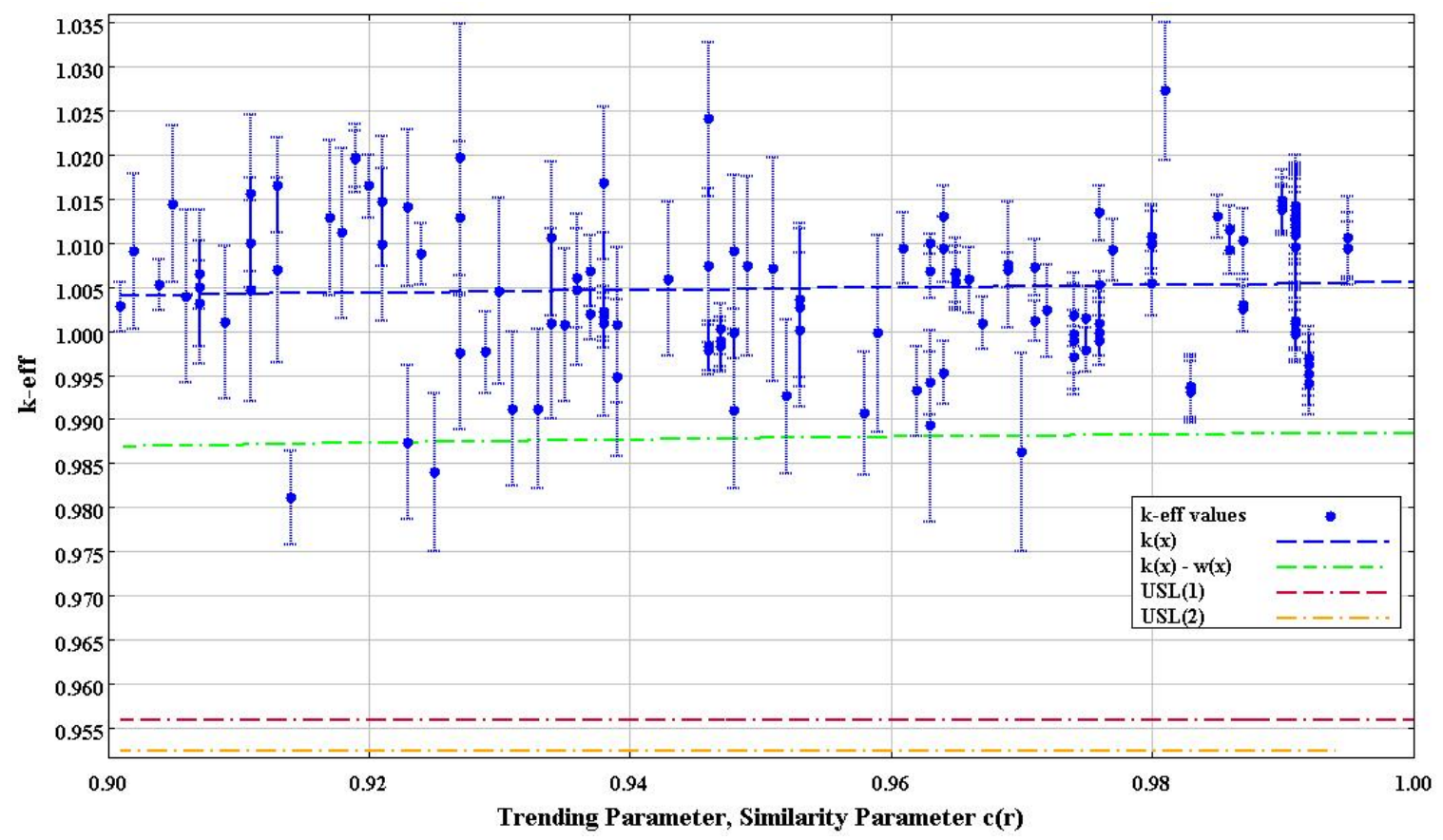

Fig. 42. USLSTATS plot for $c_{r}$ trending of experiments with $c_{r} \geq 0.9$. 


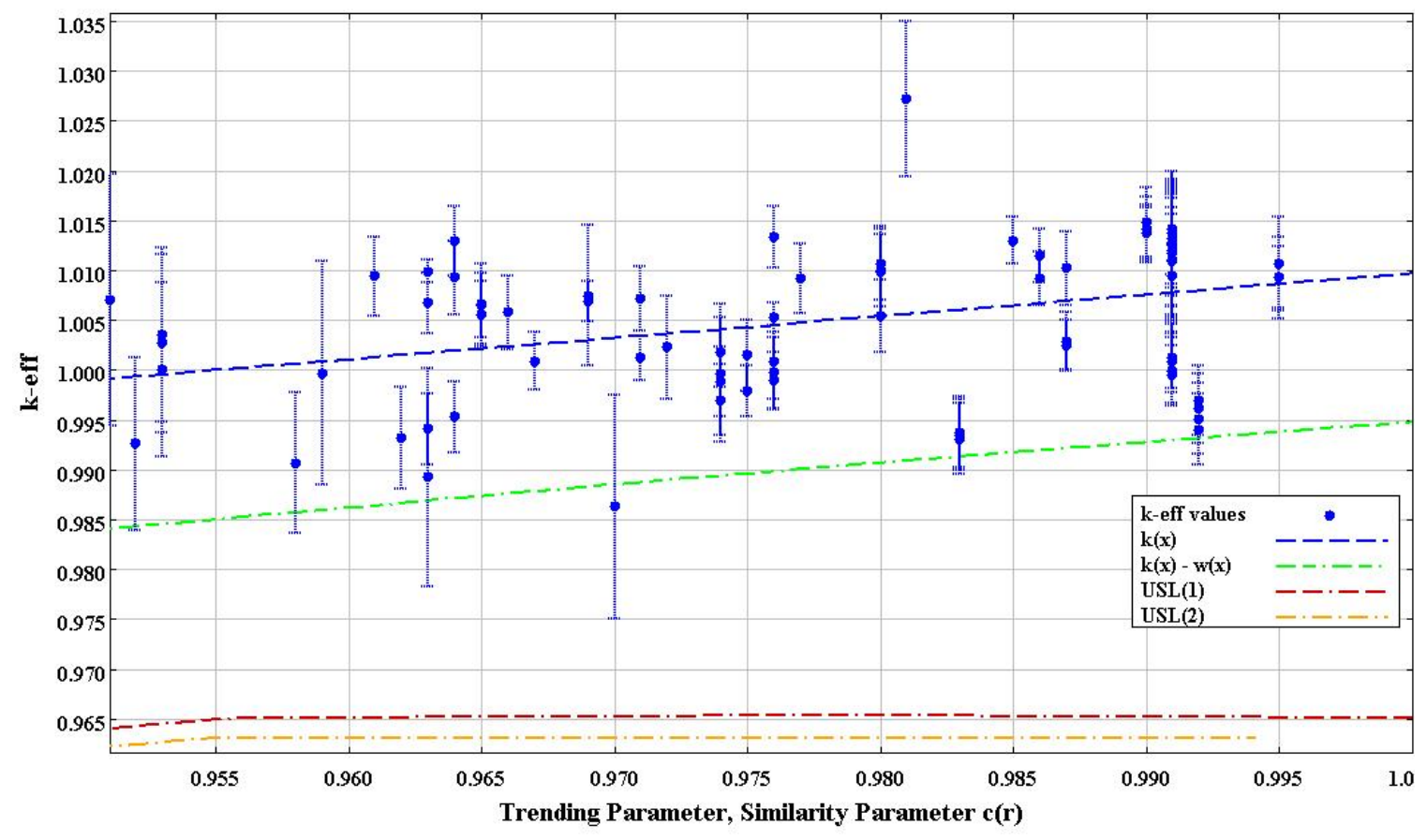

Fig. 43. USLSTATS plot for $c_{r}$ trending of experiments with $c_{r} \geq 0.95$.

\subsection{USL FOR APPLICATIONS 1-4 USING TSURFER DATA ADJUSTMENT TECHNIQUES}

In the near future, the evaluator may be able predict computational biases with a nuclear data adjustment tool such as the TSURFER code, ${ }^{11}$ which will be distributed with SCALE 6 in 2009. This code identifies a single set of adjustments to nuclear data that will result in the computational models all producing $k_{\text {eff }}$ values close to their experimental $k_{\text {eff }}$ value. Then the same data adjustments are used to predict an unbiased $k_{\text {eff }}$ value for the application and an uncertainty on the adjusted $k_{\text {eff }}$ value. The difference between the originally calculated $k_{\text {eff }}$ value and the new post-adjustment $k_{\text {eff }}$ value represents the bias in the original calculation, and the uncertainty in the adjusted value represents the uncertainty in this bias. If similar experiments are available to validate the use of a particular nuclide in the application, the uncertainty of the bias for this nuclide is reduced. If similar experiments are not available, the uncertainty in the bias for the given nuclide is high. Thus, with a complete set of experiments to validate important components in the application, a precise bias with a small uncertainty can be predicted. Where the experimental coverage is lacking, a bias can be predicted with an appropriately large uncertainty. As experienced is gained with TSURFER, it is expected to become a preferred tool for rigorous bias and bias uncertainty determination, particularly for applications for which nearly identical critical experiments are not available.

A calculation was performed using the SCALE 6 version of TSURFER, the new SCALE 6 covariance data library, and 1066 critical experiments to calculate the set of cross-section adjustments that minimize the overall chi-square statistic of the data adjustments. An additional important input to the TSURFER calculation is the set of correlations between experiment $k_{\text {eff }}$ values. For purposes of this study, it was assumed that all experiments within any one IHECSBE evaluation were $90 \%$ correlated and that there were no correlations between experiments in 
different evaluations. This approximation is arbitrary. In reality, the same fuel rods or plates are used in multiple evaluations and the correlations are far more complex than the simple assumption stated above.

The TSURFER-calculated bias and bias uncertainty values are shown in Table 19. Note that the bias uncertainty values are the uncertainties in the adjusted $k_{\text {eff }}$ values. The reduction in these uncertainties relative to the original uncertainties in the applications is due to inclusion of additional information, the critical experiments, in the validation process. The original uncertainties in the applications, due to cross section covariance data, shown in Table 1, are $0.937,0.752,0.515$ and $1.354 \% \Delta k / k$, respectively. For applications 1 and 2 , the uncertainty are reduced to approximately $10 \%$ of their original values, confirming that the benchmarks selected lead to adjustments in the cross sections that are the largest sources of uncertainty, and thus the largest potential sources of computational bias, for these cases. For application 3, the uncertainty in the bias is $31 \%$ of the original application uncertainty, indicating marginal coverage by the benchmark set. For application 4, the uncertainty in the bias is $96 \%$ of the original uncertainty, confirming the lack of available benchmarks to validate this application.

Where the 2\% additional margin used in Section 5.1 is applied, any positive bias disallowed, and a $95 \%$ confidence $(2 \sigma)$ applied for the bias uncertainty, the USL values are shown in Table 19. However, the USL values for applications 3 and 4 should be used with caution, perhaps with an increased additional margin, as it has been demonstrated that sufficient benchmarks are not available for the validation of these cases.

Table 19. Bias, bias uncertainty, and USL values computed with TSURFER

\begin{tabular}{crcc}
\hline Application & $\begin{array}{c}\text { Bias } \\
(\boldsymbol{\%} \boldsymbol{\Delta} \boldsymbol{k} / \boldsymbol{k})\end{array}$ & $\begin{array}{c}\text { Bias uncertainty } \\
(\boldsymbol{\%} \boldsymbol{\Delta} \boldsymbol{k} / \boldsymbol{k})\end{array}$ & \multicolumn{1}{c}{ USL } \\
\hline 1 & 0.341 & 0.071 & 0.979 \\
2 & 0.331 & 0.076 & 0.978 \\
3 & -0.091 & 0.159 & 0.976 \\
4 & 1.304 & 1.257 & 0.955 \\
\hline
\end{tabular}

Through further examination of the results for application 1, the individual sources of bias can be identified according the impact of the adjusted cross section on the application $k_{\text {eff }}$ value.

TSURFER ranks the bias contributions according to an L1 norm, which is based on the absolute values of the group-wise cross section adjustments. The top contributors to bias for application 1 are shown in Table 20. Comparing the TSURFER-predicted contribution to bias with the top sources of uncertainty shown in Table 1 , one finds that the ${ }^{233} \mathrm{U}$ reactions and ${ }^{16} \mathrm{O}$ elastic rank at top of both tables. However, ${ }^{1} \mathrm{H}$ elastic scattering, the second highest source of uncertainty, appears as the 11th highest source of bias. For all nuclides and reactions, the bias contribution is approximately the same or less than the uncertainty shown in Table 1, as the adjustments in the cross sections are bounded with a $\chi^{2}$ of 1.2. 
Table 20. Top contributors to TSURFER-determined bias for application 1

\begin{tabular}{cccc}
\hline Nuclide & Reaction & $\begin{array}{c}\text { Contribution to bias } \\
\text { \% } \Delta \boldsymbol{k} / \boldsymbol{k}\end{array}$ & $\begin{array}{c}\text { Fraction of bias } \\
\text { L1-norm }\end{array}$ \\
\hline${ }^{233} \mathrm{U}$ & chi & $3.2738 \mathrm{E}-01$ & $2.7907 \mathrm{E}-01$ \\
${ }^{233} \mathrm{U}$ & $\mathrm{n}, \boldsymbol{\gamma}$ & $9.8989 \mathrm{E}-02$ & $2.5125 \mathrm{E}-01$ \\
${ }^{16} \mathrm{O}$ & elastic & $-1.8796 \mathrm{E}-01$ & $1.9356 \mathrm{E}-01$ \\
${ }^{233} \mathrm{U}$ & nubar & $1.6175 \mathrm{E}-01$ & $1.3797 \mathrm{E}-01$ \\
${ }^{233} \mathrm{U}$ & fission & $-3.5477 \mathrm{E}-02$ & $6.8533 \mathrm{E}-02$ \\
${ }^{233} \mathrm{U}$ & n,n' & $-3.7597 \mathrm{E}-02$ & $3.2049 \mathrm{E}-02$ \\
${ }^{233} \mathrm{U}$ & elastic & $6.2944 \mathrm{E}-03$ & $5.7039 \mathrm{E}-03$ \\
${ }^{56} \mathrm{Fe}$ & $\mathrm{n}, \gamma$ & $6.4198 \mathrm{E}-03$ & $5.4725 \mathrm{E}-03$ \\
${ }^{14} \mathrm{~N}$ & $\mathrm{n}, \mathrm{p}$ & $6.1571 \mathrm{E}-03$ & $5.2583 \mathrm{E}-03$ \\
${ }^{1} \mathrm{H}$ & $\mathrm{n}, \boldsymbol{\gamma}$ & $5.4157 \mathrm{E}-03$ & $4.6187 \mathrm{E}-03$ \\
${ }^{1} \mathrm{H}$ & elastic & $-4.9899 \mathrm{E}-03$ & $4.4406 \mathrm{E}-03$ \\
\hline
\end{tabular}

The energy-dependent adjustments for selected cross sections are shown in Fig. 44. A maximum adjustment of $7.3 \%$ is given for ${ }^{233} \mathrm{U}$ fission where ${ }^{1} \mathrm{H}$ elastic receives a maximum adjustment of $<0.1 \%$.

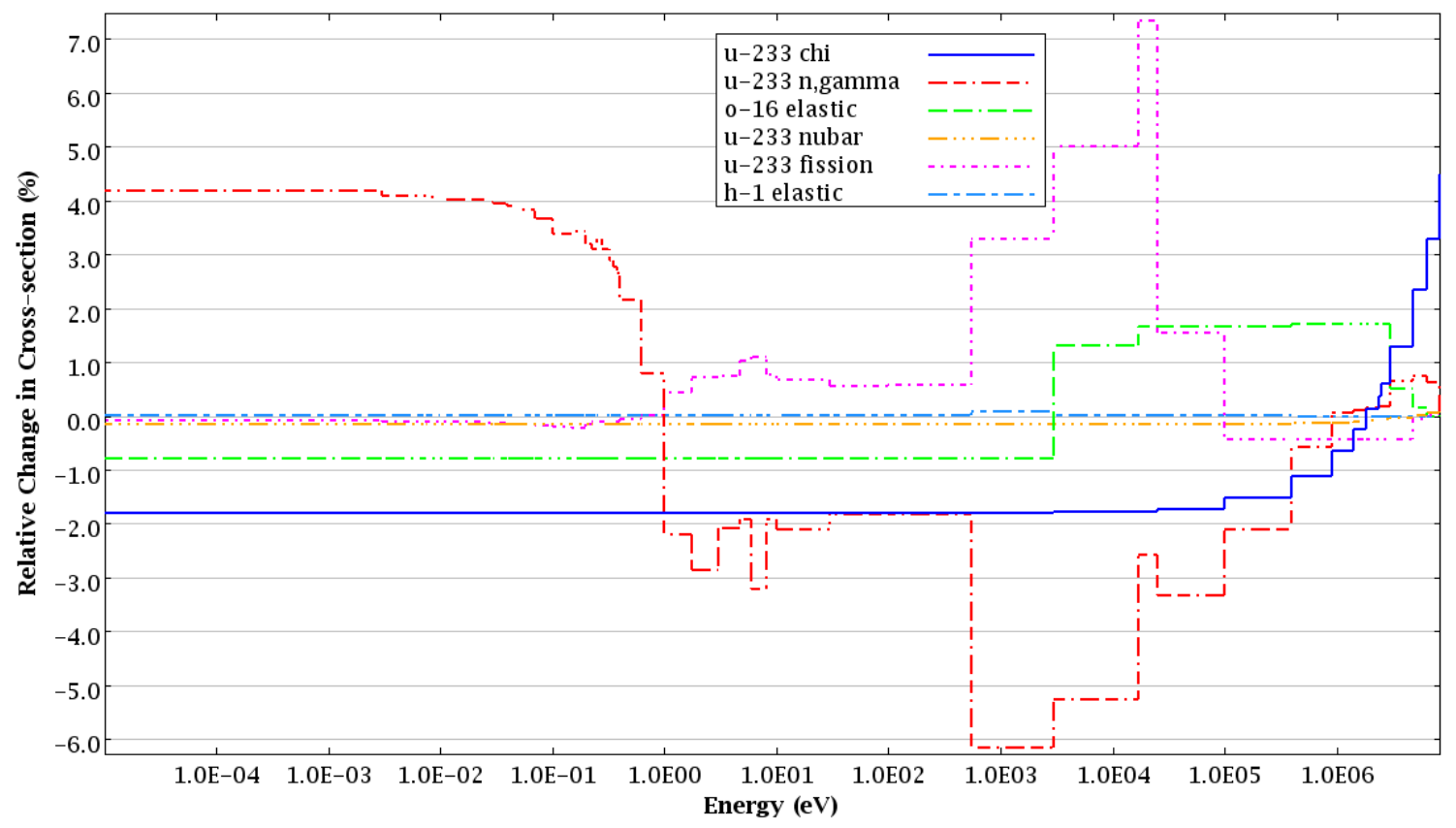

Fig. 44. Select cross-section adjustments from TSURFER analysis. 
The energy-dependent cross-section adjustments can be multiplied with the energy-dependent sensitivity of the application's $k_{\text {eff }}$ to the cross sections to form an energy-dependent bias due to a specific nuclide-reaction pair. As shown in Fig. 45, the application bias is dependent on which cross sections were modified in the adjustment procedure, and how sensitive the application is to those adjustments. For example, the maximum adjustment, shown in Fig. 44, occurs around $20 \mathrm{keV}$. However, the application is not very sensitive to the cross section in this energy range, and the bias due to this adjustment is small. In the intermediate energies, the adjustment is on the order of $1 \%$, but the application is more sensitive at these energies, so a larger bias contribution results. Also, as the thermal- and fast-energy cross sections are reduced where the intermediateenergy cross sections are increased, a negative contribution to the bias is observed for thermal and fast energies and a positive contribution to the bias is observed for intermediate energies.

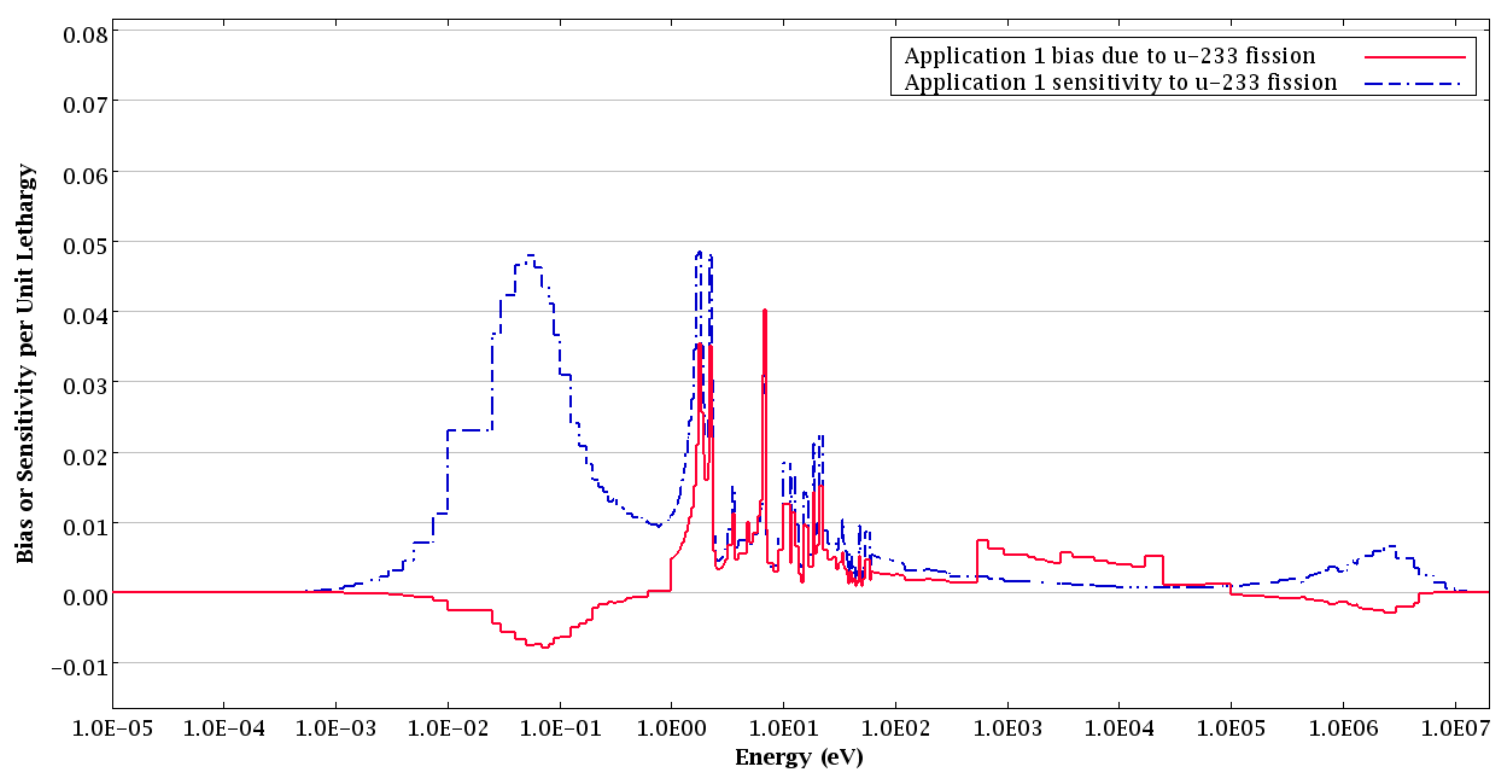

Fig. 45. Energy-dependent bias and sensitivity for ${ }^{233} \mathrm{U}$ fission for application 1.

As the TSURFER bias uncertainty is simply the uncertainty in the adjusted, or unbiased, crosssection data, the adjusted covariance matrix resulting from the TSURFER procedure can be used to provide contributions to the bias uncertainty by individual covariance matrices using the extended uncertainty edit of TSUNAMI-IP. The contributions to the uncertainty in the bias are shown in Table 21. Here, anti-correlations in the adjusted covariance data become important components in the reduced uncertainty. Since all cross sections are adjusted from the same set of benchmark experiments, the number of cross-correlations in uncertainties for different nuclides and reactions greatly increases. Where sufficient quality benchmarks are available to validate a given nuclide reaction, the uncertainty in that nuclide reaction is reduced. However, due to correlations introduced in the adjustment procedure, the uncertainty in the cross section may be increased if only limited benchmarks that have significant sensitivities to a given nuclide reaction are available.

In comparing the results shown in Table 1 to those of Table 21, the uncertainties for all nuclide-reaction pairs in applications 1-3 are reduced and new cross-correlations are introduced which further reduce the uncertainty. For application 4, the post-adjustment uncertainties for ${ }^{233} \mathrm{U}$ and ${ }^{235} \mathrm{U}$ are sufficiently reduced so they do not appear as significant sources of bias uncertainty. 
However, the uncertainties for ${ }^{56} \mathrm{Fe} \mathrm{n}, \gamma, \mathrm{Ca} n, \gamma$, and ${ }^{56} \mathrm{Fe}$ elastic show only a small reduction and increased uncertainties are observed for $\mathrm{Ca} \mathrm{n}, \mathrm{p}, \mathrm{Ca} \mathrm{n}, \alpha$, and $\mathrm{Mg}$ elastic. These results further confirm the lack of validation coverage from these components of application 4 .

Table 21. TSURFER bias uncertainty due to cross-section-covariance data

\begin{tabular}{|c|c|c|c|}
\hline System & $\begin{array}{l}\text { Standard } \\
\text { deviation } \\
\quad(\%)\end{array}$ & $\begin{array}{c}\text { Top six contributo } \\
\text { standard deviat } \\
(\%)\end{array}$ & \\
\hline \multirow{6}{*}{ Application 1} & \multirow{6}{*}{0.071} & ${ }^{233} \mathrm{U}$ chi to ${ }^{233} \mathrm{U}$ chi & 0.201 \\
\hline & & ${ }^{233} \mathrm{U} n, \gamma$ to ${ }^{233} \mathrm{U}$ chi & -0.198 \\
\hline & & ${ }^{233} \mathrm{U}$ nubar to ${ }^{233} \mathrm{U}$ chi & -0.157 \\
\hline & & ${ }^{233} \mathrm{U} n, \gamma$ to ${ }^{233} \mathrm{Un}, \gamma$ & 0.152 \\
\hline & & ${ }^{233} \mathrm{U}$ nubar to ${ }^{233} \mathrm{U}$ nubar & 0.129 \\
\hline & & ${ }^{16} \mathrm{O}$ elastic to ${ }^{233} \mathrm{U}$ chi & -0.080 \\
\hline \multirow{6}{*}{ Application 2} & \multirow{6}{*}{0.076} & ${ }^{235} \mathrm{U}$ n, $\gamma$ to ${ }^{235} \mathrm{U}$ nubar & -0.176 \\
\hline & & ${ }^{235} \mathrm{U}$ nubar to ${ }^{235} \mathrm{U}$ nubar & 0.176 \\
\hline & & ${ }^{235} \mathrm{U} n, \gamma$ to ${ }^{235} \mathrm{Un}, \gamma$ & 0.143 \\
\hline & & ${ }^{235} \mathrm{U}$ chi to ${ }^{235} \mathrm{U}$ chi & 0.137 \\
\hline & & ${ }^{235} \mathrm{U}$ nubar to ${ }^{235} \mathrm{U}$ chi & -0.127 \\
\hline & & ${ }^{235} \mathrm{U} n, \gamma$ to ${ }^{235} \mathrm{U}$ chi & -0.114 \\
\hline \multirow{6}{*}{ Application 3} & \multirow{6}{*}{0.159} & ${ }^{233} \mathrm{U}$ fission to ${ }^{233} \mathrm{U}$ fission & 0.132 \\
\hline & & ${ }^{233} \mathrm{U}$ nubar to ${ }^{233} \mathrm{U}$ nubar & 0.120 \\
\hline & & ${ }^{14} \mathrm{~N} n, \mathrm{p}$ to ${ }^{14} \mathrm{~N} \mathrm{n,p}$ & 0.104 \\
\hline & & ${ }^{233} \mathrm{U}$ fission to ${ }^{233} \mathrm{U}$ nubar & -0.100 \\
\hline & & ${ }^{1} \mathrm{H} \mathrm{n}, \gamma$ to ${ }^{233} \mathrm{U}$ fission & -0.086 \\
\hline & & ${ }^{238} \mathrm{U} n, \gamma$ to ${ }^{238} \mathrm{U} n, \gamma$ & 0.078 \\
\hline \multirow{6}{*}{ Application 4} & \multirow{6}{*}{1.257} & ${ }^{56} \mathrm{Fe} \mathrm{n}, \gamma$ to ${ }^{56} \mathrm{Fe} n, \gamma$ & 1.027 \\
\hline & & $\mathrm{Ca} n, p$ to $\mathrm{Ca} n, p$ & 0.482 \\
\hline & & $\mathrm{Ca} \mathrm{n, \gamma}$ to Ca n, $\gamma$ & 0.477 \\
\hline & & ${ }^{56} \mathrm{Fe}$ elastic to ${ }^{56} \mathrm{Fe}$ elastic & 0.266 \\
\hline & & 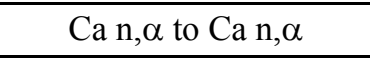 & 0.236 \\
\hline & & $\mathrm{Mg}$ elastic to Mg elastic & 0.197 \\
\hline
\end{tabular}





\section{ADDRESSING VALIDATION WEAKNESSES AND GAPS}

No critical experiments were identified that are adequately similar to applications 3 and 4 . In general, when an adequate set of critical experiments is not available to validate an application, the evaluator has a few choices in how to establish a USL.

The evaluator may be able to locate additional critical experiments that are more similar to the application based on knowledge gained through the similarity assessment. Applications 1 through 4 were compared to a 672 critical configurations. This set includes only a subset of the configurations available through the IHECSBE and does not include any configurations not documented in the IHECSBE. The analyst may be able to use the information obtained from similarity analysis, such as is documented in Section 5. of this report, to identify additional critical configurations that are similar to the applications.

The evaluator may be able to revise the application model, or the application itself, such that it is more similar to available critical experiments and provide logic in the NCS evaluation as to why the new application is bounding compared to the originally identified application. For example, as can be seen from the negative sensitivity coefficients in Fig. 25 , the ${ }^{14} \mathrm{~N}$ in application 3 reduces $k_{\text {eff. }}$ From Table 12 , the ${ }^{14} \mathrm{~N}$ sensitivity accounts for about $50 \%$ of the ideal $\mathrm{c}_{\mathrm{r}}$ value for application 3. If the $k_{\text {eff }}$ margin resulting from the presence of ${ }^{14} \mathrm{~N}$ is not needed, one could revise application 3, removing the ${ }^{14} \mathrm{~N}$ and potentially increasing the similarity of additional critical configurations. Then the analyst would provide logic in the criticality evaluation justifying the revised application 3 model as a conservative approximation.

A frequently used option is to supplement the margin of subcriticality with an additional margin penalty to cover uncertainties associated with having a validation set that is not adequately similar to the application. The TSUNAMI tools can assist with quantifying and defending such a penalty. The TSUNAMI tools combine the application sensitivity profiles with nuclear data uncertainty information contained in the covariance data files to estimate the total uncertainty on $k_{\text {eff }}$ due to uncertainty in the nuclear data. Figure 46 shows the top part of such an edit for application 4. A note of caution is in order when the cross-section uncertainty data is used for this purpose. The TSUNAMI-IP module typically modifies the cross-section covariance data file specified by the user to correct obviously incorrect uncertainty data and to provide uncertainty data where it is missing. The inclusion of the TSUNAMI-IP parameter "Cov_fix" directs TSUNAMI-IP to correct obviously large values ( $>1000 \%$ uncertainty) and to fill in missing data. In this case, TSUNAMI-IP creates a working covariance data set that includes the following types of cross-section uncertainty data:

- Detailed energy- and reaction-dependent uncertainty data generated by the experimentalists and the cross section evaluators.

- Detailed energy- and reaction-dependent uncertainty data generated after the fact by cross section evaluators.

- Approximate uncertainty data based on relatively sparse or broad energy range measurement uncertainties, such as application of the uncertainty on the $2200 \mathrm{~m} / \mathrm{second}$ cross-section data available in the Atlas of Neutron Resonances ${ }^{12}$ over the entire thermal neutron energy range.

- User-specified data for specific nuclides and reactions.

- A user-specified default value used when no other data is provided. 
the relative standard deviation of k-eff (\% delta-k/k)

with user input standard deviations for unknown covariance data

and the default standard deviation of 0.05 for unspecified covariance data is:

$1.3541+/-0.0016$ percent

* indicates default covariance data

*** indicates default covariance data used to correct zeros or large values in some groups

$\star * * *$ indicates user input covariance data used to correct zeros or large values in some groups

contributions to uncertainty in k-eff (\% delta-k/k) by individual energy covariance matrices:

covariance matrix

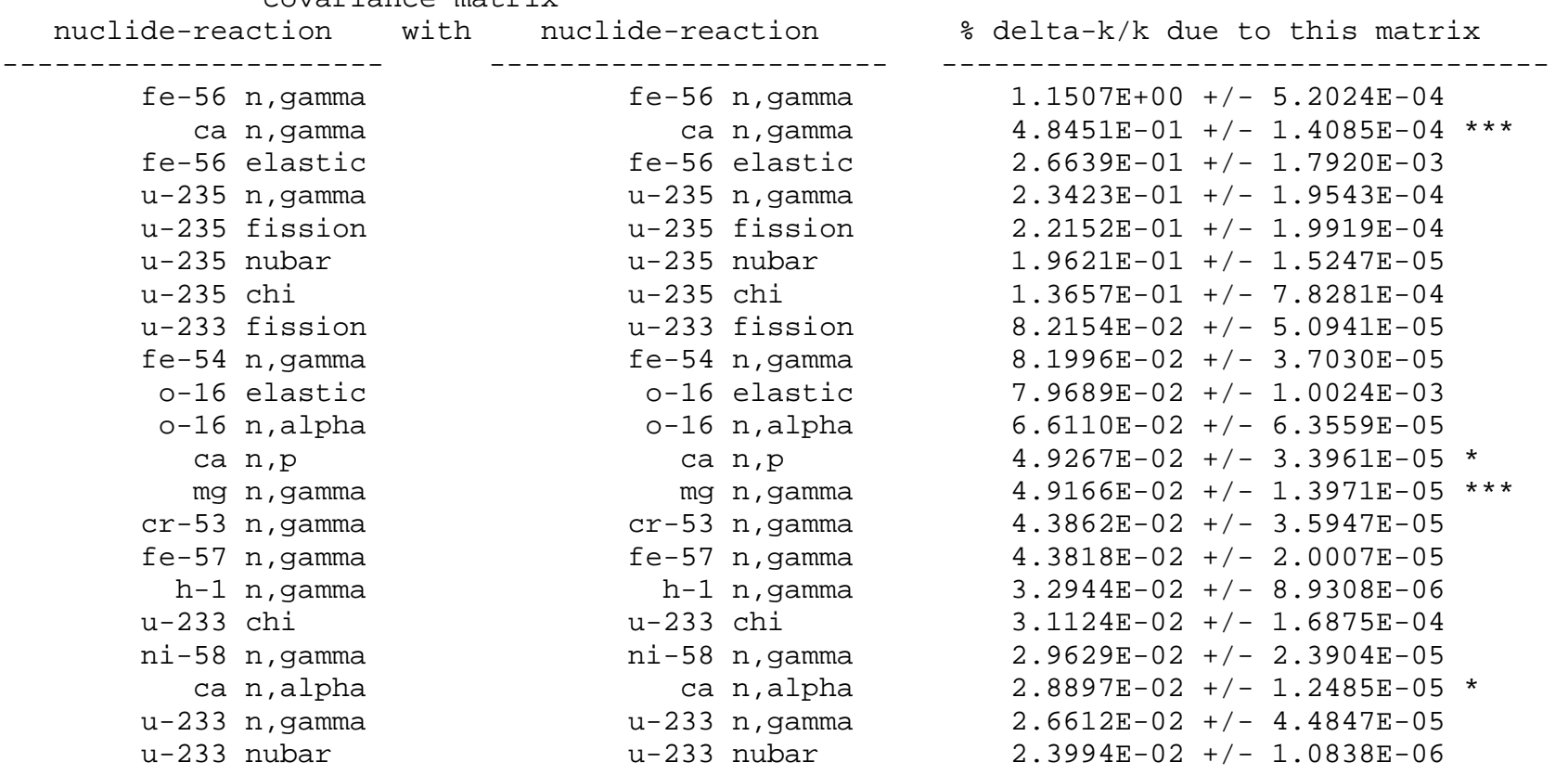

Fig. 46. Extended uncertainty edit for application 4. 
The analyst should consider the impact of using default cross-section uncertainty data on the $k_{\text {eff }}$ uncertainty values generated by TSUNAMI-IP. For example, the second data row in Fig. 46 is for the Ca $(\mathrm{n}, \gamma)$ reaction. The asterisks on the right-hand side of the row indicate that default covariance data was used to correct zeros or large cross-section uncertainty values for some energy groups. A review of the warning messages in the TSUNAMI-IP output indicates that the default value of 5\% was used to replace zero values for neutron energy groups 1 through 25 in the 44-energy group structure. This means that a default value of $5 \%$ was used for the $\mathrm{Ca}(\mathrm{n}, \gamma)$ cross-section uncertainties for neutron energies above 0.625 $\mathrm{eV}$. As can be seen in Fig. 32, application 4 is relatively insensitive to the $\mathrm{Ca}(\mathrm{n}, \gamma)$ cross sections above $0.625 \mathrm{eV}$. Thus the use of default covariance data above $0.625 \mathrm{eV}$ has little effect on the resulting $k_{\text {eff }}$ uncertainty value. If this were not the case, the user should carefully consider the uncertainty value input for the $\mathrm{Ca}(\mathrm{n}, \gamma)$ reaction in the TSUNAMI-IP covariance data block.

From the extended uncertainty edit, the 1 -standard-deviation total uncertainty in $k_{\text {eff }}$ due to cross-sectioncovariance data for application 4 is $1.3541 \pm 0.0016 \% \Delta k / k$. There is overlap between this nuclear data uncertainty, the bias and bias uncertainty that could be calculated by using critical experiments that are as similar as possible to the application, and the additional margin that is frequently adopted. Unfortunately, it is not possible to quantify how much these quantities overlap.

It could be argued that, in general, the bias and bias uncertainty calculated using critical experiments, which are similar to the application, should be consistent with the nuclear data uncertainty. The bias and bias uncertainty should be bounded by two times the nuclear data uncertainty. One can be confident that the bias and bias uncertainty will be conservatively bounded by three times the nuclear data uncertainty.

As can be seen in Table 18, the USLs for application 1 vary from 0.9559 through 0.9652 . These USLs include a $2 \% \Delta k$ additional margin. With the additional margin removed, the USLs become 0.9759 through 0.9852 , and the corresponding bias and bias uncertainty vary from -2.41 to $-1.48 \% \Delta k$. As was reported in Table 1, the nuclear data uncertainty for application 1 was calculated to be $0.937 \% \Delta k / k$. Three times this nuclear data uncertainty easily bounds the bias and bias uncertainty calculated for application 1 . Where a statistically significant set of critical experiments similar to the application is not available, three times the nuclear data uncertainty should provide an adequate bounding estimate of the potential bias and bias uncertainty. Thus for application 4 with its $1.3541 \% \Delta k / k$ nuclear data uncertainty, the USL with no additional margin should be greater than 0.9594 (i.e., $1.0-3 * 0.013541$ ).

The extended uncertainty edit also includes individual uncertainties for nuclide and reaction pairs. For example, the total one-standard-deviation uncertainty associated with ${ }^{56} \mathrm{Fe}(\mathrm{n}, \gamma), \mathrm{Ca}(\mathrm{n}, \gamma)$, and ${ }^{56} \mathrm{Fe}$ elastic scattering reactions in application 4 is $1.28 \% \Delta k / k$, which is computed from the values shown in Table 1 by adding the squares of the individual values and then taking the square root of the sum. The total for all other contributors, not just those shown in Table 1 , is only $0.451 \% \Delta k / k$. These three reactions account for more than $80 \%$ of the reduction in similarity shown in Table 16 . Considering the sensitivity of these reactions in the application 4 model, the large reactivity uncertainties associated with the nuclear data, and the lack of good validation, it would be imprudent to ignore this significant gap in the validation. In this case one could adopt a 2 or 3 standard deviation penalty (e.g., $2.54 \% \Delta k / k$ or $3.81 \% \Delta k / k$ ) in addition to whatever bias and bias uncertainty values result from the validation study. Further studies of other critical experiments with iron and/or calcium may yield some indication of the sign and magnitude of errors that may exist in associated nuclear data. Such information might be used to justify reducing or eliminating the penalty.

Note that with the TSURFER analysis, gaps in the experimental validation coverage are accounted for with the post-adjustment uncertainty, which is applied as the uncertainty in the bias. If a perfect set of 
consistent experiments were available to validate every nulide reaction in the application model, the post-adjustment uncertainty would be negligible, as there would be no remaining gap in the validation coverage. 


\section{CONCLUSIONS}

In this work, SCALE TSUNAMI tools were used to assess the similarity of four application models, provided by ISOTEK NCS staff, with a set of 672 critical experiments identified by ORNL staff as potentially useful for validation of the applications. The similarity assessment identified a large number of experiments that could be used for validation of criticality safety calculations similar to applications 1 and 2. No experiments were identified that were adequately similar to applications 3 and 4. Analysis of the similarity assessment was provided for each application.

The USLSTATS code was used to calculate USLs for application 1 for various sets of critical experiments as trended using EALF and the similarity index $\mathrm{c}_{\mathrm{r}}$. The TSURFER code was applied to determine USLs for all four applications using data adjustment techniques. These limits provide the margins needed to address uncertainty in the computational method, primarily due to nuclear data uncertainties.

Some discussion was provided as to possible approaches that could be used to address validation where an adequate set of critical experiments was not available to validate applications. 



\section{REFERENCES}

1. B. T. Rearden, "TSUNAMI-1D: Control Module for One-Dimensional Cross-Section Sensitivity and Uncertainty Analysis for Criticality," SCALE: A Modular Code System for Performing Standardized Computer Analyses for Licensing Evaluation, ORNL/TM-2005/39, Version 5.1, Vol. I, Book 2, Sect. C8, Oak Ridge National Laboratory, Oak Ridge, Tenn., November 2006.

2. B. T. Rearden, "TSUNAMI-3D: Control Module for Three-Dimensional Cross-Section Sensitivity and Uncertainty Analysis for Criticality," SCALE: A Modular Code System for Performing Standardized Computer Analyses for Licensing Evaluation, ORNL/TM-2005/39, Version 5.1, Vol. I, Book 2, Sect. C9, Oak Ridge National Laboratory, Oak Ridge, Tenn., November 2006.

3. B. T. Rearden, "TSUNAMI Utility Modules," SCALE: A Modular Code System for Performing Standardized Computer Analyses for Licensing Evaluation, ORNL/TM-2005/39, Version 5.1, Vol. III, Book 3, Sect. M18, Oak Ridge National Laboratory, Oak Ridge, Tenn., November 2006. See subsection M18.1, TSUNAMI-IP.

4. R. T. Primm, III, Criticality Safety Studies of Building 3019 Cell 4 and In-Line Storage Wells, ORNL/TM-12374, Oak Ridge National Laboratory, Oak Ridge, Tenn., November 1993.

5. B. T. Rearden and A. M. Fleckenstein, "JAVAPEÑO," SCALE: A Modular Code System for Performing Standardized Computer Analyses for Licensing Evaluation, ORNL/TM-2005/39, Version 5.1, Vol. III, Book 3, Sect. M20, Oak Ridge National Laboratory, Oak Ridge, Tenn., November 2006.

6. International Handbook of Evaluated Criticality Safety Benchmark Experiments, NEA/NSC/DOC(95)03, NEA Nuclear Science Committee, September 2006.

7. B. L. Broadhead, "SCALE 5.1 Cross-Section Covariance Libraries," SCALE: A Modular Code System for Performing Standardized Computer Analyses for Licensing Evaluation, ORNL/TM-2005/39, Version 5.1, Vol. I, Book 3, Sect. M19, Oak Ridge National Laboratory, Oak Ridge, Tenn., November 2006.

8. American National Standard ANSI/ANS-8.24-2007, "Validation of Neutron Transport Methods for Nuclear Criticality Safety Calculations," American Nuclear Society, 2007.

9. J. C. Dean and R. W. Tayloe, Jr., Guide for Validation of Nuclear Criticality Safety Calculation Methodology, NUREG/CR-6698, U. S. Nuclear Regulatory Commission, Science Applications International Corporation, January 2001.

10. V. R. Cain, A Computer Code to Perform Analyses of Criticality Validation Results, Y/DD-574, Martin Marietta Energy Systems, Inc., Oak Ridge Y-12 Plant, Oak Ridge, Tenn., September 1995.

11. B. L. Broadhead, B. T. Rearden, C. M. Hopper, J. J. Wagschal, and C. V. Parks, "Sensitivity- and Uncertainty-Based Criticality Safety Validation Techniques," Nucl. Sci. Eng. 146, 340-366 (2004).

12. S. F. Mughabghab, Atlas of Neutron Resonances, $5^{\text {th }}$ ed., Elsevier, Amsterdam, 2006. 

APPENDIX A

INPUT DECKS FOR APPLICATIONS 



\section{A.1 APPLICATION 1}

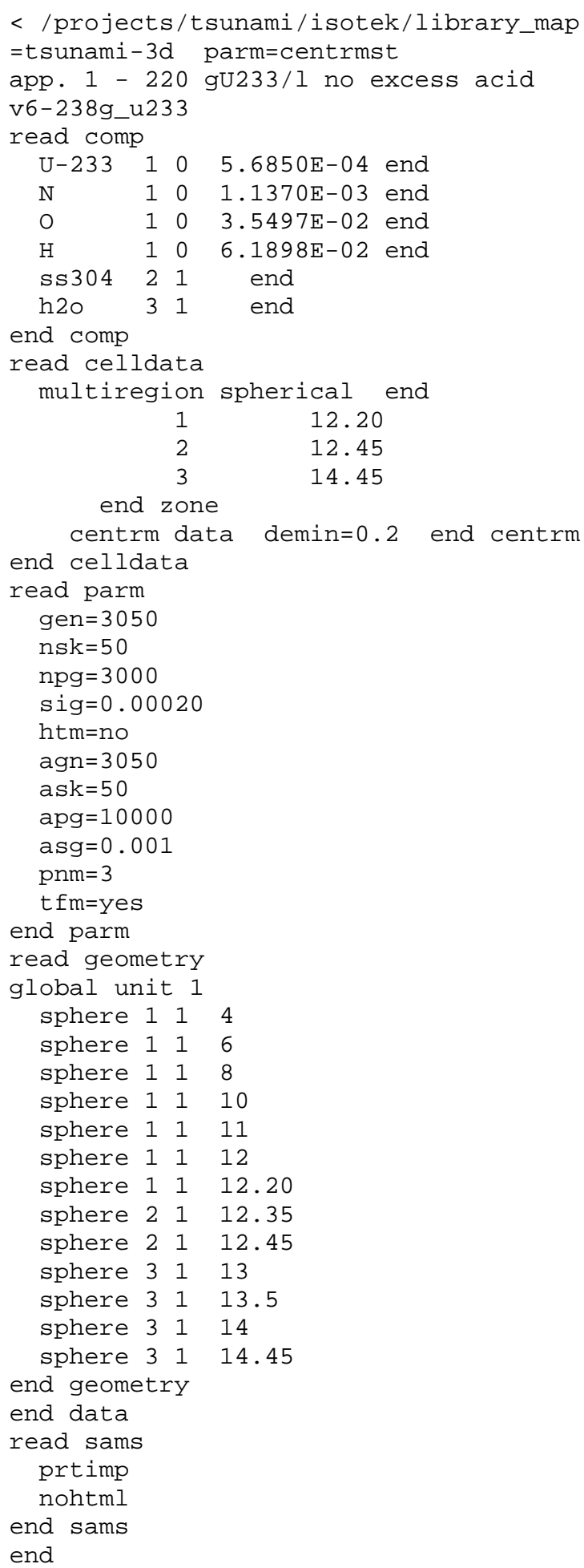




\section{A.2 APPLICATION 2}

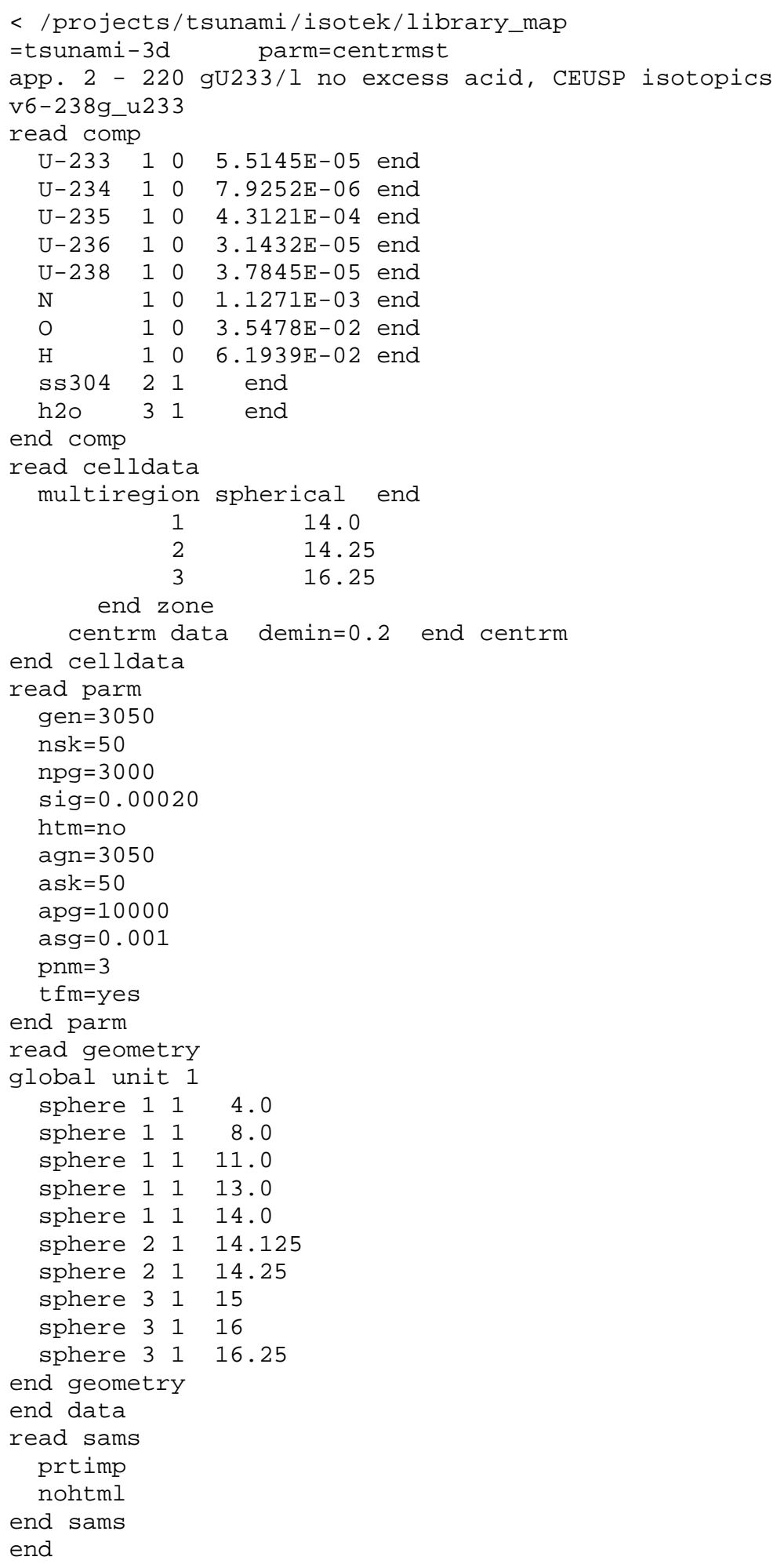




\section{A.3 APPLICATION 3}

=shell

сp /cpesrv/home05/dw8/u233/scale.rev02.xn238v6_withendf7_u233 v6-238g_u233

cp /cpesrv/home05/dw8/u233/u233_dist/centrmlib/92233-๑ 92233-๑

end

$=$ tsunami $-3 d \quad$ parm=centrmst

app. 3 - 600 gu233/1 no excess acid, 3\% U-233

v6-238g_u233

read comp

$\mathrm{U}-233 \quad 1 \odot \quad 4.6514 \mathrm{E}-05353$ end

$\mathrm{U}-235 \quad 1003.0746 \mathrm{E}-06353$ end

$\mathrm{U}-2381001.4693 \mathrm{E}-03353$ end

$\mathrm{N} \quad 1 \odot 3.0378 \mathrm{E}-03353$ end

$0 \quad 103.8560 \mathrm{E}-02353$ end

H $\quad 1 \odot 5.2818 \mathrm{E}-02353$ end

ss304 21 end

h2o 31 end

end comp

read celldata

multiregion spherical end

$\begin{array}{ll}1 & 53.0 \\ 2 & 53.25 \\ 3 & 55.25\end{array}$

end zone

centrm data demin=0.2 end centrm

end celldata

read parm

gen $=8050$

nsk $=50$

$\mathrm{npg}=8000$

sig $=0.00020$

$\mathrm{htm}=$ no

agn $=8050$

ask $=50$

apg $=50000$

asg $=0.001$

$\mathrm{pnm}=3$

$\mathrm{t} f \mathrm{~m}=\mathrm{yes}$

end parm

read geometry

global unit 1

sphere 11120

sphere 11130

$\begin{array}{lll}\text { sphere } 1 & 1 & 40\end{array}$

sphere 11145

sphere 11150

sphere 11152

sphere 1153.0

sphere $21 \quad 53.125$

sphere 2153.25

sphere 31154.0

sphere 31155.0

sphere $31 \quad 55.25$

end geometry

end data

read sams

prtimp

nohtml

end sams

end 


\section{A.4 APPLICATION 4}

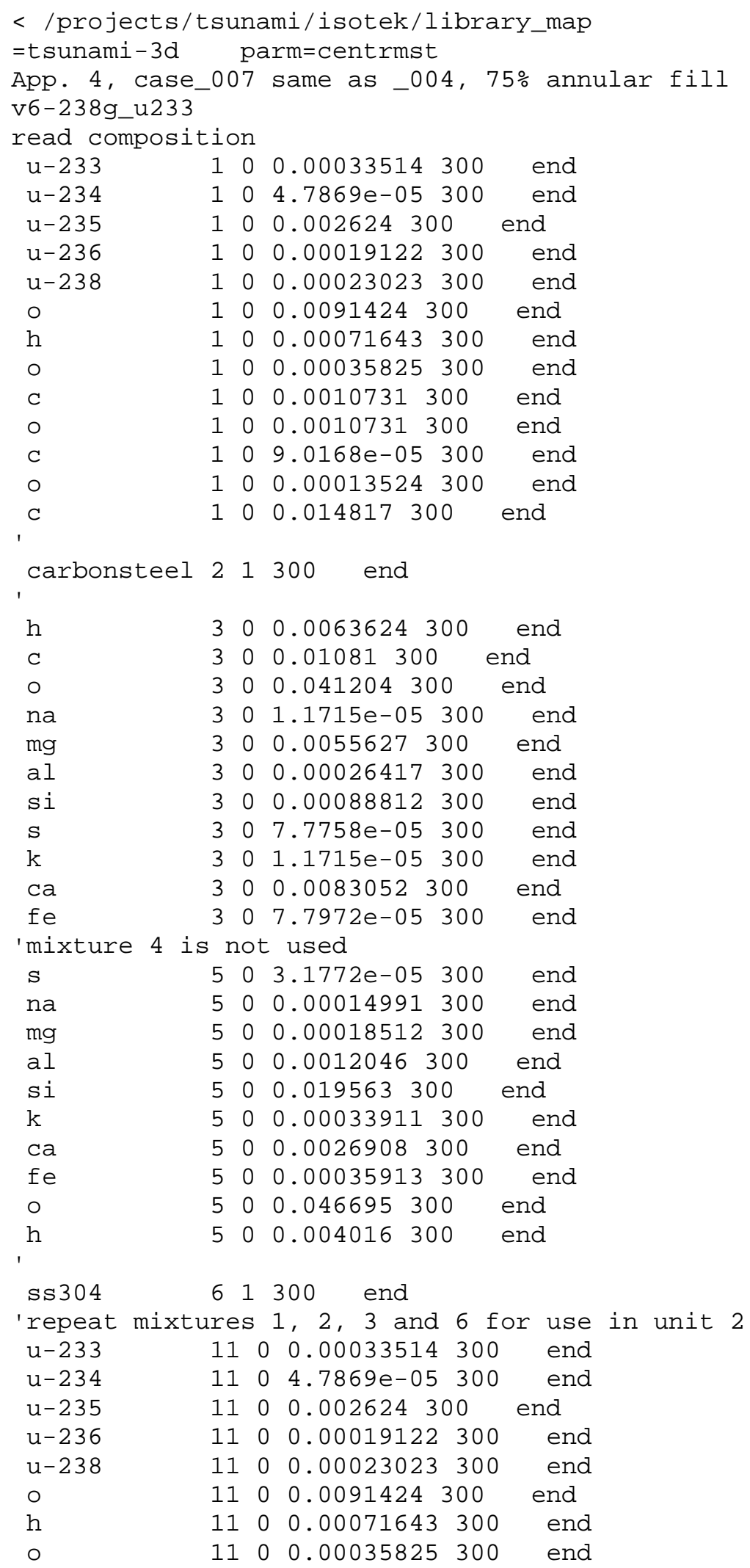




\section{A.4 APPLICATION 4 (continued)}

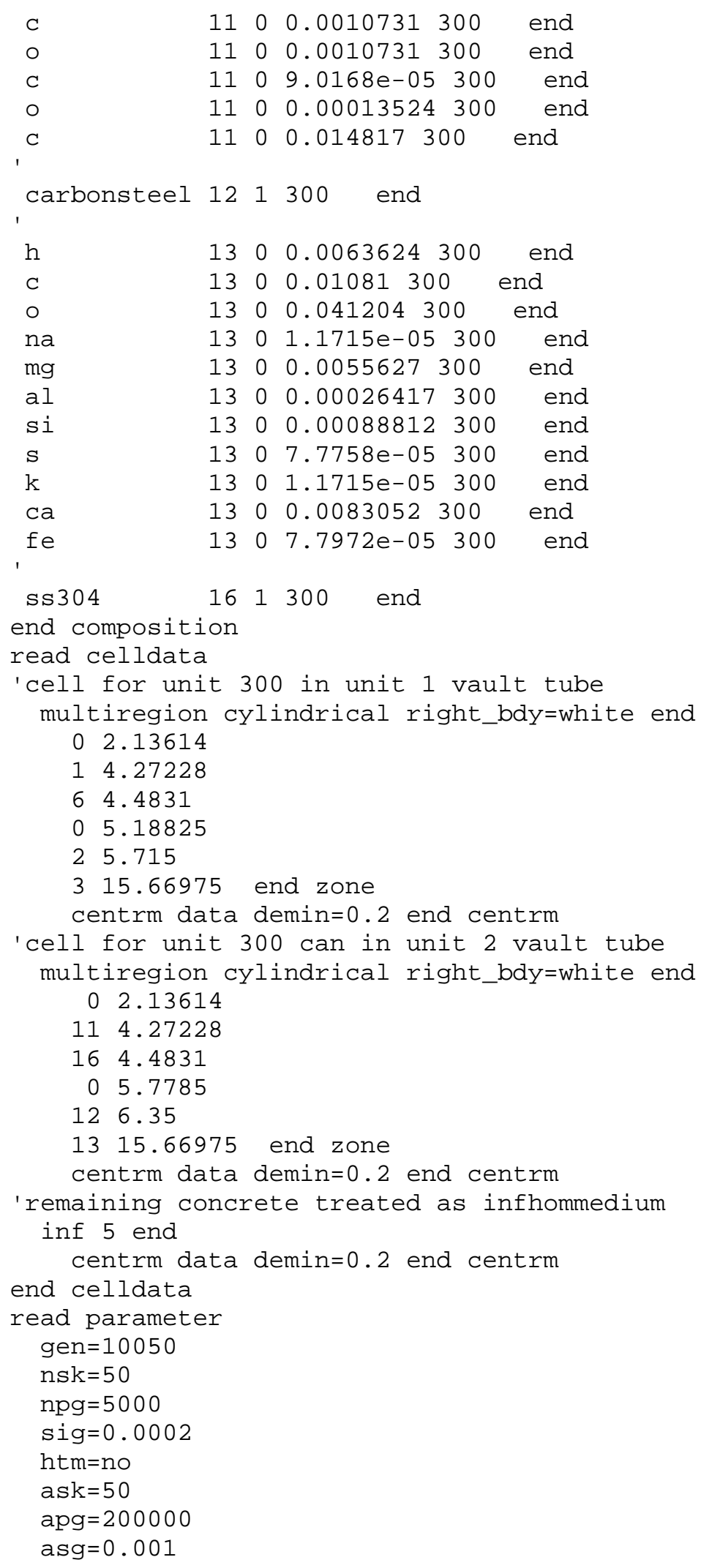




\section{A.4 APPLICATION 4 (continued)}

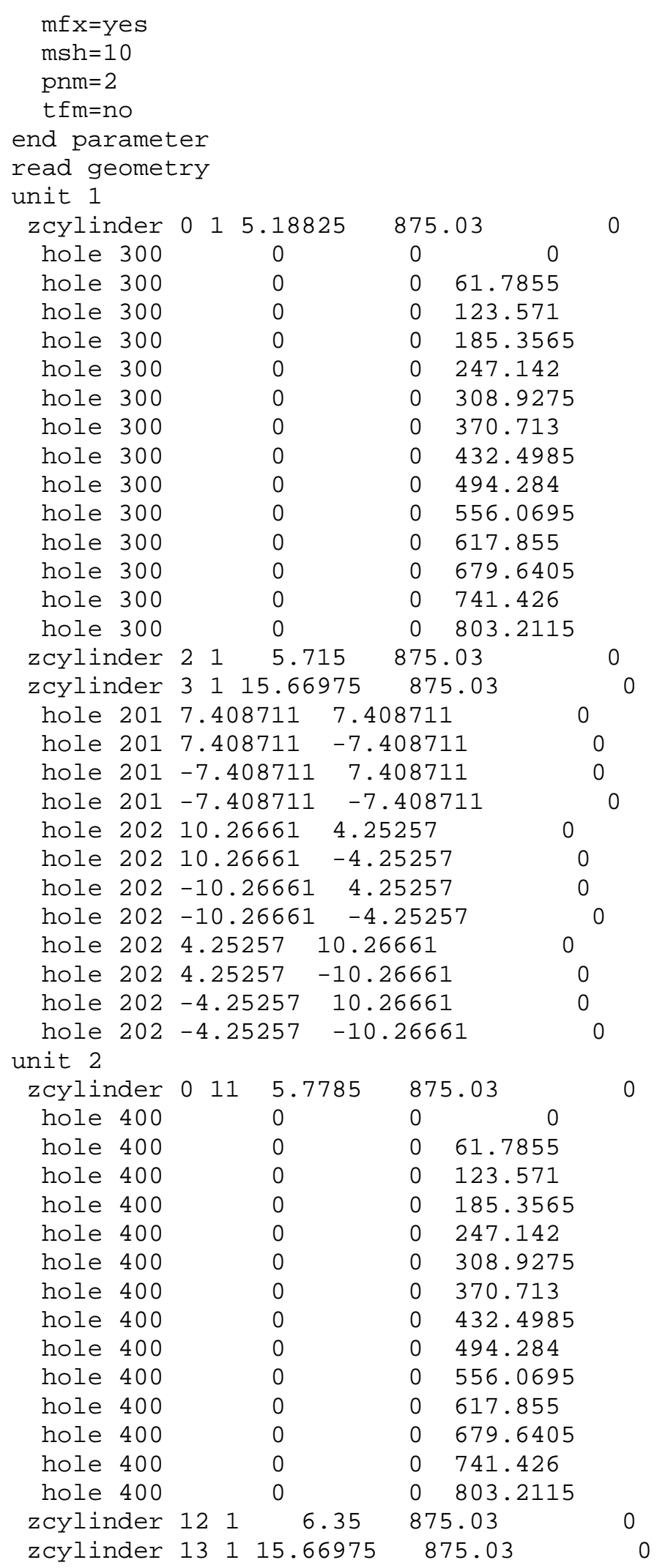




\section{A.4 APPLICATION 4 (continued)}

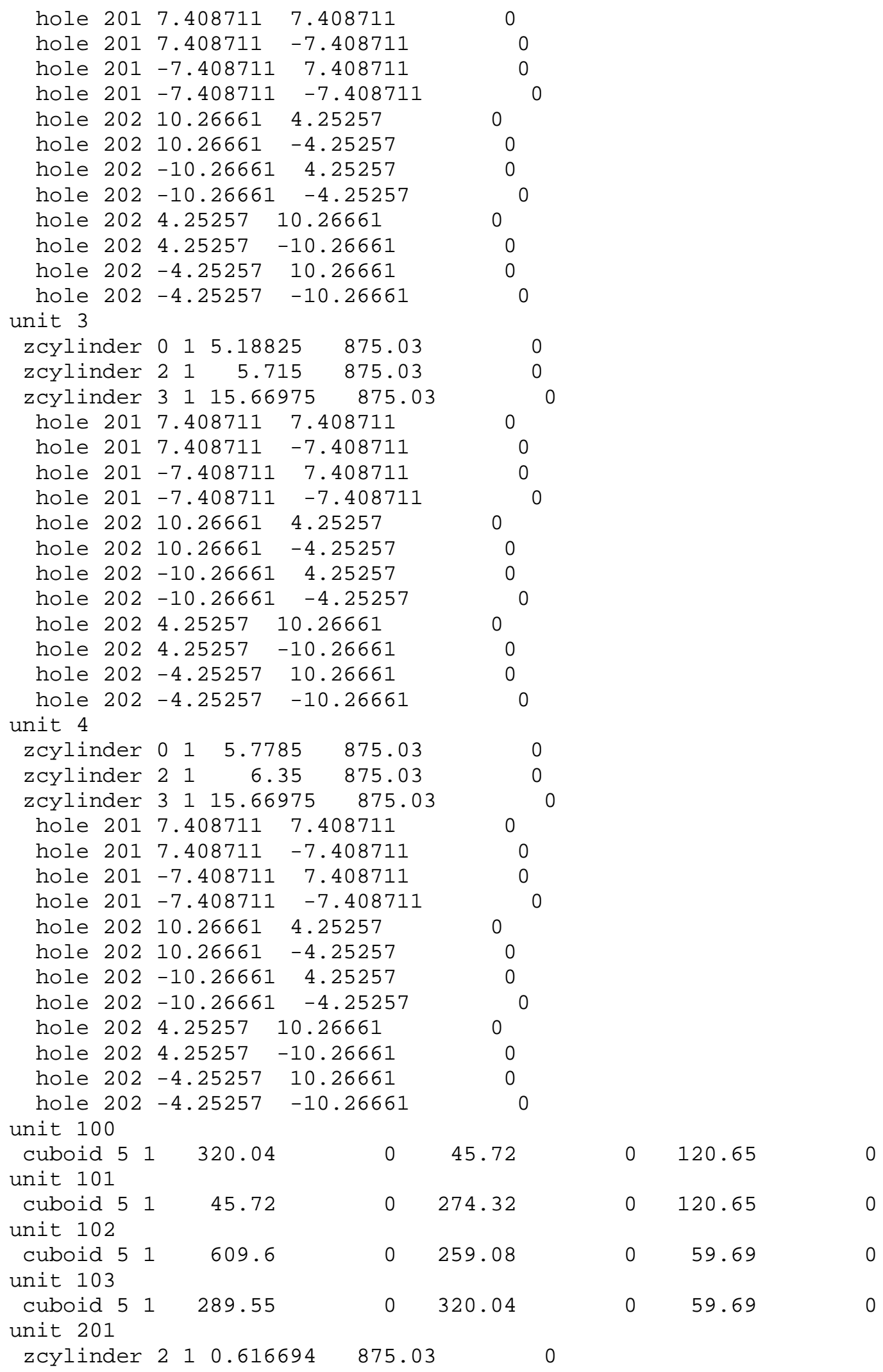




\section{A.4 APPLICATION 4 (continued)}

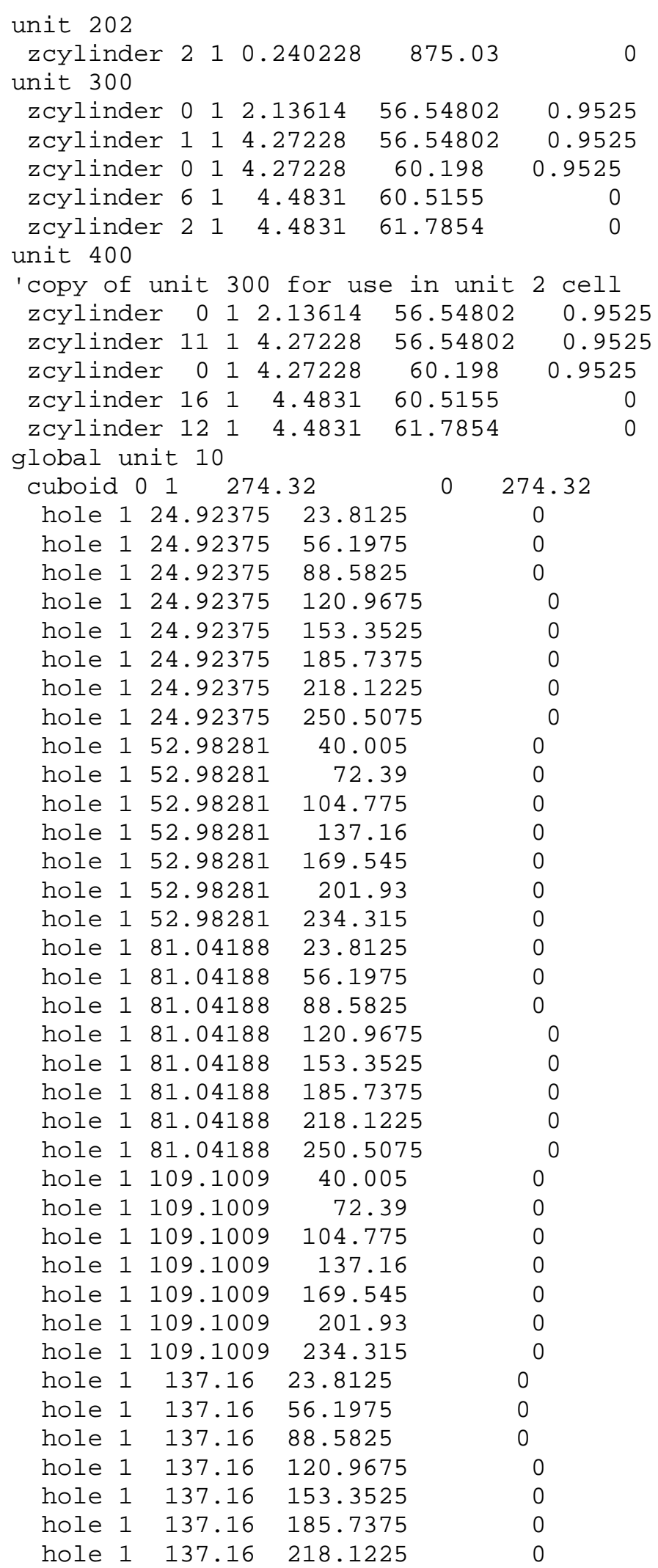




\section{A.4 APPLICATION 4 (continued)}

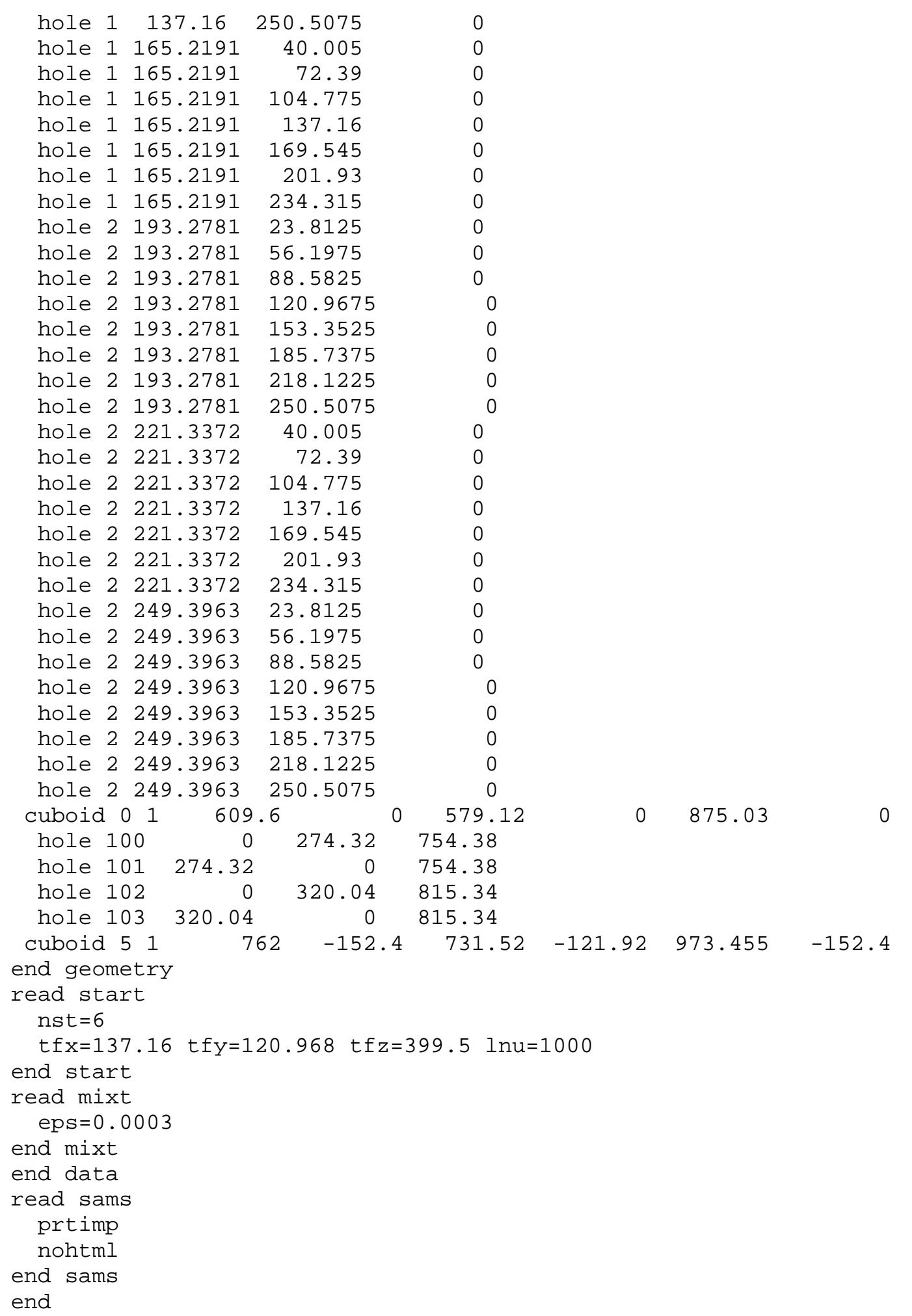





\section{APPENDIX B}

\section{LIST OF CRITICAL EXPERIMENTS}





\begin{tabular}{|c|c|c|c|c|c|c|c|c|}
\hline \multirow{2}{*}{$\begin{array}{l}\text { Exp. } \\
\text { No. }\end{array}$} & \multirow{2}{*}{$\begin{array}{c}\text { IHECSBE } \\
\text { ID }\end{array}$} & \multirow{2}{*}{$\begin{array}{c}\text { EALF } \\
(\mathrm{eV})\end{array}$} & \multicolumn{2}{|c|}{ Expected } & \multicolumn{2}{|c|}{ Calculated } & \multicolumn{2}{|c|}{ Normalized } \\
\hline & & & $k_{\text {eff }}$ & $\sigma_{\exp }$ & $k_{\text {eff }}$ & $\sigma_{\text {keff }} *$ & $k_{\text {eff }}$ & $\sigma_{\text {comb }}$ \\
\hline 2 & uct001t02 & $1.54 \mathrm{E}+00$ & 1.0015 & 0.0025 & 1.0053 & 0.0005 & 1.0037 & 0.0025 \\
\hline 3 & uct001t03 & $7.82 \mathrm{E}-01$ & 1.0007 & 0.0025 & 1.0023 & 0.0005 & 1.0016 & 0.0025 \\
\hline 4 & uct001t04 & 4.63E-01 & 1.0015 & 0.0026 & 1.0058 & 0.0003 & 1.0043 & 0.0026 \\
\hline 5 & umf001t00x & $1.11 \mathrm{E}+06$ & 1.0000 & 0.0010 & 1.0008 & & 1.0008 & 0.0010 \\
\hline 6 & umf002t01x & $1.04 \mathrm{E}+06$ & 1.0000 & 0.0010 & 1.0000 & & 1.0000 & 0.0010 \\
\hline 7 & umf002t02x & $1.07 \mathrm{E}+06$ & 1.0000 & 0.0011 & 0.9993 & & 0.9993 & 0.0011 \\
\hline 8 & umf003t01x & $1.01 \mathrm{E}+06$ & 1.0000 & 0.0010 & 0.9999 & & 0.9999 & 0.0010 \\
\hline 9 & umf003t $02 x$ & $9.27 \mathrm{E}+05$ & 1.0000 & 0.0010 & 1.0002 & & 1.0002 & 0.0010 \\
\hline 10 & umf004t01x & $9.60 \mathrm{E}+05$ & 1.0000 & 0.0007 & 1.0078 & & 1.0078 & 0.0007 \\
\hline 11 & umf004t02x & $8.58 \mathrm{E}+05$ & 1.0000 & 0.0008 & 1.0095 & & 1.0095 & 0.0008 \\
\hline 12 & umf005t01x & $9.45 \mathrm{E}+05$ & 1.0000 & 0.0030 & 0.9985 & & 0.9985 & 0.0030 \\
\hline 13 & umf005t $02 x$ & $7.67 \mathrm{E}+05$ & 1.0000 & 0.0030 & 0.9990 & & 0.9990 & 0.0030 \\
\hline 14 & umf006t00x & $8.08 \mathrm{E}+05$ & 1.0000 & 0.0014 & 1.0013 & & 1.0013 & 0.0014 \\
\hline 15 & usi001t01x & $6.78 \mathrm{E}+00$ & 1.0000 & 0.0083 & 0.9910 & & 0.9910 & 0.0083 \\
\hline 16 & usi001t02x & $7.92 \mathrm{E}+00$ & 1.0000 & 0.0085 & 0.9859 & & 0.9859 & 0.0085 \\
\hline 17 & usi001t03x & $8.52 \mathrm{E}+00$ & 1.0000 & 0.0066 & 0.9865 & & 0.9865 & 0.0066 \\
\hline 18 & usi001t04x & $3.71 \mathrm{E}+00$ & 1.0000 & 0.0061 & 0.9956 & & 0.9956 & 0.0061 \\
\hline 19 & usi001t05x & $9.12 \mathrm{E}+00$ & 1.0000 & 0.0082 & 0.9895 & & 0.9895 & 0.0082 \\
\hline 20 & usi001t06x & $4.27 \mathrm{E}+00$ & 1.0000 & 0.0061 & 0.9889 & & 0.9889 & 0.0061 \\
\hline 21 & usi001t07x & $9.55 \mathrm{E}+00$ & 1.0000 & 0.0059 & 0.9866 & & 0.9866 & 0.0059 \\
\hline 22 & usi001t08x & $4.52 \mathrm{E}+00$ & 1.0000 & 0.0056 & 0.9838 & & 0.9838 & 0.0056 \\
\hline 23 & usi001t09x & $7.31 \mathrm{E}+00$ & 1.0000 & 0.0068 & 0.9835 & & 0.9835 & 0.0068 \\
\hline 24 & usi001t10x & $1.00 \mathrm{E}+01$ & 1.0000 & 0.0053 & 0.9833 & & 0.9833 & 0.0053 \\
\hline 25 & usi001t11x & $7.72 \mathrm{E}+00$ & 1.0000 & 0.0057 & 0.9840 & & 0.9840 & 0.0057 \\
\hline 26 & usi001t12x & $4.41 \mathrm{E}+00$ & 1.0000 & 0.0091 & 0.9875 & & 0.9875 & 0.0091 \\
\hline 27 & usi001t13x & $5.03 \mathrm{E}+00$ & 1.0000 & 0.0071 & 0.9877 & & 0.9877 & 0.0071 \\
\hline 28 & usi001t14x & $2.29 \mathrm{E}+00$ & 1.0000 & 0.0052 & 0.9936 & & 0.9936 & 0.0052 \\
\hline 29 & usi001t15x & $5.40 \mathrm{E}+00$ & 1.0000 & 0.0075 & 0.9853 & & 0.9853 & 0.0075 \\
\hline 30 & usi001t16x & $1.79 \mathrm{E}+00$ & 1.0000 & 0.0028 & 0.9788 & & 0.9788 & 0.0028 \\
\hline 31 & usi001t17x & $2.53 \mathrm{E}+00$ & 1.0000 & 0.0055 & 0.9920 & & 0.9920 & 0.0055 \\
\hline 32 & usi001t18x & $5.79 \mathrm{E}+00$ & 1.0000 & 0.0057 & 0.9834 & & 0.9834 & 0.0057 \\
\hline 33 & usi001t19x & $6.03 \mathrm{E}+00$ & 1.0000 & 0.0083 & 0.9801 & & 0.9801 & 0.0083 \\
\hline 34 & usi001t20x & $2.99 \mathrm{E}+00$ & 1.0000 & 0.0056 & 0.9831 & & 0.9831 & 0.0056 \\
\hline 35 & usi001t21x & $6.28 \mathrm{E}+00$ & 1.0000 & 0.0050 & 0.9777 & & 0.9777 & 0.0050 \\
\hline 36 & usi001t $22 x$ & $6.43 \mathrm{E}+00$ & 1.0000 & 0.0049 & 0.9827 & & 0.9827 & 0.0049 \\
\hline 37 & usi001t $23 x$ & $4.70 \mathrm{E}+00$ & 1.0000 & 0.0047 & 0.9937 & & 0.9937 & 0.0047 \\
\hline 38 & usi001t24x & $1.97 \mathrm{E}+00$ & 1.0000 & 0.0081 & 0.9989 & & 0.9989 & 0.0081 \\
\hline 39 & usi001t $25 x$ & $2.25 \mathrm{E}+00$ & 1.0000 & 0.0081 & 0.9911 & & 0.9911 & 0.0081 \\
\hline 40 & usi001t26x & $2.37 \mathrm{E}+00$ & 1.0000 & 0.0065 & 0.9945 & & 0.9945 & 0.0065 \\
\hline 41 & usi001t27x & $1.24 \mathrm{E}+00$ & 1.0000 & 0.0051 & 0.9938 & & 0.9938 & 0.0051 \\
\hline
\end{tabular}




\begin{tabular}{|c|c|c|c|c|c|c|c|c|}
\hline \multirow{2}{*}{$\begin{array}{l}\text { Exp. } \\
\text { No. }\end{array}$} & \multirow{2}{*}{$\begin{array}{c}\text { IHECSBE } \\
\text { ID }\end{array}$} & \multirow{2}{*}{$\begin{array}{c}\text { EALF } \\
(\mathrm{eV})\end{array}$} & \multicolumn{2}{|c|}{ Expected } & \multicolumn{2}{|c|}{ Calculated } & \multicolumn{2}{|c|}{ Normalized } \\
\hline & & & $k_{e f f}$ & $\sigma_{\text {exp }}$ & $k_{\text {eff }}$ & $\sigma_{k e f f}$ & $k_{\text {eff }}$ & $\sigma_{\text {comb }}$ \\
\hline 42 & usi001t28x & $2.53 \mathrm{E}+00$ & 1.0000 & 0.0061 & 0.9887 & & 0.9887 & 0.0061 \\
\hline 43 & usi001t29x & $2.62 \mathrm{E}+00$ & 1.0000 & 0.0098 & 0.9824 & & 0.9824 & 0.0098 \\
\hline 44 & usi001t30x & $1.45 \mathrm{E}+00$ & 1.0000 & 0.0053 & 0.9812 & & 0.9812 & 0.0053 \\
\hline 45 & usi001t31x & $2.67 \mathrm{E}+00$ & 1.0000 & 0.0071 & 0.9959 & & 0.9959 & 0.0071 \\
\hline 46 & usi001t32x & $2.77 \mathrm{E}+00$ & 1.0000 & 0.0053 & 0.9805 & & 0.9805 & 0.0053 \\
\hline 47 & usi001t33x & $2.07 \mathrm{E}+00$ & 1.0000 & 0.0046 & 0.9976 & & 0.9976 & 0.0046 \\
\hline 48 & ust001t01x & $3.90 \mathrm{E}-02$ & 1.0000 & 0.0031 & 1.0055 & & 1.0055 & 0.0031 \\
\hline 49 & ust001t02x & $3.96 \mathrm{E}-02$ & 1.0005 & 0.0033 & 1.0055 & & 1.0050 & 0.0033 \\
\hline 50 & ust001t03x & $4.02 \mathrm{E}-02$ & 1.0006 & 0.0033 & 1.0050 & & 1.0044 & 0.0033 \\
\hline 51 & ust001t04x & $4.08 \mathrm{E}-02$ & 0.9998 & 0.0033 & 1.0050 & & 1.0052 & 0.0033 \\
\hline 52 & ust001t05x & $4.14 \mathrm{E}-02$ & 0.9999 & 0.0033 & 1.0043 & & 1.0044 & 0.0033 \\
\hline 53 & ust002t01 & $1.71 \mathrm{E}-01$ & 1.0040 & 0.0087 & 1.0075 & 0.0005 & 1.0035 & 0.0087 \\
\hline 54 & ust002t02 & $1.32 \mathrm{E}-01$ & 1.0040 & 0.0087 & 0.9966 & 0.0003 & 0.9926 & 0.0087 \\
\hline 55 & ust002t03 & $1.03 \mathrm{E}-01$ & 1.0040 & 0.0087 & 1.0130 & 0.0005 & 1.0090 & 0.0087 \\
\hline 56 & ust002t04 & 8.34E-02 & 1.0040 & 0.0087 & 1.0099 & 0.0005 & 1.0059 & 0.0087 \\
\hline 57 & ust002t05 & $7.27 \mathrm{E}-02$ & 1.0040 & 0.0087 & 1.0145 & 0.0005 & 1.0105 & 0.0087 \\
\hline 58 & ust002t06 & $6.47 \mathrm{E}-02$ & 1.0040 & 0.0087 & 1.0015 & 0.0005 & 0.9975 & 0.0087 \\
\hline 59 & ust002t07 & $6.12 \mathrm{E}-02$ & 1.0040 & 0.0087 & 0.9913 & 0.0005 & 0.9874 & 0.0087 \\
\hline 60 & ust002t08 & $5.63 \mathrm{E}-02$ & 1.0040 & 0.0087 & 1.0050 & 0.0005 & 1.0010 & 0.0087 \\
\hline 61 & ust002t09 & $5.08 \mathrm{E}-02$ & 1.0040 & 0.0087 & 0.9935 & 0.0005 & 0.9895 & 0.0087 \\
\hline 62 & ust002t10 & 4.91E-02 & 1.0040 & 0.0087 & 1.0078 & 0.0005 & 1.0038 & 0.0087 \\
\hline 63 & ust002t11 & $4.57 \mathrm{E}-02$ & 1.0040 & 0.0087 & 1.0170 & 0.0005 & 1.0129 & 0.0087 \\
\hline 64 & ust002t12 & $2.69 \mathrm{E}-01$ & 1.0040 & 0.0087 & 0.9949 & 0.0005 & 0.9909 & 0.0087 \\
\hline 65 & ust002t13 & $4.80 \mathrm{E}-01$ & 1.0040 & 0.0087 & 0.9951 & 0.0005 & 0.9912 & 0.0087 \\
\hline 66 & ust002t14 & $1.37 \mathrm{E}-01$ & 1.0040 & 0.0087 & 1.0041 & 0.0005 & 1.0001 & 0.0087 \\
\hline 67 & ust002t15 & $9.38 \mathrm{E}-02$ & 1.0040 & 0.0087 & 1.0114 & 0.0005 & 1.0074 & 0.0087 \\
\hline 68 & ust002t16 & $6.23 \mathrm{E}-02$ & 1.0040 & 0.0087 & 1.0138 & 0.0005 & 1.0098 & 0.0087 \\
\hline 69 & ust002t17 & $5.33 \mathrm{E}-02$ & 1.0040 & 0.0087 & 1.0143 & 0.0005 & 1.0103 & 0.0087 \\
\hline 70 & ust003t01 & $3.10 \mathrm{E}-01$ & 0.9995 & 0.0087 & 1.0045 & 0.0005 & 1.0050 & 0.0087 \\
\hline 71 & ust003t02 & $3.45 \mathrm{E}-01$ & 0.9991 & 0.0151 & 1.0186 & 0.0005 & 1.0196 & 0.0151 \\
\hline 72 & ust003t03 & $3.31 \mathrm{E}-01$ & 1.0007 & 0.0087 & 1.0014 & 0.0005 & 1.0007 & 0.0087 \\
\hline 73 & ust003t04 & 7.79E-01 & 1.0015 & 0.0126 & 1.0062 & 0.0005 & 1.0047 & 0.0126 \\
\hline 74 & ust003t05 & $1.05 \mathrm{E}+00$ & 1.0006 & 0.0122 & 1.0118 & 0.0005 & 1.0112 & 0.0122 \\
\hline 75 & ust003t06 & $1.27 \mathrm{E}-01$ & 1.0012 & 0.0087 & 1.0252 & 0.0005 & 1.0240 & 0.0087 \\
\hline 76 & ust003t07 & $8.21 \mathrm{E}-02$ & 1.0016 & 0.0087 & 1.0185 & 0.0005 & 1.0168 & 0.0087 \\
\hline 77 & ust003t08 & 6.77E-02 & 1.0016 & 0.0087 & 1.0144 & 0.0005 & 1.0128 & 0.0087 \\
\hline 78 & ust003t09 & $6.07 \mathrm{E}-02$ & 1.0018 & 0.0087 & 1.0147 & 0.0005 & 1.0128 & 0.0087 \\
\hline 79 & ust $003 \mathrm{t} 10$ & $4.53 \mathrm{E}-02$ & 1.0008 & 0.0087 & 1.0136 & 0.0005 & 1.0128 & 0.0087 \\
\hline 80 & ust004t01 & $1.69 \mathrm{E}-01$ & 1.0039 & 0.0088 & 1.0046 & 0.0005 & 1.0007 & 0.0088 \\
\hline 81 & ust004t02 & $1.30 \mathrm{E}-01$ & 1.0034 & 0.0086 & 1.0081 & 0.0005 & 1.0047 & 0.0086 \\
\hline
\end{tabular}




\begin{tabular}{|c|c|c|c|c|c|c|c|c|}
\hline \multirow{2}{*}{$\begin{array}{l}\text { Exp. } \\
\text { No. }\end{array}$} & \multirow{2}{*}{$\begin{array}{c}\text { IHECSBE } \\
\text { ID }\end{array}$} & \multirow{2}{*}{$\begin{array}{c}\text { EALF } \\
(\mathrm{eV})\end{array}$} & \multicolumn{2}{|c|}{ Expected } & \multicolumn{2}{|c|}{ Calculated } & \multicolumn{2}{|c|}{ Normalized } \\
\hline & & & $k_{\text {eff }}$ & $\sigma_{\text {exp }}$ & $k_{\text {eff }}$ & $\sigma_{k e f f}$ & $k_{\text {eff }}$ & $\sigma_{\text {comb }}$ \\
\hline 82 & ust004t03 & $2.69 \mathrm{E}-01$ & 1.0041 & 0.0089 & 0.9988 & 0.0005 & 0.9947 & 0.0089 \\
\hline 83 & ust004t04 & 4.82E-01 & 1.0051 & 0.0089 & 0.9890 & 0.0005 & 0.9840 & 0.0089 \\
\hline 84 & ust004t05 & $3.80 \mathrm{E}-01$ & 1.0037 & 0.0090 & 0.9949 & 0.0003 & 0.9912 & 0.0090 \\
\hline 85 & ust004t06 & 4.79E-01 & 1.0020 & 0.0105 & 1.0065 & 0.0005 & 1.0045 & 0.0105 \\
\hline 86 & ust004t07 & $3.77 \mathrm{E}-01$ & 1.0020 & 0.0104 & 1.0028 & 0.0005 & 1.0008 & 0.0104 \\
\hline 87 & ust004t08 & $1.36 \mathrm{E}-01$ & 1.0020 & 0.0102 & 1.0094 & 0.0005 & 1.0074 & 0.0102 \\
\hline 88 & ust005t01x & $6.06 \mathrm{E}-02$ & 1.0000 & 0.0040 & 1.0068 & & 1.0068 & 0.0040 \\
\hline 89 & ust005t02 & $5.33 \mathrm{E}-02$ & 1.0000 & 0.0049 & 1.0099 & 0.0005 & 1.0099 & 0.0049 \\
\hline 90 & ust006t01 & $8.55 \mathrm{E}-01$ & 1.0000 & 0.0035 & 1.0015 & 0.0005 & 1.0015 & 0.0035 \\
\hline 91 & ust006t02 & $8.56 \mathrm{E}-01$ & 1.0000 & 0.0035 & 0.9988 & 0.0005 & 0.9988 & 0.0035 \\
\hline 92 & ust006t03 & 8.57E-01 & 1.0000 & 0.0035 & 0.9970 & 0.0005 & 0.9970 & 0.0035 \\
\hline 93 & ust006t04 & 8.54E-01 & 1.0000 & 0.0035 & 1.0018 & 0.0005 & 1.0018 & 0.0035 \\
\hline 94 & ust006t05 & $8.65 \mathrm{E}-01$ & 1.0000 & 0.0035 & 0.9953 & 0.0005 & 0.9953 & 0.0035 \\
\hline 95 & ust006t06 & $8.65 \mathrm{E}-01$ & 1.0000 & 0.0035 & 0.9941 & 0.0005 & 0.9941 & 0.0035 \\
\hline 96 & ust006t07 & 4.08E-01 & 1.0000 & 0.0028 & 1.0009 & 0.0005 & 1.0009 & 0.0028 \\
\hline 97 & ust006t08 & $4.04 \mathrm{E}-01$ & 1.0000 & 0.0028 & 1.0022 & 0.0005 & 1.0022 & 0.0028 \\
\hline 98 & ust006t09 & $4.04 \mathrm{E}-01$ & 1.0000 & 0.0028 & 1.0019 & 0.0005 & 1.0019 & 0.0028 \\
\hline 99 & ust006t10 & $4.07 \mathrm{E}-01$ & 1.0000 & & 1.0028 & 0.0005 & 1.0028 & 0.0028 \\
\hline 100 & ust006t11 & $4.05 \mathrm{E}-01$ & 1.0000 & 0.0028 & 1.0017 & 0.0005 & 1.0017 & 0.0028 \\
\hline 101 & ust006t12 & $2.94 \mathrm{E}-01$ & 1.0000 & 0.0035 & 0.9962 & 0.0005 & 0.9962 & 0.0035 \\
\hline 102 & ust006t13 & $2.94 \mathrm{E}-01$ & 1.0000 & 0.0035 & 0.9970 & 0.0005 & 0.9970 & 0.0035 \\
\hline 103 & ust006t14 & $2.95 \mathrm{E}-01$ & 1.0000 & 0.0035 & 0.9940 & 0.0005 & 0.9940 & 0.0035 \\
\hline 104 & ust006t15 & $2.95 \mathrm{E}-01$ & 1.0000 & 0.0035 & 0.9951 & 0.0005 & 0.9951 & 0.0035 \\
\hline 105 & ust006t16 & $2.98 \mathrm{E}-01$ & 1.0000 & 0.0035 & 0.9931 & 0.0005 & 0.9931 & 0.0035 \\
\hline 106 & ust006t17 & $2.98 \mathrm{E}-01$ & 1.0000 & 0.0035 & 0.9938 & 0.0005 & 0.9938 & 0.0035 \\
\hline 107 & ust006t18 & $2.98 \mathrm{E}-01$ & 1.0000 & 0.0035 & 0.9935 & 0.0005 & 0.9935 & 0.0035 \\
\hline 108 & ust006t19 & $1.81 \mathrm{E}-01$ & 1.0000 & 0.0028 & 0.9997 & 0.0005 & 0.9997 & 0.0028 \\
\hline 109 & ust006t20 & $1.81 \mathrm{E}-01$ & 1.0000 & 0.0028 & 0.9988 & 0.0005 & 0.9988 & 0.0028 \\
\hline 110 & ust006t21 & $1.82 \mathrm{E}-01$ & 1.0000 & 0.0028 & 0.9979 & 0.0005 & 0.9979 & 0.0028 \\
\hline 111 & ust006t22 & $1.81 \mathrm{E}-01$ & 1.0000 & 0.0028 & 0.9983 & 0.0005 & 0.9983 & 0.0028 \\
\hline 112 & ust006t 23 & $1.81 \mathrm{E}-01$ & 1.0000 & 0.0028 & 0.9983 & 0.0005 & 0.9983 & 0.0028 \\
\hline 113 & ust006t24 & $1.81 \mathrm{E}-01$ & 1.0000 & 0.0028 & 0.9983 & 0.0005 & 0.9983 & 0.0028 \\
\hline 114 & ust006t25 & $1.81 \mathrm{E}-01$ & 1.0000 & 0.0028 & 1.0002 & 0.0005 & 1.0002 & 0.0028 \\
\hline 115 & ust008t01x & $3.68 \mathrm{E}-02$ & 1.0006 & 0.0029 & 1.0042 & & 1.0036 & 0.0029 \\
\hline 116 & ust009t01 & $3.70 \mathrm{E}-02$ & 0.9966 & 0.0044 & 0.9994 & 0.0005 & 1.0028 & 0.0044 \\
\hline 117 & ust009t02 & $3.67 \mathrm{E}-02$ & 0.9981 & 0.0040 & 1.0033 & 0.0005 & 1.0052 & 0.0040 \\
\hline 118 & ust009t03 & $3.63 \mathrm{E}-02$ & 0.9989 & 0.0038 & 1.0036 & 0.0005 & 1.0047 & 0.0038 \\
\hline 119 & ust009t04 & $3.59 \mathrm{E}-02$ & 0.9998 & 0.0038 & 1.0019 & 0.0005 & 1.0021 & 0.0038 \\
\hline 120 & ust012t01 & $1.70 \mathrm{E}-01$ & 0.9990 & 0.0028 & 1.0019 & 0.0005 & 1.0029 & 0.0028 \\
\hline 121 & ust012t02 & $1.62 \mathrm{E}-01$ & 0.9993 & 0.0025 & 1.0018 & 0.0005 & 1.0025 & 0.0025 \\
\hline
\end{tabular}




\begin{tabular}{|c|c|c|c|c|c|c|c|c|}
\hline \multirow{2}{*}{$\begin{array}{l}\text { Exp. } \\
\text { No. }\end{array}$} & \multirow{2}{*}{$\begin{array}{c}\text { IHECSBE } \\
\text { ID }\end{array}$} & \multirow{2}{*}{$\begin{array}{c}\text { EALF } \\
(\mathrm{eV})\end{array}$} & \multicolumn{2}{|c|}{ Expected } & \multicolumn{2}{|c|}{ Calculated } & \multicolumn{2}{|c|}{ Normalized } \\
\hline & & & $k_{\text {eff }}$ & $\sigma_{\text {exp }}$ & $k_{\text {eff }}$ & $\sigma_{\text {keff }}$ & $k_{\text {eff }}$ & $\sigma_{\mathrm{comb}}$ \\
\hline 122 & ust012t03 & $1.44 \mathrm{E}-01$ & 0.9994 & 0.0023 & 1.0124 & 0.0005 & 1.0130 & 0.0024 \\
\hline 123 & ust012t04 & $1.05 \mathrm{E}-01$ & 1.0000 & 0.0015 & 1.0053 & 0.0003 & 1.0053 & 0.0015 \\
\hline 124 & ust012t05 & $8.96 \mathrm{E}-02$ & 1.0000 & 0.0071 & 1.0076 & 0.0005 & 1.0076 & 0.0071 \\
\hline 125 & ust012t06x & 7.89E-02 & 0.9987 & 0.0011 & 1.0086 & & 1.0099 & 0.0011 \\
\hline 126 & ust012t07 & $5.23 \mathrm{E}-02$ & 1.0000 & 0.0038 & 1.0064 & 0.0003 & 1.0064 & 0.0038 \\
\hline 127 & ust012t08 & $5.23 \mathrm{E}-02$ & 1.0000 & 0.0048 & 1.0031 & 0.0005 & 1.0031 & 0.0048 \\
\hline 128 & ust013t01 & $1.54 \mathrm{E}-01$ & 0.9992 & 0.0073 & 1.0103 & 0.0005 & 1.0111 & 0.0073 \\
\hline 129 & ust013t02 & $1.54 \mathrm{E}-01$ & 0.9992 & 0.0070 & 1.0112 & 0.0005 & 1.0120 & 0.0070 \\
\hline 130 & ust013t03 & $1.54 \mathrm{E}-01$ & 0.9992 & 0.0069 & 1.0112 & 0.0005 & 1.0120 & 0.0069 \\
\hline 131 & ust013t04 & $1.54 \mathrm{E}-01$ & 0.9992 & 0.0073 & 1.0118 & 0.0005 & 1.0126 & 0.0073 \\
\hline 132 & ust013t05 & $1.54 \mathrm{E}-01$ & 0.9992 & 0.0067 & 1.0124 & 0.0005 & 1.0132 & 0.0067 \\
\hline 133 & ust013t06 & $1.47 \mathrm{E}-01$ & 0.9992 & 0.0050 & 1.0124 & 0.0005 & 1.0132 & 0.0050 \\
\hline 134 & ust013t07 & $1.47 \mathrm{E}-01$ & 0.9992 & 0.0054 & 1.0110 & 0.0005 & 1.0118 & 0.0054 \\
\hline 135 & ust013t08 & $1.47 \mathrm{E}-01$ & 0.9992 & 0.0050 & 1.0129 & 0.0005 & 1.0137 & 0.0050 \\
\hline 136 & ust013t09 & $1.47 \mathrm{E}-01$ & 0.9992 & 0.0045 & 1.0124 & 0.0005 & 1.0132 & 0.0045 \\
\hline 137 & ust013t10 & $1.47 \mathrm{E}-01$ & 0.9992 & 0.0046 & 1.0134 & 0.0005 & 1.0142 & 0.0046 \\
\hline 138 & ust013t11 & $1.47 \mathrm{E}-01$ & 0.9992 & 0.0054 & 1.0101 & 0.0005 & 1.0109 & 0.0054 \\
\hline 139 & ust013t12 & $1.47 \mathrm{E}-01$ & 0.9992 & 0.0050 & 1.0119 & 0.0005 & 1.0128 & 0.0050 \\
\hline 140 & ust013t13 & $1.47 \mathrm{E}-01$ & 0.9992 & 0.0062 & 1.0087 & 0.0003 & 1.0095 & 0.0062 \\
\hline 141 & ust013t14 & $1.47 \mathrm{E}-01$ & 0.9992 & 0.0051 & 1.0119 & 0.0005 & 1.0127 & 0.0051 \\
\hline 142 & ust013t15 & $1.03 \mathrm{E}-01$ & 0.9996 & 0.0077 & 1.0268 & 0.0005 & 1.0272 & 0.0077 \\
\hline 143 & ust013t16 & 8.68E-02 & 0.9996 & 0.0069 & 0.9993 & 0.0005 & 0.9997 & 0.0069 \\
\hline 144 & ust013t17 & $8.35 \mathrm{E}-02$ & 0.9996 & 0.0052 & 1.0019 & 0.0005 & 1.0023 & 0.0052 \\
\hline 145 & ust013t18 & $7.87 \mathrm{E}-02$ & 0.9996 & 0.0020 & 1.0065 & 0.0005 & 1.0069 & 0.0021 \\
\hline 146 & ust013t19 & 7.89E-02 & 0.9996 & 0.0089 & 1.0023 & 0.0005 & 1.0027 & 0.0089 \\
\hline 147 & ust013t20 & $6.03 \mathrm{E}-02$ & 0.9996 & 0.0056 & 1.0056 & 0.0005 & 1.0060 & 0.0056 \\
\hline 148 & ust013t21 & $5.55 \mathrm{E}-02$ & 0.9996 & 0.0034 & 1.0084 & 0.0005 & 1.0088 & 0.0034 \\
\hline 149 & ust014t01 & $6.02 \mathrm{E}-01$ & 0.9976 & 0.0112 & 0.9839 & 0.0005 & 0.9863 & 0.0112 \\
\hline 150 & ust014t02 & $6.40 \mathrm{E}-01$ & 0.9976 & 0.0112 & 0.9973 & 0.0005 & 0.9997 & 0.0112 \\
\hline 151 & ust014t03 & $3.06 \mathrm{E}-01$ & 1.0000 & 0.0074 & 1.0147 & 0.0005 & 1.0147 & 0.0074 \\
\hline 152 & ust014t04 & $3.00 \mathrm{E}-01$ & 1.0000 & 0.0089 & 1.0140 & 0.0005 & 1.0140 & 0.0089 \\
\hline 153 & ust014t05 & $2.71 \mathrm{E}-01$ & 1.0000 & 0.0089 & 1.0156 & 0.0005 & 1.0156 & 0.0089 \\
\hline 154 & ust014t06 & $2.62 \mathrm{E}-01$ & 1.0000 & 0.0089 & 1.0144 & 0.0005 & 1.0144 & 0.0089 \\
\hline 155 & ust014t07 & $2.54 \mathrm{E}-01$ & 1.0000 & 0.0088 & 1.0091 & 0.0005 & 1.0091 & 0.0088 \\
\hline 156 & ust014t08 & $2.44 \mathrm{E}-01$ & 1.0000 & 0.0091 & 1.0117 & 0.0005 & 1.0117 & 0.0091 \\
\hline 157 & ust014t09 & $3.06 \mathrm{E}-01$ & 1.0000 & 0.0054 & 1.0165 & 0.0005 & 1.0165 & 0.0054 \\
\hline 158 & ust014t10 & $3.59 \mathrm{E}-01$ & 0.9992 & 0.0108 & 1.0000 & 0.0005 & 1.0008 & 0.0108 \\
\hline 159 & ust014t11 & 4.37E-01 & 0.9992 & 0.0126 & 1.0062 & 0.0005 & 1.0070 & 0.0126 \\
\hline 160 & ust014t12 & $3.11 \mathrm{E}-01$ & 0.9992 & 0.0097 & 1.0103 & 0.0005 & 1.0111 & 0.0097 \\
\hline 161 & ust014t13 & $2.98 \mathrm{E}-01$ & 0.9992 & 0.0104 & 1.0061 & 0.0005 & 1.0069 & 0.0104 \\
\hline
\end{tabular}




\begin{tabular}{|c|c|c|c|c|c|c|c|c|}
\hline \multirow{2}{*}{$\begin{array}{l}\text { Exp. } \\
\text { No. }\end{array}$} & \multirow{2}{*}{$\begin{array}{c}\text { IHECSBE } \\
\text { ID }\end{array}$} & \multirow{2}{*}{$\begin{array}{c}\text { EALF } \\
(\mathrm{eV})\end{array}$} & \multicolumn{2}{|c|}{ Expected } & \multicolumn{2}{|c|}{ Calculated } & \multicolumn{2}{|c|}{ Normalized } \\
\hline & & & $k_{\text {eff }}$ & $\sigma_{\text {exp }}$ & $k_{\text {eff }}$ & $\sigma_{k e f f}$ & $k_{\text {eff }}$ & $\sigma_{\text {comb }}$ \\
\hline 162 & ust014t14 & $2.96 \mathrm{E}-01$ & 0.9966 & 0.0095 & 1.0034 & 0.0005 & 1.0068 & 0.0095 \\
\hline 163 & ust014t15 & $3.23 \mathrm{E}-01$ & 0.9966 & 0.0098 & 1.0005 & 0.0005 & 1.0039 & 0.0098 \\
\hline 164 & ust014t16 & $5.40 \mathrm{E}-01$ & 0.9965 & 0.0109 & 0.9858 & 0.0005 & 0.9892 & 0.0109 \\
\hline 165 & ust015t01x & $1.09 \mathrm{E}+00$ & 1.0000 & 0.0075 & 0.9970 & & 0.9970 & 0.0075 \\
\hline 166 & ust $015 \mathrm{t} 02 \mathrm{x}$ & $1.22 \mathrm{E}+00$ & 1.0000 & 0.0070 & 0.9916 & & 0.9916 & 0.0070 \\
\hline 167 & ust015t03x & $1.29 \mathrm{E}+00$ & 1.0000 & 0.0068 & 0.9923 & & 0.9923 & 0.0068 \\
\hline 168 & ust015t04x & $7.10 \mathrm{E}-01$ & 1.0000 & 0.0041 & 0.9931 & & 0.9931 & 0.0041 \\
\hline 169 & ust015t05x & $1.35 \mathrm{E}+00$ & 1.0000 & 0.0055 & 0.9916 & & 0.9916 & 0.0055 \\
\hline 170 & ust015t06x & $1.40 \mathrm{E}+00$ & 1.0000 & 0.0099 & 0.9820 & & 0.9820 & 0.0099 \\
\hline 171 & ust015t07x & 7.81E-01 & 1.0000 & 0.0070 & 0.9907 & & 0.9907 & 0.0070 \\
\hline 172 & ust015t08x & $1.45 \mathrm{E}+00$ & 1.0000 & 0.0067 & 0.9782 & & 0.9782 & 0.0067 \\
\hline 173 & ust015t09x & $1.48 \mathrm{E}+00$ & 1.0000 & 0.0050 & 0.9736 & & 0.9736 & 0.0050 \\
\hline 174 & ust $015 \mathrm{t} 10 \mathrm{x}$ & $1.12 \mathrm{E}+00$ & 1.0000 & 0.0051 & 0.9932 & & 0.9932 & 0.0051 \\
\hline 175 & ust015t11x & $6.83 \mathrm{E}-01$ & 1.0000 & 0.0075 & 1.0004 & & 1.0004 & 0.0075 \\
\hline 176 & ust015t12x & $7.56 \mathrm{E}-01$ & 1.0000 & 0.0069 & 1.0002 & & 1.0002 & 0.0069 \\
\hline 177 & ust015t13x & $7.96 \mathrm{E}-01$ & 1.0000 & 0.0069 & 0.9978 & & 0.9978 & 0.0069 \\
\hline 178 & ust $015 \mathrm{t} 14 \mathrm{x}$ & $4.58 \mathrm{E}-01$ & 1.0000 & 0.0036 & 1.0016 & & 1.0016 & 0.0036 \\
\hline 179 & ust015t15x & $8.35 \mathrm{E}-01$ & 1.0000 & 0.0060 & 0.9952 & & 0.9952 & 0.0060 \\
\hline 180 & ust015t16x & $8.56 \mathrm{E}-01$ & 1.0000 & 0.0043 & 0.9939 & & 0.9939 & 0.0043 \\
\hline 181 & ust015t17x & $4.95 \mathrm{E}-01$ & 1.0000 & 0.0029 & 1.0009 & & 1.0009 & 0.0029 \\
\hline 182 & ust $015 \mathrm{t} 18 \mathrm{x}$ & $8.86 \mathrm{E}-01$ & 1.0000 & 0.0056 & 0.9797 & & 0.9797 & 0.0056 \\
\hline 183 & ust015t19x & $9.00 \mathrm{E}-01$ & 1.0000 & 0.0052 & 0.9799 & & 0.9799 & 0.0052 \\
\hline 184 & ust015t20x & $2.84 \mathrm{E}-01$ & 1.0000 & 0.0079 & 1.0032 & & 1.0032 & 0.0079 \\
\hline 185 & ust015t21x & $3.11 \mathrm{E}-01$ & 1.0000 & 0.0070 & 1.0050 & & 1.0050 & 0.0070 \\
\hline 186 & ust $015 \mathrm{t} 22 \mathrm{x}$ & $3.25 \mathrm{E}-01$ & 1.0000 & 0.0062 & 1.0027 & & 1.0027 & 0.0062 \\
\hline 187 & ust015t23x & $3.38 \mathrm{E}-01$ & 1.0000 & 0.0055 & 1.0003 & & 1.0003 & 0.0055 \\
\hline 188 & ust015t24x & $3.46 \mathrm{E}-01$ & 1.0000 & 0.0051 & 0.9966 & & 0.9966 & 0.0051 \\
\hline 189 & ust015t25x & $2.20 \mathrm{E}-01$ & 1.0000 & 0.0023 & 1.0012 & & 1.0012 & 0.0023 \\
\hline 190 & ust015t26x & $1.25 \mathrm{E}-01$ & 1.0000 & 0.0066 & 1.0020 & & 1.0020 & 0.0066 \\
\hline 191 & ust015t27x & $1.29 \mathrm{E}-01$ & 1.0000 & 0.0063 & 1.0059 & & 1.0059 & 0.0063 \\
\hline 192 & ust015t28x & $1.31 \mathrm{E}-01$ & 1.0000 & 0.0058 & 1.0036 & & 1.0036 & 0.0058 \\
\hline 193 & ust015t29x & $1.33 \mathrm{E}-01$ & 1.0000 & 0.0051 & 1.0019 & & 1.0019 & 0.0051 \\
\hline 194 & ust015t30x & $1.35 \mathrm{E}-01$ & 1.0000 & 0.0048 & 1.0010 & & 1.0010 & 0.0048 \\
\hline 195 & ust015t31x & $1.36 \mathrm{E}-01$ & 1.0000 & 0.0055 & 1.0001 & & 1.0001 & 0.0055 \\
\hline 196 & ust016t01 & $2.86 \mathrm{E}-01$ & 0.9987 & 0.0037 & 1.0094 & 0.0005 & 1.0107 & 0.0037 \\
\hline 197 & ust016t02 & $2.86 \mathrm{E}-01$ & 0.9983 & 0.0044 & 1.0081 & 0.0005 & 1.0098 & 0.0044 \\
\hline 198 & ust016t03 & $2.86 \mathrm{E}-01$ & 0.9992 & 0.0036 & 1.0092 & 0.0005 & 1.0100 & 0.0036 \\
\hline 199 & ust016t04 & $2.86 \mathrm{E}-01$ & 0.9992 & 0.0035 & 1.0046 & 0.0005 & 1.0054 & 0.0035 \\
\hline 200 & ust016t06 & $2.86 \mathrm{E}-01$ & 0.9993 & 0.0034 & 1.0005 & 0.0005 & 1.0012 & 0.0034 \\
\hline 201 & ust016t07 & $2.86 \mathrm{E}-01$ & 1.0008 & 0.0034 & 1.0007 & 0.0005 & 0.9999 & 0.0034 \\
\hline
\end{tabular}




\begin{tabular}{|c|c|c|c|c|c|c|c|c|}
\hline \multirow{2}{*}{$\begin{array}{l}\text { Exp. } \\
\text { No. }\end{array}$} & \multirow{2}{*}{$\begin{array}{c}\text { IHECSBE } \\
\text { ID }\end{array}$} & \multirow{2}{*}{$\begin{array}{c}\text { EALF } \\
(\mathrm{eV})\end{array}$} & \multicolumn{2}{|c|}{ Expected } & \multicolumn{2}{|c|}{ Calculated } & \multicolumn{2}{|c|}{ Normalized } \\
\hline & & & $k_{e f f}$ & $\sigma_{\text {exp }}$ & $k_{\text {eff }}$ & $\sigma_{k e f f}$ & $k_{\text {eff }}$ & $\sigma_{\text {comb }}$ \\
\hline 202 & ust016t08 & $2.86 \mathrm{E}-01$ & 1.0011 & 0.0028 & 1.0007 & 0.0005 & 0.9996 & 0.0028 \\
\hline 203 & ust016t09 & $2.85 \mathrm{E}-01$ & 1.0000 & 0.0027 & 1.0009 & 0.0005 & 1.0009 & 0.0027 \\
\hline 204 & ust016t10 & $2.82 \mathrm{E}-01$ & 1.0000 & 0.0030 & 1.0093 & 0.0005 & 1.0093 & 0.0030 \\
\hline 205 & ust016t11 & $2.83 \mathrm{E}-01$ & 0.9992 & 0.0041 & 1.0085 & 0.0005 & 1.0093 & 0.0041 \\
\hline 206 & ust016t12 & $2.83 \mathrm{E}-01$ & 0.9992 & 0.0047 & 1.0098 & 0.0005 & 1.0106 & 0.0047 \\
\hline 207 & ust016t13 & $1.42 \mathrm{E}-01$ & 0.9993 & 0.0036 & 1.0095 & 0.0005 & 1.0102 & 0.0036 \\
\hline 208 & ust016t14 & $1.42 \mathrm{E}-01$ & 1.0000 & 0.0026 & 1.0092 & 0.0005 & 1.0092 & 0.0026 \\
\hline 209 & ust016t15 & $1.42 \mathrm{E}-01$ & 1.0000 & 0.0027 & 1.0116 & 0.0005 & 1.0116 & 0.0027 \\
\hline 210 & ust016t16 & $1.43 \mathrm{E}-01$ & 0.9994 & 0.0031 & 1.0128 & 0.0005 & 1.0134 & 0.0031 \\
\hline 211 & ust016t17 & $1.44 \mathrm{E}-01$ & 1.0000 & 0.0028 & 0.9989 & 0.0005 & 0.9989 & 0.0028 \\
\hline 212 & ust016t18 & $1.43 \mathrm{E}-01$ & 0.9988 & 0.0036 & 0.9996 & 0.0005 & 1.0008 & 0.0036 \\
\hline 213 & ust016t19 & $1.43 \mathrm{E}-01$ & 1.0000 & 0.0035 & 0.9997 & 0.0005 & 0.9997 & 0.0035 \\
\hline 214 & ust016t21 & $1.41 \mathrm{E}-01$ & 1.0000 & 0.0028 & 1.0137 & 0.0005 & 1.0137 & 0.0028 \\
\hline 215 & ust016t22 & $1.41 \mathrm{E}-01$ & 1.0000 & 0.0034 & 1.0148 & 0.0005 & 1.0148 & 0.0034 \\
\hline 216 & ust016t23 & $1.41 \mathrm{E}-01$ & 1.0000 & 0.0031 & 1.0142 & 0.0005 & 1.0142 & 0.0031 \\
\hline 217 & ust016t24 & $1.41 \mathrm{E}-01$ & 1.0012 & 0.0024 & 1.0150 & 0.0005 & 1.0138 & 0.0025 \\
\hline 218 & ust016t25 & 7.98E-02 & 0.9981 & 0.0040 & 1.0047 & 0.0005 & 1.0066 & 0.0040 \\
\hline 219 & ust016t26 & 7.97E-02 & 0.9980 & & 1.0109 & 0.0005 & 1.0129 & 0.0034 \\
\hline 220 & ust016t27 & 7.98E-02 & 0.9988 & 0.0037 & 1.0081 & 0.0005 & 1.0094 & 0.0037 \\
\hline 221 & ust016t28 & $7.95 \mathrm{E}-02$ & 0.9986 & 0.0037 & 1.0044 & 0.0005 & 1.0058 & 0.0037 \\
\hline 222 & ust016t29 & 7.95E-02 & 0.9985 & 0.0031 & 1.0050 & 0.0005 & 1.0065 & 0.0031 \\
\hline 223 & ust016t30 & $7.96 \mathrm{E}-02$ & 0.9993 & 0.0032 & 1.0049 & 0.0005 & 1.0056 & 0.0032 \\
\hline 224 & ust016t31 & $5.61 \mathrm{E}-02$ & 0.9990 & 0.0034 & 1.0154 & 0.0005 & 1.0164 & 0.0034 \\
\hline 225 & ust016t32 & $5.61 \mathrm{E}-02$ & 0.9985 & 0.0032 & 1.0180 & 0.0004 & 1.0195 & 0.0032 \\
\hline 226 & ust016t33 & $5.61 \mathrm{E}-02$ & 0.9986 & 0.0039 & 1.0182 & 0.0005 & 1.0196 & 0.0039 \\
\hline 227 & ust017t01 & $1.13 \mathrm{E}-01$ & 0.9997 & 0.0032 & 1.0069 & 0.0005 & 1.0072 & 0.0032 \\
\hline 228 & ust017t02 & $1.10 \mathrm{E}-01$ & 1.0000 & 0.0025 & 0.9979 & 0.0005 & 0.9979 & 0.0025 \\
\hline 229 & ust017t03 & $1.06 \mathrm{E}-01$ & 1.0001 & 0.0035 & 1.0093 & 0.0005 & 1.0092 & 0.0035 \\
\hline 230 & ust017t04 & $8.13 \mathrm{E}-02$ & 0.9994 & 0.0040 & 1.0088 & 0.0005 & 1.0094 & 0.0040 \\
\hline 231 & ust017t05 & 7.95E-02 & 1.0000 & 0.0029 & 1.0067 & 0.0005 & 1.0067 & 0.0029 \\
\hline 232 & ust017t06 & $5.29 \mathrm{E}-02$ & 1.0000 & 0.0029 & 1.0052 & 0.0005 & 1.0052 & 0.0029 \\
\hline 233 & ust017t07 & $5.39 \mathrm{E}-02$ & 1.0000 & 0.0037 & 1.0042 & 0.0005 & 1.0042 & 0.0037 \\
\hline 234 & $\mathrm{hmt} 025 \mathrm{t} 01$ & $2.74 \mathrm{E}+00$ & 1.0037 & 0.0047 & 1.0123 & 0.0005 & 1.0085 & 0.0047 \\
\hline 235 & $\mathrm{hmt} 025 \mathrm{t} 02$ & $1.93 \mathrm{E}-01$ & 1.0007 & 0.0054 & 1.0076 & 0.0005 & 1.0069 & 0.0054 \\
\hline 236 & hmf030t00 & $2.14 \mathrm{E}+05$ & 1.0000 & 0.0009 & 1.0031 & 0.0005 & 1.0031 & 0.0010 \\
\hline 237 & lct049t01 & $2.13 \mathrm{E}+00$ & 1.0000 & 0.0034 & 0.9902 & 0.0005 & 0.9902 & 0.0034 \\
\hline 238 & lct049t02 & $2.14 \mathrm{E}+00$ & 1.0000 & 0.0034 & 0.9902 & 0.0005 & 0.9902 & 0.0034 \\
\hline 239 & lct049t03 & $2.26 \mathrm{E}+00$ & 1.0000 & 0.0034 & 0.9917 & 0.0005 & 0.9917 & 0.0034 \\
\hline 240 & lct049t04 & $2.37 \mathrm{E}+00$ & 1.0000 & 0.0034 & 0.9918 & 0.0005 & 0.9918 & 0.0034 \\
\hline 241 & lct049t05 & $1.20 \mathrm{E}+00$ & 1.0000 & 0.0042 & 0.9895 & 0.0005 & 0.9895 & 0.0042 \\
\hline
\end{tabular}




\begin{tabular}{|c|c|c|c|c|c|c|c|c|}
\hline \multirow{2}{*}{$\begin{array}{l}\text { Exp. } \\
\text { No. }\end{array}$} & \multirow{2}{*}{$\begin{array}{l}\text { IHECSBE } \\
\text { ID }\end{array}$} & \multirow{2}{*}{$\begin{array}{c}\text { EALF } \\
(\mathrm{eV})\end{array}$} & \multicolumn{2}{|c|}{ Expected } & \multicolumn{2}{|c|}{ Calculated } & \multicolumn{2}{|c|}{ Normalized } \\
\hline & & & $k_{e f f}$ & $\sigma_{\text {exp }}$ & $k_{\text {eff }}$ & $\sigma_{k e f f}$ & $k_{\text {eff }}$ & $\sigma_{\text {comb }}$ \\
\hline 242 & lct049t06 & $1.21 \mathrm{E}+00$ & 1.0000 & 0.0042 & 0.9919 & 0.0005 & 0.9919 & 0.0042 \\
\hline 243 & lct049t07 & $1.16 \mathrm{E}+00$ & 1.0000 & 0.0042 & 0.9907 & 0.0005 & 0.9907 & 0.0042 \\
\hline 244 & lct049t08 & $1.25 \mathrm{E}+00$ & 1.0000 & 0.0042 & 0.9908 & 0.0005 & 0.9908 & 0.0042 \\
\hline 245 & lct049t09 & 7.71E-01 & 1.0000 & 0.0037 & 0.9889 & 0.0005 & 0.9889 & 0.0037 \\
\hline 246 & lct049t10 & $7.76 \mathrm{E}-01$ & 1.0000 & 0.0037 & 0.9913 & 0.0005 & 0.9913 & 0.0037 \\
\hline 247 & lct049t11 & $7.75 \mathrm{E}-01$ & 1.0000 & 0.0037 & 0.9905 & 0.0005 & 0.9905 & 0.0037 \\
\hline 248 & lct049t12 & $8.17 \mathrm{E}-01$ & 1.0000 & 0.0037 & 0.9903 & 0.0004 & 0.9903 & 0.0037 \\
\hline 249 & lct049t13 & $1.48 \mathrm{E}+00$ & 1.0000 & 0.0036 & 0.9906 & 0.0005 & 0.9906 & 0.0036 \\
\hline 250 & lct049t14 & $1.48 \mathrm{E}+00$ & 1.0000 & 0.0036 & 0.9918 & 0.0005 & 0.9918 & 0.0036 \\
\hline 251 & lct049t15 & $1.48 \mathrm{E}+00$ & 1.0000 & 0.0036 & 0.9926 & 0.0005 & 0.9926 & 0.0036 \\
\hline 252 & lct049t16 & $1.15 \mathrm{E}+00$ & 1.0000 & 0.0036 & 0.9911 & 0.0005 & 0.9911 & 0.0036 \\
\hline 253 & lct049t17 & $1.23 \mathrm{E}+00$ & 1.0000 & 0.0036 & 0.9914 & 0.0005 & 0.9914 & 0.0036 \\
\hline 254 & lct049t18 & $1.06 \mathrm{E}+00$ & 1.0000 & 0.0030 & 0.9960 & 0.0005 & 0.9960 & 0.0030 \\
\hline 255 & mcf001t01 & $1.22 \mathrm{E}+05$ & 0.9866 & 0.0023 & 1.0045 & 0.0005 & 1.0181 & 0.0024 \\
\hline 256 & mci005t00 & $1.72 \mathrm{E}+02$ & 1.1526 & 0.0056 & 1.1642 & 0.0005 & 1.0101 & 0.0056 \\
\hline 257 & $\mathrm{mcm} 001 \mathrm{t} 01$ & $4.03 \mathrm{E}+02$ & 0.9999 & 0.0056 & 0.9898 & 0.0005 & 0.9899 & 0.0056 \\
\hline 258 & mcm001t02 & $4.05 \mathrm{E}+02$ & 0.9996 & 0.0053 & 0.9878 & 0.0005 & 0.9882 & 0.0053 \\
\hline 259 & $\mathrm{mcm} 001 \mathrm{t} 03$ & $4.31 \mathrm{E}+01$ & 1.0011 & & 0.9973 & & 0.9962 & 0.0039 \\
\hline 260 & $\mathrm{mcm} 001 \mathrm{t} 04$ & $4.24 \mathrm{E}+01$ & 1.0004 & 0.0036 & 0.9982 & 0.0005 & 0.9978 & 0.0036 \\
\hline 261 & $\mathrm{mcm} 001 \mathrm{t} 05$ & $4.31 \mathrm{E}+01$ & 1.0005 & 0.0043 & 1.0020 & 0.0005 & 1.0015 & 0.0043 \\
\hline 262 & mcm001t06 & $3.99 \mathrm{E}+01$ & 0.9970 & 0.0042 & 0.9974 & 0.0005 & 1.0004 & 0.0042 \\
\hline 263 & $\mathrm{mcm} 001 \mathrm{t} 07$ & $3.82 \mathrm{E}+01$ & 0.9990 & 0.0038 & 0.9960 & 0.0005 & 0.9970 & 0.0038 \\
\hline 264 & $\mathrm{mcm} 001 \mathrm{t} 08$ & $3.66 \mathrm{E}+01$ & 0.9985 & 0.0044 & 0.9957 & 0.0005 & 0.9972 & 0.0044 \\
\hline 265 & mem001t09 & $3.61 \mathrm{E}+01$ & 1.0001 & 0.0046 & 0.9968 & 0.0005 & 0.9967 & 0.0046 \\
\hline 266 & $\mathrm{mcm} 001 \mathrm{t} 10$ & $3.60 \mathrm{E}+01$ & 0.9988 & 0.0045 & 0.9987 & 0.0005 & 0.9999 & 0.0045 \\
\hline 267 & mcm001t11 & $4.33 \mathrm{E}+01$ & 0.9998 & 0.0040 & 1.0002 & 0.0005 & 1.0004 & 0.0040 \\
\hline 268 & $\mathrm{mcm} 001 \mathrm{t} 12$ & $4.35 \mathrm{E}+01$ & 0.9995 & 0.0037 & 1.0013 & 0.0005 & 1.0018 & 0.0037 \\
\hline 269 & $\mathrm{mcm} 001 \mathrm{t} 13$ & $4.44 \mathrm{E}+01$ & 1.0007 & 0.0040 & 0.9992 & 0.0005 & 0.9985 & 0.0040 \\
\hline 270 & $\mathrm{mcm} 001 \mathrm{t} 14$ & $4.41 \mathrm{E}+01$ & 0.9989 & 0.0039 & 1.0009 & 0.0005 & 1.0020 & 0.0039 \\
\hline 271 & $\mathrm{mcm} 001 \mathrm{t} 15$ & $4.54 \mathrm{E}+01$ & 1.0004 & 0.0041 & 1.0006 & 0.0005 & 1.0002 & 0.0041 \\
\hline 272 & $\mathrm{mcm} 001 \mathrm{t} 16$ & $4.77 \mathrm{E}+01$ & 1.0009 & 0.0041 & 0.9993 & 0.0005 & 0.9984 & 0.0041 \\
\hline 273 & $\mathrm{mcm} 001 \mathrm{t} 17$ & $4.32 \mathrm{E}+01$ & 1.0001 & 0.0041 & 1.0018 & 0.0005 & 1.0017 & 0.0041 \\
\hline 274 & $\mathrm{mcm} 001 \mathrm{t} 18$ & $4.24 \mathrm{E}+01$ & 1.0010 & 0.0041 & 1.0008 & 0.0005 & 0.9998 & 0.0041 \\
\hline 275 & mem001t19 & $4.22 \mathrm{E}+01$ & 1.0007 & 0.0038 & 0.9988 & 0.0005 & 0.9981 & 0.0038 \\
\hline 276 & mmf008t01 & $2.91 \mathrm{E}+04$ & 0.9920 & 0.0063 & 1.0137 & 0.0005 & 1.0219 & 0.0063 \\
\hline 277 & mmf008t02 & $3.22 \mathrm{E}+05$ & 1.0010 & 0.0023 & 1.0270 & 0.0005 & 1.0259 & 0.0023 \\
\hline 278 & mmf008t03 & $6.87 \mathrm{E}+04$ & 0.9860 & 0.0044 & 1.0062 & 0.0005 & 1.0205 & 0.0044 \\
\hline 279 & mmf008t04 & $2.43 \mathrm{E}+05$ & 0.9730 & 0.0045 & 1.0315 & 0.0005 & 1.0601 & 0.0045 \\
\hline 280 & mmf008t05 & $2.57 \mathrm{E}+05$ & 1.0060 & 0.0069 & 1.0214 & 0.0005 & 1.0153 & 0.0069 \\
\hline 281 & mmf008t06 & $2.19 \mathrm{E}+04$ & 0.9710 & 0.0042 & 1.0285 & 0.0005 & 1.0592 & 0.0042 \\
\hline
\end{tabular}




\begin{tabular}{|c|c|c|c|c|c|c|c|c|}
\hline \multirow{2}{*}{$\begin{array}{l}\text { Exp. } \\
\text { No. }\end{array}$} & \multirow{2}{*}{$\begin{array}{c}\text { IHECSBE } \\
\text { ID }\end{array}$} & \multirow{2}{*}{$\begin{array}{l}\text { EALF } \\
(\mathrm{eV})\end{array}$} & \multicolumn{2}{|c|}{ Expected } & \multicolumn{2}{|c|}{ Calculated } & \multicolumn{2}{|c|}{ Normalized } \\
\hline & & & $k_{\text {eff }}$ & $\sigma_{\text {exp }}$ & $k_{\text {eff }}$ & $\sigma_{\text {keff }}$ & $k_{\text {eff }}$ & $\sigma_{\text {comb }}$ \\
\hline 282 & $\mathrm{mmf008t07}$ & $3.60 \mathrm{E}+05$ & 1.0300 & 0.0025 & 1.0491 & 0.0005 & 1.0185 & 0.0025 \\
\hline 283 & het010-01 & 7.81E-01 & 1.0000 & 0.0050 & 0.9990 & 0.0003 & 0.9990 & 0.0050 \\
\hline 284 & $\operatorname{hct} 010-02$ & $7.87 \mathrm{E}-01$ & 1.0000 & 0.0050 & 0.9960 & 0.0003 & 0.9960 & 0.0050 \\
\hline 285 & het010-03 & $3.12 \mathrm{E}-01$ & 1.0000 & 0.0050 & 0.9987 & 0.0003 & 0.9987 & 0.0050 \\
\hline 286 & het010-04 & $1.87 \mathrm{E}-01$ & 1.0000 & 0.0050 & 0.9981 & 0.0003 & 0.9981 & 0.0050 \\
\hline 287 & het010-05 & $1.36 \mathrm{E}-01$ & 1.0000 & 0.0050 & 0.9998 & 0.0003 & 0.9998 & 0.0050 \\
\hline 288 & het010-06 & $1.37 \mathrm{E}-01$ & 1.0000 & 0.0050 & 0.9976 & 0.0003 & 0.9976 & 0.0050 \\
\hline 289 & het010-07 & $1.09 \mathrm{E}-01$ & 1.0000 & 0.0050 & 1.0010 & 0.0003 & 1.0010 & 0.0050 \\
\hline 290 & het010-08 & $1.09 \mathrm{E}-01$ & 1.0000 & 0.0050 & 1.0012 & 0.0003 & 1.0012 & 0.0050 \\
\hline 291 & het010-09 & $1.11 \mathrm{E}-01$ & 1.0000 & 0.0050 & 0.9997 & 0.0003 & 0.9997 & 0.0050 \\
\hline 292 & het010-10 & $9.57 \mathrm{E}-02$ & 1.0000 & 0.0050 & 1.0025 & 0.0003 & 1.0025 & 0.0050 \\
\hline 293 & $\operatorname{hct} 010-11$ & 9.63E-02 & 1.0000 & 0.0050 & 1.0001 & 0.0003 & 1.0001 & 0.0050 \\
\hline 294 & het010-12 & 8.61E-02 & 1.0000 & 0.0050 & 0.9992 & 0.0003 & 0.9992 & 0.0050 \\
\hline 295 & $\operatorname{hct} 010-13$ & 8.05E-02 & 1.0000 & 0.0050 & 1.0017 & 0.0003 & 1.0017 & 0.0050 \\
\hline 296 & het010-14 & $9.51 \mathrm{E}-02$ & 1.0000 & 0.0050 & 1.0008 & 0.0003 & 1.0008 & 0.0050 \\
\hline 297 & het010-15 & $1.00 \mathrm{E}-01$ & 1.0000 & 0.0050 & 1.0009 & 0.0003 & 1.0009 & 0.0050 \\
\hline 298 & $\operatorname{hct} 011-01$ & 7.21E-01 & 0.9988 & 0.0042 & 0.9941 & 0.0003 & 0.9953 & 0.0042 \\
\hline 299 & het011-02 & $5.53 \mathrm{E}-01$ & 0.9988 & 0.0042 & 0.9953 & 0.0003 & 0.9965 & 0.0042 \\
\hline 300 & het011-03 & $4.33 \mathrm{E}-01$ & 0.9988 & 0.0042 & 0.9961 & 0.0003 & 0.9973 & 0.0042 \\
\hline 301 & $\operatorname{hct} 012-01$ & $6.04 \mathrm{E}-01$ & 0.9987 & 0.0032 & 0.9939 & 0.0003 & 0.9952 & 0.0032 \\
\hline 302 & $\operatorname{hct012-02}$ & 4.59E-01 & 0.9987 & 0.0034 & 0.9937 & 0.0003 & 0.9950 & 0.0034 \\
\hline 303 & het013-01 & $4.56 \mathrm{E}-01$ & 0.9988 & 0.0042 & 0.9960 & 0.0003 & 0.9972 & 0.0042 \\
\hline 304 & hct013-02 & $3.17 \mathrm{E}-01$ & 0.9988 & 0.0043 & 0.9959 & 0.0003 & 0.9971 & 0.0043 \\
\hline 305 & het014-01 & $1.17 \mathrm{E}-01$ & 0.9986 & 0.0048 & 1.0002 & 0.0003 & 1.0016 & 0.0048 \\
\hline 306 & het014-02 & $9.78 \mathrm{E}-02$ & 0.9986 & 0.0049 & 1.0001 & 0.0003 & 1.0015 & 0.0049 \\
\hline 307 & hmt006-01 & $8.46 \mathrm{E}-02$ & 1.0000 & 0.0044 & 0.9957 & 0.0003 & 0.9957 & 0.0044 \\
\hline 308 & $\mathrm{hmt} 006-02$ & 7.03E-02 & 1.0000 & 0.0040 & 0.9956 & 0.0003 & 0.9956 & 0.0040 \\
\hline 309 & hmt006-03 & $6.31 \mathrm{E}-02$ & 1.0000 & 0.0040 & 1.0011 & 0.0003 & 1.0011 & 0.0040 \\
\hline 310 & hmt006-04 & $6.18 \mathrm{E}-02$ & 1.0000 & 0.0040 & 0.9949 & 0.0003 & 0.9949 & 0.0040 \\
\hline 311 & $\mathrm{hmt006-05}$ & $5.83 \mathrm{E}-02$ & 1.0000 & 0.0040 & 0.9949 & 0.0003 & 0.9949 & 0.0040 \\
\hline 312 & $\mathrm{hmt006-06}$ & $5.58 \mathrm{E}-02$ & 1.0000 & 0.0040 & 0.9936 & 0.0003 & 0.9936 & 0.0040 \\
\hline 313 & hmt006-07 & $5.41 \mathrm{E}-02$ & 1.0000 & 0.0040 & 0.9923 & 0.0003 & 0.9923 & 0.0040 \\
\hline 314 & hmt006-08 & $5.22 \mathrm{E}-02$ & 1.0000 & 0.0040 & 0.9899 & 0.0002 & 0.9899 & 0.0040 \\
\hline 315 & hmt006-09 & $5.19 \mathrm{E}-02$ & 1.0000 & 0.0040 & 0.9933 & 0.0002 & 0.9933 & 0.0040 \\
\hline 316 & $\mathrm{hmt006-10}$ & $8.21 \mathrm{E}-02$ & 1.0000 & 0.0040 & 1.0029 & 0.0003 & 1.0029 & 0.0040 \\
\hline 317 & $\mathrm{hmt006-11}$ & $6.21 \mathrm{E}-02$ & 1.0000 & 0.0040 & 0.9959 & 0.0003 & 0.9959 & 0.0040 \\
\hline 318 & hmt006-12 & $5.40 \mathrm{E}-02$ & 1.0000 & 0.0040 & 0.9989 & 0.0003 & 0.9989 & 0.0040 \\
\hline 319 & $\mathrm{hmt} 006-15$ & $5.63 \mathrm{E}-02$ & 1.0000 & 0.0040 & 0.9885 & 0.0003 & 0.9885 & 0.0040 \\
\hline 320 & $\mathrm{hmt} 006-13$ & $8.24 \mathrm{E}-02$ & 1.0000 & 0.0061 & 1.0164 & 0.0003 & 1.0164 & 0.0061 \\
\hline 321 & hmt006-14 & $5.68 \mathrm{E}-02$ & 1.0000 & 0.0040 & 0.9911 & 0.0003 & 0.9911 & 0.0040 \\
\hline
\end{tabular}




\begin{tabular}{|c|c|c|c|c|c|c|c|c|}
\hline \multirow{2}{*}{$\begin{array}{l}\text { Exp. } \\
\text { No. }\end{array}$} & \multirow{2}{*}{$\begin{array}{c}\text { IHECSBE } \\
\text { ID }\end{array}$} & \multirow{2}{*}{$\begin{array}{c}\text { EALF } \\
(\mathrm{eV})\end{array}$} & \multicolumn{2}{|c|}{ Expected } & \multicolumn{2}{|c|}{ Calculated } & \multicolumn{2}{|c|}{ Normalized } \\
\hline & & & $k_{\text {eff }}$ & $\sigma_{\text {exp }}$ & $k_{e f f}$ & $\sigma_{\text {keff }}$ & $k_{e f f}$ & $\sigma_{\text {comb }}$ \\
\hline 322 & hmt006-16 & $6.32 \mathrm{E}-02$ & 1.0000 & 0.0040 & 0.9980 & 0.0003 & 0.9980 & 0.0040 \\
\hline 323 & hmt006-17 & $7.43 \mathrm{E}-02$ & 1.0000 & 0.0040 & 0.9931 & 0.0003 & 0.9931 & 0.0040 \\
\hline 324 & hmt006-18 & 8.02E-02 & 1.0000 & 0.0040 & 0.9928 & 0.0003 & 0.9928 & 0.0040 \\
\hline 325 & hmt006-19 & $5.23 \mathrm{E}-02$ & 1.0000 & 0.0040 & 0.9961 & 0.0003 & 0.9961 & 0.0040 \\
\hline 326 & hmt006-20 & $6.45 \mathrm{E}-02$ & 1.0000 & 0.0040 & 0.9957 & 0.0003 & 0.9957 & 0.0040 \\
\hline 327 & $\mathrm{hmt} 006-21$ & 6.91E-02 & 1.0000 & 0.0040 & 0.9992 & 0.0003 & 0.9992 & 0.0040 \\
\hline 328 & hmt006-22 & 7.39E-02 & 1.0000 & 0.0040 & 0.9988 & 0.0003 & 0.9988 & 0.0040 \\
\hline 329 & $\mathrm{hmt} 006-23$ & 7.57E-02 & 1.0000 & 0.0040 & 1.0015 & 0.0003 & 1.0015 & 0.0040 \\
\hline 330 & hst001-01 & $8.21 \mathrm{E}-02$ & 1.0004 & 0.0060 & 1.0010 & 0.0004 & 1.0006 & 0.0060 \\
\hline 331 & hst001-02 & $2.80 \mathrm{E}-01$ & 1.0021 & 0.0072 & 0.9992 & 0.0004 & 0.9971 & 0.0072 \\
\hline 332 & hst001-03 & $8.06 \mathrm{E}-02$ & 1.0003 & 0.0035 & 1.0035 & 0.0004 & 1.0032 & 0.0035 \\
\hline 333 & hst001-04 & $2.99 \mathrm{E}-01$ & 1.0008 & 0.0053 & 1.0001 & 0.0004 & 0.9993 & 0.0053 \\
\hline 334 & hst001-05 & 4.30E-02 & 1.0001 & 0.0049 & 1.0013 & 0.0003 & 1.0012 & 0.0049 \\
\hline 335 & hst001-06 & $4.46 \mathrm{E}-02$ & 1.0002 & 0.0046 & 1.0041 & 0.0004 & 1.0039 & 0.0046 \\
\hline 336 & hst001-07 & $7.78 \mathrm{E}-02$ & 1.0008 & 0.0040 & 0.9991 & 0.0004 & 0.9983 & 0.0040 \\
\hline 337 & hst001-08 & 8.22E-02 & 0.9998 & 0.0038 & 1.0000 & 0.0004 & 1.0002 & 0.0038 \\
\hline 338 & hst001-09 & $2.99 \mathrm{E}-01$ & 1.0008 & 0.0054 & 0.9966 & 0.0004 & 0.9958 & 0.0054 \\
\hline 339 & hst001-10 & 4.62E-02 & 0.9993 & 0.0054 & 0.9939 & 0.0003 & 0.9946 & 0.0054 \\
\hline 340 & hst005-11 & $2.49 \mathrm{E}-01$ & 1.0000 & 0.0083 & 0.9994 & 0.0003 & 0.9994 & 0.0083 \\
\hline 341 & hst005-12 & $2.56 \mathrm{E}-01$ & 1.0000 & 0.0084 & 1.0082 & 0.0003 & 1.0082 & 0.0084 \\
\hline 342 & hst005-14 & $2.66 \mathrm{E}-01$ & 1.0000 & 0.0058 & 1.0072 & 0.0003 & 1.0072 & 0.0058 \\
\hline 343 & hst005-15 & $2.27 \mathrm{E}-01$ & 1.0000 & 0.0059 & 1.0022 & 0.0003 & 1.0022 & 0.0059 \\
\hline 344 & hst005-17 & $3.29 \mathrm{E}-01$ & 1.0000 & 0.0057 & 0.9887 & 0.0003 & 0.9887 & 0.0057 \\
\hline 345 & hst006-01 & $2.11 \mathrm{E}-01$ & 0.9973 & 0.0050 & 0.9841 & 0.0004 & 0.9867 & 0.0050 \\
\hline 346 & hst006-08 & $2.01 \mathrm{E}-01$ & 0.9973 & 0.0050 & 0.9837 & 0.0003 & 0.9863 & 0.0050 \\
\hline 347 & hst006-12 & $2.12 \mathrm{E}-01$ & 0.9973 & 0.0050 & 0.9826 & 0.0004 & 0.9853 & 0.0050 \\
\hline 348 & hst006-27 & $2.09 \mathrm{E}-01$ & 0.9973 & 0.0050 & 0.9841 & 0.0004 & 0.9868 & 0.0050 \\
\hline 349 & hst007-01 & 4.74E-02 & 1.0000 & 0.0035 & 1.0135 & 0.0003 & 1.0135 & 0.0035 \\
\hline 350 & hst007-02 & $2.70 \mathrm{E}-01$ & 1.0000 & 0.0050 & 1.0132 & 0.0003 & 1.0132 & 0.0050 \\
\hline 351 & hst007-03 & $4.63 \mathrm{E}-02$ & 1.0000 & 0.0035 & 1.0117 & 0.0003 & 1.0117 & 0.0035 \\
\hline 352 & hst007-04 & $2.40 \mathrm{E}-01$ & 1.0000 & 0.0035 & 1.0140 & 0.0003 & 1.0140 & 0.0035 \\
\hline 353 & hst007-05 & $5.04 \mathrm{E}-02$ & 1.0000 & 0.0035 & 1.0070 & 0.0003 & 1.0070 & 0.0035 \\
\hline 354 & hst007-06 & $2.76 \mathrm{E}-01$ & 1.0000 & 0.0035 & 1.0042 & 0.0004 & 1.0042 & 0.0035 \\
\hline 355 & hst007-07 & 4.97E-02 & 1.0000 & 0.0035 & 1.0065 & 0.0003 & 1.0065 & 0.0035 \\
\hline 356 & hst007-08 & $2.71 \mathrm{E}-01$ & 1.0000 & 0.0035 & 1.0032 & 0.0003 & 1.0032 & 0.0035 \\
\hline 357 & hst007-09 & $5.14 \mathrm{E}-02$ & 1.0000 & 0.0035 & 1.0069 & 0.0003 & 1.0069 & 0.0035 \\
\hline 358 & hst007-10 & $5.30 \mathrm{E}-02$ & 1.0000 & 0.0035 & 1.0150 & 0.0003 & 1.0150 & 0.0035 \\
\hline 359 & hst007-11 & $2.58 \mathrm{E}-01$ & 1.0000 & 0.0035 & 1.0091 & 0.0003 & 1.0091 & 0.0035 \\
\hline 360 & hst007-12 & $5.13 \mathrm{E}-02$ & 1.0000 & 0.0035 & 1.0149 & 0.0003 & 1.0149 & 0.0035 \\
\hline 361 & hst007-13 & $2.33 \mathrm{E}-01$ & 1.0000 & 0.0035 & 1.0127 & 0.0003 & 1.0127 & 0.0035 \\
\hline
\end{tabular}




\begin{tabular}{|c|c|c|c|c|c|c|c|c|}
\hline \multirow{2}{*}{$\begin{array}{l}\text { Exp. } \\
\text { No. }\end{array}$} & \multirow{2}{*}{$\begin{array}{c}\text { IHECSBE } \\
\text { ID }\end{array}$} & \multirow{2}{*}{$\begin{array}{c}\text { EALF } \\
(\mathrm{eV})\end{array}$} & \multicolumn{2}{|c|}{ Expected } & \multicolumn{2}{|c|}{ Calculated } & \multicolumn{2}{|c|}{ Normalized } \\
\hline & & & $k_{\text {eff }}$ & $\sigma_{\text {exp }}$ & $k_{\text {eff }}$ & $\sigma_{k e f f}$ & $k_{\text {eff }}$ & $\sigma_{\mathrm{comb}}$ \\
\hline 362 & hst007-14 & $2.41 \mathrm{E}-01$ & 1.0000 & 0.0035 & 1.0105 & 0.0003 & 1.0105 & 0.0035 \\
\hline 363 & hst007-15 & $2.43 \mathrm{E}-01$ & 1.0000 & 0.0035 & 1.0087 & 0.0003 & 1.0087 & 0.0035 \\
\hline 364 & hst007-16 & $2.57 \mathrm{E}-01$ & 1.0000 & 0.0035 & 1.0071 & 0.0004 & 1.0071 & 0.0035 \\
\hline 365 & hst007-17 & $2.42 \mathrm{E}-01$ & 1.0000 & 0.0035 & 1.0098 & 0.0003 & 1.0098 & 0.0035 \\
\hline 366 & hst009-01 & $5.28 \mathrm{E}-01$ & 0.9990 & 0.0043 & 1.0030 & 0.0004 & 1.0040 & 0.0043 \\
\hline 367 & hst009-02 & $3.23 \mathrm{E}-01$ & 1.0000 & 0.0039 & 1.0037 & 0.0003 & 1.0037 & 0.0039 \\
\hline 368 & hst009-03 & $1.60 \mathrm{E}-01$ & 1.0000 & 0.0036 & 1.0031 & 0.0003 & 1.0031 & 0.0036 \\
\hline 369 & hst009-04 & $9.10 \mathrm{E}-02$ & 0.9986 & 0.0035 & 0.9975 & 0.0003 & 0.9989 & 0.0035 \\
\hline 370 & hst010-01 & $5.25 \mathrm{E}-02$ & 1.0000 & 0.0029 & 1.0033 & 0.0003 & 1.0033 & 0.0029 \\
\hline 371 & hst010-02 & $5.31 \mathrm{E}-02$ & 1.0000 & 0.0029 & 1.0033 & 0.0003 & 1.0033 & 0.0029 \\
\hline 372 & hst010-04 & $5.62 \mathrm{E}-02$ & 0.9992 & 0.0029 & 0.9991 & 0.0003 & 0.9999 & 0.0029 \\
\hline 373 & hst010-03 & $5.53 \mathrm{E}-02$ & 1.0000 & 0.0029 & 1.0014 & 0.0003 & 1.0014 & 0.0029 \\
\hline 374 & hst011-01 & $3.96 \mathrm{E}-02$ & 1.0000 & 0.0023 & 1.0072 & 0.0003 & 1.0072 & 0.0023 \\
\hline 375 & hst011-02 & $3.94 \mathrm{E}-02$ & 1.0000 & 0.0023 & 1.0035 & 0.0003 & 1.0035 & 0.0023 \\
\hline 376 & hst012-01 & $3.24 \mathrm{E}-02$ & 0.9999 & 0.0058 & 1.0023 & & 1.0024 & 0.0058 \\
\hline 377 & hst013-01 & $3.23 \mathrm{E}-02$ & 1.0012 & 0.0026 & 1.0000 & & 0.9988 & 0.0026 \\
\hline 378 & hst014-01 & 4.59E-02 & 1.0000 & 0.0028 & 1.0018 & 0.0003 & 1.0018 & 0.0028 \\
\hline 379 & hst015-01 & $5.76 \mathrm{E}-02$ & 1.0000 & 0.0032 & 1.0056 & 0.0003 & 1.0056 & 0.0032 \\
\hline 380 & hst015-02 & $5.59 \mathrm{E}-02$ & 1.0000 & 0.0034 & 0.9973 & 0.0003 & 0.9973 & 0.0034 \\
\hline 381 & hst016-01 & 7.82E-02 & 1.0000 & 0.0036 & 0.9998 & 0.0003 & 0.9998 & 0.0036 \\
\hline 382 & hst017-01 & $9.77 \mathrm{E}-02$ & 1.0000 & 0.0028 & 1.0003 & 0.0003 & 1.0003 & 0.0028 \\
\hline 383 & hst017-02 & $1.08 \mathrm{E}-01$ & 1.0000 & 0.0040 & 0.9891 & 0.0004 & 0.9891 & 0.0040 \\
\hline 384 & hst017-03 & $1.02 \mathrm{E}-01$ & 1.0000 & 0.0036 & 0.9850 & 0.0004 & 0.9850 & 0.0036 \\
\hline 385 & hst018-01 & $1.60 \mathrm{E}-01$ & 1.0000 & 0.0034 & 0.9991 & 0.0003 & 0.9991 & 0.0034 \\
\hline 386 & hst018-02 & $1.87 \mathrm{E}-01$ & 1.0000 & 0.0046 & 0.9926 & 0.0004 & 0.9926 & 0.0046 \\
\hline 387 & hst018-03 & $1.71 \mathrm{E}-01$ & 1.0000 & 0.0042 & 0.9969 & 0.0004 & 0.9969 & 0.0042 \\
\hline 388 & hst019-01 & $3.12 \mathrm{E}-01$ & 1.0000 & 0.0041 & 1.0073 & 0.0003 & 1.0073 & 0.0041 \\
\hline 389 & hst025-01 & $4.06 \mathrm{E}-02$ & 1.0002 & 0.0025 & 1.0025 & 0.0003 & 1.0023 & 0.0025 \\
\hline 390 & hst025-02 & $4.06 \mathrm{E}-02$ & 1.0007 & 0.0025 & 1.0021 & 0.0003 & 1.0014 & 0.0025 \\
\hline 391 & hst025-04 & 4.14E-02 & 1.0003 & 0.0027 & 1.0029 & 0.0003 & 1.0026 & 0.0027 \\
\hline 392 & hst025-05 & $4.88 \mathrm{E}-02$ & 1.0013 & 0.0030 & 1.0048 & 0.0003 & 1.0035 & 0.0030 \\
\hline 393 & hst027-01 & $7.46 \mathrm{E}-02$ & 1.0000 & 0.0046 & 0.9985 & 0.0004 & 0.9985 & 0.0046 \\
\hline 394 & hst28i-1 & 4.67E-02 & 1.0000 & 0.0023 & 0.9998 & 0.0003 & 0.9998 & 0.0023 \\
\hline 395 & hst28i-3 & $4.68 \mathrm{E}-02$ & 1.0000 & 0.0026 & 1.0018 & 0.0003 & 1.0018 & 0.0026 \\
\hline 396 & hst28i-5 & 4.69E-02 & 1.0000 & 0.0031 & 0.9970 & 0.0003 & 0.9970 & 0.0031 \\
\hline 397 & hst28i-7 & $4.71 \mathrm{E}-02$ & 1.0000 & 0.0038 & 1.0013 & 0.0003 & 1.0013 & 0.0038 \\
\hline 398 & hst28i-9 & $1.44 \mathrm{E}-01$ & 1.0000 & 0.0049 & 1.0009 & 0.0004 & 1.0009 & 0.0049 \\
\hline 399 & hst28i-11 & $1.45 \mathrm{E}-01$ & 1.0000 & 0.0051 & 1.0023 & 0.0004 & 1.0023 & 0.0051 \\
\hline 400 & hst28i-13 & $1.48 \mathrm{E}-01$ & 1.0000 & 0.0058 & 1.0014 & 0.0003 & 1.0014 & 0.0058 \\
\hline 401 & hst28i-15 & $1.49 \mathrm{E}-01$ & 1.0000 & 0.0064 & 1.0094 & 0.0003 & 1.0094 & 0.0064 \\
\hline
\end{tabular}




\begin{tabular}{|c|c|c|c|c|c|c|c|c|}
\hline \multirow{2}{*}{$\begin{array}{l}\text { Exp. } \\
\text { No. }\end{array}$} & \multirow{2}{*}{$\begin{array}{c}\text { IHECSBE } \\
\text { ID }\end{array}$} & \multirow{2}{*}{$\begin{array}{c}\text { EALF } \\
(\mathrm{eV})\end{array}$} & \multicolumn{2}{|c|}{ Expected } & \multicolumn{2}{|c|}{ Calculated } & \multicolumn{2}{|c|}{ Normalized } \\
\hline & & & $k_{\text {eff }}$ & $\sigma_{\text {exp }}$ & $k_{\text {eff }}$ & $\sigma_{k e f f}$ & $k_{\text {eff }}$ & $\sigma_{\text {comb }}$ \\
\hline 402 & hst28i-17 & $1.51 \mathrm{E}-01$ & 1.0000 & 0.0066 & 1.0001 & 0.0003 & 1.0001 & 0.0066 \\
\hline 403 & hst29i-01 & $1.57 \mathrm{E}-01$ & 1.0000 & 0.0066 & 1.0030 & 0.0003 & 1.0030 & 0.0066 \\
\hline 404 & hst30i-01 & 4.74E-02 & 1.0000 & 0.0039 & 1.0000 & 0.0003 & 1.0000 & 0.0039 \\
\hline 405 & hst30i-04 & $1.58 \mathrm{E}-01$ & 1.0000 & 0.0064 & 1.0051 & 0.0004 & 1.0051 & 0.0064 \\
\hline 406 & hst032-01 & $3.11 \mathrm{E}-02$ & 1.0015 & 0.0026 & 0.9991 & 0.0002 & 0.9976 & 0.0026 \\
\hline 407 & hst033-02a & $3.10 \mathrm{E}-01$ & 0.9979 & 0.0112 & 0.9992 & 0.0003 & 1.0013 & 0.0112 \\
\hline 408 & hst033-02b & $3.19 \mathrm{E}-01$ & 1.0000 & 0.0109 & 0.9987 & 0.0003 & 0.9987 & 0.0109 \\
\hline 409 & hst033-02c & $3.23 \mathrm{E}-01$ & 0.9979 & 0.0067 & 0.9981 & 0.0003 & 1.0002 & 0.0067 \\
\hline 410 & hst033-03a & $2.96 \mathrm{E}-01$ & 0.9942 & 0.0115 & 1.0005 & 0.0003 & 1.0064 & 0.0115 \\
\hline 411 & hst033-03b & $2.93 \mathrm{E}-01$ & 0.9979 & 0.0112 & 1.0037 & 0.0003 & 1.0058 & 0.0112 \\
\hline 412 & hst033-03c & $2.75 \mathrm{E}-01$ & 0.9979 & 0.0072 & 1.0115 & 0.0003 & 1.0136 & 0.0072 \\
\hline 413 & hst033-10c & $2.77 \mathrm{E}-01$ & 0.9979 & 0.0072 & 1.0034 & 0.0003 & 1.0055 & 0.0072 \\
\hline 414 & hst033-10a & $2.96 \mathrm{E}-01$ & 0.9942 & 0.0115 & 1.0002 & 0.0003 & 1.0060 & 0.0115 \\
\hline 415 & hst033-10d & $3.01 \mathrm{E}-01$ & 0.9979 & 0.0106 & 0.9937 & 0.0003 & 0.9958 & 0.0106 \\
\hline 416 & hst035-01 & $3.73 \mathrm{E}-02$ & 1.0000 & 0.0031 & 1.0021 & 0.0003 & 1.0021 & 0.0031 \\
\hline 417 & hst035-05 & 4.94E-02 & 1.0000 & 0.0033 & 1.0044 & 0.0003 & 1.0044 & 0.0033 \\
\hline 418 & hst035-07 & $8.06 \mathrm{E}-02$ & 1.0000 & 0.0035 & 1.0054 & 0.0003 & 1.0054 & 0.0035 \\
\hline 419 & hst037-01 & $3.83 \mathrm{E}-02$ & 0.9980 & & 1.0103 & 0.0003 & 1.0123 & 0.0034 \\
\hline 420 & hst037-03 & $4.42 \mathrm{E}-02$ & 0.9970 & 0.0042 & 1.0072 & 0.0003 & 1.0102 & 0.0042 \\
\hline 421 & hst037-06 & $5.12 \mathrm{E}-02$ & 0.9960 & 0.0051 & 1.0122 & 0.0003 & 1.0163 & 0.0051 \\
\hline 422 & hst042-01 & $3.14 \mathrm{E}-02$ & 0.9957 & 0.0039 & 0.9970 & 0.0002 & 1.0013 & 0.0039 \\
\hline 423 & hst042-02 & $3.14 \mathrm{E}-02$ & 0.9965 & 0.0036 & 0.9970 & 0.0002 & 1.0005 & 0.0036 \\
\hline 424 & hst042-03 & $3.08 \mathrm{E}-02$ & 0.9994 & 0.0028 & 1.0007 & 0.0002 & 1.0013 & 0.0028 \\
\hline 425 & hst042-04 & $3.06 \mathrm{E}-02$ & 1.0000 & 0.0034 & 1.0021 & 0.0002 & 1.0021 & 0.0034 \\
\hline 426 & hst042-05 & $3.04 \mathrm{E}-02$ & 1.0000 & 0.0034 & 1.0000 & 0.0002 & 1.0000 & 0.0034 \\
\hline 427 & hst042-06 & $3.05 \mathrm{E}-02$ & 1.0000 & 0.0037 & 1.0003 & 0.0002 & 1.0003 & 0.0037 \\
\hline 428 & hst042-07 & $3.04 \mathrm{E}-02$ & 1.0000 & 0.0036 & 1.0011 & 0.0002 & 1.0011 & 0.0036 \\
\hline 429 & hst042-08 & $3.03 \mathrm{E}-02$ & 1.0000 & 0.0035 & 1.0014 & 0.0002 & 1.0014 & 0.0035 \\
\hline 430 & hst043-01 & 7.34E-02 & 0.9986 & 0.0031 & 0.9975 & 0.0004 & 0.9989 & 0.0031 \\
\hline 431 & hst043-02 & $3.34 \mathrm{E}-02$ & 0.9995 & 0.0026 & 1.0078 & 0.0003 & 1.0083 & 0.0026 \\
\hline 432 & hst043-03 & $3.20 \mathrm{E}-02$ & 0.9990 & 0.0025 & 1.0028 & 0.0002 & 1.0038 & 0.0025 \\
\hline 433 & imf003 & $7.08 \mathrm{E}+05$ & 1.0000 & 0.0017 & 1.0046 & & 1.0046 & 0.0017 \\
\hline 434 & imf004 & $6.66 \mathrm{E}+05$ & 1.0000 & 0.0030 & 1.0091 & & 1.0091 & 0.0030 \\
\hline 435 & imf005 & $6.43 \mathrm{E}+05$ & 1.0000 & 0.0021 & 1.0246 & & 1.0246 & 0.0021 \\
\hline 436 & imf006 & $6.54 \mathrm{E}+05$ & 1.0000 & 0.0023 & 1.0013 & & 1.0013 & 0.0023 \\
\hline 437 & lct009-01 & $1.15 \mathrm{E}-01$ & 1.0000 & 0.0021 & 0.9946 & 0.0002 & 0.9946 & 0.0021 \\
\hline 438 & lct009-02 & $1.15 \mathrm{E}-01$ & 1.0000 & 0.0021 & 0.9943 & 0.0003 & 0.9943 & 0.0021 \\
\hline 439 & lct009-03 & $1.15 \mathrm{E}-01$ & 1.0000 & 0.0021 & 0.9939 & 0.0003 & 0.9939 & 0.0021 \\
\hline 440 & lct009-04 & $1.15 \mathrm{E}-01$ & 1.0000 & 0.0021 & 0.9945 & 0.0003 & 0.9945 & 0.0021 \\
\hline 441 & lct009-05 & $1.16 \mathrm{E}-01$ & 1.0000 & 0.0021 & 0.9956 & 0.0003 & 0.9956 & 0.0021 \\
\hline
\end{tabular}




\begin{tabular}{|c|c|c|c|c|c|c|c|c|}
\hline \multirow{2}{*}{$\begin{array}{l}\text { Exp. } \\
\text { No. }\end{array}$} & \multirow{2}{*}{$\begin{array}{c}\text { IHECSBE } \\
\text { ID }\end{array}$} & \multirow{2}{*}{$\begin{array}{c}\text { EALF } \\
(\mathrm{eV})\end{array}$} & \multicolumn{2}{|c|}{ Expected } & \multicolumn{2}{|c|}{ Calculated } & \multicolumn{2}{|c|}{ Normalized } \\
\hline & & & $k_{e f f}$ & $\sigma_{\text {exp }}$ & $k_{\text {eff }}$ & $\sigma_{k e f f}$ & $k_{\text {eff }}$ & $\sigma_{\text {comb }}$ \\
\hline 442 & lct009-06 & $1.15 \mathrm{E}-01$ & 1.0000 & 0.0021 & 0.9946 & 0.0003 & 0.9946 & 0.0021 \\
\hline 443 & lct009-07 & $1.16 \mathrm{E}-01$ & 1.0000 & 0.0021 & 0.9956 & 0.0003 & 0.9956 & 0.0021 \\
\hline 444 & lct009-08 & $1.15 \mathrm{E}-01$ & 1.0000 & 0.0021 & 0.9946 & 0.0002 & 0.9946 & 0.0021 \\
\hline 445 & lct009-09 & $1.16 \mathrm{E}-01$ & 1.0000 & 0.0021 & 0.9952 & 0.0003 & 0.9952 & 0.0021 \\
\hline 446 & $1 c t 009-10$ & $1.16 \mathrm{E}-01$ & 1.0000 & 0.0021 & 0.9941 & 0.0003 & 0.9941 & 0.0021 \\
\hline 447 & $\operatorname{lct} 009-11$ & $1.15 \mathrm{E}-01$ & 1.0000 & 0.0021 & 0.9940 & 0.0003 & 0.9940 & 0.0021 \\
\hline 448 & $\operatorname{lct} 009-13$ & $1.15 \mathrm{E}-01$ & 1.0000 & 0.0021 & 0.9947 & 0.0003 & 0.9947 & 0.0021 \\
\hline 449 & lct009-14 & $1.16 \mathrm{E}-01$ & 1.0000 & 0.0021 & 0.9931 & 0.0003 & 0.9931 & 0.0021 \\
\hline 450 & lct009-15 & $1.15 \mathrm{E}-01$ & 1.0000 & 0.0021 & 0.9953 & 0.0003 & 0.9953 & 0.0021 \\
\hline 451 & lct009-16 & $1.16 \mathrm{E}-01$ & 1.0000 & 0.0021 & 0.9946 & 0.0003 & 0.9946 & 0.0021 \\
\hline 452 & $\operatorname{lct} 009-17$ & $1.15 \mathrm{E}-01$ & 1.0000 & 0.0021 & 0.9953 & 0.0003 & 0.9953 & 0.0021 \\
\hline 453 & lct009-18 & $1.16 \mathrm{E}-01$ & 1.0000 & 0.0021 & 0.9941 & 0.0003 & 0.9941 & 0.0021 \\
\hline 454 & lct009-19 & $1.15 \mathrm{E}-01$ & 1.0000 & 0.0021 & 0.9953 & 0.0002 & 0.9953 & 0.0021 \\
\hline 455 & lct009-20 & $1.16 \mathrm{E}-01$ & 1.0000 & 0.0021 & 0.9948 & 0.0002 & 0.9948 & 0.0021 \\
\hline 456 & $\operatorname{lct009-21}$ & $1.15 \mathrm{E}-01$ & 1.0000 & 0.0021 & 0.9952 & 0.0003 & 0.9952 & 0.0021 \\
\hline 457 & lct009-22 & $1.16 \mathrm{E}-01$ & 1.0000 & 0.0021 & 0.9946 & 0.0003 & 0.9946 & 0.0021 \\
\hline 458 & $1 c t 009-23$ & $1.16 \mathrm{E}-01$ & 1.0000 & 0.0021 & 0.9950 & 0.0003 & 0.9950 & 0.0021 \\
\hline 459 & $\operatorname{lct} 009-24$ & $1.15 \mathrm{E}-01$ & 1.0000 & & 0.9938 & 0.0003 & 0.9938 & 0.0021 \\
\hline 460 & lct009-25 & $1.14 \mathrm{E}-01$ & 1.0000 & 0.0021 & 0.9945 & 0.0003 & 0.9945 & 0.0021 \\
\hline 461 & lct009-26 & $1.14 \mathrm{E}-01$ & 1.0000 & 0.0021 & 0.9947 & 0.0003 & 0.9947 & 0.0021 \\
\hline 462 & $1 c t 009-27$ & $1.14 \mathrm{E}-01$ & 1.0000 & 0.0021 & 0.9950 & 0.0003 & 0.9950 & 0.0021 \\
\hline 463 & $\operatorname{lct} 010-01$ & $1.21 \mathrm{E}-01$ & 1.0000 & 0.0021 & 1.0059 & 0.0003 & 1.0059 & 0.0021 \\
\hline 464 & $\operatorname{lct} 010-02$ & $1.18 \mathrm{E}-01$ & 1.0000 & 0.0021 & 1.0054 & 0.0003 & 1.0054 & 0.0021 \\
\hline 465 & $\operatorname{lct} 010-03$ & $1.16 \mathrm{E}-01$ & 1.0000 & 0.0021 & 1.0034 & 0.0003 & 1.0034 & 0.0021 \\
\hline 466 & lct010-04 & $1.13 \mathrm{E}-01$ & 1.0000 & 0.0021 & 0.9930 & 0.0003 & 0.9930 & 0.0021 \\
\hline 467 & $\operatorname{lct} 010-05$ & $3.85 \mathrm{E}-01$ & 1.0000 & 0.0021 & 0.9955 & 0.0002 & 0.9955 & 0.0021 \\
\hline 468 & lct010-06 & $2.80 \mathrm{E}-01$ & 1.0000 & 0.0021 & 0.9961 & 0.0003 & 0.9961 & 0.0021 \\
\hline 469 & $\operatorname{lct} 010-07$ & $2.20 \mathrm{E}-01$ & 1.0000 & 0.0021 & 0.9979 & 0.0003 & 0.9979 & 0.0021 \\
\hline 470 & lct010-08 & $1.93 \mathrm{E}-01$ & 1.0000 & 0.0021 & 0.9941 & 0.0003 & 0.9941 & 0.0021 \\
\hline 471 & lct010-09 & $1.25 \mathrm{E}-01$ & 1.0000 & 0.0021 & 1.0005 & 0.0002 & 1.0005 & 0.0021 \\
\hline 472 & $\operatorname{lct} 010-10$ & $1.21 \mathrm{E}-01$ & 1.0000 & 0.0021 & 1.0003 & 0.0003 & 1.0003 & 0.0021 \\
\hline 473 & $\operatorname{lct} 010-11$ & $1.18 \mathrm{E}-01$ & 1.0000 & 0.0021 & 0.9998 & 0.0003 & 0.9998 & 0.0021 \\
\hline 474 & $\operatorname{lct} 010-12$ & $1.15 \mathrm{E}-01$ & 1.0000 & 0.0021 & 0.9976 & 0.0003 & 0.9976 & 0.0021 \\
\hline 475 & $\operatorname{lct} 010-13$ & $1.13 \mathrm{E}-01$ & 1.0000 & 0.0021 & 0.9934 & 0.0003 & 0.9934 & 0.0021 \\
\hline 476 & $\operatorname{lct} 010-14$ & $3.22 \mathrm{E}-01$ & 1.0000 & 0.0028 & 0.9965 & 0.0003 & 0.9965 & 0.0028 \\
\hline 477 & $\operatorname{lct} 010-15$ & $3.08 \mathrm{E}-01$ & 1.0000 & 0.0028 & 0.9969 & 0.0003 & 0.9969 & 0.0028 \\
\hline 478 & $\operatorname{lct} 010-16$ & $2.97 \mathrm{E}-01$ & 1.0000 & 0.0028 & 0.9962 & 0.0019 & 0.9962 & 0.0034 \\
\hline 479 & $\operatorname{lct} 010-17$ & $2.91 \mathrm{E}-01$ & 1.0000 & 0.0028 & 0.9964 & 0.0003 & 0.9964 & 0.0028 \\
\hline 480 & $\operatorname{lct} 010-18$ & $2.87 \mathrm{E}-01$ & 1.0000 & 0.0028 & 0.9958 & 0.0003 & 0.9958 & 0.0028 \\
\hline 481 & lct010-19 & $2.80 \mathrm{E}-01$ & 1.0000 & 0.0028 & 0.9940 & 0.0003 & 0.9940 & 0.0028 \\
\hline
\end{tabular}




\begin{tabular}{|c|c|c|c|c|c|c|c|c|}
\hline \multirow{2}{*}{$\begin{array}{l}\text { Exp. } \\
\text { No. }\end{array}$} & \multirow{2}{*}{$\begin{array}{c}\text { IHECSBE } \\
\text { ID }\end{array}$} & \multirow{2}{*}{$\begin{array}{c}\text { EALF } \\
(\mathrm{eV})\end{array}$} & \multicolumn{2}{|c|}{ Expected } & \multicolumn{2}{|c|}{ Calculated } & \multicolumn{2}{|c|}{ Normalized } \\
\hline & & & $k_{e f f}$ & $\sigma_{\text {exp }}$ & $k_{\text {eff }}$ & $\sigma_{k e f f}$ & $k_{\text {eff }}$ & $\sigma_{\text {comb }}$ \\
\hline 482 & $\operatorname{lct} 010-20$ & $3.08 \mathrm{E}-01$ & 1.0000 & 0.0028 & 0.9993 & 0.0003 & 0.9993 & 0.0028 \\
\hline 483 & $\operatorname{lct} 010-21$ & 2.99E-01 & 1.0000 & 0.0028 & 0.9990 & 0.0003 & 0.9990 & 0.0028 \\
\hline 484 & $\operatorname{lct} 010-22$ & $2.86 \mathrm{E}-01$ & 1.0000 & 0.0028 & 0.9972 & 0.0003 & 0.9972 & 0.0028 \\
\hline 485 & $\operatorname{lct} 010-23$ & $2.79 \mathrm{E}-01$ & 1.0000 & 0.0028 & 0.9942 & 0.0002 & 0.9942 & 0.0028 \\
\hline 486 & $\operatorname{lct} 010-24$ & $6.55 \mathrm{E}-01$ & 1.0000 & 0.0028 & 0.9917 & 0.0003 & 0.9917 & 0.0028 \\
\hline 487 & $\operatorname{lct} 010-25$ & $6.04 \mathrm{E}-01$ & 1.0000 & 0.0028 & 0.9930 & 0.0003 & 0.9930 & 0.0028 \\
\hline 488 & $\operatorname{lct} 010-26$ & $5.57 \mathrm{E}-01$ & 1.0000 & 0.0028 & 0.9941 & 0.0003 & 0.9941 & 0.0028 \\
\hline 489 & $\operatorname{lct} 010-27$ & $5.17 \mathrm{E}-01$ & 1.0000 & 0.0028 & 0.9942 & 0.0003 & 0.9942 & 0.0028 \\
\hline 490 & $\operatorname{lct} 010-28$ & 4.84E-01 & 1.0000 & 0.0028 & 0.9947 & 0.0003 & 0.9947 & 0.0028 \\
\hline 491 & $\operatorname{lct} 010-29$ & $2.86 \mathrm{E}-01$ & 1.0000 & 0.0028 & 0.9858 & 0.0003 & 0.9858 & 0.0028 \\
\hline 492 & $\operatorname{lct} 010-30$ & $2.84 \mathrm{E}-01$ & 1.0000 & 0.0028 & 0.9845 & 0.0003 & 0.9845 & 0.0028 \\
\hline 493 & $\operatorname{lct} 012-01$ & $1.74 \mathrm{E}-01$ & 1.0000 & 0.0034 & 0.9810 & 0.0003 & 0.9810 & 0.0034 \\
\hline 494 & $1 c t 012-02$ & $1.81 \mathrm{E}-01$ & 1.0000 & 0.0034 & 0.9816 & 0.0002 & 0.9816 & 0.0034 \\
\hline 495 & $\operatorname{lct} 012-03$ & $1.83 \mathrm{E}-01$ & 1.0000 & 0.0034 & 0.9813 & 0.0003 & 0.9813 & 0.0034 \\
\hline 496 & $\operatorname{lct} 012-04$ & $1.90 \mathrm{E}-01$ & 1.0000 & 0.0034 & 0.9817 & 0.0002 & 0.9817 & 0.0034 \\
\hline 497 & $\operatorname{lct} 012-05$ & $1.89 \mathrm{E}-01$ & 1.0000 & 0.0034 & 0.9805 & 0.0003 & 0.9805 & 0.0034 \\
\hline 498 & lct012-06 & $1.89 \mathrm{E}-01$ & 1.0000 & 0.0034 & 0.9829 & 0.0002 & 0.9829 & 0.0034 \\
\hline 499 & $\operatorname{lct} 012-07$ & $1.90 \mathrm{E}-01$ & 1.0000 & & 0.9834 & 0.0003 & 0.9834 & 0.0034 \\
\hline 500 & $\operatorname{lct} 012-08$ & $1.84 \mathrm{E}-01$ & 1.0000 & 0.0049 & 0.9817 & 0.0003 & 0.9817 & 0.0049 \\
\hline 501 & lct012-09 & $1.71 \mathrm{E}-01$ & 1.0000 & 0.0034 & 0.9803 & 0.0003 & 0.9803 & 0.0034 \\
\hline 502 & $1 \mathrm{ct} 012-10$ & $1.80 \mathrm{E}-01$ & 1.0000 & 0.0034 & 0.9827 & 0.0003 & 0.9827 & 0.0034 \\
\hline 503 & $\operatorname{lct} 017-01$ & $1.00 \mathrm{E}-01$ & 1.0000 & 0.0031 & 0.9992 & 0.0003 & 0.9992 & 0.0031 \\
\hline 504 & $\operatorname{lct} 017-02$ & $9.87 \mathrm{E}-02$ & 1.0000 & 0.0031 & 0.9987 & 0.0002 & 0.9987 & 0.0031 \\
\hline 505 & $\operatorname{lct} 017-03$ & $9.67 \mathrm{E}-02$ & 1.0000 & 0.0031 & 0.9956 & 0.0003 & 0.9956 & 0.0031 \\
\hline 506 & lct017-04 & $2.14 \mathrm{E}-01$ & 1.0000 & 0.0031 & 0.9937 & 0.0003 & 0.9937 & 0.0031 \\
\hline 507 & lct017-05 & $1.88 \mathrm{E}-01$ & 1.0000 & 0.0031 & 0.9952 & 0.0002 & 0.9952 & 0.0031 \\
\hline 508 & lct017-06 & $1.77 \mathrm{E}-01$ & 1.0000 & 0.0031 & 0.9953 & 0.0003 & 0.9953 & 0.0031 \\
\hline 509 & lct017-07 & $1.67 \mathrm{E}-01$ & 1.0000 & 0.0031 & 0.9950 & 0.0002 & 0.9950 & 0.0031 \\
\hline 510 & lct017-08 & $1.38 \mathrm{E}-01$ & 1.0000 & 0.0031 & 0.9935 & 0.0002 & 0.9935 & 0.0031 \\
\hline 511 & lct017-09 & $1.12 \mathrm{E}-01$ & 1.0000 & 0.0031 & 0.9923 & 0.0003 & 0.9923 & 0.0031 \\
\hline 512 & $\operatorname{lct} 017-10$ & $1.02 \mathrm{E}-01$ & 1.0000 & 0.0031 & 0.9954 & 0.0002 & 0.9954 & 0.0031 \\
\hline 513 & $\operatorname{lct} 017-11$ & $1.00 \mathrm{E}-01$ & 1.0000 & 0.0031 & 0.9953 & 0.0003 & 0.9953 & 0.0031 \\
\hline 514 & $\operatorname{lct} 017-12$ & $9.87 \mathrm{E}-02$ & 1.0000 & 0.0031 & 0.9951 & 0.0003 & 0.9951 & 0.0031 \\
\hline 515 & $\operatorname{lct} 017-13$ & $9.72 \mathrm{E}-02$ & 1.0000 & 0.0031 & 0.9945 & 0.0002 & 0.9945 & 0.0031 \\
\hline 516 & $\operatorname{lct} 017-14$ & $9.66 \mathrm{E}-02$ & 1.0000 & 0.0031 & 0.9946 & 0.0003 & 0.9946 & 0.0031 \\
\hline 517 & $\operatorname{lct} 017-15$ & $1.84 \mathrm{E}-01$ & 1.0000 & 0.0028 & 0.9925 & 0.0003 & 0.9925 & 0.0028 \\
\hline 518 & $\operatorname{lct} 017-16$ & $1.77 \mathrm{E}-01$ & 1.0000 & 0.0028 & 0.9940 & 0.0003 & 0.9940 & 0.0028 \\
\hline 519 & $\operatorname{lct} 017-17$ & $1.72 \mathrm{E}-01$ & 1.0000 & 0.0028 & 0.9945 & 0.0003 & 0.9945 & 0.0028 \\
\hline 520 & $\operatorname{lct} 017-18$ & $1.71 \mathrm{E}-01$ & 1.0000 & 0.0028 & 0.9927 & 0.0003 & 0.9927 & 0.0028 \\
\hline 521 & lct017-19 & $1.68 \mathrm{E}-01$ & 1.0000 & 0.0028 & 0.9929 & 0.0003 & 0.9929 & 0.0028 \\
\hline
\end{tabular}




\begin{tabular}{|c|c|c|c|c|c|c|c|c|}
\hline \multirow{2}{*}{$\begin{array}{l}\text { Exp. } \\
\text { No. }\end{array}$} & \multirow{2}{*}{$\begin{array}{c}\text { IHECSBE } \\
\text { ID }\end{array}$} & \multirow{2}{*}{$\begin{array}{c}\text { EALF } \\
(\mathrm{eV})\end{array}$} & \multicolumn{2}{|c|}{ Expected } & \multicolumn{2}{|c|}{ Calculated } & \multicolumn{2}{|c|}{ Normalized } \\
\hline & & & $k_{\text {eff }}$ & $\sigma_{\text {exp }}$ & $k_{\text {eff }}$ & $\sigma_{k e f f}$ & $k_{\text {eff }}$ & $\sigma_{\mathrm{comb}}$ \\
\hline 522 & $\operatorname{lct} 017-20$ & $1.66 \mathrm{E}-01$ & 1.0000 & 0.0028 & 0.9910 & 0.0002 & 0.9910 & 0.0028 \\
\hline 523 & lct017-21 & $1.65 \mathrm{E}-01$ & 1.0000 & 0.0028 & 0.9912 & 0.0003 & 0.9912 & 0.0028 \\
\hline 524 & lct017-22 & $1.64 \mathrm{E}-01$ & 1.0000 & 0.0028 & 0.9901 & 0.0002 & 0.9901 & 0.0028 \\
\hline 525 & $\operatorname{lct} 017-23$ & $1.76 \mathrm{E}-01$ & 1.0000 & 0.0028 & 0.9952 & 0.0003 & 0.9952 & 0.0028 \\
\hline 526 & $\operatorname{lct} 017-24$ & $1.71 \mathrm{E}-01$ & 1.0000 & 0.0028 & 0.9958 & 0.0003 & 0.9958 & 0.0028 \\
\hline 527 & lct017-25 & $1.63 \mathrm{E}-01$ & 1.0000 & 0.0028 & 0.9917 & 0.0003 & 0.9917 & 0.0028 \\
\hline 528 & $\operatorname{lct} 017-26$ & $4.08 \mathrm{E}-01$ & 1.0000 & 0.0028 & 0.9883 & 0.0002 & 0.9883 & 0.0028 \\
\hline 529 & $\operatorname{lct} 017-27$ & $3.47 \mathrm{E}-01$ & 1.0000 & 0.0028 & 0.9900 & 0.0003 & 0.9900 & 0.0028 \\
\hline 530 & lct017-28 & $3.01 \mathrm{E}-01$ & 1.0000 & 0.0028 & 0.9913 & 0.0002 & 0.9913 & 0.0028 \\
\hline 531 & lct017-29 & $2.67 \mathrm{E}-01$ & 1.0000 & 0.0028 & 0.9916 & 0.0003 & 0.9916 & 0.0028 \\
\hline 532 & lct18c1 & $2.03 \mathrm{E}-01$ & 1.0000 & 0.0020 & 0.9972 & 0.0003 & 0.9972 & 0.0020 \\
\hline 533 & lct19c1 & $3.34 \mathrm{E}-01$ & 1.0000 & 0.0063 & 1.0066 & 0.0003 & 1.0066 & 0.0063 \\
\hline 534 & $1 \mathrm{ct} 19 \mathrm{c} 2$ & $1.65 \mathrm{E}-01$ & 1.0000 & 0.0058 & 1.0025 & 0.0003 & 1.0025 & 0.0058 \\
\hline 535 & lct19c3 & $5.45 \mathrm{E}-02$ & 1.0000 & 0.0061 & 1.0040 & 0.0002 & 1.0040 & 0.0061 \\
\hline 536 & lct20c1 & 7.99E-02 & 1.0000 & 0.0061 & 0.9935 & 0.0003 & 0.9935 & 0.0061 \\
\hline 537 & $1 \mathrm{ct} 20 \mathrm{c} 2$ & $6.92 \mathrm{E}-02$ & 1.0000 & 0.0061 & 0.9988 & 0.0003 & 0.9988 & 0.0061 \\
\hline 538 & lct20c3 & $6.72 \mathrm{E}-02$ & 1.0000 & 0.0061 & 1.0012 & 0.0003 & 1.0012 & 0.0061 \\
\hline 539 & $1 \mathrm{ct} 20 \mathrm{c} 4$ & $6.63 \mathrm{E}-02$ & 1.0000 & 0.0061 & 1.0007 & 0.0002 & 1.0007 & 0.0061 \\
\hline 540 & lct20c5 & $6.52 \mathrm{E}-02$ & 1.0000 & 0.0061 & 1.0017 & 0.0002 & 1.0017 & 0.0061 \\
\hline 541 & lct20c6 & $6.45 \mathrm{E}-02$ & 1.0000 & 0.0061 & 1.0025 & 0.0003 & 1.0025 & 0.0061 \\
\hline 542 & lct20c7 & $6.25 \mathrm{E}-02$ & 1.0000 & 0.0061 & 1.0016 & 0.0003 & 1.0016 & 0.0061 \\
\hline 543 & $\operatorname{lct} 21 \mathrm{c} 1$ & $1.34 \mathrm{E}-01$ & 1.0000 & 0.0072 & 1.0075 & 0.0003 & 1.0075 & 0.0072 \\
\hline 544 & $\operatorname{lct} 21 \mathrm{c} 2$ & $1.31 \mathrm{E}-01$ & 1.0000 & 0.0072 & 1.0076 & 0.0003 & 1.0076 & 0.0072 \\
\hline 545 & lct $21 \mathrm{c} 3$ & $1.28 \mathrm{E}-01$ & 1.0000 & 0.0072 & 1.0076 & 0.0003 & 1.0076 & 0.0072 \\
\hline 546 & $\operatorname{lct} 21 \mathrm{c} 4$ & $7.55 \mathrm{E}-02$ & 1.0000 & 0.0050 & 1.0103 & 0.0002 & 1.0103 & 0.0050 \\
\hline 547 & $\operatorname{lct} 21 \mathrm{c} 5$ & 7.44E-02 & 1.0000 & 0.0050 & 1.0106 & 0.0002 & 1.0106 & 0.0050 \\
\hline 548 & $\operatorname{lct} 22 \mathrm{c} 1$ & $7.11 \mathrm{E}-01$ & 1.0000 & 0.0046 & 0.9942 & 0.0003 & 0.9942 & 0.0046 \\
\hline 549 & lct21c6 & $7.25 \mathrm{E}-02$ & 1.0000 & 0.0050 & 1.0102 & 0.0002 & 1.0102 & 0.0050 \\
\hline 550 & $1 \mathrm{ct} 22 \mathrm{c} 2$ & $2.97 \mathrm{E}-01$ & 1.0000 & 0.0046 & 0.9998 & 0.0003 & 0.9998 & 0.0046 \\
\hline 551 & lct22c3 & $1.28 \mathrm{E}-01$ & 1.0000 & 0.0036 & 1.0019 & 0.0003 & 1.0019 & 0.0036 \\
\hline 552 & $\operatorname{lct} 22 \mathrm{c} 4$ & 8.44E-02 & 1.0000 & 0.0037 & 1.0045 & 0.0003 & 1.0045 & 0.0037 \\
\hline 553 & $\operatorname{lct} 22 \mathrm{c} 5$ & $6.98 \mathrm{E}-02$ & 1.0000 & 0.0038 & 1.0009 & 0.0003 & 1.0009 & 0.0038 \\
\hline 554 & lct $22 \mathrm{c} 6$ & $5.50 \mathrm{E}-02$ & 1.0000 & 0.0046 & 1.0004 & 0.0002 & 1.0004 & 0.0046 \\
\hline 555 & $\operatorname{lct} 22 \mathrm{c} 7$ & $5.46 \mathrm{E}-02$ & 1.0000 & 0.0046 & 1.0029 & 0.0003 & 1.0029 & 0.0046 \\
\hline 556 & $\operatorname{lct} 23 \mathrm{c} 1$ & 8.30E-02 & 1.0000 & 0.0044 & 1.0020 & 0.0001 & 1.0020 & 0.0044 \\
\hline 557 & $1 c t 23 c 2$ & 7.73E-02 & 1.0000 & 0.0044 & 1.0014 & 0.0001 & 1.0014 & 0.0044 \\
\hline 558 & $\operatorname{lct} 23 \mathrm{c} 3$ & $7.55 \mathrm{E}-02$ & 1.0000 & 0.0044 & 1.0014 & 0.0001 & 1.0014 & 0.0044 \\
\hline 559 & $\operatorname{lct} 23 \mathrm{c} 4$ & $7.38 \mathrm{E}-02$ & 1.0000 & 0.0044 & 1.0021 & 0.0001 & 1.0021 & 0.0044 \\
\hline 560 & lct $23 \mathrm{c} 5$ & 7.23E-02 & 1.0000 & 0.0044 & 1.0013 & 0.0001 & 1.0013 & 0.0044 \\
\hline 561 & lct $23 \mathrm{c} 6$ & 7.09E-02 & 1.0000 & 0.0044 & 1.0006 & 0.0001 & 1.0006 & 0.0044 \\
\hline
\end{tabular}




\begin{tabular}{|c|c|c|c|c|c|c|c|c|}
\hline \multirow{2}{*}{$\begin{array}{l}\text { Exp. } \\
\text { No. }\end{array}$} & \multirow{2}{*}{$\begin{array}{c}\text { IHECSBE } \\
\text { ID }\end{array}$} & \multirow{2}{*}{$\begin{array}{c}\text { EALF } \\
(\mathrm{eV})\end{array}$} & \multicolumn{2}{|c|}{ Expected } & \multicolumn{2}{|c|}{ Calculated } & \multicolumn{2}{|c|}{ Normalized } \\
\hline & & & $k_{\text {eff }}$ & $\sigma_{\text {exp }}$ & $k_{e f f}$ & $\sigma_{k e f f}$ & $k_{\text {eff }}$ & $\sigma_{\text {comb }}$ \\
\hline 562 & $\operatorname{lct} 24 \mathrm{c} 1$ & $1.07 \mathrm{E}+00$ & 1.0000 & 0.0054 & 0.9926 & 0.0003 & 0.9926 & 0.0054 \\
\hline 563 & $1 c t 24 c 2$ & $1.46 \mathrm{E}-01$ & 1.0000 & 0.0040 & 1.0028 & 0.0003 & 1.0028 & 0.0040 \\
\hline 564 & $1 \mathrm{ct} 25 \mathrm{c} 1$ & 4.49E-01 & 1.0000 & 0.0041 & 0.9791 & 0.0003 & 0.9791 & 0.0041 \\
\hline 565 & $1 \mathrm{ct} 25 \mathrm{c} 2$ & $2.07 \mathrm{E}-01$ & 1.0000 & 0.0044 & 0.9869 & 0.0003 & 0.9869 & 0.0044 \\
\hline 566 & $1 \mathrm{ct} 25 \mathrm{c} 3$ & $1.00 \mathrm{E}-01$ & 1.0000 & 0.0047 & 0.9943 & 0.0003 & 0.9943 & 0.0047 \\
\hline 567 & $1 c t 25 c 4$ & 7.04E-02 & 1.0000 & 0.0052 & 0.9978 & 0.0003 & 0.9978 & 0.0052 \\
\hline 568 & $1 \mathrm{ct} 26 \mathrm{c} 1$ & $2.48 \mathrm{E}-01$ & 1.0000 & 0.0034 & 0.9970 & 0.0003 & 0.9970 & 0.0034 \\
\hline 569 & $1 \mathrm{ct} 26 \mathrm{c} 2$ & $4.20 \mathrm{E}-01$ & 0.9996 & 0.0034 & 0.9957 & 0.0003 & 0.9961 & 0.0034 \\
\hline 570 & $1 \mathrm{ct} 26 \mathrm{c} 3$ & $1.04 \mathrm{E}+00$ & 1.0018 & 0.0062 & 0.9993 & 0.0003 & 0.9975 & 0.0062 \\
\hline 571 & $1 c t 26 c 4$ & $1.64 \mathrm{E}+00$ & 0.9978 & 0.0062 & 0.9962 & 0.0003 & 0.9983 & 0.0062 \\
\hline 572 & lct32a1 & 7.11E-01 & 1.0000 & 0.0045 & 0.9980 & 0.0003 & 0.9980 & 0.0045 \\
\hline 573 & $1 c t 32 a 2$ & $9.40 \mathrm{E}-01$ & 1.0000 & 0.0041 & 0.9974 & 0.0003 & 0.9974 & 0.0041 \\
\hline 574 & $1 c t 32 \mathrm{a} 3$ & $1.36 \mathrm{E}+00$ & 1.0000 & 0.0042 & 0.9969 & 0.0003 & 0.9969 & 0.0042 \\
\hline 575 & $1 c t 32 \mathrm{a} 4$ & $6.98 \mathrm{E}-02$ & 1.0000 & 0.0037 & 1.0061 & 0.0003 & 1.0061 & 0.0037 \\
\hline 576 & lct32a5 & $1.04 \mathrm{E}-01$ & 1.0000 & 0.0032 & 1.0015 & 0.0003 & 1.0015 & 0.0032 \\
\hline 577 & $1 c t 32 a 6$ & $1.23 \mathrm{E}-01$ & 1.0000 & 0.0033 & 1.0012 & 0.0003 & 1.0012 & 0.0033 \\
\hline 578 & $1 c t 32 \mathrm{a} 7$ & $5.46 \mathrm{E}-02$ & 1.0000 & 0.0045 & 1.0077 & 0.0002 & 1.0077 & 0.0045 \\
\hline 579 & lct32a8 & 7.91E-02 & 1.0000 & 0.0038 & 1.0089 & 0.0002 & 1.0089 & 0.0038 \\
\hline 580 & $1 c t 32 a 9$ & $9.18 \mathrm{E}-02$ & 1.0000 & 0.0037 & 1.0087 & 0.0003 & 1.0087 & 0.0037 \\
\hline 581 & $1 \operatorname{ct} 040-01$ & $1.50 \mathrm{E}-01$ & 1.0000 & 0.0039 & 0.9954 & 0.0003 & 0.9954 & 0.0039 \\
\hline 582 & $1 c t 040-02$ & $1.72 \mathrm{E}-01$ & 1.0000 & 0.0041 & 0.9933 & 0.0003 & 0.9933 & 0.0041 \\
\hline 583 & $1 \mathrm{ct} 040-03$ & $1.62 \mathrm{E}-01$ & 1.0000 & 0.0041 & 0.9921 & 0.0003 & 0.9921 & 0.0041 \\
\hline 584 & $1 \operatorname{ct} 042-01$ & $1.75 \mathrm{E}-01$ & 1.0000 & 0.0016 & 0.9926 & 0.0002 & 0.9926 & 0.0016 \\
\hline 585 & $1 c t 042-02$ & $1.82 \mathrm{E}-01$ & 1.0000 & 0.0016 & 0.9924 & 0.0003 & 0.9924 & 0.0016 \\
\hline 586 & $1 c t 042-03$ & $1.89 \mathrm{E}-01$ & 1.0000 & 0.0016 & 0.9940 & 0.0002 & 0.9940 & 0.0016 \\
\hline 587 & lct042-04 & $1.87 \mathrm{E}-01$ & 1.0000 & 0.0017 & 0.9939 & 0.0002 & 0.9939 & 0.0017 \\
\hline 588 & $1 c t 042-05$ & $1.84 \mathrm{E}-01$ & 1.0000 & 0.0033 & 0.9938 & 0.0003 & 0.9938 & 0.0033 \\
\hline 589 & lct042-06 & $1.75 \mathrm{E}-01$ & 1.0000 & 0.0016 & 0.9933 & 0.0002 & 0.9933 & 0.0016 \\
\hline 590 & $1 c t 042-07$ & $1.79 \mathrm{E}-01$ & 1.0000 & 0.0018 & 0.9922 & 0.0002 & 0.9922 & 0.0018 \\
\hline 591 & lct079-1 & $3.11 \mathrm{E}-01$ & 0.9999 & 0.0016 & 0.9915 & 0.0005 & 0.9916 & 0.0017 \\
\hline 592 & lct079-2 & $3.13 \mathrm{E}-01$ & 1.0002 & 0.0016 & 0.9911 & 0.0005 & 0.9909 & 0.0017 \\
\hline 593 & lct079-3 & $3.17 \mathrm{E}-01$ & 1.0005 & 0.0016 & 0.9917 & 0.0005 & 0.9912 & 0.0017 \\
\hline 594 & 1ct079-4 & $3.20 \mathrm{E}-01$ & 1.0004 & 0.0016 & 0.9912 & 0.0005 & 0.9908 & 0.0017 \\
\hline 595 & lct079-5 & $3.26 \mathrm{E}-01$ & 1.0004 & 0.0016 & 0.9925 & 0.0005 & 0.9921 & 0.0017 \\
\hline 596 & lct079-6 & $1.10 \mathrm{E}-01$ & 0.9994 & 0.0008 & 0.9956 & 0.0005 & 0.9962 & 0.0009 \\
\hline 597 & lct079-7 & $1.11 \mathrm{E}-01$ & 1.0003 & 0.0008 & 0.9959 & 0.0005 & 0.9956 & 0.0009 \\
\hline 598 & $1 c t 079-8$ & $1.11 \mathrm{E}-01$ & 1.0008 & 0.0008 & 0.9970 & 0.0005 & 0.9962 & 0.0009 \\
\hline 599 & lct079-9 & $1.12 \mathrm{E}-01$ & 1.0003 & 0.0008 & 0.9950 & 0.0005 & 0.9947 & 0.0009 \\
\hline 600 & $1 \mathrm{ct} 079-10$ & $1.13 \mathrm{E}-01$ & 1.0009 & 0.0008 & 0.9961 & 0.0005 & 0.9952 & 0.0009 \\
\hline 601 & $1 \mathrm{st} 01 \mathrm{c} 1$ & $6.43 \mathrm{E}-02$ & 0.9991 & 0.0029 & 1.0026 & 0.0003 & 1.0035 & 0.0029 \\
\hline
\end{tabular}




\begin{tabular}{|c|c|c|c|c|c|c|c|c|}
\hline \multirow{2}{*}{$\begin{array}{l}\text { Exp. } \\
\text { No. }\end{array}$} & \multirow{2}{*}{$\begin{array}{c}\text { IHECSBE } \\
\text { ID }\end{array}$} & \multirow{2}{*}{$\begin{array}{c}\text { EALF } \\
(\mathrm{eV})\end{array}$} & \multicolumn{2}{|c|}{ Expected } & \multicolumn{2}{|c|}{ Calculated } & \multicolumn{2}{|c|}{ Normalized } \\
\hline & & & $k_{\text {eff }}$ & $\sigma_{\text {exp }}$ & $k_{\text {eff }}$ & $\sigma_{k e f f}$ & $k_{\text {eff }}$ & $\sigma_{\mathrm{comb}}$ \\
\hline 602 & lst03c1 & 4.10E-02 & 0.9997 & 0.0039 & 0.9970 & 0.0002 & 0.9973 & 0.0039 \\
\hline 603 & $1 \mathrm{st} 03 \mathrm{c} 2$ & $3.91 \mathrm{E}-02$ & 0.9993 & 0.0042 & 0.9964 & 0.0003 & 0.9971 & 0.0042 \\
\hline 604 & $1 \mathrm{st} 03 \mathrm{c} 3$ & $3.88 \mathrm{E}-02$ & 0.9995 & 0.0042 & 1.0005 & 0.0002 & 1.0010 & 0.0042 \\
\hline 605 & $1 \mathrm{st} 03 \mathrm{c} 4$ & $3.86 \mathrm{E}-02$ & 0.9995 & 0.0042 & 0.9942 & 0.0003 & 0.9946 & 0.0042 \\
\hline 606 & $1 \mathrm{st} 03 \mathrm{c} 5$ & $3.59 \mathrm{E}-02$ & 0.9997 & 0.0048 & 1.0076 & 0.0002 & 1.0079 & 0.0048 \\
\hline 607 & 1 st $03 \mathrm{c} 6$ & $3.56 \mathrm{E}-02$ & 0.9999 & 0.0049 & 0.9980 & 0.0003 & 0.9981 & 0.0049 \\
\hline 608 & $1 \mathrm{st} 03 \mathrm{c} 7$ & $3.54 \mathrm{E}-02$ & 0.9994 & 0.0049 & 0.9965 & 0.0002 & 0.9970 & 0.0049 \\
\hline 609 & $1 \mathrm{st} 03 \mathrm{c} 8$ & $3.44 \mathrm{E}-02$ & 0.9993 & 0.0052 & 1.0002 & 0.0002 & 1.0009 & 0.0052 \\
\hline 610 & 1 st $03 \mathrm{c} 9$ & $3.43 \mathrm{E}-02$ & 0.9996 & 0.0052 & 0.9968 & 0.0002 & 0.9972 & 0.0052 \\
\hline 611 & 1st04-R1 & $4.16 \mathrm{E}-02$ & 0.9994 & 0.0008 & 0.9943 & 0.0002 & 0.9949 & 0.0008 \\
\hline 612 & 1st04-R29 & $4.06 \mathrm{E}-02$ & 0.9999 & 0.0009 & 0.9954 & 0.0003 & 0.9954 & 0.0009 \\
\hline 613 & lst04-R33 & $3.93 \mathrm{E}-02$ & 0.9999 & 0.0009 & 0.9944 & 0.0002 & 0.9945 & 0.0009 \\
\hline 614 & 1st04-R34 & $3.86 \mathrm{E}-02$ & 0.9999 & 0.0010 & 0.9961 & 0.0002 & 0.9961 & 0.0010 \\
\hline 615 & 1st04-R46 & $3.80 \mathrm{E}-02$ & 0.9999 & 0.0010 & 0.9966 & 0.0002 & 0.9967 & 0.0010 \\
\hline 616 & 1st04-R51 & $3.74 \mathrm{E}-02$ & 0.9994 & 0.0011 & 1.0043 & 0.0002 & 1.0049 & 0.0011 \\
\hline 617 & 1st04-R54 & $3.71 \mathrm{E}-02$ & 0.9996 & 0.0011 & 0.9960 & 0.0002 & 0.9964 & 0.0011 \\
\hline 618 & $1 \mathrm{st} 05 \mathrm{c} 1$ & $4.07 \mathrm{E}-02$ & 1.0000 & 0.0042 & 0.9980 & 0.0002 & 0.9980 & 0.0042 \\
\hline 619 & $1 \mathrm{st} 05 \mathrm{c} 2$ & $4.07 \mathrm{E}-02$ & 1.0000 & 0.0051 & 0.9984 & 0.0003 & 0.9984 & 0.0051 \\
\hline 620 & $1 \mathrm{st} 05 \mathrm{c} 3$ & $4.09 \mathrm{E}-02$ & 1.0000 & 0.0064 & 0.9986 & 0.0003 & 0.9986 & 0.0064 \\
\hline 621 & lst06c1 & $4.80 \mathrm{E}-02$ & 1.0000 & 0.0037 & 0.9990 & 0.0003 & 0.9990 & 0.0037 \\
\hline 622 & 1st06c2 & $4.82 \mathrm{E}-02$ & 1.0000 & 0.0038 & 1.0061 & 0.0003 & 1.0061 & 0.0038 \\
\hline 623 & lst06c3 & $4.86 \mathrm{E}-02$ & 1.0000 & 0.0041 & 0.9992 & 0.0003 & 0.9992 & 0.0041 \\
\hline 624 & 1st06c4 & $4.87 \mathrm{E}-02$ & 1.0000 & 0.0041 & 1.0000 & 0.0003 & 1.0000 & 0.0041 \\
\hline 625 & lst06c5 & 4.92E-02 & 1.0000 & 0.0047 & 1.0025 & 0.0004 & 1.0025 & 0.0047 \\
\hline 626 & 1st07-R14 & 4.23E-02 & 0.9961 & 0.0009 & 0.9963 & 0.0002 & 1.0002 & 0.0009 \\
\hline 627 & 1st07-R30 & 4.10E-02 & 0.9973 & 0.0009 & 0.9980 & 0.0002 & 1.0007 & 0.0009 \\
\hline 628 & 1st07-R32 & $3.97 \mathrm{E}-02$ & 0.9985 & 0.0010 & 0.9971 & 0.0002 & 0.9986 & 0.0010 \\
\hline 629 & 1st07-R36 & $3.89 \mathrm{E}-02$ & 0.9988 & 0.0011 & 0.9998 & 0.0002 & 1.0010 & 0.0011 \\
\hline 630 & 1st07-R49 & $3.83 \mathrm{E}-02$ & 0.9983 & 0.0011 & 0.9987 & 0.0002 & 1.0004 & 0.0011 \\
\hline 631 & 1st08-R72 & $3.79 \mathrm{E}-02$ & 0.9999 & 0.0014 & 1.0037 & 0.0002 & 1.0038 & 0.0014 \\
\hline 632 & 1st08-R74 & $3.80 \mathrm{E}-02$ & 1.0002 & 0.0015 & 1.0003 & 0.0002 & 1.0001 & 0.0015 \\
\hline 633 & lst08-R76 & $3.80 \mathrm{E}-02$ & 0.9999 & 0.0014 & 1.0026 & 0.0003 & 1.0027 & 0.0014 \\
\hline 634 & 1st08-R78 & $3.80 \mathrm{E}-02$ & 0.9999 & 0.0014 & 1.0034 & 0.0002 & 1.0035 & 0.0014 \\
\hline 635 & lst09-R92 & $3.85 \mathrm{E}-02$ & 0.9998 & 0.0014 & 0.9969 & 0.0002 & 0.9971 & 0.0014 \\
\hline 636 & 1st09-R93 & $3.85 \mathrm{E}-02$ & 0.9999 & 0.0014 & 0.9997 & 0.0002 & 0.9998 & 0.0014 \\
\hline 637 & 1st09-R94 & $3.85 \mathrm{E}-02$ & 0.9999 & 0.0014 & 1.0018 & 0.0002 & 1.0019 & 0.0014 \\
\hline 638 & lst10-R83 & $3.80 \mathrm{E}-02$ & 0.9999 & 0.0015 & 1.0017 & 0.0002 & 1.0018 & 0.0015 \\
\hline 639 & lst10-R85 & $3.80 \mathrm{E}-02$ & 0.9999 & 0.0014 & 1.0016 & 0.0003 & 1.0017 & 0.0014 \\
\hline 640 & lst10-R86 & $3.80 \mathrm{E}-02$ & 1.0000 & 0.0014 & 1.0020 & 0.0002 & 1.0020 & 0.0014 \\
\hline 641 & lst10-R88 & $3.80 \mathrm{E}-02$ & 1.0001 & 0.0014 & 1.0021 & 0.0003 & 1.0020 & 0.0014 \\
\hline
\end{tabular}




\begin{tabular}{|c|c|c|c|c|c|c|c|c|}
\hline \multirow{2}{*}{$\begin{array}{l}\text { Exp. } \\
\text { No. }\end{array}$} & \multirow{2}{*}{$\begin{array}{c}\text { IHECSBE } \\
\text { ID }\end{array}$} & \multirow{2}{*}{$\begin{array}{c}\text { EALF } \\
(\mathrm{eV})\end{array}$} & \multicolumn{2}{|c|}{ Expected } & \multicolumn{2}{|c|}{ Calculated } & \multicolumn{2}{|c|}{ Normalized } \\
\hline & & & $k_{\text {eff }}$ & $\sigma_{\text {exp }}$ & $k_{\text {eff }}$ & $\sigma_{\text {keff }}$ & $k_{\text {eff }}$ & $\sigma_{\text {comb }}$ \\
\hline 642 & 1st16-105 & $5.14 \mathrm{E}-02$ & 0.9996 & 0.0013 & 1.0064 & 0.0004 & 1.0068 & 0.0014 \\
\hline 643 & lst16-R113 & 4.90E-02 & 0.9999 & 0.0013 & 1.0068 & 0.0004 & 1.0069 & 0.0014 \\
\hline 644 & 1st16-R125 & 4.52E-02 & 0.9994 & 0.0014 & 1.0053 & 0.0004 & 1.0059 & 0.0015 \\
\hline 645 & 1st16-R129 & 4.39E-02 & 0.9996 & 0.0014 & 1.0103 & 0.0004 & 1.0107 & 0.0015 \\
\hline 646 & 1st16-R131 & 4.26E-02 & 0.9995 & 0.0014 & 1.0040 & 0.0003 & 1.0045 & 0.0014 \\
\hline 647 & 1st16-R140 & 4.17E-02 & 0.9992 & 0.0015 & 1.0030 & 0.0004 & 1.0038 & 0.0015 \\
\hline 648 & 1st16-R196 & $4.11 \mathrm{E}-02$ & 0.9994 & 0.0015 & 1.0042 & 0.0003 & 1.0048 & 0.0015 \\
\hline 649 & 1st17-R104 & $5.16 \mathrm{E}-02$ & 0.9981 & 0.0013 & 1.0094 & 0.0003 & 1.0113 & 0.0013 \\
\hline 650 & 1st17-R122 & 4.93E-02 & 0.9986 & 0.0013 & 1.0042 & 0.0003 & 1.0056 & 0.0013 \\
\hline 651 & 1st17-R123 & 4.52E-02 & 0.9989 & 0.0014 & 1.0027 & 0.0003 & 1.0038 & 0.0014 \\
\hline 652 & 1st17-R126 & $4.40 \mathrm{E}-02$ & 0.9992 & 0.0014 & 1.0031 & 0.0003 & 1.0039 & 0.0014 \\
\hline 653 & 1st17-R130 & 4.27E-02 & 0.9987 & 0.0015 & 1.0027 & 0.0003 & 1.0040 & 0.0015 \\
\hline 654 & 1st17-R147 & 4.20E-02 & 0.9996 & 0.0015 & 1.0023 & 0.0003 & 1.0027 & 0.0015 \\
\hline 655 & $1 \mathrm{st} 18 \mathrm{c} 1$ & $4.16 \mathrm{E}-02$ & 0.9992 & 0.0010 & 1.0025 & 0.0003 & 1.0033 & 0.0010 \\
\hline 656 & $1 \mathrm{st} 18 \mathrm{c} 3$ & 4.19E-02 & 0.9996 & 0.0010 & 1.0028 & 0.0003 & 1.0032 & 0.0010 \\
\hline 657 & $1 \mathrm{st} 18 \mathrm{c} 4$ & $4.20 \mathrm{E}-02$ & 0.9997 & 0.0010 & 0.9920 & 0.0002 & 0.9922 & 0.0010 \\
\hline 658 & $1 \mathrm{st} 18 \mathrm{c} 5$ & $4.20 \mathrm{E}-02$ & 0.9992 & 0.0010 & 1.0024 & 0.0003 & 1.0032 & 0.0010 \\
\hline 659 & $1 \mathrm{st} 18 \mathrm{c} 6$ & 4.20E-02 & 0.9996 & 0.0010 & 1.0023 & 0.0002 & 1.0027 & 0.0010 \\
\hline 660 & lst19c1 & $4.21 \mathrm{E}-02$ & 0.9994 & 0.0009 & 1.0022 & 0.0003 & 1.0028 & 0.0009 \\
\hline 661 & 1st19c2 & $4.20 \mathrm{E}-02$ & 0.9997 & 0.0009 & 1.0039 & 0.0002 & 1.0042 & 0.0009 \\
\hline 662 & 1st19c3 & $4.20 \mathrm{E}-02$ & 0.9995 & 0.0009 & 1.0037 & 0.0002 & 1.0042 & 0.0009 \\
\hline 663 & 1st19c4 & $4.21 \mathrm{E}-02$ & 0.9999 & 0.0009 & 1.0042 & 0.0003 & 1.0043 & 0.0009 \\
\hline 664 & 1st19c5 & 4.21E-02 & 0.9996 & 0.0009 & 1.0041 & 0.0003 & 1.0045 & 0.0009 \\
\hline 665 & $1 \mathrm{st} 19 \mathrm{c} 6$ & $4.21 \mathrm{E}-02$ & 0.9998 & 0.0009 & 1.0046 & 0.0003 & 1.0048 & 0.0009 \\
\hline 666 & 1st20c1 & $3.78 \mathrm{E}-02$ & 0.9995 & 0.0010 & 1.0003 & 0.0002 & 1.0008 & 0.0010 \\
\hline 667 & $1 s t 20 \mathrm{c} 2$ & $3.69 \mathrm{E}-02$ & 0.9996 & 0.0010 & 0.9991 & 0.0003 & 0.9995 & 0.0010 \\
\hline 668 & 1st20c3 & $3.59 \mathrm{E}-02$ & 0.9997 & 0.0012 & 0.9988 & 0.0002 & 0.9991 & 0.0012 \\
\hline 669 & 1st20c4 & $3.54 \mathrm{E}-02$ & 0.9998 & 0.0012 & 0.9994 & 0.0002 & 0.9996 & 0.0012 \\
\hline 670 & $1 \mathrm{st} 21 \mathrm{c} 1$ & $3.80 \mathrm{E}-02$ & 0.9983 & 0.0009 & 0.9983 & 0.0002 & 1.0000 & 0.0009 \\
\hline 671 & $1 \mathrm{st} 21 \mathrm{c} 2$ & $3.71 \mathrm{E}-02$ & 0.9985 & 0.0010 & 0.9985 & 0.0002 & 1.0000 & 0.0010 \\
\hline 672 & lst21c3 & $3.60 \mathrm{E}-02$ & 0.9989 & 0.0011 & 0.9974 & 0.0002 & 0.9985 & 0.0011 \\
\hline 673 & $1 \mathrm{st} 21 \mathrm{c} 4$ & $3.55 \mathrm{E}-02$ & 0.9993 & 0.0012 & 0.9994 & 0.0002 & 1.0001 & 0.0012 \\
\hline
\end{tabular}

* Where the calculation $\sigma_{\text {keff }}$ is omitted, the case is a 1-dimensional discrete ordinance calculation that used a $k_{\text {eff }}$ convergence criterion of $10^{-6}$. 



\section{APPENDIX C}

INPUT FILE FOR TSUNAMI-IP CALCULATION FOR APPLICATION 1 



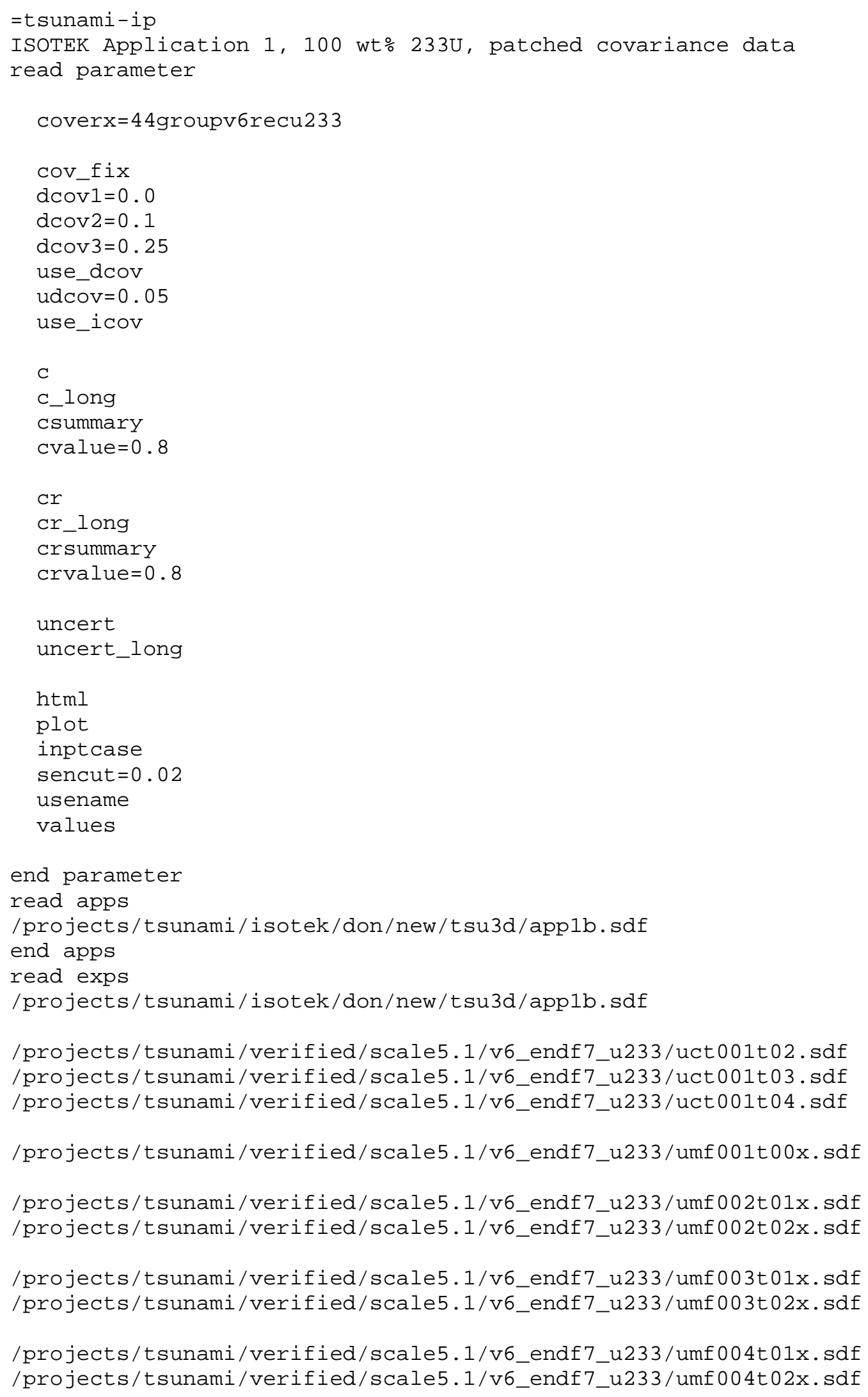


/projects/tsunami/verified/scale5.1/v6_endf7_u233/umf005t01x.sdf /projects/tsunami/verified/scale5.1/v6_endf7_u233/umf005t02x.sdf

/projects/tsunami/verified/scale5.1/v6_endf7_u233/umfo06t@ox.sdf

/projects/tsunami/verified/scale5.1/v6_endf7_u233/usi001t01x.sdf /projects/tsunami/verified/scale5.1/v6_endf7_u233/usi001t02x.sdf /projects/tsunami/verified/scale5.1/v6_endf7_u233/usi001t03x.sdf /projects/tsunami/verified/scale5.1/v6_endf7_u233/usi001to4x.sdf /projects/tsunami/verified/scale5.1/v6_endf7_u233/usi001t05x.sdf /projects/tsunami/verified/scale5.1/v6_endf7_u233/usi001t06x.sdf /projects/tsunami/verified/scale5.1/v6_endf7_u233/usi001t07x.sdf /projects/tsunami/verified/scale5.1/v6_endf7_u233/usi001t08x.sdf /projects/tsunami/verified/scale5.1/v6_endf7_u233/usi001to9x.sdf /projects/tsunami/verified/scale5.1/v6_endf7_u233/usio01t10x.sdf /projects/tsunami/verified/scale5.1/v6_endf7_u233/usi001t11x.sdf /projects/tsunami/verified/scale5.1/v6_endf7_u233/usi001t12x.sdf /projects/tsunami/verified/scale5.1/v6_endf7_u233/usi001t13x.sdf /projects/tsunami/verified/scale5.1/v6_endf7_u233/usi001t14x.sdf /projects/tsunami/verified/scale5.1/v6_endf7_u233/usio01t15x.sdf /projects/tsunami/verified/scale5.1/v6_endf7_u233/usio01t16x.sdf /projects/tsunami/verified/scale5.1/v6_endf7_u233/usio01t17x.sdf /projects/tsunami/verified/scale5.1/v6_endf7_u233/usi001t18x.sdf /projects/tsunami/verified/scale5.1/v6_endf7_u233/usi001t19x.sdf /projects/tsunami/verified/scale5.1/v6_endf7_u233/usi001t20x.sdf /projects/tsunami/verified/scale5.1/v6_endf7_u233/usio01t21x.sdf /projects/tsunami/verified/scale5.1/v6_endf7_u233/usi001t22x.sdf /projects/tsunami/verified/scale5.1/v6_endf7_u233/usi001t23x.sdf /projects/tsunami/verified/scale5.1/v6_endf7_u233/usi001t24x.sdf /projects/tsunami/verified/scale5.1/v6_endf7_u233/usi001t25x.sdf /projects/tsunami/verified/scale5.1/v6_endf7_u233/usio01t26x.sdf /projects/tsunami/verified/scale5.1/v6_endf7_u233/usi001t27x.sdf /projects/tsunami/verified/scale5.1/v6_endf7_u233/usi001t28x.sdf /projects/tsunami/verified/scale5.1/v6_endf7_u233/usi001t29x.sdf /projects/tsunami/verified/scale5.1/v6_endf7_u233/usi001t30x.sdf /projects/tsunami/verified/scale5.1/v6_endf7_u233/usio01t31x.sdf /projects/tsunami/verified/scale5.1/v6_endf7_u233/usi001t32x.sdf /projects/tsunami/verified/scale5.1/v6_endf7_u233/usi001t33x.sdf

/projects/tsunami/verified/scale5.1/v6_endf7_u233/ust001t01x.sdf /projects/tsunami/verified/scale5.1/v6_endf7_u233/ust001to2x.sdf /projects/tsunami/verified/scale5.1/v6_endf7_u233/ust001t03x.sdf /projects/tsunami/verified/scale5.1/v6_endf7_u233/ust001t04x.sdf /projects/tsunami/verified/scale5.1/v6_endf7_u233/ust001t05x.sdf

/projects/tsunami/verified/scale5.1/v6_endf7_u233/ust002t01.sdf /projects/tsunami/verified/scale5.1/v6_endf7_u233/ust002t02.sdf /projects/tsunami/verified/scale5.1/v6_endf7_u233/ust002t03.sdf /projects/tsunami/verified/scale5.1/v6_endf7_u233/ust002t04.sdf /projects/tsunami/verified/scale5.1/v6_endf7_u233/ust002t05.sdf /projects/tsunami/verified/scale5.1/v6_endf7_u233/ust002t06.sdf /projects/tsunami/verified/scale5.1/v6_endf7_u233/ust002t07.sdf /projects/tsunami/verified/scale5.1/v6_endf7_u233/ust002t08.sdf /projects/tsunami/verified/scale5.1/v6_endf7_u233/ust002t09.sdf /projects/tsunami/verified/scale5.1/v6_endf7_u233/ust002t10.sdf /projects/tsunami/verified/scale5.1/v6_endf7_u233/ust002t11.sdf /projects/tsunami/verified/scale5.1/v6_endf7_u233/ust002t12.sdf 
/projects/tsunami/verified/scale5.1/v6_endf7_u233/ust002t13.sdf /projects/tsunami/verified/scale5.1/v6_endf7_u233/ust002t14.sdf /projects/tsunami/verified/scale5.1/v6_endf7_u233/ust002t15.sdf /projects/tsunami/verified/scale5.1/v6_endf7_u233/ust002t16.sdf /projects/tsunami/verified/scale5.1/v6_endf7_u233/ust@०2t17.sdf

/projects/tsunami/verified/scale5.1/v6_endf7_u233/ust003t01.sdf /projects/tsunami/verified/scale5.1/v6_endf7_u233/ust003t02.sdf /projects/tsunami/verified/scale5.1/v6_endf7_u233/ust003to3.sdf /projects/tsunami/verified/scale5.1/v6_endf7_u233/ust003t@4.sdf /projects/tsunami/verified/scale5.1/v6_endf7_u233/ust003t05.sdf /projects/tsunami/verified/scale5.1/v6_endf7_u233/ust003to6.sdf /projects/tsunami/verified/scale5.1/v6_endf7_u233/ust003t07.sdf /projects/tsunami/verified/scale5.1/v6_endf7_u233/ust003t08.sdf /projects/tsunami/verified/scale5.1/v6_endf7_u233/ust003to9.sdf /projects/tsunami/verified/scale5.1/v6_endf7_u233/ust003t10.sdf

/projects/tsunami/verified/scale5.1/v6_endf7_u233/ust004t01.sdf /projects/tsunami/verified/scale5.1/v6_endf7_u233/ust@04t02.sdf /projects/tsunami/verified/scale5.1/v6_endf7_u233/ust004t03.sdf /projects/tsunami/verified/scale5.1/v6_endf7_u233/ust004t04.sdf /projects/tsunami/verified/scale5.1/v6_endf7_u233/ust004t05.sdf /projects/tsunami/verified/scale5.1/v6_endf7_u233/usto04to6.sdf /projects/tsunami/verified/scale5.1/v6_endf7_u233/ust004t07.sdf /projects/tsunami/verified/scale5.1/v6_endf7_u233/ust@๑4t@8.sdf

/projects/tsunami/verified/scale5.1/v6_endf7_u233/ust005t01x.sdf /projects/tsunami/verified/scale5.1/v6_endf7_u233/usto05to2.sdf

/projects/tsunami/verified/scale5.1/v6_endf7_u233/ust006t01.sdf /projects/tsunami/verified/scale5.1/v6_endf7_u233/ust006t02.sdf /projects/tsunami/verified/scale5.1/v6_endf7_u233/ust006t03.sdf /projects/tsunami/verified/scale5.1/v6_endf7_u233/ust006t04.sdf /projects/tsunami/verified/scale5.1/v6_endf7_u233/ust006t05.sdf /projects/tsunami/verified/scale5.1/v6_endf7_u233/ust006t06.sdf /projects/tsunami/verified/scale5.1/v6_endf7_u233/ust@06to7.sdf /projects/tsunami/verified/scale5.1/v6_endf7_u233/ust006t08.sdf /projects/tsunami/verified/scale5.1/v6_endf7_u233/ust006t09.sdf /projects/tsunami/verified/scale5.1/v6_endf7_u233/ust006t10.sdf /projects/tsunami/verified/scale5.1/v6_endf7_u233/ust006t11.sdf /projects/tsunami/verified/scale5.1/v6_endf7_u233/ust006t12.sdf /projects/tsunami/verified/scale5.1/v6_endf7_u233/ust006t13.sdf /projects/tsunami/verified/scale5.1/v6_endf7_u233/ust006t14.sdf /projects/tsunami/verified/scale5.1/v6_endf7_u233/ust006t15.sdf /projects/tsunami/verified/scale5.1/v6_endf7_u233/usto06t16.sdf /projects/tsunami/verified/scale5.1/v6_endf7_u233/ust006t17.sdf /projects/tsunami/verified/scale5.1/v6_endf7_u233/usto06t18.sdf /projects/tsunami/verified/scale5.1/v6_endf7_u233/ust006t19.sdf /projects/tsunami/verified/scale5.1/v6_endf7_u233/ust006t20.sdf /projects/tsunami/verified/scale5.1/v6_endf7_u233/ust@06t21.sdf /projects/tsunami/verified/scale5.1/v6_endf7_u233/ust006t22.sdf /projects/tsunami/verified/scale5.1/v6_endf7_u233/ust006t23.sdf /projects/tsunami/verified/scale5.1/v6_endf7_u233/usto06t24.sdf /projects/tsunami/verified/scale5.1/v6_endf7_u233/ust006t25.sdf

/projects/tsunami/verified/scale5.1/v6_endf7_u233/ust@08t01x.sdf 
/projects/tsunami/verified/scale5.1/v6_endf7_u233/ust009t01.sdf /projects/tsunami/verified/scale5.1/v6_endf7_u233/ust@09t02.sdf /projects/tsunami/verified/scale5.1/v6_endf7_u233/ust@o9t03.sdf /projects/tsunami/verified/scale5.1/v6_endf7_u233/usto09to4.sdf

/projects/tsunami/verified/scale5.1/v6_endf7_u233/ust012t01.sdf /projects/tsunami/verified/scale5.1/v6_endf7_u233/ust012t02.sdf /projects/tsunami/verified/scale5.1/v6_endf7_u233/ust012t03.sdf /projects/tsunami/verified/scale5.1/v6_endf7_u233/ust012to4.sdf /projects/tsunami/verified/scale5.1/v6_endf7_u233/ust012t05.sdf /projects/tsunami/verified/scale5.1/v6_endf7_u233/ust012t06x.sdf /projects/tsunami/verified/scale5.1/v6_endf7_u233/ust012t07.sdf /projects/tsunami/verified/scale5.1/v6_endf7_u233/ust012t08.sdf

/projects/tsunami/verified/scale5.1/v6_endf7_u233/ust013t01.sdf /projects/tsunami/verified/scale5.1/v6_endf7_u233/usto13to2.sdf /projects/tsunami/verified/scale5.1/v6_endf7_u233/ust013t03.sdf /projects/tsunami/verified/scale5.1/v6_endf7_u233/ust013to4.sdf /projects/tsunami/verified/scale5.1/v6_endf7_u233/ust013t05.sdf /projects/tsunami/verified/scale5.1/v6_endf7_u233/ust013to6.sdf /projects/tsunami/verified/scale5.1/v6_endf7_u233/ust013to7.sdf /projects/tsunami/verified/scale5.1/v6_endf7_u233/ust013to8.sdf /projects/tsunami/verified/scale5.1/v6_endf7_u233/ust013t09.sdf /projects/tsunami/verified/scale5.1/v6_endf7_u233/ust013t10.sdf /projects/tsunami/verified/scale5.1/v6_endf7_u233/ust013t11.sdf /projects/tsunami/verified/scale5.1/v6_endf7_u233/ust013t12.sdf /projects/tsunami/verified/scale5.1/v6_endf7_u233/ust013t13.sdf /projects/tsunami/verified/scale5.1/v6_endf7_u233/ust013t14.sdf /projects/tsunami/verified/scale5.1/v6_endf7_u233/ust013t15.sdf /projects/tsunami/verified/scale5.1/v6_endf7_u233/ust013t16.sdf /projects/tsunami/verified/scale5.1/v6_endf7_u233/ust013t17.sdf /projects/tsunami/verified/scale5.1/v6_endf7_u233/ust013t18.sdf /projects/tsunami/verified/scale5.1/v6_endf7_u233/ust013t19.sdf /projects/tsunami/verified/scale5.1/v6_endf7_u233/ust013t20.sdf /projects/tsunami/verified/scale5.1/v6_endf7_u233/ust013t21.sdf

/projects/tsunami/verified/scale5.1/v6_endf7_u233/ust014t01.sdf /projects/tsunami/verified/scale5.1/v6_endf7_u233/ust014t02.sdf /projects/tsunami/verified/scale5.1/v6_endf7_u233/ust014t03.sdf /projects/tsunami/verified/scale5.1/v6_endf7_u233/ust014t04.sdf /projects/tsunami/verified/scale5.1/v6_endf7_u233/ust014t05.sdf /projects/tsunami/verified/scale5.1/v6_endf7_u233/ust014t06.sdf /projects/tsunami/verified/scale5.1/v6_endf7_u233/ust014to7.sdf /projects/tsunami/verified/scale5.1/v6_endf7_u233/ust014t08.sdf /projects/tsunami/verified/scale5.1/v6_endf7_u233/ust014to9.sdf /projects/tsunami/verified/scale5.1/v6_endf7_u233/ust014t10.sdf /projects/tsunami/verified/scale5.1/v6_endf7_u233/ust014t11.sdf /projects/tsunami/verified/scale5.1/v6_endf7_u233/ust014t12.sdf /projects/tsunami/verified/scale5.1/v6_endf7_u233/ust014t13.sdf /projects/tsunami/verified/scale5.1/v6_endf7_u233/ust014t14.sdf /projects/tsunami/verified/scale5.1/v6_endf7_u233/ust014t15.sdf /projects/tsunami/verified/scale5.1/v6_endf7_u233/ust014t16.sdf

/projects/tsunami/verified/scale5.1/v6_endf7_u233/ust015t01x.sdf /projects/tsunami/verified/scale5.1/v6_endf7_u233/ust015t02x.sdf /projects/tsunami/verified/scale5.1/v6_endf7_u233/ust015t03x.sdf /projects/tsunami/verified/scale5.1/v6_endf7_u233/ust015to4x.sdf 
/projects/tsunami/verified/scale5.1/v6_endf7_u233/ust015t05x.sdf /projects/tsunami/verified/scale5.1/v6_endf7_u233/ust015t06x.sdf /projects/tsunami/verified/scale5.1/v6_endf7_u233/ust015t07x.sdf /projects/tsunami/verified/scale5.1/v6_endf7_u233/ust015t08x.sdf /projects/tsunami/verified/scale5.1/v6_endf7_u233/ust015to9x.sdf /projects/tsunami/verified/scale5.1/v6_endf7_u233/ust015t10x.sdf /projects/tsunami/verified/scale5.1/v6_endf7_u233/ust015t11x.sdf /projects/tsunami/verified/scale5.1/v6_endf7_u233/ust015t12x.sdf /projects/tsunami/verified/scale5.1/v6_endf7_u233/ust015t13x.sdf /projects/tsunami/verified/scale5.1/v6_endf7_u233/ust015t14x.sdf /projects/tsunami/verified/scale5.1/v6_endf7_u233/ust015t15x.sdf /projects/tsunami/verified/scale5.1/v6_endf7_u233/ust015t16x.sdf /projects/tsunami/verified/scale5.1/v6_endf7_u233/ust015t17x.sdf /projects/tsunami/verified/scale5.1/v6_endf7_u233/ust015t18x.sdf /projects/tsunami/verified/scale5.1/v6_endf7_u233/ust015t19x.sdf /projects/tsunami/verified/scale5.1/v6_endf7_u233/ust015t20x.sdf /projects/tsunami/verified/scale5.1/v6_endf7_u233/ust015t21x.sdf /projects/tsunami/verified/scale5.1/v6_endf7_u233/ust015t22x.sdf /projects/tsunami/verified/scale5.1/v6_endf7_u233/ust015t23x.sdf /projects/tsunami/verified/scale5.1/v6_endf7_u233/ust015t24x.sdf /projects/tsunami/verified/scale5.1/v6_endf7_u233/ust015t25x.sdf /projects/tsunami/verified/scale5.1/v6_endf7_u233/ust015t26x.sdf /projects/tsunami/verified/scale5.1/v6_endf7_u233/ust015t27x.sdf /projects/tsunami/verified/scale5.1/v6_endf7_u233/ust015t28x.sdf /projects/tsunami/verified/scale5.1/v6_endf7_u233/ust015t29x.sdf /projects/tsunami/verified/scale5.1/v6_endf7_u233/ust015t30x.sdf /projects/tsunami/verified/scale5.1/v6_endf7_u233/ust015t31x.sdf

/projects/tsunami/verified/scale5.1/v6_endf7_u233/ust016t01.sdf /projects/tsunami/verified/scale5.1/v6_endf7_u233/ust016t02.sdf /projects/tsunami/verified/scale5.1/v6_endf7_u233/ust016t03.sdf /projects/tsunami/verified/scale5.1/v6_endf7_u233/ust016t04.sdf /projects/tsunami/verified/scale5.1/v6_endf7_u233/ust016t06.sdf /projects/tsunami/verified/scale5.1/v6_endf7_u233/ust016to7.sdf /projects/tsunami/verified/scale5.1/v6_endf7_u233/ust016t08.sdf /projects/tsunami/verified/scale5.1/v6_endf7_u233/usto16t09.sdf /projects/tsunami/verified/scale5.1/v6_endf7_u233/ust016t10.sdf /projects/tsunami/verified/scale5.1/v6_endf7_u233/ust016t11.sdf /projects/tsunami/verified/scale5.1/v6_endf7_u233/ust016t12.sdf /projects/tsunami/verified/scale5.1/v6_endf7_u233/ust016t13.sdf /projects/tsunami/verified/scale5.1/v6_endf7_u233/ust016t14.sdf /projects/tsunami/verified/scale5.1/v6_endf7_u233/ust016t15.sdf /projects/tsunami/verified/scale5.1/v6_endf7_u233/ust016t16.sdf /projects/tsunami/verified/scale5.1/v6_endf7_u233/ust016t17.sdf /projects/tsunami/verified/scale5.1/v6_endf7_u233/ust016t18.sdf /projects/tsunami/verified/scale5.1/v6_endf7_u233/ust016t19.sdf /projects/tsunami/verified/scale5.1/v6_endf7_u233/usto16t21.sdf /projects/tsunami/verified/scale5.1/v6_endf7_u233/ust016t22.sdf /projects/tsunami/verified/scale5.1/v6_endf7_u233/ust016t23.sdf /projects/tsunami/verified/scale5.1/v6_endf7_u233/ust016t24.sdf /projects/tsunami/verified/scale5.1/v6_endf7_u233/ust016t25.sdf /projects/tsunami/verified/scale5.1/v6_endf7_u233/ust016t26.sdf /projects/tsunami/verified/scale5.1/v6_endf7_u233/usto16t27.sdf /projects/tsunami/verified/scale5.1/v6_endf7_u233/ust016t28.sdf /projects/tsunami/verified/scale5.1/v6_endf7_u233/ust016t29.sdf /projects/tsunami/verified/scale5.1/v6_endf7_u233/ust016t30.sdf /projects/tsunami/verified/scale5.1/v6_endf7_u233/ust016t31.sdf 
/projects/tsunami/verified/scale5.1/v6_endf7_u233/ust016t32.sdf /projects/tsunami/verified/scale5.1/v6_endf7_u233/ust016t33.sdf

/projects/tsunami/verified/scale5.1/v6_endf7_u233/ust017t01.sdf /projects/tsunami/verified/scale5.1/v6_endf7_u233/ust017to2.sdf /projects/tsunami/verified/scale5.1/v6_endf7_u233/ust017to3.sdf /projects/tsunami/verified/scale5.1/v6_endf7_u233/ust017to4.sdf /projects/tsunami/verified/scale5.1/v6_endf7_u233/ust017t05.sdf /projects/tsunami/verified/scale5.1/v6_endf7_u233/ust017to6.sdf /projects/tsunami/verified/scale5.1/v6_endf7_u233/ust017to7.sdf

/projects/tsunami/verified/scale5.1/v6_endf7_u233/hmt025t01.sdf /projects/tsunami/verified/scale5.1/v6_endf7_u233/hmt@25t@2.sdf

/projects/tsunami/verified/scale5.1/v6_endf7_u233/hmf030t00.sdf

/projects/tsunami/verified/scale5.1/v6_endf7_u233/lct@49t01.sdf /projects/tsunami/verified/scale5.1/v6_endf7_u233/lct049t02.sdf /projects/tsunami/verified/scale5.1/v6_endf7_u233/lcto49to3.sdf /projects/tsunami/verified/scale5.1/v6_endf7_u233/lcto49to4.sdf /projects/tsunami/verified/scale5.1/v6_endf7_u233/lct@49t05.sdf /projects/tsunami/verified/scale5.1/v6_endf7_u233/lct049to6.sdf /projects/tsunami/verified/scale5.1/v6_endf7_u233/lcto49to7.sdf /projects/tsunami/verified/scale5.1/v6_endf7_u233/lcto49to8.sdf /projects/tsunami/verified/scale5.1/v6_endf7_u233/lcto49to9.sdf /projects/tsunami/verified/scale5.1/v6_endf7_u233/lcto49t10.sdf /projects/tsunami/verified/scale5.1/v6_endf7_u233/lcto49t11.sdf /projects/tsunami/verified/scale5.1/v6_endf7_u233/lct@49t12.sdf /projects/tsunami/verified/scale5.1/v6_endf7_u233/lct049t13.sdf /projects/tsunami/verified/scale5.1/v6_endf7_u233/lcto49t14.sdf /projects/tsunami/verified/scale5.1/v6_endf7_u233/lcto49t15.sdf /projects/tsunami/verified/scale5.1/v6_endf7_u233/lcto49t16.sdf /projects/tsunami/verified/scale5.1/v6_endf7_u233/lct049t17.sdf /projects/tsunami/verified/scale5.1/v6_endf7_u233/lcto49t18.sdf

/projects/tsunami/verified/scale5.1/v6_endf7_u233/mcf001t01.sdf /projects/tsunami/verified/scale5.1/v6_endf7_u233/mci@o5t@0.sdf

/projects/tsunami/verified/scale5.1/v6_endf7_u233/mcm001t01.sdf /projects/tsunami/verified/scale5.1/v6_endf7_u233/mcm001t02.sdf /projects/tsunami/verified/scale5.1/v6_endf7_u233/mcmo01to3.sdf /projects/tsunami/verified/scale5.1/v6_endf7_u233/mcm001to4.sdf /projects/tsunami/verified/scale5.1/v6_endf7_u233/mcm001t05.sdf /projects/tsunami/verified/scale5.1/v6_endf7_u233/mcm001to6.sdf /projects/tsunami/verified/scale5.1/v6_endf7_u233/mcm001to7.sdf /projects/tsunami/verified/scale5.1/v6_endf7_u233/mcmo01to8.sdf /projects/tsunami/verified/scale5.1/v6_endf7_u233/mcm001t09.sdf /projects/tsunami/verified/scale5.1/v6_endf7_u233/mcm001t10.sdf /projects/tsunami/verified/scale5.1/v6_endf7_u233/mcmo01t11.sdf /projects/tsunami/verified/scale5.1/v6_endf7_u233/mcm001t12.sdf /projects/tsunami/verified/scale5.1/v6_endf7_u233/mcm001t13.sdf /projects/tsunami/verified/scale5.1/v6_endf7_u233/mcmo01t14.sdf /projects/tsunami/verified/scale5.1/v6_endf7_u233/mcm001t15.sdf /projects/tsunami/verified/scale5.1/v6_endf7_u233/mcmo01t16.sdf /projects/tsunami/verified/scale5.1/v6_endf7_u233/mcm001t17.sdf /projects/tsunami/verified/scale5.1/v6_endf7_u233/mcm001t18.sdf 
/projects/tsunami/verified/scale5.1/v6_endf7_u233/mcm001t19.sdf

/projects/tsunami/verified/scale5.1/v6_endf7_u233/mmf008t01.sdf /projects/tsunami/verified/scale5.1/v6_endf7_u233/mmfö8to2.sdf /projects/tsunami/verified/scale5.1/v6_endf7_u233/mmfo08t03.sdf /projects/tsunami/verified/scale5.1/v6_endf7_u233/mmfo08t04.sdf /projects/tsunami/verified/scale5.1/v6_endf7_u233/mmf008t05.sdf /projects/tsunami/verified/scale5.1/v6_endf7_u233/mmfo08t06.sdf /projects/tsunami/verified/scale5.1/v6_endf7_u233/mmf008t07.sdf

/projects/tsunami/heu/hct010-01.sdf /projects/tsunami/heu/hct010-02.sdf /projects/tsunami/heu/hct010-03.sdf /projects/tsunami/heu/hct010-04.sdf /projects/tsunami/heu/hct010-05.sdf /projects/tsunami/heu/hct010-06.sdf /projects/tsunami/heu/hct010-07.sdf /projects/tsunami/heu/hct010-08.sdf /projects/tsunami/heu/hct010-09.sdf /projects/tsunami/heu/hcto10-10.sdf /projects/tsunami/heu/hct010-11.sdf /projects/tsunami/heu/hct010-12.sdf /projects/tsunami/heu/hcto10-13.sdf /projects/tsunami/heu/hct010-14.sdf /projects/tsunami/heu/hct010-15.sdf

/projects/tsunami/heu/hct011-01.sdf /projects/tsunami/heu/hct011-02.sdf /projects/tsunami/heu/hct011-03.sdf

/projects/tsunami/heu/hct012-01.sdf /projects/tsunami/heu/hct012-02.sdf

/projects/tsunami/heu/hct013-01.sdf /projects/tsunami/heu/hct013-02.sdf

/projects/tsunami/heu/hct014-01.sdf /projects/tsunami/heu/hct014-02.sdf

/projects/tsunami/heu/hmt@06-01.sdf /projects/tsunami/heu/hmt@06-02.sdf /projects/tsunami/heu/hmt@06-03.sdf /projects/tsunami/heu/hmt@06-04.sdf /projects/tsunami/heu/hmt@06-05.sdf /projects/tsunami/heu/hmt@06-06.sdf /projects/tsunami/heu/hmt@06-07.sdf /projects/tsunami/heu/hmt@06-08.sdf /projects/tsunami/heu/hmt@06-09.sdf /projects/tsunami/heu/hmt@06-10.sdf /projects/tsunami/heu/hmt@06-11. sdf /projects/tsunami/heu/hmt@06-12.sdf /projects/tsunami/heu/hmt@06-15.sdf /projects/tsunami/heu/hmt@06-13.sdf /projects/tsunami/heu/hmt@06-14.sdf /projects/tsunami/heu/hmt006-16.sdf /projects/tsunami/heu/hmt@06-17.sdf /projects/tsunami/heu/hmt@®6-18.sdf 
/projects/tsunami/heu/hmt006-19.sdf /projects/tsunami/heu/hmt@06-20.sdf /projects/tsunami/heu/hmt006-21.sdf /projects/tsunami/heu/hmt@06-22.sdf /projects/tsunami/heu/hmt@०6-23.sdf

/projects/tsunami/heu/hst@01-01.sdf /projects/tsunami/heu/hst001-02.sdf /projects/tsunami/heu/hst001-03.sdf /projects/tsunami/heu/hst@01-04.sdf /projects/tsunami/heu/hst001-05.sdf /projects/tsunami/heu/hsto01-06.sdf /projects/tsunami/heu/hst@01-07.sdf /projects/tsunami/heu/hst@01-08.sdf /projects/tsunami/heu/hst001-09.sdf /projects/tsunami/heu/hsto01-10.sdf

/projects/tsunami/heu/hst005-11.sdf /projects/tsunami/heu/hstoo5-12.sdf /projects/tsunami/heu/hsto05-14.sdf /projects/tsunami/heu/hst005-15.sdf /projects/tsunami/heu/hst@o5-17.sdf

/projects/tsunami/heu/hst006-01.sdf /projects/tsunami/heu/hst@06-08.sdf /projects/tsunami/heu/hst@o6-12.sdf /projects/tsunami/heu/hst@®6-27.sdf

/projects/tsunami/heu/hst@07-01.sdf /projects/tsunami/heu/hst007-02.sdf /projects/tsunami/heu/hst007-03.sdf /projects/tsunami/heu/hst $007-04$.sdf /projects/tsunami/heu/hst007-05.sdf /projects/tsunami/heu/hst007-06.sdf /projects/tsunami/heu/hst007-07.sdf /projects/tsunami/heu/hst@07-08.sdf /projects/tsunami/heu/hst007-09.sdf /projects/tsunami/heu/hsto07-10.sdf /projects/tsunami/heu/hsto07-11.sdf /projects/tsunami/heu/hst@o7-12.sdf /projects/tsunami/heu/hsto07-13.sdf /projects/tsunami/heu/hsto07-14.sdf /projects/tsunami/heu/hsto07-15.sdf /projects/tsunami/heu/hsto07-16.sdf /projects/tsunami/heu/hst@०7-17.sdf

/projects/tsunami/heu/hst@09-01.sdf /projects/tsunami/heu/hst@09-02.sdf /projects/tsunami/heu/hsto09-03.sdf /projects/tsunami/heu/hsto®-04.sdf

/projects/tsunami/heu/hst010-01.sdf /projects/tsunami/heu/hst010-02.sdf /projects/tsunami/heu/hsto10-04.sdf /projects/tsunami/heu/hsto10-03.sdf

/projects/tsunami/heu/hst011-01.sdf 


$$
\begin{aligned}
& \text { /projects/tsunami/heu/hst@11-02.sdf } \\
& \text { /projects/tsunami/heu/hst012-01.sdf } \\
& \text { /projects/tsunami/heu/hst013-01.sdf } \\
& \text { /projects/tsunami/heu/hst014-01.sdf } \\
& \text { /projects/tsunami/heu/hst015-01.sdf } \\
& \text { /projects/tsunami/heu/hsto15-02.sdf } \\
& \text { /projects/tsunami/heu/hst016-01.sdf } \\
& \text { /projects/tsunami/heu/hst017-01.sdf } \\
& \text { /projects/tsunami/heu/hst017-02.sdf } \\
& \text { /projects/tsunami/heu/hst017-03.sdf } \\
& \text { /projects/tsunami/heu/hst018-01.sdf } \\
& \text { /projects/tsunami/heu/hsto18-02.sdf } \\
& \text { /projects/tsunami/heu/hsto18-03.sdf } \\
& \text { /projects/tsunami/heu/hst019-01.sdf } \\
& \text { /projects/tsunami/heu/hst025-01.sdf } \\
& \text { /projects/tsunami/heu/hsto25-02.sdf } \\
& \text { /projects/tsunami/heu/hsto25-04.sdf } \\
& \text { /projects/tsunami/heu/hst@25-05.sdf } \\
& \text { /projects/tsunami/heu/hst@27-01.sdf } \\
& \text { /projects/tsunami/heu/hst28i-1.sdf } \\
& \text { /projects/tsunami/heu/hst28i-3.sdf } \\
& \text { /projects/tsunami/heu/hst28i-5.sdf } \\
& \text { /projects/tsunami/heu/hst28i-7.sdf } \\
& \text { /projects/tsunami/heu/hst28i-9.sdf } \\
& \text { /projects/tsunami/heu/hst28i-11.sdf } \\
& \text { /projects/tsunami/heu/hst28i-13.sdf } \\
& \text { /projects/tsunami/heu/hst28i-15.sdf } \\
& \text { /projects/tsunami/heu/hst28i-17.sdf } \\
& \text { /projects/tsunami/heu/hst29i-01.sdf } \\
& \text { /projects/tsunami/heu/hst30i-01.sdf } \\
& \text { /projects/tsunami/heu/hst30i-04.sdf } \\
& \text { /projects/tsunami/heu/hst@32-01.sdf } \\
& \text { /projects/tsunami/heu/hst } 033-02 \text { a.sdf } \\
& \text { /projects/tsunami/heu/hst033-02b.sdf } \\
& \text { /projects/tsunami/heu/hst033-02c.sdf } \\
& \text { /projects/tsunami/heu/hst033-03a.sdf } \\
& \text { /projects/tsunami/heu/hst033-03b.sdf } \\
& \text { /projects/tsunami/heu/hst033-03c.sdf } \\
& \text { /projects/tsunami/heu/hst033-10c.sdf } \\
& \text { /projects/tsunami/heu/hst033-10a.sdf } \\
& \text { /projects/tsunami/heu/hst@33-10d.sdf }
\end{aligned}
$$


/projects/tsunami/heu/hst035-01.sdf /projects/tsunami/heu/hst035-05.sdf /projects/tsunami/heu/hst@35-07.sdf

/projects/tsunami/heu/hst037-01.sdf /projects/tsunami/heu/hst037-03.sdf /projects/tsunami/heu/hst@37-06.sdf

/projects/tsunami/heu/hst042-01.sdf /projects/tsunami/heu/hst042-02.sdf /projects/tsunami/heu/hsto42-03.sdf /projects/tsunami/heu/hsto42-04.sdf /projects/tsunami/heu/hst042-05.sdf /projects/tsunami/heu/hsto42-06.sdf /projects/tsunami/heu/hsto42-07.sdf /projects/tsunami/heu/hst042-08.sdf

/projects/tsunami/heu/hst@43-01.sdf /projects/tsunami/heu/hsto43-02.sdf /projects/tsunami/heu/hst@43-03.sdf

/projects/tsunami/ieu/imfø๑3.sdf

/projects/tsunami/ieu/imfoø4.sdf

/projects/tsunami/ieu/imfo05.sdf

/projects/tsunami/ieu/imfoø6.sdf

/projects/tsunami/leu/lct@๑9-01.sdf /projects/tsunami/leu/lct@o9-02.sdf /projects/tsunami/leu/lctø09-03.sdf /projects/tsunami/leu/lct@०9-04.sdf /projects/tsunami/leu/lct@o9-05.sdf /projects/tsunami/leu/lcto09-06.sdf /projects/tsunami/leu/lct@o9-07.sdf /projects/tsunami/leu/lct@o9-08.sdf /projects/tsunami/leu/lcto®9-09.sdf /projects/tsunami/leu/lctoo9-10.sdf /projects/tsunami/leu/lcto09-11.sdf /projects/tsunami/leu/lcto09-13.sdf /projects/tsunami/leu/lctoo9-14.sdf /projects/tsunami/leu/lctoo9-15.sdf /projects/tsunami/leu/lctoo9-16.sdf /projects/tsunami/leu/lcto09-17.sdf /projects/tsunami/leu/lctoo9-18.sdf /projects/tsunami/leu/lcto®9-19.sdf /projects/tsunami/leu/lctoo9-20.sdf /projects/tsunami/leu/lctoo9-21.sdf /projects/tsunami/leu/lctoo9-22.sdf /projects/tsunami/leu/lctoo9-23.sdf /projects/tsunami/leu/lctoo9-24.sdf /projects/tsunami/leu/lctoo9-25.sdf /projects/tsunami/leu/lctoo9-26.sdf /projects/tsunami/leu/lct@o9-27.sdf

/projects/tsunami/leu/lct010-01.sdf 
/projects/tsunami/leu/lct $010-02$.sdf /projects/tsunami/leu/lct010-03.sdf /projects/tsunami/leu/lct010-04.sdf /projects/tsunami/leu/lct010-05.sdf /projects/tsunami/leu/lct010-06.sdf /projects/tsunami/leu/lct010-07.sdf /projects/tsunami/leu/lct010-08.sdf /projects/tsunami/leu/lct010-09.sdf /projects/tsunami/leu/lct010-10.sdf /projects/tsunami/leu/lcto10-11.sdf /projects/tsunami/leu/lcto10-12.sdf /projects/tsunami/leu/lcto10-13.sdf /projects/tsunami/leu/lct010-14.sdf /projects/tsunami/leu/lct010-15.sdf /projects/tsunami/leu/lcto10-16.sdf /projects/tsunami/leu/lcto10-17.sdf /projects/tsunami/leu/lct010-18.sdf /projects/tsunami/leu/lct010-19.sdf /projects/tsunami/leu/lcto10-20.sdf /projects/tsunami/leu/lcto10-21.sdf /projects/tsunami/leu/lct010-22.sdf /projects/tsunami/leu/lct010-23.sdf /projects/tsunami/leu/lcto10-24.sdf /projects/tsunami/leu/lct010-25.sdf /projects/tsunami/leu/lcto10-26.sdf /projects/tsunami/leu/lcto10-27.sdf /projects/tsunami/leu/lcto10-28.sdf /projects/tsunami/leu/lct010-29.sdf /projects/tsunami/leu/lct010-30.sdf

/projects/tsunami/leu/lct012-01.sdf /projects/tsunami/leu/lct012-02.sdf /projects/tsunami/leu/lct012-03.sdf /projects/tsunami/leu/lct012-04.sdf /projects/tsunami/leu/lct012-05.sdf /projects/tsunami/leu/lcto12-06.sdf /projects/tsunami/leu/lct012-07.sdf /projects/tsunami/leu/lcto12-08.sdf /projects/tsunami/leu/lcto12-09.sdf /projects/tsunami/leu/lct012-10.sdf

/projects/tsunami/leu/lct017-01.sdf /projects/tsunami/leu/lcto17-02.sdf /projects/tsunami/leu/lct017-03.sdf /projects/tsunami/leu/lct017-04.sdf /projects/tsunami/leu/lct017-05.sdf /projects/tsunami/leu/lct017-06.sdf /projects/tsunami/leu/lct017-07.sdf /projects/tsunami/leu/lcto17-08.sdf /projects/tsunami/leu/lcto17-09.sdf /projects/tsunami/leu/lct017-10.sdf /projects/tsunami/leu/lcto17-11.sdf /projects/tsunami/leu/lcto17-12.sdf /projects/tsunami/leu/lcto17-13.sdf /projects/tsunami/leu/lct017-14.sdf /projects/tsunami/leu/lct017-15.sdf /projects/tsunami/leu/lcto17-16.sdf 
/projects/tsunami/leu/lct017-17.sdf /projects/tsunami/leu/lct017-18.sdf /projects/tsunami/leu/lct017-19.sdf /projects/tsunami/leu/lcto17-20.sdf /projects/tsunami/leu/lcto17-21.sdf /projects/tsunami/leu/lct017-22.sdf /projects/tsunami/leu/lct017-23.sdf /projects/tsunami/leu/lct017-24.sdf /projects/tsunami/leu/lcto17-25.sdf /projects/tsunami/leu/lcto17-26.sdf /projects/tsunami/leu/lcto17-27.sdf /projects/tsunami/leu/lct017-28.sdf /projects/tsunami/leu/lct017-29.sdf

/projects/tsunami/leu/lct18c1.sdf

/projects/tsunami/leu/lct19c1.sdf /projects/tsunami/leu/lct19c2.sdf /projects/tsunami/leu/lct19c3.sdf

/projects/tsunami/leu/lct20c1.sdf /projects/tsunami/leu/lct20c2.sdf /projects/tsunami/leu/lct20c3.sdf /projects/tsunami/leu/lct20c4.sdf /projects/tsunami/leu/lct20c5.sdf /projects/tsunami/leu/lct20c6.sdf /projects/tsunami/leu/lct20c7.sdf

/projects/tsunami/leu/lct21c1.sdf /projects/tsunami/leu/lct21c2.sdf /projects/tsunami/leu/lct21c3.sdf /projects/tsunami/leu/lct21c4.sdf /projects/tsunami/leu/lct21c5.sdf /projects/tsunami/leu/lct22c1.sdf /projects/tsunami/leu/lct21c6.sdf

/projects/tsunami/leu/lct22c2.sdf /projects/tsunami/leu/lct22c3.sdf /projects/tsunami/leu/lct22c4.sdf /projects/tsunami/leu/lct22c5.sdf /projects/tsunami/leu/lct22c6.sdf /projects/tsunami/leu/lct22c7.sdf

/projects/tsunami/leu/lct23c1.sdf /projects/tsunami/leu/lct23c2.sdf /projects/tsunami/leu/lct23c3.sdf /projects/tsunami/leu/lct23c4.sdf /projects/tsunami/leu/lct23c5.sdf /projects/tsunami/leu/lct23c6.sdf

/projects/tsunami/leu/lct24c1.sdf /projects/tsunami/leu/lct24c2.sdf

/projects/tsunami/leu/lct25c1.sdf /projects/tsunami/leu/lct25c2.sdf /projects/tsunami/leu/lct25c3.sdf /projects/tsunami/leu/lct25c4.sdf 
/projects/tsunami/leu/lct26c1.sdf /projects/tsunami/leu/lct26c2.sdf /projects/tsunami/leu/lct26c3.sdf /projects/tsunami/leu/lct26c4.sdf

/projects/tsunami/leu/lct32a1.sdf /projects/tsunami/leu/lct32a2.sdf /projects/tsunami/leu/lct32a3.sdf /projects/tsunami/leu/lct32a4.sdf /projects/tsunami/leu/lct32a5.sdf /projects/tsunami/leu/lct32a6.sdf /projects/tsunami/leu/lct32a7.sdf /projects/tsunami/leu/lct32a8.sdf /projects/tsunami/leu/lct32a9.sdf

/projects/tsunami/leu/lct@40-01.sdf /projects/tsunami/leu/lct@40-02.sdf /projects/tsunami/leu/lct@40-03.sdf

/projects/tsunami/leu/lct@42-01.sdf /projects/tsunami/leu/lcto42-02.sdf /projects/tsunami/leu/lcto42-03.sdf /projects/tsunami/leu/lcto42-04.sdf /projects/tsunami/leu/lcto42-05.sdf /projects/tsunami/leu/lcto42-06.sdf /projects/tsunami/leu/lct@42-07.sdf

/projects/tsunami/leu/lct@79-1.sdf /projects/tsunami/leu/lcto79-2.sdf /projects/tsunami/leu/lcto79-3.sdf /projects/tsunami/leu/lct079-4.sdf /projects/tsunami/leu/lct@79-5.sdf /projects/tsunami/leu/lcto79-6.sdf /projects/tsunami/leu/lcto79-7.sdf /projects/tsunami/leu/lcto79-8.sdf /projects/tsunami/leu/lcto79-9.sdf /projects/tsunami/leu/lcto79-10.sdf

/projects/tsunami/leu/lsto1c1.sdf

/projects/tsunami/leu/lsto3c1.sdf /projects/tsunami/leu/lsto3c2.sdf /projects/tsunami/leu/lst@3c3.sdf /projects/tsunami/leu/lst@3c4.sdf /projects/tsunami/leu/lsto3c5.sdf /projects/tsunami/leu/lsto3c6.sdf /projects/tsunami/leu/lste3c7.sdf /projects/tsunami/leu/lste3c8.sdf /projects/tsunami/leu/lsto3c9.sdf

/projects/tsunami/leu/lsto4-R1.sdf /projects/tsunami/leu/lsto4-R29.sdf /projects/tsunami/leu/lsto4-R33.sdf /projects/tsunami/leu/lsto4-R34.sdf /projects/tsunami/leu/lsto4-R46.sdf /projects/tsunami/leu/lsto4-R51.sdf 
/projects/tsunami/leu/lst@4-R54.sdf

/projects/tsunami/leu/lsto5c1.sdf /projects/tsunami/leu/lste5c2.sdf /projects/tsunami/leu/lst05c3.sdf

/projects/tsunami/leu/lst@6c1.sdf /projects/tsunami/leu/lst@6c2.sdf /projects/tsunami/leu/lsto6c3.sdf /projects/tsunami/leu/lste6c4.sdf /projects/tsunami/leu/lsto6c5.sdf

/projects/tsunami/leu/lste7-R14.sdf /projects/tsunami/leu/lsto7-R30.sdf /projects/tsunami/leu/lsto7-R32.sdf /projects/tsunami/leu/lsto7-R36.sdf /projects/tsunami/leu/lsto7-R49.sdf

/projects/tsunami/leu/lsto8-R72.sdf /projects/tsunami/leu/lsto8-R74.sdf /projects/tsunami/leu/lste8-R76.sdf /projects/tsunami/leu/lst@8-R78.sdf

/projects/tsunami/leu/lsto9-R92.sdf /projects/tsunami/leu/lsto9-R93.sdf /projects/tsunami/leu/lsto9-R94.sdf

/projects/tsunami/leu/lst10-R83.sdf /projects/tsunami/leu/lst10-R85.sdf /projects/tsunami/leu/lst10-R86.sdf /projects/tsunami/leu/lst10-R88.sdf

/projects/tsunami/leu/lst16-105.sdf /projects/tsunami/leu/lst16-R113.sdf /projects/tsunami/leu/lst16-R125.sdf /projects/tsunami/leu/lst16-R129.sdf /projects/tsunami/leu/lst16-R131.sdf /projects/tsunami/leu/lst16-R140.sdf /projects/tsunami/leu/lst16-R196.sdf

/projects/tsunami/leu/lst17-R104.sdf /projects/tsunami/leu/lst17-R122.sdf /projects/tsunami/leu/lst17-R123.sdf /projects/tsunami/leu/lst17-R126.sdf /projects/tsunami/leu/lst17-R130.sdf /projects/tsunami/leu/lst17-R147.sdf

/projects/tsunami/leu/lst18c1.sdf /projects/tsunami/leu/lst18c3.sdf /projects/tsunami/leu/lst18c4.sdf /projects/tsunami/leu/lst18c5.sdf /projects/tsunami/leu/lst18c6.sdf

/projects/tsunami/leu/lst19c1.sdf /projects/tsunami/leu/lst19c2.sdf /projects/tsunami/leu/lst19c3.sdf /projects/tsunami/leu/lst19c4.sdf 


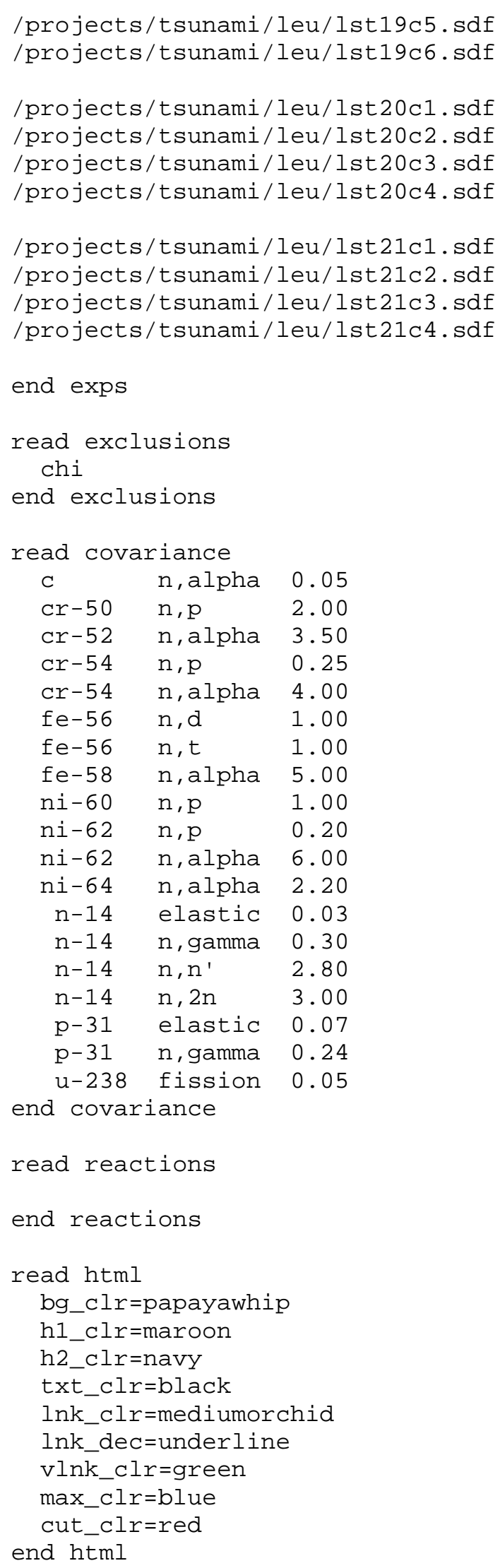


end

C-18 


\section{APPENDIX D}

SIMILARITY LISTING FOR APPLICATIONS 1 THROUGH 4 



\begin{tabular}{|c|c|c|c|c|c|c|c|}
\hline \multicolumn{2}{|c|}{ Application 1} & \multicolumn{2}{|c|}{ Application 2} & \multicolumn{2}{|c|}{ Application 3} & \multicolumn{2}{|c|}{ Application 4} \\
\hline Exp. ID & $\mathrm{c}_{\mathrm{r}}$ & Exp. ID & $\mathrm{c}_{\mathrm{r}}$ & Exp. ID & $\mathrm{c}_{\mathrm{r}}$ & Exp. ID & $\mathrm{c}_{\mathrm{r}}$ \\
\hline ust016t10 & 0.995 & hst001-08 & 0.985 & lst05c1 & 0.687 & hst007-13 & 0.301 \\
\hline ust016t11 & 0.995 & hst001-03 & 0.984 & $1 \mathrm{st} 05 \mathrm{c} 2$ & 0.687 & hst007-04 & 0.299 \\
\hline ust016t12 & 0.995 & hst001-07 & 0.983 & $1 s t 05 \mathrm{c} 3$ & 0.681 & hst007-17 & 0.295 \\
\hline ust006t13 & 0.992 & hst043-01 & 0.983 & 1st04-R54 & 0.637 & hst007-14 & 0.294 \\
\hline ust006t12 & 0.992 & hst001-01 & 0.979 & lst07-R49 & 0.634 & hst007-15 & 0.293 \\
\hline ust006t14 & 0.992 & hst027-01 & 0.974 & lst04-R46 & 0.634 & hst007-16 & 0.281 \\
\hline ust006t15 & 0.992 & hst017-01 & 0.974 & lst04-R34 & 0.630 & hst007-11 & 0.279 \\
\hline ust013t01 & 0.991 & hst017-02 & 0.973 & 1st07-R36 & 0.629 & hst007-02 & 0.278 \\
\hline ust013t02 & 0.991 & hst018-01 & 0.969 & 1st09-R94 & 0.626 & hst005-14 & 0.272 \\
\hline ust013t03 & 0.991 & hst017-03 & 0.968 & lst10-R83 & 0.626 & hst005-15 & 0.269 \\
\hline ust013t04 & 0.991 & hst28i-11 & 0.966 & lst10-R86 & 0.625 & hst005-17 & 0.268 \\
\hline ust013t05 & 0.991 & hst28i-9 & 0.966 & 1st10-R88 & 0.625 & hst007-08 & 0.268 \\
\hline ust016t06 & 0.991 & hst28i-13 & 0.965 & 1st08-R74 & 0.625 & hst005-11 & 0.263 \\
\hline ust016t09 & 0.991 & hst018-02 & 0.965 & lst09-R93 & 0.625 & hst005-12 & 0.262 \\
\hline ust016t07 & 0.991 & hst28i-15 & 0.964 & lst10-R85 & 0.625 & hst007-06 & 0.259 \\
\hline ust016t08 & 0.991 & hst009-04 & 0.962 & 1st08-R76 & 0.625 & het010-02 & 0.256 \\
\hline ust013t06 & 0.991 & hst016-01 & 0.961 & lst08-R78 & 0.625 & hst007-12 & 0.254 \\
\hline ust013t07 & 0.991 & hst001-09 & 0.961 & lst09-R92 & 0.625 & het010-01 & 0.253 \\
\hline ust013t08 & 0.991 & hst001-04 & 0.960 & 1st07-R32 & 0.624 & hst009-01 & 0.253 \\
\hline ust013t09 & 0.991 & hst018-03 & 0.960 & 1st04-R33 & 0.624 & lct32a3 & 0.248 \\
\hline ust013t11 & 0.991 & hst29i-01 & 0.960 & lst08-R72 & 0.624 & hst009-02 & 0.247 \\
\hline ust013t12 & 0.991 & hst001-02 & 0.959 & 1st04-R29 & 0.621 & $\operatorname{lct} 24 \mathrm{c} 1$ & 0.247 \\
\hline ust013t13 & 0.991 & hst30i-04 & 0.958 & lst07-R30 & 0.620 & lct32a2 & 0.242 \\
\hline ust013t14 & 0.991 & hst28i-17 & 0.956 & lst07-R14 & 0.616 & lct $22 \mathrm{c} 1$ & 0.239 \\
\hline ust013t10 & 0.991 & hst015-01 & 0.954 & lst04-R1 & 0.614 & het010-03 & 0.239 \\
\hline ust016t21 & 0.990 & hst009-03 & 0.950 & lst04-R51 & 0.613 & lct32a1 & 0.239 \\
\hline ust016t22 & 0.990 & hst010-04 & 0.947 & ust001t05x & 0.604 & hst019-01 & 0.235 \\
\hline ust016t23 & 0.990 & hst010-03 & 0.946 & ust $001 \mathrm{t} 04 \mathrm{x}$ & 0.604 & hst007-03 & 0.235 \\
\hline ust016t24 & 0.990 & hst015-02 & 0.946 & ust001t $03 \mathrm{x}$ & 0.603 & hst009-03 & 0.231 \\
\hline ust012t01 & 0.987 & hst010-01 & 0.942 & ust001t02x & 0.601 & het010-04 & 0.231 \\
\hline ust012t02 & 0.987 & hst010-02 & 0.942 & ust001t01x & 0.600 & lct049t18 & 0.230 \\
\hline ust016t13 & 0.987 & hst $001-10$ & 0.941 & ust009t01 & 0.593 & hst033-03a & 0.229 \\
\hline ust016t14 & 0.986 & hst019-01 & 0.939 & ust009t02 & 0.591 & hst033-10a & 0.229 \\
\hline ust016t15 & 0.986 & hst001-06 & 0.937 & ust009t03 & 0.586 & hst001-04 & 0.229 \\
\hline ust012t03 & 0.985 & hst007-08 & 0.933 & ust008t01x & 0.585 & lct049t02 & 0.229 \\
\hline ust006t16 & 0.983 & hst006-01 & 0.932 & lst03c1 & 0.584 & lct049t03 & 0.229 \\
\hline ust006t18 & 0.983 & hst28i-5 & 0.932 & ust009t04 & 0.579 & lct049t01 & 0.229 \\
\hline ust006t17 & 0.983 & hst006-08 & 0.931 & 1st03c2 & 0.578 & lct049t04 & 0.229 \\
\hline ust013t15 & 0.981 & hst $28 \mathrm{i}-3$ & 0.931 & $1 \mathrm{st} 03 \mathrm{c} 4$ & 0.576 & hst007-10 & 0.228 \\
\hline ust016t01 & 0.980 & hst28i-1 & 0.931 & $1 \mathrm{st} 03 \mathrm{c} 3$ & 0.574 & hst001-09 & 0.228 \\
\hline
\end{tabular}




\begin{tabular}{|c|c|c|c|c|c|c|c|}
\hline \multicolumn{2}{|c|}{ Application 1} & \multicolumn{2}{|c|}{ Application 2} & \multicolumn{2}{|c|}{ Application 3} & \multicolumn{2}{|c|}{ Application 4} \\
\hline Exp. ID & $\mathrm{c}_{\mathrm{r}}$ & Exp. ID & $\mathrm{c}_{\mathrm{r}}$ & Exp. ID & $\mathrm{c}_{\mathrm{r}}$ & Exp. ID & $\mathrm{c}_{\mathrm{r}}$ \\
\hline ust016t04 & 0.980 & hst001-05 & 0.930 & lst21c3 & 0.572 & hst033-03c & 0.227 \\
\hline ust016t02 & 0.980 & hst30i-01 & 0.929 & lst $21 \mathrm{c} 4$ & 0.570 & lct049t13 & 0.227 \\
\hline ust016t03 & 0.980 & hst007-06 & 0.928 & $1 \mathrm{st} 21 \mathrm{c} 2$ & 0.569 & hst006-08 & 0.227 \\
\hline ust017t03 & 0.977 & hst28i-7 & 0.926 & lst20c3 & 0.569 & hst033-03b & 0.227 \\
\hline ust012t04 & 0.976 & hst014-01 & 0.925 & $1 \mathrm{st} 21 \mathrm{c} 1$ & 0.568 & lct049t15 & 0.226 \\
\hline ust016t19 & 0.976 & hst007-09 & 0.923 & lst20c1 & 0.568 & lct049t14 & 0.226 \\
\hline ust016t16 & 0.976 & hst006-27 & 0.920 & lst20c4 & 0.567 & hst006-27 & 0.226 \\
\hline ust016t18 & 0.976 & het010-06 & 0.918 & ust002t11 & 0.567 & hst001-02 & 0.226 \\
\hline ust016t17 & 0.976 & hst006-12 & 0.917 & 1st20c2 & 0.566 & hst033-10d & 0.226 \\
\hline ust017t02 & 0.975 & hst007-07 & 0.917 & $1 \mathrm{st} 03 \mathrm{c} 5$ & 0.564 & hst $033-02 a$ & 0.225 \\
\hline ust006t01 & 0.975 & hst007-15 & 0.917 & 1 st $03 \mathrm{c} 6$ & 0.563 & lct049t17 & 0.225 \\
\hline ust006t02 & 0.974 & hst007-14 & 0.916 & 1 st $03 \mathrm{c} 7$ & 0.557 & lct049t05 & 0.225 \\
\hline ust006t03 & 0.974 & hst007-17 & 0.915 & lst $18 \mathrm{c} 3$ & 0.556 & lct049t06 & 0.225 \\
\hline ust006t04 & 0.974 & hst025-05 & 0.912 & $1 \mathrm{st} 18 \mathrm{c} 5$ & 0.556 & lct049t16 & 0.225 \\
\hline ust013t16 & 0.974 & het010-07 & 0.911 & $1 \mathrm{st} 18 \mathrm{c} 6$ & 0.556 & lct049t07 & 0.225 \\
\hline ust013t17 & 0.972 & hst007-05 & 0.910 & 1st19c2 & 0.556 & hst006-01 & 0.224 \\
\hline ust015t $25 x$ & 0.971 & hst009-02 & 0.909 & lst19c6 & 0.556 & lct049t08 & 0.224 \\
\hline ust017t01 & 0.971 & hst007-13 & 0.909 & 1st16-R196 & 0.556 & hst033-10c & 0.223 \\
\hline ust014t01 & 0.970 & het010-09 & 0.909 & 1st19c5 & 0.556 & hst30i-04 & 0.223 \\
\hline ust012t05 & 0.969 & hst007-16 & 0.909 & lst19c4 & 0.556 & $1 \mathrm{ct} 22 \mathrm{c} 2$ & 0.223 \\
\hline ust013t18 & 0.969 & hst007-04 & 0.908 & lst19c1 & 0.556 & hst006-12 & 0.223 \\
\hline ust $015 \mathrm{t} 17 \mathrm{x}$ & 0.967 & het010-04 & 0.908 & 1st19c3 & 0.556 & hst28i-17 & 0.223 \\
\hline ust016t28 & 0.966 & hst035-07 & 0.906 & lst18c4 & 0.555 & hst29i-01 & 0.222 \\
\hline ust016t30 & 0.965 & het $010-08$ & 0.905 & lst16-R140 & 0.554 & hst018-03 & 0.222 \\
\hline ust016t29 & 0.965 & het $010-03$ & 0.903 & 1 st $03 \mathrm{c} 8$ & 0.552 & lct26c4 & 0.221 \\
\hline ust016t25 & 0.965 & hst025-02 & 0.903 & 1st17-R147 & 0.552 & lct049t12 & 0.221 \\
\hline ust016t27 & 0.964 & hst025-01 & 0.903 & 1 st $03 \mathrm{c} 9$ & 0.552 & lct049t09 & 0.221 \\
\hline ust016t26 & 0.964 & hst007-11 & 0.901 & ust002t10 & 0.549 & lct049t11 & 0.221 \\
\hline ust006t05 & 0.964 & hst011-01 & 0.899 & $1 \mathrm{st} 18 \mathrm{c} 1$ & 0.548 & lct049t10 & 0.221 \\
\hline ust006t06 & 0.963 & hst007-02 & 0.898 & 1st16-R131 & 0.546 & hst018-02 & 0.221 \\
\hline ust014t16 & 0.963 & hst011-02 & 0.897 & lst16-R129 & 0.545 & hst28i-15 & 0.220 \\
\hline ust012t06x & 0.963 & hst025-04 & 0.897 & 1st17-R130 & 0.544 & hst033-02b & 0.220 \\
\hline ust017t05 & 0.963 & hst037-06 & 0.897 & lst16-R125 & 0.543 & hst28i-13 & 0.218 \\
\hline ust $015 \mathrm{t} 10 \mathrm{x}$ & 0.962 & het $010-10$ & 0.897 & 1st17-R126 & 0.542 & hst018-01 & 0.218 \\
\hline ust017t04 & 0.961 & het010-11 & 0.892 & lst17-R123 & 0.541 & lct $26 \mathrm{c} 3$ & 0.218 \\
\hline ust014t02 & 0.959 & hst005-12 & 0.887 & lst16-R113 & 0.540 & hst28i-11 & 0.218 \\
\hline ust 015 t $07 x$ & 0.958 & hst007-12 & 0.886 & ust002t09 & 0.540 & hst28i-9 & 0.217 \\
\hline ust013t19 & 0.953 & het $010-15$ & 0.885 & 1st16-105 & 0.539 & hst007-09 & 0.217 \\
\hline ust002t14 & 0.953 & hst007-03 & 0.882 & lst17-R122 & 0.536 & lct $25 \mathrm{c} 1$ & 0.216 \\
\hline ust002t01 & 0.953 & hst037-03 & 0.879 & 1st17-R104 & 0.535 & hst007-07 & 0.216 \\
\hline
\end{tabular}




\begin{tabular}{|c|c|c|c|c|c|c|c|}
\hline \multicolumn{2}{|c|}{ Application 1} & \multicolumn{2}{|c|}{ Application 2} & \multicolumn{2}{|c|}{ Application 3} & \multicolumn{2}{|c|}{ Application 4} \\
\hline Exp. ID & $\mathrm{c}_{\mathrm{r}}$ & Exp. ID & $\mathrm{c}_{\mathrm{r}}$ & Exp. ID & $\mathrm{c}_{\mathrm{r}}$ & Exp. ID & $\mathrm{c}_{\mathrm{r}}$ \\
\hline ust002t02 & 0.952 & hst005-11 & 0.875 & ust017t07 & 0.531 & hct010-06 & 0.215 \\
\hline ust014t11 & 0.951 & hst035-05 & 0.874 & ust002t17 & 0.528 & hst $033-02 \mathrm{c}$ & 0.213 \\
\hline ust004t08 & 0.949 & hst009-01 & 0.873 & ust003t10 & 0.524 & hst007-01 & 0.212 \\
\hline ust002t03 & 0.948 & hst007-10 & 0.871 & ust002t08 & 0.521 & hst009-04 & 0.210 \\
\hline ust002t12 & 0.948 & hst007-01 & 0.870 & 1st06c5 & 0.521 & $\operatorname{lct} 18 \mathrm{c} 1$ & 0.207 \\
\hline ust006t19 & 0.948 & het010-12 & 0.864 & 1st06c3 & 0.520 & het011-01 & 0.207 \\
\hline ust006t20 & 0.947 & het010-14 & 0.860 & ust017t06 & 0.520 & het010-08 & 0.207 \\
\hline ust006t24 & 0.947 & lct $18 \mathrm{c} 1$ & 0.858 & $1 \mathrm{st} 06 \mathrm{c} 1$ & 0.519 & het010-09 & 0.206 \\
\hline ust006t25 & 0.947 & hst005-17 & 0.857 & lst06c4 & 0.519 & het012-01 & 0.206 \\
\hline ust006t23 & 0.947 & hst005-15 & 0.853 & lst06c2 & 0.518 & het010-15 & 0.205 \\
\hline ust006t22 & 0.946 & hst037-01 & 0.845 & ust005t02 & 0.514 & het010-14 & 0.205 \\
\hline ust006t21 & 0.946 & het010-13 & 0.841 & ust012t07 & 0.513 & hst007-05 & 0.205 \\
\hline ust003t06 & 0.946 & lct32a6 & 0.836 & ust012t08 & 0.512 & $1 \mathrm{ct} 26 \mathrm{c} 2$ & 0.205 \\
\hline ust002t15 & 0.946 & $\operatorname{lct} 22 \mathrm{c} 3$ & 0.835 & ust002t07 & 0.505 & het010-07 & 0.204 \\
\hline ust002t04 & 0.943 & hst005-14 & 0.833 & ust016t32 & 0.505 & $1 \mathrm{ct} 24 \mathrm{c} 2$ & 0.204 \\
\hline ust004t03 & 0.939 & lct32a5 & 0.832 & ust016t33 & 0.505 & hst035-07 & 0.203 \\
\hline ust004t01 & 0.939 & lct22c4 & 0.829 & ust016t31 & 0.505 & het012-02 & 0.202 \\
\hline ust006t07 & 0.938 & het010-01 & 0.828 & ust002t16 & 0.502 & hst017-03 & 0.202 \\
\hline ust006t11 & 0.938 & hst035-01 & 0.826 & ust013t21 & 0.500 & hst017-02 & 0.202 \\
\hline ust006t08 & 0.938 & hst043-02 & 0.825 & ust002t06 & 0.499 & lct010-16 & 0.201 \\
\hline ust004t07 & 0.938 & lct32a4 & 0.821 & ust013t20 & 0.491 & lct010-19 & 0.201 \\
\hline ust003t07 & 0.938 & $1 \mathrm{ct} 24 \mathrm{c} 2$ & 0.819 & ust005t01x & 0.490 & lct079-5 & 0.201 \\
\hline ust006t09 & 0.937 & lct079-6 & 0.819 & ust002t05 & 0.487 & lct010-18 & 0.200 \\
\hline ust005t01x & 0.937 & lct20c6 & 0.818 & ust002t04 & 0.472 & het010-11 & 0.200 \\
\hline ust004t02 & 0.936 & lct079-7 & 0.817 & ust013t19 & 0.471 & hst017-01 & 0.200 \\
\hline ust013t20 & 0.936 & lct20c5 & 0.816 & ust017t04 & 0.467 & lct010-23 & 0.200 \\
\hline ust003t03 & 0.935 & het010-02 & 0.816 & ust017t05 & 0.466 & lct079-4 & 0.200 \\
\hline ust002t05 & 0.934 & lct20c4 & 0.814 & ust016t26 & 0.460 & lct010-30 & 0.200 \\
\hline ust014t10 & 0.934 & $1 \mathrm{ct} 22 \mathrm{c} 5$ & 0.814 & ust016t27 & 0.460 & lct010-17 & 0.199 \\
\hline ust004t05 & 0.933 & lct20c7 & 0.812 & ust003t09 & 0.459 & lct26c1 & 0.199 \\
\hline ust002t13 & 0.931 & lct079-8 & 0.812 & ust016t25 & 0.459 & lct $25 \mathrm{c} 2$ & 0.198 \\
\hline ust004t06 & 0.930 & lct20c3 & 0.812 & ust002t15 & 0.458 & het $010-10$ & 0.198 \\
\hline usi001t33x & 0.929 & lct079-9 & 0.811 & ust012t06x & 0.456 & lct010-29 & 0.198 \\
\hline ust003t02 & 0.927 & lct20c2 & 0.807 & ust002t03 & 0.456 & lct22c3 & 0.198 \\
\hline ust003t08 & 0.927 & lct079-10 & 0.806 & ust016t29 & 0.455 & het011-02 & 0.197 \\
\hline ust002t06 & 0.927 & $1 \mathrm{ct} 22 \mathrm{c} 2$ & 0.803 & ust016t30 & 0.455 & lct010-28 & 0.197 \\
\hline ust004t04 & 0.925 & lct009-27 & 0.798 & ust016t28 & 0.454 & $\operatorname{lct} 19 \mathrm{c} 1$ & 0.197 \\
\hline ust013t21 & 0.924 & lct009-26 & 0.798 & ust012t05 & 0.451 & het010-12 & 0.196 \\
\hline ust002t07 & 0.923 & lct009-25 & 0.798 & ust004t02 & 0.446 & $\mathrm{hmt} 006-23$ & 0.196 \\
\hline ust014t04 & 0.923 & lct009-02 & 0.797 & ust013t18 & 0.445 & lct040-03 & 0.196 \\
\hline
\end{tabular}




\begin{tabular}{|c|c|c|c|c|c|c|c|}
\hline \multicolumn{2}{|c|}{ Application 1} & \multicolumn{2}{|c|}{ Application 2} & \multicolumn{2}{|c|}{ Application 3} & \multicolumn{2}{|c|}{ Application 4} \\
\hline Exp. ID & $\mathrm{c}_{\mathrm{r}}$ & Exp. ID & $\mathrm{c}_{\mathrm{r}}$ & Exp. ID & $\mathrm{c}_{\mathrm{r}}$ & Exp. ID & $\mathrm{c}_{\mathrm{r}}$ \\
\hline ust014t03 & 0.921 & lct009-11 & 0.797 & ust017t01 & 0.444 & lct010-15 & 0.196 \\
\hline ust002t16 & 0.921 & lct009-06 & 0.797 & ust017t03 & 0.444 & lct040-01 & 0.195 \\
\hline ust016t31 & 0.920 & lct009-18 & 0.797 & ust003t08 & 0.443 & lct010-14 & 0.195 \\
\hline ust016t33 & 0.919 & lct009-23 & 0.797 & ust017t02 & 0.443 & $\operatorname{lct} 010-22$ & 0.194 \\
\hline ust016t32 & 0.919 & lct009-04 & 0.797 & ust013t17 & 0.439 & lct010-27 & 0.194 \\
\hline ust014t12 & 0.918 & $\operatorname{lct} 040-01$ & 0.797 & ust012t04 & 0.438 & het013-01 & 0.193 \\
\hline ust003t09 & 0.917 & lct009-10 & 0.797 & ust006t21 & 0.438 & het011-03 & 0.193 \\
\hline usi001t30x & 0.914 & lct009-01 & 0.797 & ust006t22 & 0.438 & het010-13 & 0.193 \\
\hline ust014t13 & 0.913 & lct009-03 & 0.797 & ust006t23 & 0.438 & hmt006-22 & 0.193 \\
\hline ust014t09 & 0.913 & lct009-08 & 0.797 & ust002t02 & 0.438 & hst016-01 & 0.193 \\
\hline ust003t04 & 0.911 & lct009-09 & 0.796 & ust006t25 & 0.438 & lct079-3 & 0.193 \\
\hline ust014t05 & 0.911 & lct009-13 & 0.796 & ust006t24 & 0.438 & lct $21 \mathrm{c} 1$ & 0.192 \\
\hline ust005t02 & 0.911 & lct009-16 & 0.796 & ust006t20 & 0.437 & lct079-2 & 0.192 \\
\hline ust002t08 & 0.909 & lct009-24 & 0.796 & ust006t19 & 0.437 & lct079-1 & 0.192 \\
\hline ust012t08 & 0.907 & lct009-05 & 0.796 & ust013t16 & 0.436 & $1 \mathrm{ct} 21 \mathrm{c} 2$ & 0.192 \\
\hline ust012t07 & 0.907 & lct009-15 & 0.796 & ust016t16 & 0.434 & lct $21 \mathrm{c} 3$ & 0.192 \\
\hline ust003t01 & 0.907 & lct009-14 & 0.796 & ust004t01 & 0.434 & hst001-01 & 0.189 \\
\hline ust014t15 & 0.906 & lct009-19 & 0.796 & ust016t17 & 0.433 & hst001-03 & 0.189 \\
\hline ust014t06 & 0.905 & lct009-21 & 0.796 & ust016t18 & 0.433 & hst001-08 & 0.189 \\
\hline ust017t06 & 0.904 & lct009-22 & 0.796 & ust004t08 & 0.433 & lct040-02 & 0.188 \\
\hline ust014t07 & 0.902 & lct009-17 & 0.795 & ust014t08 & 0.433 & het013-02 & 0.188 \\
\hline ust006t 10 & 0.901 & lct009-07 & 0.795 & ust016t19 & 0.433 & hmt006-21 & 0.187 \\
\hline ust002t17 & 0.895 & lct009-20 & 0.794 & ust002t14 & 0.432 & hst001-07 & 0.187 \\
\hline ust003t05 & 0.895 & lct26c1 & 0.793 & ust014t07 & 0.431 & hst010-04 & 0.187 \\
\hline ust014t08 & 0.893 & $1 \mathrm{ct} 23 \mathrm{c} 2$ & 0.792 & ust014t06 & 0.430 & hst010-03 & 0.186 \\
\hline ust014t14 & 0.892 & $\operatorname{lct} 23 \mathrm{c} 1$ & 0.790 & ust014t05 & 0.428 & hst027-01 & 0.186 \\
\hline ust017t07 & 0.892 & lct32a9 & 0.789 & ust013t15 & 0.426 & hmt006-18 & 0.185 \\
\hline ust002t09 & 0.886 & $\operatorname{lct} 23 \mathrm{c} 3$ & 0.788 & ust002t01 & 0.426 & lct010-21 & 0.185 \\
\hline usi001t $23 x$ & 0.881 & 1st16-105 & 0.785 & ust012t03 & 0.424 & hst010-02 & 0.185 \\
\hline uct001t03 & 0.879 & 1st17-R104 & 0.785 & ust014t14 & 0.422 & lct010-20 & 0.185 \\
\hline ust002t 10 & 0.873 & 1st17-R122 & 0.785 & ust014t03 & 0.422 & lct $21 \mathrm{c} 4$ & 0.184 \\
\hline usi001t20x & 0.867 & hmt006-19 & 0.784 & ust003t07 & 0.421 & lct $21 \mathrm{c} 5$ & 0.184 \\
\hline usi001t16x & 0.843 & lct $21 \mathrm{c} 3$ & 0.783 & ust014t09 & 0.421 & hst010-01 & 0.184 \\
\hline ust002t11 & 0.837 & $\operatorname{lct} 21 \mathrm{c} 2$ & 0.783 & ust014t04 & 0.421 & hst037-06 & 0.183 \\
\hline usi001t08x & 0.835 & hst033-03a & 0.782 & ust012t02 & 0.420 & lct $21 \mathrm{c} 6$ & 0.183 \\
\hline ust $003 \mathrm{t} 10$ & 0.833 & lct040-03 & 0.781 & ust012t01 & 0.420 & lct $22 \mathrm{c} 4$ & 0.182 \\
\hline ust015t09x & 0.814 & lct20c1 & 0.781 & ust016t15 & 0.419 & $\mathrm{hmt} 006-20$ & 0.182 \\
\hline usi001t $32 x$ & 0.805 & $\mathrm{hmt} 006-20$ & 0.780 & ust016t14 & 0.419 & lct009-07 & 0.182 \\
\hline ust015t19x & 0.805 & hst033-10a & 0.780 & ust014t15 & 0.419 & lct009-20 & 0.182 \\
\hline usi001t11x & 0.789 & lct079-4 & 0.779 & ust016t13 & 0.419 & lct19c2 & 0.182 \\
\hline
\end{tabular}




\begin{tabular}{|c|c|c|c|c|c|c|c|}
\hline \multicolumn{2}{|c|}{ Application 1} & \multicolumn{2}{|c|}{ Application 2} & \multicolumn{2}{|c|}{ Application 3} & \multicolumn{2}{|c|}{ Application 4} \\
\hline Exp. ID & $\mathrm{c}_{\mathrm{r}}$ & Exp. ID & $\mathrm{c}_{\mathrm{r}}$ & Exp. ID & $c_{r}$ & Exp. ID & $\mathrm{c}_{\mathrm{r}}$ \\
\hline usi001t06x & 0.779 & lst16-R113 & 0.779 & ust014t13 & 0.417 & lct009-14 & 0.182 \\
\hline ust $015 \mathrm{t} 31 \mathrm{x}$ & 0.778 & 1 st06c1 & 0.779 & ust014t12 & 0.416 & lct009-09 & 0.182 \\
\hline usi001t $22 x$ & 0.772 & $\operatorname{lct} 23 \mathrm{c} 4$ & 0.778 & ust014t10 & 0.407 & lct009-16 & 0.182 \\
\hline uct001t02 & 0.761 & $\operatorname{lct} 21 \mathrm{c} 1$ & 0.778 & ust016t22 & 0.404 & lct009-22 & 0.182 \\
\hline ust015t14x & 0.742 & lct079-5 & 0.774 & ust016t24 & 0.404 & $\operatorname{lct} 010-13$ & 0.182 \\
\hline ust $015 \mathrm{t} 04 \mathrm{x}$ & 0.735 & hmt006-21 & 0.774 & ust006t10 & 0.404 & lct009-05 & 0.181 \\
\hline usi001t $27 x$ & 0.685 & hst033-02a & 0.774 & ust016t21 & 0.404 & lct009-15 & 0.181 \\
\hline ust $015 \mathrm{t} 08 \mathrm{x}$ & 0.684 & $\operatorname{lct} 32 \mathrm{a} 8$ & 0.773 & ust016t23 & 0.404 & lct009-19 & 0.181 \\
\hline usi001t09x & 0.681 & $\operatorname{lct} 010-13$ & 0.773 & ust004t03 & 0.403 & lct009-17 & 0.181 \\
\hline ust015t18x & 0.681 & lct26c2 & 0.773 & $1 c t 017-08$ & 0.402 & $\operatorname{lct} 009-21$ & 0.181 \\
\hline usi001t $21 \mathrm{x}$ & 0.677 & $1 \mathrm{st} 01 \mathrm{c} 1$ & 0.772 & ust006t17 & 0.402 & lct009-08 & 0.181 \\
\hline usi001t17x & 0.663 & lct010-04 & 0.772 & ust006t18 & 0.402 & $\operatorname{lct} 32 \mathrm{a} 6$ & 0.181 \\
\hline usi001t31x & 0.663 & $\mathrm{hmt} 006-04$ & 0.771 & lct017-09 & 0.402 & lct009-01 & 0.181 \\
\hline ust 001 t $05 x$ & 0.656 & hmt006-03 & 0.769 & ust006t16 & 0.401 & lct009-18 & 0.181 \\
\hline usi001t10x & 0.654 & hmt006-22 & 0.769 & $1 c t 017-07$ & 0.401 & lct009-03 & 0.181 \\
\hline ust 001 t $04 x$ & 0.649 & 1st06c2 & 0.769 & $1 c t 017-05$ & 0.401 & lct009-06 & 0.181 \\
\hline usi001t04x & 0.647 & $\operatorname{lct} 23 \mathrm{c} 5$ & 0.768 & lct017-06 & 0.401 & lct009-23 & 0.181 \\
\hline ust001t03x & 0.642 & hmt006-02 & 0.768 & $\operatorname{lct} 017-04$ & 0.400 & lct009-02 & 0.181 \\
\hline ust001t02x & 0.635 & hmt006-23 & 0.767 & ust016t02 & 0.400 & lct009-04 & 0.181 \\
\hline ust001t01x & 0.627 & lct32a1 & 0.766 & ust002t12 & 0.399 & lct009-11 & 0.181 \\
\hline ust015t30x & 0.592 & lct $25 \mathrm{c} 3$ & 0.766 & ust016t03 & 0.399 & lct009-13 & 0.181 \\
\hline hst043-01 & 0.586 & lst17-R123 & 0.765 & ust013t14 & 0.399 & lct009-10 & 0.181 \\
\hline usi001t29x & 0.574 & hst033-03b & 0.765 & ust006t09 & 0.399 & lct009-24 & 0.181 \\
\hline usi001t19x & 0.568 & lct079-2 & 0.765 & ust013t10 & 0.399 & lct009-25 & 0.180 \\
\hline ust015t06x & 0.563 & lct010-30 & 0.765 & ust016t04 & 0.399 & lct009-26 & 0.180 \\
\hline usi001t14x & 0.563 & lct079-1 & 0.764 & ust013t13 & 0.399 & lct009-27 & 0.180 \\
\hline hst001-08 & 0.559 & lst16-R125 & 0.764 & ust016t01 & 0.399 & lct010-04 & 0.180 \\
\hline hst001-07 & 0.558 & lct $21 \mathrm{c} 6$ & 0.763 & ust013t07 & 0.399 & lct010-05 & 0.180 \\
\hline hst001-03 & 0.555 & hst012-01 & 0.762 & ust006t08 & 0.399 & lct079-10 & 0.180 \\
\hline usi001t07x & 0.551 & hmt006-05 & 0.762 & ust013t08 & 0.399 & hst015-02 & 0.180 \\
\hline hst001-01 & 0.549 & 1 st06c3 & 0.760 & ust013t09 & 0.399 & hmt006-17 & 0.179 \\
\hline hst027-01 & 0.547 & lct010-08 & 0.760 & ust013t12 & 0.399 & hst015-01 & 0.179 \\
\hline ust015t16x & 0.545 & lct079-3 & 0.760 & ust013t06 & 0.399 & lct079-9 & 0.179 \\
\hline uct001t04 & 0.531 & lct $21 \mathrm{c} 5$ & 0.759 & ust013t11 & 0.399 & $\operatorname{lct} 23 \mathrm{c} 1$ & 0.179 \\
\hline hst017-01 & 0.530 & lct010-29 & 0.759 & $\operatorname{lct} 017-22$ & 0.398 & lct010-24 & 0.179 \\
\hline hst015-01 & 0.527 & hmt006-11 & 0.758 & ust006t07 & 0.398 & hst043-01 & 0.178 \\
\hline hst017-02 & 0.524 & hmt006-17 & 0.758 & ust006t11 & 0.398 & lct010-07 & 0.178 \\
\hline hst001-06 & 0.521 & lct $25 \mathrm{c} 4$ & 0.758 & ust013t05 & 0.398 & lct010-08 & 0.178 \\
\hline hst001-10 & 0.520 & $\operatorname{lct} 22 \mathrm{c} 1$ & 0.758 & ust013t02 & 0.397 & lct079-8 & 0.178 \\
\hline hst017-03 & 0.516 & $\mathrm{hmt} 006-01$ & 0.757 & ust013t01 & 0.397 & $\operatorname{lct} 23 \mathrm{c} 4$ & 0.178 \\
\hline
\end{tabular}




\begin{tabular}{|c|c|c|c|c|c|c|c|}
\hline \multicolumn{2}{|c|}{ Application 1} & \multicolumn{2}{|c|}{ Application 2} & \multicolumn{2}{|c|}{ Application 3} & \multicolumn{2}{|c|}{ Application 4} \\
\hline Exp. ID & $\mathrm{c}_{\mathrm{r}}$ & Exp. ID & $\mathrm{c}_{\mathrm{r}}$ & Exp. ID & $c_{r}$ & Exp. ID & $\mathrm{c}_{\mathrm{r}}$ \\
\hline hst015-02 & 0.515 & $\operatorname{lct} 21 \mathrm{c} 4$ & 0.757 & ust013t03 & 0.397 & $\operatorname{lct} 23 \mathrm{c} 5$ & 0.178 \\
\hline hst016-01 & 0.515 & lst17-R126 & 0.757 & ust013t04 & 0.397 & lct $23 \mathrm{c} 6$ & 0.178 \\
\hline hst001-05 & 0.513 & hst043-03 & 0.756 & $\operatorname{lct} 017-14$ & 0.396 & lct32a5 & 0.178 \\
\hline hst28i-5 & 0.509 & $\operatorname{lct} 010-23$ & 0.755 & $\operatorname{lct} 012-01$ & 0.396 & lct010-12 & 0.178 \\
\hline hst28i-1 & 0.508 & 1 st $06 \mathrm{c} 4$ & 0.755 & ust014t11 & 0.394 & $1 \mathrm{ct} 23 \mathrm{c} 2$ & 0.178 \\
\hline ust $015 \mathrm{t} 24 \mathrm{x}$ & 0.507 & $\operatorname{lct} 010-19$ & 0.755 & $\operatorname{lct} 017-21$ & 0.394 & $\operatorname{lct} 23 \mathrm{c} 3$ & 0.178 \\
\hline hst $28 \mathrm{i}-3$ & 0.507 & lct $22 \mathrm{c} 6$ & 0.755 & $\operatorname{lct} 017-13$ & 0.394 & hst035-05 & 0.178 \\
\hline hst018-01 & 0.506 & $\operatorname{lct} 32 \mathrm{a} 2$ & 0.754 & lct012-09 & 0.394 & lct25c3 & 0.177 \\
\hline ust015t29x & 0.501 & 1st16-R129 & 0.752 & $\operatorname{lct} 017-03$ & 0.392 & lct079-7 & 0.177 \\
\hline hst014-01 & 0.500 & $1 \mathrm{ct} 25 \mathrm{c} 2$ & 0.752 & $1 c t 012-02$ & 0.392 & $\operatorname{lct} 079-6$ & 0.177 \\
\hline ust009t01 & 0.499 & lct $23 \mathrm{c} 6$ & 0.750 & $1 \mathrm{ct} 012-03$ & 0.392 & hst037-03 & 0.177 \\
\hline hst30i-01 & 0.497 & hmt006-13 & 0.749 & ust006t14 & 0.392 & lct010-06 & 0.176 \\
\hline hst001-09 & 0.496 & $1 \mathrm{ct} 22 \mathrm{c} 7$ & 0.749 & ust006t15 & 0.391 & lct010-25 & 0.176 \\
\hline hst018-02 & 0.496 & $1 \mathrm{st} 03 \mathrm{c} 1$ & 0.748 & $\operatorname{lct} 017-25$ & 0.391 & lct32a4 & 0.176 \\
\hline hst001-02 & 0.495 & hmt006-10 & 0.747 & ust006t12 & 0.391 & hst28i-7 & 0.175 \\
\hline hst28i-11 & 0.494 & hmt006-18 & 0.747 & $\operatorname{lct} 012-10$ & 0.391 & $\operatorname{lct} 22 \mathrm{c} 5$ & 0.175 \\
\hline hst001-04 & 0.493 & $\mathrm{hmt006-06}$ & 0.746 & lct012-06 & 0.391 & hst30i-01 & 0.175 \\
\hline hst28i-7 & 0.491 & lct32a7 & 0.746 & lct012-08 & 0.391 & hmt006-14 & 0.175 \\
\hline usi001t18x & 0.491 & lct010-18 & 0.746 & ust006t13 & 0.391 & $\mathrm{hmt} 006-16$ & 0.174 \\
\hline hst28i-9 & 0.491 & lst17-R130 & 0.746 & lct012-07 & 0.391 & $\mathrm{hmt} 006-13$ & 0.174 \\
\hline hst28i-13 & 0.491 & hst033-02b & 0.745 & $\operatorname{lct} 017-20$ & 0.391 & hmt006-15 & 0.174 \\
\hline usi001t28x & 0.491 & hst013-01 & 0.745 & $\operatorname{lct} 012-05$ & 0.390 & hst025-05 & 0.173 \\
\hline hst025-02 & 0.485 & 1 st06c5 & 0.744 & lct012-04 & 0.390 & lct010-26 & 0.173 \\
\hline hst018-03 & 0.484 & lst16-R131 & 0.744 & $\operatorname{lct} 017-12$ & 0.389 & hst28i-3 & 0.173 \\
\hline hst28i-15 & 0.484 & lct010-12 & 0.743 & ust016t08 & 0.388 & hst $28 \mathrm{i}-5$ & 0.173 \\
\hline hst025-05 & 0.483 & lct040-02 & 0.742 & ust003t06 & 0.388 & lct010-11 & 0.173 \\
\hline usi001t t05x & 0.480 & lct010-17 & 0.740 & ust004t05 & 0.388 & lct20c1 & 0.173 \\
\hline ust015t05x & 0.477 & lst $18 \mathrm{c} 4$ & 0.740 & lct017-19 & 0.388 & hst28i-1 & 0.173 \\
\hline hst010-04 & 0.477 & lct010-07 & 0.738 & ust016t07 & 0.388 & hst014-01 & 0.172 \\
\hline hst010-01 & 0.477 & hmt006-16 & 0.738 & ust016t06 & 0.387 & 1st06c5 & 0.172 \\
\hline hst010-03 & 0.477 & $1 s t 03 c 2$ & 0.737 & ust016t09 & 0.387 & hmt006-10 & 0.171 \\
\hline hst025-01 & 0.475 & $1 s t 18 \mathrm{c} 3$ & 0.737 & ust004t07 & 0.386 & hst037-01 & 0.171 \\
\hline hst010-02 & 0.475 & 1 st18c1 & 0.737 & $\operatorname{lct} 017-11$ & 0.386 & $1 \mathrm{ct} 20 \mathrm{c} 2$ & 0.171 \\
\hline hst025-04 & 0.472 & $1 \mathrm{st} 18 \mathrm{c} 5$ & 0.736 & lct017-10 & 0.384 & lct32a9 & 0.171 \\
\hline ust $015 \mathrm{t} 15 \mathrm{x}$ & 0.471 & 1st19c1 & 0.736 & ust014t16 & 0.383 & lst06c4 & 0.171 \\
\hline hst29i-01 & 0.471 & 1st19c3 & 0.735 & $\operatorname{lct} 017-29$ & 0.383 & hst011-01 & 0.170 \\
\hline hst30i-04 & 0.467 & 1st18c6 & 0.735 & ust004t04 & 0.378 & lct20c3 & 0.170 \\
\hline hst28i-17 & 0.464 & 1st19c2 & 0.735 & $\operatorname{lct} 017-02$ & 0.378 & hmt006-19 & 0.170 \\
\hline ust009t02 & 0.464 & $1 \mathrm{st} 03 \mathrm{c} 3$ & 0.735 & ust004t06 & 0.377 & hst001-10 & 0.170 \\
\hline hst019-01 & 0.460 & $1 s t 19 \mathrm{c} 5$ & 0.735 & ust014t02 & 0.377 & lct20c4 & 0.170 \\
\hline
\end{tabular}




\begin{tabular}{|c|c|c|c|c|c|c|c|}
\hline \multicolumn{2}{|c|}{ Application 1} & \multicolumn{2}{|c|}{ Application 2} & \multicolumn{2}{|c|}{ Application 3} & \multicolumn{2}{|c|}{ Application 4} \\
\hline Exp. ID & $\mathrm{c}_{\mathrm{r}}$ & Exp. ID & $\mathrm{c}_{\mathrm{r}}$ & Exp. ID & $\mathrm{c}_{\mathrm{r}}$ & Exp. ID & $\mathrm{c}_{\mathrm{r}}$ \\
\hline hst009-04 & 0.458 & 1st19c6 & 0.734 & ust002t13 & 0.376 & hst011-02 & 0.170 \\
\hline hst011-01 & 0.455 & lst19c4 & 0.733 & $\operatorname{lct} 017-17$ & 0.375 & 1st06c3 & 0.170 \\
\hline hst011-02 & 0.453 & 1st17-R147 & 0.731 & lct017-01 & 0.375 & lct20c7 & 0.170 \\
\hline hst007-09 & 0.445 & lct010-22 & 0.730 & ust016t11 & 0.374 & $\operatorname{lct} 20 \mathrm{c} 5$ & 0.170 \\
\hline hst006-01 & 0.443 & 1st07-R14 & 0.730 & ust016t10 & 0.374 & hmt006-01 & 0.170 \\
\hline hst007-07 & 0.439 & lct010-06 & 0.729 & ust016t12 & 0.374 & hmt006-08 & 0.170 \\
\hline het010-07 & 0.438 & 1st16-R140 & 0.728 & ust014t01 & 0.373 & lct20c6 & 0.170 \\
\hline ust015t23x & 0.438 & hmt006-07 & 0.724 & lct042-01 & 0.372 & hmt006-09 & 0.169 \\
\hline hst006-08 & 0.434 & lst04-R1 & 0.722 & lct017-16 & 0.371 & lct32a8 & 0.169 \\
\hline het010-06 & 0.434 & lct $25 \mathrm{c} 1$ & 0.720 & lct042-06 & 0.370 & lst01c1 & 0.169 \\
\hline ust008t01x & 0.432 & hst033-10c & 0.720 & lct042-02 & 0.369 & hmt006-07 & 0.169 \\
\hline het010-09 & 0.432 & 1st16-R196 & 0.720 & lct017-15 & 0.367 & hmt006-12 & 0.169 \\
\hline hst006-12 & 0.428 & $1 \mathrm{ct} 19 \mathrm{c} 2$ & 0.717 & lct042-07 & 0.367 & hst035-01 & 0.169 \\
\hline hst007-05 & 0.428 & hst $033-03 \mathrm{c}$ & 0.717 & lct042-05 & 0.367 & hmt006-06 & 0.169 \\
\hline het010-10 & 0.427 & hst033-10d & 0.716 & lct042-04 & 0.366 & hst025-01 & 0.169 \\
\hline ust015t28x & 0.424 & $1 \mathrm{st} 21 \mathrm{c} 1$ & 0.716 & lct042-03 & 0.366 & lct010-10 & 0.169 \\
\hline hct010-08 & 0.424 & lct010-15 & 0.714 & lct010-06 & 0.362 & hst001-06 & 0.169 \\
\hline ust009t03 & 0.423 & 1st07-R30 & 0.713 & lct010-07 & 0.361 & 1 st06c2 & 0.169 \\
\hline hst006-27 & 0.423 & lct32a3 & 0.711 & lct010-08 & 0.361 & lct22c6 & 0.168 \\
\hline hst009-03 & 0.420 & lct010-11 & 0.711 & ust006t06 & 0.361 & lct32a7 & 0.168 \\
\hline hct010-11 & 0.418 & 1st04-R29 & 0.707 & ust006t05 & 0.360 & hst025-04 & 0.168 \\
\hline hst007-08 & 0.418 & hst $033-02 c$ & 0.706 & lct017-28 & 0.360 & hst001-05 & 0.168 \\
\hline hst037-06 & 0.417 & hmt006-12 & 0.705 & lct017-24 & 0.359 & $\operatorname{lct} 25 \mathrm{c} 4$ & 0.168 \\
\hline hst007-06 & 0.412 & lct010-14 & 0.703 & ust $015 \mathrm{t} 25 \mathrm{x}$ & 0.359 & hmt006-05 & 0.167 \\
\hline hst035-05 & 0.411 & lct010-05 & 0.703 & lct017-23 & 0.358 & lct $22 \mathrm{c} 7$ & 0.167 \\
\hline usi001t15x & 0.409 & 1st20c1 & 0.702 & ust006t04 & 0.356 & hst025-02 & 0.167 \\
\hline hst037-03 & 0.408 & 1st07-R32 & 0.696 & lct010-05 & 0.355 & hmt006-11 & 0.167 \\
\hline hst035-07 & 0.406 & hmt006-14 & 0.694 & ust006t01 & 0.355 & lct010-09 & 0.167 \\
\hline usi001t03x & 0.406 & $1 \mathrm{st} 03 \mathrm{c} 4$ & 0.694 & ust006t02 & 0.355 & hmt006-02 & 0.167 \\
\hline het010-03 & 0.406 & lct010-21 & 0.693 & ust006t03 & 0.355 & 1st06c1 & 0.167 \\
\hline usi001t26x & 0.405 & lct010-28 & 0.691 & lct009-26 & 0.353 & hmt006-03 & 0.166 \\
\hline het010-04 & 0.403 & 1st04-R33 & 0.691 & lct009-27 & 0.353 & hmt006-04 & 0.165 \\
\hline hst043-02 & 0.403 & lct19c3 & 0.690 & ust003t01 & 0.352 & lst16-105 & 0.163 \\
\hline hst007-03 & 0.400 & lct010-10 & 0.689 & lct009-25 & 0.352 & lst16-R113 & 0.162 \\
\hline ust015t03x & 0.398 & 1st20c2 & 0.689 & lct009-24 & 0.352 & lst17-R104 & 0.161 \\
\hline hst007-12 & 0.396 & $\operatorname{lct} 24 \mathrm{c} 1$ & 0.687 & lct009-04 & 0.352 & hst043-02 & 0.161 \\
\hline het010-15 & 0.395 & $1 \mathrm{st} 21 \mathrm{c} 2$ & 0.683 & ust003t02 & 0.351 & lct012-04 & 0.161 \\
\hline hst007-14 & 0.392 & lct010-20 & 0.683 & lct009-01 & 0.351 & lct012-08 & 0.161 \\
\hline ust015t13x & 0.391 & hmt006-15 & 0.679 & lct009-02 & 0.351 & lct012-05 & 0.160 \\
\hline hst007-15 & 0.391 & hmt006-08 & 0.678 & lct009-03 & 0.351 & lct012-07 & 0.160 \\
\hline
\end{tabular}




\begin{tabular}{|c|c|c|c|c|c|c|c|}
\hline \multicolumn{2}{|c|}{ Application 1} & \multicolumn{2}{|c|}{ Application 2} & \multicolumn{2}{|c|}{ Application 3} & \multicolumn{2}{|c|}{ Application 4} \\
\hline Exp. ID & $\mathrm{c}_{\mathrm{r}}$ & Exp. ID & $\mathrm{c}_{\mathrm{r}}$ & Exp. ID & $\mathrm{c}_{\mathrm{r}}$ & Exp. ID & $\mathrm{c}_{\mathrm{r}}$ \\
\hline hst007-17 & 0.390 & lct19c1 & 0.678 & $\operatorname{lct} 009-13$ & 0.351 & 1st17-R122 & 0.160 \\
\hline $\operatorname{lct} 32 \mathrm{a} 6$ & 0.387 & 1st07-R36 & 0.675 & $\operatorname{lct} 009-11$ & 0.351 & lct012-06 & 0.160 \\
\hline het010-12 & 0.386 & 1st04-R34 & 0.673 & lct009-10 & 0.351 & lct012-02 & 0.160 \\
\hline $\operatorname{lct} 32 \mathrm{a} 5$ & 0.386 & $1 s t 21 \mathrm{c} 3$ & 0.671 & $\operatorname{lct} 009-15$ & 0.351 & lct012-03 & 0.160 \\
\hline hst007-13 & 0.383 & lct010-09 & 0.670 & lct009-18 & 0.351 & lst16-R125 & 0.160 \\
\hline hst007-04 & 0.382 & hst042-01 & 0.669 & $\operatorname{lct} 009-14$ & 0.351 & hst012-01 & 0.160 \\
\hline hst007-01 & 0.380 & hst042-02 & 0.669 & lct009-05 & 0.350 & hst043-03 & 0.160 \\
\hline hst037-01 & 0.379 & lct26c3 & 0.667 & 1ct009-06 & 0.350 & $\operatorname{lct} 012-10$ & 0.160 \\
\hline hst007-16 & 0.378 & 1 st $03 \mathrm{c} 5$ & 0.665 & lct009-23 & 0.350 & hst013-01 & 0.160 \\
\hline ust 015 t $27 x$ & 0.375 & lct010-03 & 0.665 & lct009-08 & 0.350 & lct010-03 & 0.160 \\
\hline ust009t04 & 0.375 & 1st09-R92 & 0.664 & $\operatorname{lct} 009-21$ & 0.350 & $1 s t 18 \mathrm{c} 1$ & 0.159 \\
\hline $\operatorname{lct} 32 \mathrm{a} 4$ & 0.374 & 1 st $03 \mathrm{c} 6$ & 0.663 & $\operatorname{lct} 009-17$ & 0.350 & lst16-R129 & 0.159 \\
\hline hmt006-04 & 0.373 & lct010-16 & 0.663 & lct009-19 & 0.350 & lct012-01 & 0.159 \\
\hline hmt006-02 & 0.372 & 1st09-R93 & 0.661 & $\operatorname{lct} 009-16$ & 0.350 & 1st18c6 & 0.159 \\
\hline $\operatorname{lct} 22 \mathrm{c} 4$ & 0.372 & lst04-R51 & 0.660 & lct009-07 & 0.350 & 1 st $18 \mathrm{c} 5$ & 0.159 \\
\hline lct079-6 & 0.371 & 1st08-R74 & 0.660 & lct009-20 & 0.350 & lct012-09 & 0.158 \\
\hline hst009-02 & 0.371 & 1st20c3 & 0.659 & lct009-22 & 0.350 & 1st16-R131 & 0.158 \\
\hline lct20c6 & 0.371 & 1st09-R94 & 0.659 & lct079-6 & 0.350 & lst17-R123 & 0.158 \\
\hline lct $18 \mathrm{c} 1$ & 0.371 & lst10-R83 & 0.659 & lct009-09 & 0.349 & lct19c3 & 0.158 \\
\hline hst007-10 & 0.370 & 1st10-R86 & 0.659 & lct079-7 & 0.349 & lct017-29 & 0.158 \\
\hline lct079-7 & 0.368 & lst10-R88 & 0.659 & lct079-8 & 0.349 & lst18c4 & 0.158 \\
\hline hst007-02 & 0.368 & 1st08-R76 & 0.659 & $\operatorname{lct} 010-13$ & 0.348 & lct017-22 & 0.158 \\
\hline lct20c5 & 0.367 & 1st10-R85 & 0.658 & lct010-04 & 0.348 & $1 \mathrm{st} 18 \mathrm{c} 3$ & 0.158 \\
\hline ust015t $22 x$ & 0.367 & hmt006-09 & 0.658 & lct079-9 & 0.347 & 1st17-R126 & 0.157 \\
\hline hmt006-03 & 0.367 & lst07-R49 & 0.657 & lct079-10 & 0.346 & $1 \mathrm{st} 19 \mathrm{c} 5$ & 0.157 \\
\hline hmt006-19 & 0.366 & 1st08-R78 & 0.656 & lct010-19 & 0.345 & 1st19c6 & 0.157 \\
\hline hst007-11 & 0.366 & lst04-R46 & 0.656 & $1 \mathrm{ct} 010-23$ & 0.345 & lst19c4 & 0.157 \\
\hline hst035-01 & 0.365 & 1st08-R72 & 0.654 & ust 003 t03 & 0.345 & 1st19c3 & 0.157 \\
\hline lct20c4 & 0.364 & lct049t10 & 0.653 & $\operatorname{lct} 010-30$ & 0.345 & hst042-01 & 0.157 \\
\hline hmt006-01 & 0.363 & lct049t09 & 0.652 & lct079-1 & 0.344 & hst042-02 & 0.157 \\
\hline $1 \mathrm{ct} 22 \mathrm{c} 5$ & 0.363 & lct049t11 & 0.651 & lct079-2 & 0.344 & $1 \mathrm{st} 19 \mathrm{c} 2$ & 0.157 \\
\hline hct010-13 & 0.362 & ust013t11 & 0.649 & lct079-3 & 0.343 & lct017-21 & 0.157 \\
\hline het010-14 & 0.362 & ust013t07 & 0.649 & $\operatorname{lct} 010-29$ & 0.340 & lst16-R140 & 0.157 \\
\hline lct20c7 & 0.361 & ust013t08 & 0.649 & lct010-18 & 0.338 & lst17-R130 & 0.157 \\
\hline $1 \mathrm{ct} 22 \mathrm{c} 3$ & 0.360 & ust013t09 & 0.649 & lct079-4 & 0.338 & $1 \mathrm{st} 19 \mathrm{c} 1$ & 0.156 \\
\hline lct20c3 & 0.360 & ust013t06 & 0.649 & lct079-5 & 0.338 & lct017-19 & 0.156 \\
\hline lct079-8 & 0.359 & ust013t10 & 0.649 & lst01c1 & 0.336 & lct017-20 & 0.156 \\
\hline 1st17-R104 & 0.359 & ust013t12 & 0.649 & lct010-17 & 0.334 & 1st16-R196 & 0.156 \\
\hline lst17-R122 & 0.359 & ust $013 \mathrm{t} 13$ & 0.649 & $\operatorname{lct} 010-12$ & 0.331 & lst17-R147 & 0.155 \\
\hline usi001t13x & 0.358 & ust013t14 & 0.649 & $\operatorname{lct} 010-22$ & 0.330 & lct017-25 & 0.155 \\
\hline
\end{tabular}




\begin{tabular}{|c|c|c|c|c|c|c|c|}
\hline \multicolumn{2}{|c|}{ Application 1} & \multicolumn{2}{|c|}{ Application 2} & \multicolumn{2}{|c|}{ Application 3} & \multicolumn{2}{|c|}{ Application 4} \\
\hline Exp. ID & $\mathrm{c}_{\mathrm{r}}$ & Exp. ID & $\mathrm{c}_{\mathrm{r}}$ & Exp. ID & $\mathrm{c}_{\mathrm{r}}$ & Exp. ID & $\mathrm{c}_{\mathrm{r}}$ \\
\hline usi001t02x & 0.358 & ust013t03 & 0.649 & lct20c7 & 0.329 & het014-01 & 0.155 \\
\hline usi001t $25 x$ & 0.357 & ust $013 \mathrm{t} 01$ & 0.649 & lct20c6 & 0.329 & $\operatorname{lct} 017-28$ & 0.154 \\
\hline lct079-9 & 0.357 & $1 \mathrm{st} 21 \mathrm{c} 4$ & 0.649 & lct20c5 & 0.328 & lct042-03 & 0.154 \\
\hline lst16-105 & 0.352 & ust $013 \mathrm{t} 02$ & 0.649 & lct20c4 & 0.327 & lct042-04 & 0.154 \\
\hline $1 \mathrm{ct} 20 \mathrm{c} 2$ & 0.351 & ust013t04 & 0.649 & lct20c3 & 0.327 & lct042-02 & 0.154 \\
\hline ust $015 \mathrm{t} 02 \mathrm{x}$ & 0.350 & ust $013 \mathrm{t} 05$ & 0.648 & lct26c1 & 0.327 & $\operatorname{lct} 042-05$ & 0.154 \\
\hline hmt006-11 & 0.348 & $\operatorname{lct} 049 \mathrm{t} 12$ & 0.647 & uct001t03 & 0.327 & 1st20c1 & 0.154 \\
\hline lct079-10 & 0.348 & $\operatorname{lct} 010-27$ & 0.646 & ust015t17x & 0.326 & hst042-03 & 0.153 \\
\hline $\mathrm{hmt} 006-05$ & 0.345 & ust016t21 & 0.645 & $1 \mathrm{ct} 20 \mathrm{c} 2$ & 0.324 & $1 \mathrm{st} 03 \mathrm{c} 1$ & 0.153 \\
\hline lst16-R113 & 0.344 & ust $016 \mathrm{t} 23$ & 0.645 & lct010-15 & 0.324 & hst032-01 & 0.153 \\
\hline ust015t12x & 0.343 & ust016t24 & 0.645 & lct010-28 & 0.322 & lct017-14 & 0.153 \\
\hline hmt006-10 & 0.342 & ust016t22 & 0.645 & lct010-16 & 0.322 & $1 s t 03 \mathrm{c} 3$ & 0.153 \\
\hline lct32a9 & 0.340 & ust013t17 & 0.643 & $1 \mathrm{ct} 26 \mathrm{c} 2$ & 0.321 & lst21c1 & 0.153 \\
\hline hst009-01 & 0.337 & ust $013 \mathrm{t} 16$ & 0.643 & lct010-14 & 0.320 & lct017-09 & 0.153 \\
\hline lct009-27 & 0.336 & ust013t15 & 0.643 & lct040-01 & 0.320 & lct042-01 & 0.153 \\
\hline lst17-R123 & 0.336 & lct017-09 & 0.642 & ust003t04 & 0.317 & 1st20c2 & 0.153 \\
\hline lct009-26 & 0.336 & ust013t18 & 0.641 & lct040-03 & 0.316 & lct017-13 & 0.153 \\
\hline lct009-25 & 0.335 & lct010-02 & 0.641 & lct20c1 & 0.316 & lct017-17 & 0.153 \\
\hline hmt006-13 & 0.335 & 1st20c4 & 0.640 & lct010-11 & 0.315 & lct042-07 & 0.153 \\
\hline hmt006-20 & 0.334 & ust012t04 & 0.640 & lct010-21 & 0.312 & $1 \mathrm{st} 03 \mathrm{c} 2$ & 0.153 \\
\hline lct009-02 & 0.333 & ust016t12 & 0.639 & ust015t07x & 0.310 & lct010-01 & 0.152 \\
\hline lct009-04 & 0.333 & ust016t11 & 0.639 & lct010-20 & 0.310 & $\operatorname{lct} 017-12$ & 0.152 \\
\hline lct009-11 & 0.333 & lct010-01 & 0.639 & ust003t05 & 0.307 & lst03c4 & 0.152 \\
\hline lct009-10 & 0.333 & ust016t10 & 0.639 & lct21c3 & 0.307 & lct042-06 & 0.152 \\
\hline het010-01 & 0.332 & ust012t03 & 0.638 & lct010-27 & 0.306 & lct010-02 & 0.152 \\
\hline lct009-24 & 0.332 & ust012t02 & 0.637 & $1 \mathrm{ct} 21 \mathrm{c} 2$ & 0.306 & lct017-16 & 0.152 \\
\hline lct009-18 & 0.332 & lct26c4 & 0.637 & lct $21 \mathrm{c} 6$ & 0.306 & lct017-10 & 0.152 \\
\hline lct009-06 & 0.332 & ust012t06x & 0.636 & lct $21 \mathrm{c} 5$ & 0.305 & 1st21c2 & 0.152 \\
\hline lct009-23 & 0.332 & ust012t05 & 0.635 & ust015t31x & 0.305 & lct017-15 & 0.152 \\
\hline lct009-01 & 0.332 & ust012t01 & 0.635 & lct $21 \mathrm{c} 1$ & 0.305 & lct017-11 & 0.152 \\
\hline lct009-03 & 0.332 & lct017-14 & 0.630 & lct $21 \mathrm{c} 4$ & 0.304 & hst042-04 & 0.151 \\
\hline lct009-13 & 0.331 & lct012-01 & 0.629 & lct017-27 & 0.304 & lct017-03 & 0.151 \\
\hline hst005-12 & 0.331 & ust016t28 & 0.629 & lct010-10 & 0.303 & lct017-08 & 0.151 \\
\hline lct009-08 & 0.331 & ust016t30 & 0.629 & lct040-02 & 0.299 & het014-02 & 0.151 \\
\hline lct $24 \mathrm{c} 2$ & 0.330 & ust016t29 & 0.628 & ust015t10x & 0.298 & 1 st $03 \mathrm{c} 5$ & 0.151 \\
\hline lst03c1 & 0.330 & 1st04-R54 & 0.628 & lct010-03 & 0.296 & 1st20c3 & 0.151 \\
\hline lct009-09 & 0.329 & ust016t13 & 0.628 & lct010-09 & 0.295 & lst03c6 & 0.150 \\
\hline lct009-05 & 0.329 & ust016t14 & 0.627 & lct049t10 & 0.294 & lct017-04 & 0.150 \\
\hline lct009-15 & 0.329 & het012-02 & 0.627 & lct049t11 & 0.293 & lct017-05 & 0.150 \\
\hline lct009-14 & 0.329 & lct017-13 & 0.627 & lct049t09 & 0.293 & hst042-06 & 0.150 \\
\hline
\end{tabular}




\begin{tabular}{|c|c|c|c|c|c|c|c|}
\hline \multicolumn{2}{|c|}{ Application 1} & \multicolumn{2}{|c|}{ Application 2} & \multicolumn{2}{|c|}{ Application 3} & \multicolumn{2}{|c|}{ Application 4} \\
\hline Exp. ID & $\mathrm{c}_{\mathrm{r}}$ & Exp. ID & $\mathrm{c}_{\mathrm{r}}$ & Exp. ID & $\mathrm{c}_{\mathrm{r}}$ & Exp. ID & $\mathrm{c}_{\mathrm{r}}$ \\
\hline lct009-16 & 0.329 & ust016t15 & 0.627 & usi001t30x & 0.293 & lct017-07 & 0.150 \\
\hline lct009-21 & 0.329 & lct017-08 & 0.627 & $\operatorname{lct} 049 \mathrm{t} 12$ & 0.292 & 1st21c3 & 0.150 \\
\hline lct009-19 & 0.329 & lct049t16 & 0.627 & lct26c3 & 0.292 & $\operatorname{lct} 017-06$ & 0.150 \\
\hline lst07-R14 & 0.329 & ust016t25 & 0.626 & lct017-26 & 0.289 & hst042-05 & 0.149 \\
\hline lct009-17 & 0.328 & lct017-03 & 0.625 & lct19c3 & 0.289 & 1st20c4 & 0.149 \\
\hline lct009-22 & 0.328 & ust016t27 & 0.625 & lct $18 \mathrm{c} 1$ & 0.287 & 1st04-R1 & 0.149 \\
\hline lst16-R125 & 0.328 & ust016t26 & 0.625 & usi001t33x & 0.286 & 1st07-R14 & 0.149 \\
\hline ust $015 \mathrm{t} 26 \mathrm{x}$ & 0.328 & lct049t13 & 0.625 & lct19c2 & 0.284 & 1 st $03 \mathrm{c} 7$ & 0.149 \\
\hline lct009-07 & 0.327 & lct049t07 & 0.624 & lct049t16 & 0.282 & $1 \mathrm{st} 21 \mathrm{c} 4$ & 0.149 \\
\hline lct009-20 & 0.326 & het012-01 & 0.624 & lct010-02 & 0.282 & hst042-07 & 0.149 \\
\hline lst17-R126 & 0.325 & $1 \mathrm{st} 03 \mathrm{c} 7$ & 0.624 & lct049t06 & 0.281 & 1st07-R30 & 0.148 \\
\hline lct26c1 & 0.325 & lct049t06 & 0.623 & lct049t07 & 0.281 & 1st04-R29 & 0.147 \\
\hline hst012-01 & 0.325 & lct049t15 & 0.623 & lct010-01 & 0.281 & hst042-08 & 0.147 \\
\hline hmt006-17 & 0.324 & lct049t05 & 0.622 & lct049t05 & 0.281 & 1 st $03 \mathrm{c} 8$ & 0.147 \\
\hline ust015t21x & 0.324 & lct012-02 & 0.622 & lct049t08 & 0.281 & 1 st03c9 & 0.147 \\
\hline lct $25 \mathrm{c} 4$ & 0.323 & lct049t14 & 0.622 & lct26c4 & 0.281 & 1st08-R72 & 0.147 \\
\hline lst06c1 & 0.323 & lct012-03 & 0.621 & lct049t17 & 0.281 & 1st08-R78 & 0.147 \\
\hline hmt006-06 & 0.323 & lct012-05 & 0.620 & lct049t15 & 0.280 & $\operatorname{lct} 017-02$ & 0.146 \\
\hline hst005-11 & 0.323 & lct017-12 & 0.620 & lct049t14 & 0.280 & 1st04-R51 & 0.146 \\
\hline lct $25 \mathrm{c} 3$ & 0.322 & lct012-04 & 0.620 & lct049t13 & 0.279 & 1st07-R32 & 0.146 \\
\hline lct32a8 & 0.322 & lct012-07 & 0.620 & usi001t16x & 0.279 & 1st08-R76 & 0.146 \\
\hline hst043-03 & 0.321 & lct012-06 & 0.619 & lct049t18 & 0.278 & 1st04-R33 & 0.146 \\
\hline lct23c2 & 0.321 & ust017t01 & 0.619 & lct19c1 & 0.278 & $\operatorname{lct} 017-01$ & 0.146 \\
\hline lct23c1 & 0.319 & lct049t17 & 0.619 & lct010-26 & 0.277 & 1st09-R92 & 0.146 \\
\hline lst01c1 & 0.318 & lct017-07 & 0.619 & hst013-01 & 0.277 & lst09-R93 & 0.146 \\
\hline lst03c2 & 0.317 & ust005t01x & 0.619 & ust015t14x & 0.270 & 1st09-R94 & 0.146 \\
\hline 1st04-R1 & 0.316 & lct049t08 & 0.618 & usi001t20x & 0.269 & 1st08-R74 & 0.145 \\
\hline lct079-2 & 0.316 & lct012-08 & 0.618 & lct010-25 & 0.269 & 1st07-R36 & 0.145 \\
\hline lct079-1 & 0.315 & ust016t06 & 0.618 & uct001t02 & 0.265 & lst10-R83 & 0.145 \\
\hline lst16-R129 & 0.314 & ust006t13 & 0.618 & lct $22 \mathrm{c} 7$ & 0.265 & 1st10-R85 & 0.145 \\
\hline lct079-4 & 0.314 & ust016t09 & 0.618 & lct32a7 & 0.264 & lst10-R86 & 0.145 \\
\hline lct $23 \mathrm{c} 3$ & 0.313 & ust017t03 & 0.618 & lct22c6 & 0.264 & lst10-R88 & 0.145 \\
\hline lst17-R130 & 0.313 & ust006t12 & 0.617 & lct049t02 & 0.264 & lct017-23 & 0.144 \\
\hline $1 \mathrm{st} 03 \mathrm{c} 3$ & 0.312 & ust016t07 & 0.617 & hst042-01 & 0.264 & 1st04-R34 & 0.144 \\
\hline $\mathrm{hmt} 006-21$ & 0.312 & ust016t08 & 0.617 & hst042-02 & 0.264 & $\operatorname{lct} 017-24$ & 0.144 \\
\hline lct20c1 & 0.311 & ust006t14 & 0.617 & lct049t01 & 0.264 & lst07-R49 & 0.143 \\
\hline het010-02 & 0.311 & ust006t15 & 0.616 & hst042-06 & 0.263 & 1st04-R46 & 0.143 \\
\hline 1st07-R30 & 0.310 & lct017-11 & 0.616 & lct010-24 & 0.262 & 1st04-R54 & 0.141 \\
\hline $\operatorname{lct} 079-3$ & 0.309 & lct017-06 & 0.615 & $\operatorname{lct} 049 \mathrm{t} 03$ & 0.262 & $\operatorname{lct} 017-26$ & 0.140 \\
\hline hst005-17 & 0.308 & ust017t05 & 0.615 & hst042-03 & 0.262 & ust $006 \mathrm{t} 25$ & 0.138 \\
\hline
\end{tabular}




\begin{tabular}{|c|c|c|c|c|c|c|c|}
\hline \multicolumn{2}{|c|}{ Application 1} & \multicolumn{2}{|c|}{ Application 2} & \multicolumn{2}{|c|}{ Application 3} & \multicolumn{2}{|c|}{ Application 4} \\
\hline Exp. ID & $\mathrm{c}_{\mathrm{r}}$ & Exp. ID & $\mathrm{c}_{\mathrm{r}}$ & Exp. ID & $\mathrm{c}_{\mathrm{r}}$ & Exp. ID & $\mathrm{c}_{\mathrm{r}}$ \\
\hline lct079-5 & 0.306 & lct012-09 & 0.614 & usi001t $23 x$ & 0.262 & ust006t 23 & 0.137 \\
\hline 1st16-R131 & 0.306 & $\operatorname{lct} 012-10$ & 0.614 & lct049t04 & 0.262 & ust006t19 & 0.137 \\
\hline usi001t12x & 0.305 & lct049t18 & 0.613 & hst032-01 & 0.261 & ust006t22 & 0.137 \\
\hline 1st06c2 & 0.305 & lct017-05 & 0.612 & hst042-07 & 0.260 & ust006t24 & 0.137 \\
\hline lst $18 \mathrm{c} 4$ & 0.304 & ust017t02 & 0.611 & lct32a8 & 0.260 & ust006t20 & 0.137 \\
\hline hst005-15 & 0.303 & lct017-22 & 0.611 & hst042-04 & 0.260 & ust006t21 & 0.137 \\
\hline lct22c6 & 0.303 & lct017-10 & 0.610 & ust015t19x & 0.259 & lct017-27 & 0.134 \\
\hline usi001t01x & 0.303 & ust $013 \mathrm{t} 20$ & 0.610 & hst042-05 & 0.259 & 1st05c3 & 0.133 \\
\hline hst033-03a & 0.302 & ust017t04 & 0.609 & lct32a9 & 0.258 & lst05c1 & 0.133 \\
\hline 1st04-R29 & 0.302 & ust $013 \mathrm{t} 21$ & 0.607 & hst042-08 & 0.258 & 1 st $05 \mathrm{c} 2$ & 0.133 \\
\hline hst013-01 & 0.301 & het014-01 & 0.607 & lct $25 \mathrm{c} 4$ & 0.256 & ust006t10 & 0.131 \\
\hline usi001t $24 \mathrm{x}$ & 0.301 & lct017-02 & 0.606 & lct32a4 & 0.256 & ust006t08 & 0.127 \\
\hline lst18c3 & 0.300 & lct017-21 & 0.606 & ust015t04x & 0.255 & ust006t09 & 0.127 \\
\hline $\operatorname{lct} 21 \mathrm{c} 3$ & 0.299 & ust $015 \mathrm{t} 25 \mathrm{x}$ & 0.604 & ust015t09x & 0.254 & ust006t11 & 0.126 \\
\hline lst19c1 & 0.299 & hst042-03 & 0.604 & usi001t08x & 0.254 & ust006t07 & 0.125 \\
\hline lct010-04 & 0.299 & 1 st $03 \mathrm{c} 8$ & 0.604 & lct32a5 & 0.253 & het010-05 & 0.116 \\
\hline lct040-01 & 0.299 & ust013t19 & 0.603 & lct $22 \mathrm{c} 5$ & 0.252 & $\mathrm{hmt} 025 \mathrm{t} 01$ & 0.105 \\
\hline lct26c2 & 0.299 & hst032-01 & 0.602 & lct32a6 & 0.252 & usi001t16x & 0.103 \\
\hline hst033-10a & 0.299 & lct017-20 & 0.602 & lct $25 \mathrm{c} 3$ & 0.251 & ust $015 \mathrm{t} 25 \mathrm{x}$ & 0.102 \\
\hline lct21c2 & 0.299 & ust016t19 & 0.601 & hst037-01 & 0.250 & hmf030t00 & 0.089 \\
\hline $1 \mathrm{ct} 23 \mathrm{c} 4$ & 0.299 & ust016t16 & 0.600 & lct $22 \mathrm{c} 4$ & 0.249 & ust015t17x & 0.088 \\
\hline hst033-02a & 0.299 & ust016t31 & 0.600 & $\operatorname{lct} 24 \mathrm{c} 2$ & 0.249 & usi001t30x & 0.083 \\
\hline lct22c2 & 0.299 & ust016t17 & 0.600 & $1 \mathrm{ct} 25 \mathrm{c} 2$ & 0.249 & ust015t07x & 0.083 \\
\hline 1st17-R147 & 0.297 & ust016t18 & 0.600 & hst035-01 & 0.248 & usi001t20x & 0.082 \\
\hline $\mathrm{hmt} 006-16$ & 0.297 & ust016t32 & 0.600 & hst025-02 & 0.247 & ust $015 \mathrm{t} 14 \mathrm{x}$ & 0.081 \\
\hline lst $18 \mathrm{c} 5$ & 0.297 & ust016t33 & 0.600 & hst025-01 & 0.246 & usi001t08x & 0.081 \\
\hline ust015t01x & 0.297 & lct017-01 & 0.599 & lct $22 \mathrm{c} 3$ & 0.245 & usi001t06x & 0.079 \\
\hline 1st19c3 & 0.297 & 1 st03c9 & 0.597 & usi001t32x & 0.245 & $\mathrm{hmt} 025 \mathrm{t} 02$ & 0.077 \\
\hline $1 s t 19 \mathrm{c} 2$ & 0.296 & lct017-25 & 0.597 & lct $25 \mathrm{c} 1$ & 0.243 & ust015t04x & 0.076 \\
\hline lct $22 \mathrm{c} 7$ & 0.296 & ust005t02 & 0.597 & usi001t06x & 0.241 & usi001t $27 x$ & 0.074 \\
\hline hmt006-18 & 0.295 & lct017-04 & 0.596 & hst043-03 & 0.241 & usi001t17x & 0.072 \\
\hline lst $18 \mathrm{c} 6$ & 0.295 & ust012t08 & 0.595 & ust015t30x & 0.241 & usi001t04x & 0.072 \\
\hline lct010-13 & 0.295 & het013-01 & 0.595 & hst025-04 & 0.241 & usi001t $23 x$ & 0.068 \\
\hline lst19c5 & 0.295 & lct017-19 & 0.595 & $1 \mathrm{ct} 23 \mathrm{c} 2$ & 0.240 & usi001t33x & 0.068 \\
\hline lst18c1 & 0.295 & ust012t07 & 0.595 & $\operatorname{lct} 23 \mathrm{c} 3$ & 0.240 & ust006t06 & 0.066 \\
\hline ust015t11x & 0.294 & hct013-02 & 0.594 & hst012-01 & 0.240 & ust006t05 & 0.066 \\
\hline lst19c6 & 0.294 & het011-03 & 0.594 & hst037-03 & 0.239 & usi001t14x & 0.065 \\
\hline lst19c4 & 0.293 & ust006t16 & 0.593 & lct $23 c 4$ & 0.239 & usi001t11x & 0.065 \\
\hline $\mathrm{hmt} 006-22$ & 0.293 & het011-02 & 0.593 & $\operatorname{lct} 23 \mathrm{c} 1$ & 0.239 & ust006t17 & 0.065 \\
\hline lct32a7 & 0.293 & het014-02 & 0.593 & lct $23 \mathrm{c} 5$ & 0.238 & ust015t10x & 0.065 \\
\hline
\end{tabular}




\begin{tabular}{|c|c|c|c|c|c|c|c|}
\hline \multicolumn{2}{|c|}{ Application 1} & \multicolumn{2}{|c|}{ Application 2} & \multicolumn{2}{|c|}{ Application 3} & \multicolumn{2}{|c|}{ Application 4} \\
\hline Exp. ID & $\mathrm{c}_{\mathrm{r}}$ & Exp. ID & $\mathrm{c}_{\mathrm{r}}$ & Exp. ID & $\mathrm{c}_{\mathrm{r}}$ & Exp. ID & $\mathrm{c}_{\mathrm{r}}$ \\
\hline $\operatorname{lct} 21 \mathrm{c} 1$ & 0.292 & ust006t18 & 0.592 & $1 \mathrm{ct} 22 \mathrm{c} 2$ & 0.236 & ust006t18 & 0.064 \\
\hline lst07-R32 & 0.292 & ust006t17 & 0.592 & hst043-02 & 0.235 & ust006t16 & 0.064 \\
\hline lct010-08 & 0.291 & ust015t17x & 0.591 & lct $23 \mathrm{c} 6$ & 0.234 & ust006t01 & 0.063 \\
\hline hmt006-07 & 0.291 & ust016t01 & 0.590 & usi001t11x & 0.232 & ust006t04 & 0.063 \\
\hline hst $033-03 b$ & 0.290 & ust016t04 & 0.590 & hst001-05 & 0.231 & ust006t02 & 0.063 \\
\hline lst16-R140 & 0.289 & ust016t02 & 0.590 & usi001t $27 \mathrm{x}$ & 0.229 & ust006t03 & 0.063 \\
\hline 1st06c3 & 0.289 & ust016t03 & 0.590 & hst28i-1 & 0.229 & uct001t03 & 0.062 \\
\hline lct $25 \mathrm{c} 2$ & 0.286 & het011-01 & 0.589 & hst28i-3 & 0.229 & ust006t12 & 0.062 \\
\hline lct010-30 & 0.286 & ust006t01 & 0.588 & hst001-06 & 0.228 & ust006t14 & 0.062 \\
\hline $1 \mathrm{st} 21 \mathrm{c} 1$ & 0.286 & ust006t03 & 0.588 & hst28i-5 & 0.228 & ust006t13 & 0.061 \\
\hline lst04-R33 & 0.285 & ust006t02 & 0.587 & hst037-06 & 0.228 & ust006t15 & 0.061 \\
\hline lct010-29 & 0.285 & ust006t04 & 0.587 & usi001t $22 x$ & 0.227 & ust014t15 & 0.060 \\
\hline lct $23 \mathrm{c} 5$ & 0.284 & ust $015 \mathrm{t} 10 \mathrm{x}$ & 0.586 & hst28i-7 & 0.226 & ust014t14 & 0.060 \\
\hline $\mathrm{hmt} 006-23$ & 0.283 & lct049t02 & 0.586 & lct32a1 & 0.226 & ust014t12 & 0.059 \\
\hline ust015t20x & 0.283 & lct049t01 & 0.586 & hst30i-01 & 0.226 & ust003t05 & 0.059 \\
\hline 1st16-R196 & 0.281 & ust017t06 & 0.580 & uct001t04 & 0.225 & ust014t02 & 0.059 \\
\hline lst06c4 & 0.281 & lct049t03 & 0.580 & hst001-10 & 0.224 & ust014t10 & 0.059 \\
\hline hst033-02b & 0.278 & ust015t07x & 0.579 & ust015t18x & 0.223 & ust014t13 & 0.059 \\
\hline lct040-03 & 0.278 & lct049t04 & 0.579 & lct22c1 & 0.222 & ust014t11 & 0.059 \\
\hline $1 \mathrm{ct} 19 \mathrm{c} 2$ & 0.277 & lct017-17 & 0.575 & lct32a2 & 0.221 & ust014t16 & 0.058 \\
\hline lct010-23 & 0.272 & hst042-04 & 0.573 & hst035-05 & 0.220 & usi001t09x & 0.058 \\
\hline lst07-R36 & 0.270 & ust002t04 & 0.573 & hst025-05 & 0.220 & ust014t01 & 0.058 \\
\hline lct010-12 & 0.269 & ust002t07 & 0.573 & hst007-03 & 0.218 & ust003t04 & 0.057 \\
\hline lct010-19 & 0.269 & ust002t06 & 0.571 & ust015t08x & 0.218 & ust014t09 & 0.057 \\
\hline 1st04-R34 & 0.268 & ust002t05 & 0.571 & het010-13 & 0.218 & ust014t05 & 0.057 \\
\hline lst20c1 & 0.267 & ust002t15 & 0.570 & hst027-01 & 0.216 & ust014t06 & 0.057 \\
\hline lct32a1 & 0.267 & ust014t01 & 0.569 & hst007-07 & 0.216 & ust014t08 & 0.057 \\
\hline hmt006-12 & 0.266 & ust002t03 & 0.569 & hst007-09 & 0.214 & ust014t03 & 0.057 \\
\hline lct010-07 & 0.264 & lct042-01 & 0.569 & usi001t17x & 0.214 & ust014t04 & 0.057 \\
\hline lst06c5 & 0.262 & lct017-16 & 0.568 & het010-12 & 0.212 & ust014t07 & 0.057 \\
\hline lct $21 \mathrm{c} 6$ & 0.262 & lct017-29 & 0.566 & hst007-05 & 0.212 & uct001t02 & 0.057 \\
\hline lct010-18 & 0.261 & ust002t02 & 0.566 & hst007-12 & 0.211 & ust002t13 & 0.057 \\
\hline lct010-06 & 0.261 & $1 \mathrm{st} 05 \mathrm{c} 1$ & 0.566 & hst007-01 & 0.211 & ust004t06 & 0.056 \\
\hline hst005-14 & 0.260 & ust002t16 & 0.566 & ust015t29x & 0.209 & ust004t04 & 0.056 \\
\hline lct010-22 & 0.260 & ust006t05 & 0.565 & lct32a3 & 0.209 & usi001t $22 x$ & 0.055 \\
\hline lct040-02 & 0.258 & lct042-06 & 0.565 & usi001t31x & 0.206 & ust004t07 & 0.055 \\
\hline lct010-17 & 0.257 & ust003t07 & 0.565 & usi001t04x & 0.206 & ust004t05 & 0.055 \\
\hline lct $23 \mathrm{c} 6$ & 0.257 & ust002t14 & 0.565 & $\operatorname{lct} 24 \mathrm{c} 1$ & 0.205 & ust012t01 & 0.054 \\
\hline lct $21 \mathrm{c} 5$ & 0.256 & ust003t08 & 0.565 & het010-10 & 0.205 & ust012t02 & 0.054 \\
\hline lct19c3 & 0.255 & ust006t06 & 0.564 & hst001-07 & 0.205 & ust012t03 & 0.053 \\
\hline
\end{tabular}




\begin{tabular}{|c|c|c|c|c|c|c|c|}
\hline \multicolumn{2}{|c|}{ Application 1} & \multicolumn{2}{|c|}{ Application 2} & \multicolumn{2}{|c|}{ Application 3} & \multicolumn{2}{|c|}{ Application 4} \\
\hline Exp. ID & $\mathrm{c}_{\mathrm{r}}$ & Exp. ID & $\mathrm{c}_{\mathrm{r}}$ & Exp. ID & $\mathrm{c}_{\mathrm{r}}$ & Exp. ID & $\mathrm{c}_{\mathrm{r}}$ \\
\hline $1 \mathrm{st} 03 \mathrm{c} 4$ & 0.254 & ust002t08 & 0.563 & het010-11 & 0.204 & ust $003 \mathrm{t} 02$ & 0.053 \\
\hline 1st20c2 & 0.254 & lct042-02 & 0.562 & hct010-14 & 0.204 & ust $002 \mathrm{t} 12$ & 0.053 \\
\hline $\operatorname{lct} 21 \mathrm{c} 4$ & 0.252 & ust003t09 & 0.562 & hst001-03 & 0.203 & ust004t03 & 0.052 \\
\hline 1st09-R92 & 0.252 & lct017-15 & 0.561 & usi001t09x & 0.203 & usi001t32x & 0.052 \\
\hline 1st07-R49 & 0.252 & lct042-05 & 0.561 & hst001-08 & 0.203 & ust $003 \mathrm{t} 03$ & 0.052 \\
\hline $\operatorname{lct} 32 \mathrm{a} 2$ & 0.251 & $1 \mathrm{st} 05 \mathrm{c} 2$ & 0.560 & hst $28 \mathrm{i}-9$ & 0.203 & ust016t02 & 0.052 \\
\hline $\operatorname{lct} 22 \mathrm{c} 1$ & 0.251 & ust004t08 & 0.560 & hst28i-11 & 0.203 & ust016t03 & 0.052 \\
\hline 1st04-R46 & 0.251 & lct042-03 & 0.560 & hst007-10 & 0.202 & ust016t04 & 0.052 \\
\hline $\operatorname{lct} 010-11$ & 0.250 & lct042-04 & 0.560 & hst011-02 & 0.202 & ust016t01 & 0.052 \\
\hline lct010-28 & 0.250 & lct042-07 & 0.560 & hst001-01 & 0.201 & ust003t01 & 0.052 \\
\hline hst033-02c & 0.249 & ust002t01 & 0.558 & usi001t $21 x$ & 0.201 & ust012t04 & 0.052 \\
\hline 1st08-R74 & 0.249 & $\operatorname{lct} 010-25$ & 0.557 & hst28i-13 & 0.201 & ust016t07 & 0.052 \\
\hline lst09-R93 & 0.248 & ust017t07 & 0.557 & hst011-01 & 0.201 & ust016t08 & 0.052 \\
\hline lst10-R83 & 0.247 & ust003t06 & 0.556 & hst035-07 & 0.201 & ust003t10 & 0.052 \\
\hline 1st08-R76 & 0.246 & hst042-06 & 0.556 & hst28i-15 & 0.200 & ust016t06 & 0.052 \\
\hline $1 \mathrm{st} 21 \mathrm{c} 2$ & 0.246 & ust002t17 & 0.553 & het010-15 & 0.199 & ust016t09 & 0.052 \\
\hline 1st10-R86 & 0.246 & ust014t16 & 0.553 & het010-07 & 0.198 & ust012t07 & 0.051 \\
\hline lst10-R88 & 0.246 & $1 \mathrm{ct} 010-24$ & 0.553 & hct010-08 & 0.197 & ust012t08 & 0.051 \\
\hline lst10-R85 & 0.246 & ust002t09 & 0.552 & hst28i-17 & 0.197 & ust017t01 & 0.051 \\
\hline 1st09-R94 & 0.246 & $1 \mathrm{ct} 010-26$ & 0.552 & hct010-09 & 0.197 & ust012t05 & 0.051 \\
\hline lct010-21 & 0.244 & hst042-05 & 0.548 & hst014-01 & 0.196 & ust005t02 & 0.051 \\
\hline hst033-10c & 0.244 & ust014t02 & 0.548 & hst29i-01 & 0.196 & umf006t00x & 0.051 \\
\hline $1 \mathrm{ct} 25 \mathrm{c} 1$ & 0.244 & lct017-24 & 0.547 & hmt006-09 & 0.195 & usi001t10x & 0.051 \\
\hline 1st08-R78 & 0.243 & lct017-23 & 0.545 & hmt006-08 & 0.194 & ust012t06x & 0.051 \\
\hline lct010-03 & 0.242 & usi001t33x & 0.543 & hst30i-04 & 0.192 & umf002t01x & 0.051 \\
\hline lct010-15 & 0.241 & ust002t12 & 0.543 & usi001t10x & 0.191 & ust001t05x & 0.051 \\
\hline 1st04-R51 & 0.241 & ust002t10 & 0.542 & $\mathrm{hmt} 006-15$ & 0.191 & ust001t04x & 0.051 \\
\hline lst08-R72 & 0.240 & ust004t02 & 0.542 & $\mathrm{hmt} 006-07$ & 0.191 & umf003t $02 x$ & 0.050 \\
\hline lct010-10 & 0.240 & ust014t11 & 0.538 & $\mathrm{hmt} 006-12$ & 0.188 & ust $001 \mathrm{t} 03 \mathrm{x}$ & 0.050 \\
\hline lct010-02 & 0.240 & hst042-07 & 0.538 & het010-06 & 0.187 & umf002t02x & 0.050 \\
\hline lst21c3 & 0.239 & $1 \mathrm{st} 05 \mathrm{c} 3$ & 0.537 & hst015-02 & 0.185 & ust017t03 & 0.050 \\
\hline hst033-03c & 0.239 & ust004t01 & 0.536 & usi001t14x & 0.185 & ust005t01x & 0.050 \\
\hline hmt006-14 & 0.238 & lct017-28 & 0.533 & hmt006-14 & 0.185 & ust016t10 & 0.050 \\
\hline lct010-01 & 0.236 & ust006t19 & 0.532 & ust015t24x & 0.185 & ust016t11 & 0.050 \\
\hline lct010-20 & 0.235 & ust006t20 & 0.532 & ust015t16x & 0.183 & ust016t12 & 0.050 \\
\hline hct014-01 & 0.234 & ust006t24 & 0.531 & hmt006-06 & 0.183 & ust017t06 & 0.050 \\
\hline lct010-14 & 0.233 & ust006t25 & 0.531 & ust015t06x & 0.183 & ust $001 \mathrm{t} 02 \mathrm{x}$ & 0.050 \\
\hline hst033-10d & 0.232 & ust $004 \mathrm{t} 03$ & 0.531 & hst015-01 & 0.183 & ust $017 \mathrm{t} 02$ & 0.050 \\
\hline hmt006-08 & 0.230 & ust006t23 & 0.530 & ust015t28x & 0.182 & ust017t07 & 0.050 \\
\hline 1 st $03 \mathrm{c} 5$ & 0.228 & ust006t22 & 0.530 & usi001t29x & 0.180 & umf003t01x & 0.050 \\
\hline
\end{tabular}




\begin{tabular}{|c|c|c|c|c|c|c|c|}
\hline \multicolumn{2}{|c|}{ Application 1} & \multicolumn{2}{|c|}{ Application 2} & \multicolumn{2}{|c|}{ Application 3} & \multicolumn{2}{|c|}{ Application 4} \\
\hline Exp. ID & $\mathrm{c}_{\mathrm{r}}$ & Exp. ID & $\mathrm{c}_{\mathrm{r}}$ & Exp. ID & $\mathrm{c}_{\mathrm{r}}$ & Exp. ID & $\mathrm{c}_{\mathrm{r}}$ \\
\hline 1 st $03 \mathrm{c} 6$ & 0.227 & uct001t03 & 0.530 & hmt006-19 & 0.177 & ust002t01 & 0.050 \\
\hline lct010-09 & 0.226 & ust006t21 & 0.530 & hct010-04 & 0.175 & ust001t01x & 0.050 \\
\hline lct19c1 & 0.225 & ust004t07 & 0.527 & hst010-01 & 0.175 & usi001t21x & 0.050 \\
\hline 1st20c3 & 0.223 & ust003t03 & 0.524 & hst010-02 & 0.174 & ust004t01 & 0.050 \\
\hline lct010-05 & 0.223 & ust004t05 & 0.520 & hst017-01 & 0.174 & ust017t04 & 0.050 \\
\hline hmt006-15 & 0.222 & hst042-08 & 0.520 & hst016-01 & 0.174 & ust017t05 & 0.050 \\
\hline 1st04-R54 & 0.221 & ust002t13 & 0.519 & hst001-02 & 0.173 & umf001t00x & 0.049 \\
\hline lct017-09 & 0.220 & usi001t30x & 0.518 & hst001-09 & 0.173 & umf005t01x & 0.049 \\
\hline het014-02 & 0.219 & ust004t06 & 0.518 & hst010-03 & 0.172 & ust015t09x & 0.049 \\
\hline lct010-27 & 0.218 & ust014t10 & 0.515 & hst043-01 & 0.172 & ust016t32 & 0.049 \\
\hline lct012-01 & 0.216 & ust002t11 & 0.514 & hst005-12 & 0.172 & umf004t01x & 0.049 \\
\hline lst21c4 & 0.214 & ust003t10 & 0.511 & hst001-04 & 0.172 & ust002t11 & 0.049 \\
\hline hst042-01 & 0.213 & ust006t11 & 0.511 & usi001t19x & 0.172 & ust016t16 & 0.049 \\
\hline hst042-02 & 0.213 & ust006t07 & 0.510 & hst010-04 & 0.172 & ust016t31 & 0.049 \\
\hline lct017-08 & 0.206 & ust006t08 & 0.510 & hmt006-05 & 0.171 & ust016t33 & 0.049 \\
\hline lct012-02 & 0.204 & ust004t04 & 0.509 & hst007-14 & 0.170 & ust016t17 & 0.049 \\
\hline lct017-03 & 0.204 & ust006t09 & 0.509 & hst007-13 & 0.170 & umf005t02x & 0.049 \\
\hline hmt006-09 & 0.204 & ust003t02 & 0.507 & hst007-17 & 0.170 & ust016t18 & 0.049 \\
\hline lct012-03 & 0.202 & usi001t $23 x$ & 0.502 & hst007-15 & 0.170 & ust016t19 & 0.049 \\
\hline lct017-14 & 0.202 & ust003t04 & 0.495 & hst006-08 & 0.170 & ust016t13 & 0.049 \\
\hline lct012-05 & 0.202 & ust014t12 & 0.494 & hst005-11 & 0.169 & ust016t14 & 0.049 \\
\hline lct32a3 & 0.202 & ust015t31x & 0.492 & hst007-04 & 0.169 & ust016t15 & 0.049 \\
\hline lct012-07 & 0.202 & ust014t13 & 0.489 & hst017-03 & 0.169 & ust002t14 & 0.049 \\
\hline lct012-06 & 0.201 & ust015t09x & 0.488 & hst007-08 & 0.168 & ust $004 \mathrm{t} 08$ & 0.049 \\
\hline 1st20c4 & 0.201 & ust015t19x & 0.488 & hst006-01 & 0.168 & ust $002 \mathrm{t} 10$ & 0.048 \\
\hline lct012-04 & 0.201 & ust003t01 & 0.483 & hst017-02 & 0.166 & ust013t21 & 0.048 \\
\hline hct012-02 & 0.201 & ust014t04 & 0.482 & hst007-06 & 0.166 & ust002t02 & 0.048 \\
\hline lct017-07 & 0.201 & ust003t05 & 0.479 & hst006-27 & 0.166 & umf004t02x & 0.048 \\
\hline hct012-01 & 0.200 & ust014t03 & 0.478 & ust015t27x & 0.165 & ust003t06 & 0.048 \\
\hline lct017-13 & 0.199 & usi001t20x & 0.477 & hst018-01 & 0.165 & ust003t09 & 0.048 \\
\hline lct012-08 & 0.199 & usi001t32x & 0.473 & hst007-16 & 0.165 & ust $004 \mathrm{t} 02$ & 0.048 \\
\hline lct017-06 & 0.197 & ust014t15 & 0.472 & hst006-12 & 0.165 & ust002t09 & 0.048 \\
\hline lct017-02 & 0.196 & ust014t09 & 0.470 & usi001t07x & 0.164 & ust002t17 & 0.048 \\
\hline lct012-09 & 0.196 & ust014t05 & 0.469 & hst005-14 & 0.164 & ust $013 \mathrm{t} 20$ & 0.048 \\
\hline lct26c3 & 0.194 & ust006t10 & 0.464 & $\mathrm{hmt} 006-04$ & 0.164 & ust016t26 & 0.048 \\
\hline lct017-12 & 0.194 & ust014t06 & 0.463 & hmt006-11 & 0.163 & ust016t21 & 0.048 \\
\hline lct012-10 & 0.193 & ust014t07 & 0.459 & hmt006-16 & 0.163 & ust016t22 & 0.048 \\
\hline lct017-05 & 0.193 & ust014t14 & 0.458 & ust015t23x & 0.163 & ust $016 \mathrm{t} 23$ & 0.048 \\
\hline lct017-22 & 0.192 & usi001t08x & 0.451 & hst007-11 & 0.163 & ust016t24 & 0.048 \\
\hline lct010-26 & 0.192 & ust014t08 & 0.451 & hst007-02 & 0.162 & ust016t27 & 0.048 \\
\hline
\end{tabular}




\begin{tabular}{|c|c|c|c|c|c|c|c|}
\hline \multicolumn{2}{|c|}{ Application 1} & \multicolumn{2}{|c|}{ Application 2} & \multicolumn{2}{|c|}{ Application 3} & \multicolumn{2}{|c|}{ Application 4} \\
\hline Exp. ID & $\mathrm{c}_{\mathrm{r}}$ & Exp. ID & $\mathrm{c}_{\mathrm{r}}$ & Exp. ID & $\mathrm{c}_{\mathrm{r}}$ & Exp. ID & $\mathrm{c}_{\mathrm{r}}$ \\
\hline lct010-25 & 0.191 & usi001t $22 x$ & 0.441 & hmt006-03 & 0.162 & ust002t03 & 0.048 \\
\hline lct017-01 & 0.191 & usi001t16x & 0.440 & hct010-03 & 0.161 & ust003t08 & 0.048 \\
\hline lct017-11 & 0.191 & ust $015 \mathrm{t} 14 \mathrm{x}$ & 0.438 & ust015t15x & 0.161 & ust016t25 & 0.048 \\
\hline het013-01 & 0.188 & uct001t02 & 0.438 & ust015t05x & 0.158 & ust013t02 & 0.047 \\
\hline lct017-21 & 0.186 & usi001t11x & 0.437 & hst018-03 & 0.158 & ust013t03 & 0.047 \\
\hline lct017-10 & 0.185 & ust015t04x & 0.431 & usi001t $28 x$ & 0.157 & ust013t04 & 0.047 \\
\hline het011-02 & 0.184 & usi001t06x & 0.414 & hst018-02 & 0.156 & ust013t05 & 0.047 \\
\hline lct017-20 & 0.183 & lct017-26 & 0.414 & hst005-17 & 0.154 & ust002t08 & 0.047 \\
\hline het013-02 & 0.183 & lct017-27 & 0.412 & hst005-15 & 0.154 & ust013t01 & 0.047 \\
\hline het011-03 & 0.182 & ust $015 \mathrm{t} 18 \mathrm{x}$ & 0.406 & hmt006-02 & 0.152 & ust013t10 & 0.047 \\
\hline lct017-25 & 0.181 & ust 015 t $08 x$ & 0.403 & hst009-04 & 0.152 & ust013t14 & 0.047 \\
\hline lct010-24 & 0.181 & usi001t21x & 0.381 & usi001t18x & 0.151 & ust013t06 & 0.047 \\
\hline 1st03c7 & 0.177 & usi001t31x & 0.381 & hst019-01 & 0.150 & ust013t07 & 0.047 \\
\hline lct017-19 & 0.176 & ust001t05x & 0.375 & hmt006-20 & 0.150 & ust013t08 & 0.047 \\
\hline umf001t00x & 0.176 & usi001t27x & 0.373 & ust015t26x & 0.149 & ust013t09 & 0.047 \\
\hline umf003t01x & 0.176 & ust001t04x & 0.372 & hmt006-17 & 0.147 & ust013t11 & 0.047 \\
\hline umf002t02x & 0.175 & usi001t09x & 0.371 & usi001t05x & 0.145 & ust013t13 & 0.047 \\
\hline umf003t02x & 0.175 & ust001t03x & 0.369 & hmt006-13 & 0.144 & ust002t15 & 0.047 \\
\hline umf005t01x & 0.175 & ust 001 t $02 x$ & 0.366 & hmt006-10 & 0.143 & ust003t07 & 0.047 \\
\hline lct017-04 & 0.175 & ust015t30x & 0.365 & hmt006-21 & 0.143 & ust013t12 & 0.047 \\
\hline lst05c1 & 0.175 & ust001t01x & 0.363 & hmt006-01 & 0.142 & ust002t16 & 0.047 \\
\hline umf006t00x & 0.175 & usi001t10x & 0.361 & ust015t22x & 0.141 & ust013t15 & 0.047 \\
\hline umf002t01x & 0.175 & usi001t17x & 0.351 & hct010-01 & 0.138 & ust002t04 & 0.047 \\
\hline umf005t02x & 0.174 & usi001t04x & 0.336 & hst009-03 & 0.138 & ust016t29 & 0.047 \\
\hline umf004t01x & 0.173 & usi001t29x & 0.326 & hmt006-22 & 0.137 & ust016t30 & 0.047 \\
\hline lct017-29 & 0.171 & ust015t06x & 0.325 & ust015t13x & 0.137 & ust002t06 & 0.047 \\
\hline hct011-01 & 0.171 & ust015t16x & 0.317 & hmt006-18 & 0.136 & ust002t07 & 0.047 \\
\hline lct $24 \mathrm{c} 1$ & 0.169 & usi001t19x & 0.314 & hmt006-23 & 0.135 & ust016t28 & 0.047 \\
\hline umf004t02x & 0.168 & ust015t29x & 0.304 & hst033-03a & 0.135 & ust009t01 & 0.047 \\
\hline lst05c2 & 0.168 & ust $015 \mathrm{t} 24 \mathrm{x}$ & 0.301 & ust015t03x & 0.135 & ust013t19 & 0.047 \\
\hline lct017-17 & 0.165 & usi001t07x & 0.299 & hct010-02 & 0.135 & ust $015 \mathrm{t} 19 \mathrm{x}$ & 0.047 \\
\hline $\operatorname{lct} 26 \mathrm{c} 4$ & 0.163 & usi001t14x & 0.292 & hst033-10a & 0.134 & ust002t05 & 0.047 \\
\hline $1 \mathrm{st} 03 \mathrm{c} 8$ & 0.161 & uct001t04 & 0.288 & hst033-03b & 0.133 & ust013t18 & 0.047 \\
\hline lct017-16 & 0.161 & usi001t $28 \mathrm{x}$ & 0.273 & usi001t26x & 0.132 & ust013t16 & 0.046 \\
\hline lct017-28 & 0.161 & ust $015 \mathrm{t} 05 \mathrm{x}$ & 0.270 & hst033-02a & 0.131 & ust013t17 & 0.046 \\
\hline lct017-24 & 0.161 & ust $015 \mathrm{t} 15 \mathrm{x}$ & 0.270 & usi001t15x & 0.128 & ust009t02 & 0.046 \\
\hline lct042-01 & 0.158 & usi001t18x & 0.267 & ust015t $21 \mathrm{x}$ & 0.128 & ust008t01x & 0.045 \\
\hline lct017-23 & 0.157 & ust009t01 & 0.256 & hst033-03c & 0.125 & usi001t $31 x$ & 0.045 \\
\hline $\operatorname{lct} 049 \operatorname{t10}$ & 0.156 & usi001t05x & 0.256 & hst033-02b & 0.125 & ust009t03 & 0.045 \\
\hline lct042-06 & 0.155 & ust $015 \mathrm{t} 23 \mathrm{x}$ & 0.255 & usi001t03x & 0.125 & usi001t07x & 0.044 \\
\hline
\end{tabular}




\begin{tabular}{|c|c|c|c|c|c|c|c|}
\hline \multicolumn{2}{|c|}{ Application 1} & \multicolumn{2}{|c|}{ Application 2} & \multicolumn{2}{|c|}{ Application 3} & \multicolumn{2}{|c|}{ Application 4} \\
\hline Exp. ID & $\mathrm{c}_{\mathrm{r}}$ & Exp. ID & $\mathrm{c}_{\mathrm{r}}$ & Exp. ID & $\mathrm{c}_{\mathrm{r}}$ & Exp. ID & $\mathrm{c}_{\mathrm{r}}$ \\
\hline 1 st03c9 & 0.155 & ust015t28x & 0.252 & hst033-10c & 0.125 & ust009t04 & 0.043 \\
\hline lct017-15 & 0.155 & ust009t02 & 0.228 & ust $015 \mathrm{t} 12 \mathrm{x}$ & 0.123 & ust015t08x & 0.043 \\
\hline lct049t11 & 0.154 & ust $015 \mathrm{t} 03 \mathrm{x}$ & 0.220 & ust015t02x & 0.121 & usi001t19x & 0.043 \\
\hline lct049t09 & 0.153 & usi001t26x & 0.220 & hst033-10d & 0.121 & mci005t00 & 0.043 \\
\hline lct049t12 & 0.149 & ust015t13x & 0.219 & hst009-02 & 0.121 & ust015t31x & 0.042 \\
\hline hst042-03 & 0.147 & ust $015 \mathrm{t} 27 \mathrm{x}$ & 0.218 & usi001t $25 \mathrm{x}$ & 0.119 & uct001t04 & 0.042 \\
\hline lct042-02 & 0.147 & usi001t15x & 0.217 & hst033-02c & 0.117 & $\operatorname{lct} 017-18$ & 0.041 \\
\hline hst032-01 & 0.147 & $\mathrm{hmt} 025 \mathrm{t} 01$ & 0.212 & het014-02 & 0.116 & ust $015 \mathrm{t} 18 \mathrm{x}$ & 0.041 \\
\hline lct042-07 & 0.147 & usi001t03x & 0.212 & ust015t20x & 0.116 & usi001t29x & 0.040 \\
\hline lct042-05 & 0.146 & ust $015 \mathrm{t} 22 \mathrm{x}$ & 0.208 & usi001t13x & 0.114 & usi001t $05 x$ & 0.039 \\
\hline lct042-03 & 0.145 & ust008t01x & 0.202 & usi001t02x & 0.112 & usi001t18x & 0.038 \\
\hline $\operatorname{lct} 042-04$ & 0.145 & ust009t03 & 0.195 & hst009-01 & 0.111 & ust015t26x & 0.038 \\
\hline lct010-16 & 0.141 & usi001t $25 \mathrm{x}$ & 0.191 & ust015t11x & 0.109 & ust $015 \mathrm{t} 30 \mathrm{x}$ & 0.038 \\
\hline lst05c3 & 0.137 & ust $015 \mathrm{t} 02 \mathrm{x}$ & 0.190 & ust015t01x & 0.106 & ust015t06x & 0.037 \\
\hline lct049t13 & 0.134 & ust $015 \mathrm{t} 12 \mathrm{x}$ & 0.188 & het014-01 & 0.106 & ust015t29x & 0.036 \\
\hline lct049t15 & 0.132 & usi001t13x & 0.186 & usi001t24x & 0.104 & ust015t $27 x$ & 0.036 \\
\hline lct049t16 & 0.132 & ust $015 \mathrm{t} 26 \mathrm{x}$ & 0.186 & lct017-18 & 0.102 & usi001t $28 x$ & 0.035 \\
\hline lct049t06 & 0.131 & usi001t02x & 0.183 & usi001t12x & 0.100 & ust015t16x & 0.035 \\
\hline lct049t14 & 0.131 & $\mathrm{hmt} 025 \mathrm{t} 02$ & 0.181 & usi001t01x & 0.097 & ust015t28x & 0.035 \\
\hline lct049t07 & 0.130 & ust015t21x & 0.180 & hct013-02 & 0.093 & usi001t $03 x$ & 0.034 \\
\hline lct049t05 & 0.128 & lct017-18 & 0.156 & hct012-02 & 0.092 & ust015t05x & 0.033 \\
\hline lct049t08 & 0.126 & ust015t11x & 0.156 & hct011-03 & 0.085 & ust $015 t 24 x$ & 0.033 \\
\hline lct049t17 & 0.125 & ust009t04 & 0.156 & hct012-01 & 0.083 & usi001t $15 x$ & 0.033 \\
\hline $\operatorname{lct} 017-27$ & 0.117 & ust015t01x & 0.156 & het013-01 & 0.080 & $\mathrm{mmf} 008 \mathrm{t} 07$ & 0.033 \\
\hline hst042-04 & 0.115 & usi001t $24 \mathrm{x}$ & 0.156 & hct011-02 & 0.077 & ust $015 \mathrm{t} 15 \mathrm{x}$ & 0.032 \\
\hline lct049t18 & 0.107 & usi001t12x & 0.154 & het011-01 & 0.073 & imf004 & 0.032 \\
\hline lct017-26 & 0.105 & ust015t20x & 0.153 & mci005t00 & 0.040 & ust015t20x & 0.032 \\
\hline lct049t02 & 0.102 & usi001t01x & 0.151 & mcm001t09 & 0.034 & usi001t $02 x$ & 0.031 \\
\hline lct049t01 & 0.101 & $\mathrm{hmf} 030 \mathrm{t} 00$ & 0.129 & mcm001t 08 & 0.034 & ust $015 \mathrm{t} 23 \mathrm{x}$ & 0.031 \\
\hline hst042-06 & 0.098 & $\mathrm{mcm} 001 \mathrm{t} 08$ & 0.032 & $\mathrm{mcm} 001 \mathrm{t} 07$ & 0.034 & usi001t $26 x$ & 0.031 \\
\hline lct049t03 & 0.096 & mcm001t09 & 0.032 & mcm001t06 & 0.034 & imf006 & 0.030 \\
\hline lct049t04 & 0.096 & $\mathrm{mcm} 001 \mathrm{t} 03$ & 0.032 & $\operatorname{mcm} 001 \mathrm{t} 10$ & 0.033 & usi001t13x & 0.030 \\
\hline hst042-05 & 0.090 & $\mathrm{mcm} 001 \mathrm{t} 06$ & 0.032 & umf006t00x & 0.033 & ust015t03x & 0.030 \\
\hline hst042-07 & 0.079 & $\mathrm{mcm} 001 \mathrm{t} 07$ & 0.032 & $\mathrm{mcm} 001 \mathrm{t} 04$ & 0.033 & ust015t21x & 0.030 \\
\hline hst042-08 & 0.062 & $\mathrm{mcm} 001 \mathrm{t} 04$ & 0.031 & $\mathrm{mcm} 001 \mathrm{t} 03$ & 0.033 & ust $015 \mathrm{t} 22 \mathrm{x}$ & 0.030 \\
\hline lct017-18 & 0.046 & imf004 & 0.031 & mcm001t05 & 0.032 & imf003 & 0.030 \\
\hline $\mathrm{mcm} 001 \mathrm{t} 08$ & 0.033 & $\mathrm{mcm} 001 \mathrm{t} 05$ & 0.031 & mcm001t11 & 0.032 & ust $015 \mathrm{t} 13 \mathrm{x}$ & 0.029 \\
\hline mem001t09 & 0.033 & mcm001t11 & 0.030 & umf003t $02 x$ & 0.032 & usi001t $25 x$ & 0.029 \\
\hline $\mathrm{mcm} 001 \mathrm{t} 03$ & 0.033 & mcm001t17 & 0.030 & mcm001t14 & 0.032 & usi001t $01 x$ & 0.028 \\
\hline $\mathrm{mcm} 001 \mathrm{t} 06$ & 0.032 & mcm001t14 & 0.030 & mem001t19 & 0.032 & ust 015 t $02 x$ & 0.028 \\
\hline
\end{tabular}




\begin{tabular}{|c|c|c|c|c|c|c|c|}
\hline \multicolumn{2}{|c|}{ Application 1} & \multicolumn{2}{|c|}{ Application 2} & \multicolumn{2}{|c|}{ Application 3} & \multicolumn{2}{|c|}{ Application 4} \\
\hline Exp. ID & $\mathrm{c}_{\mathrm{r}}$ & Exp. ID & $\mathrm{c}_{\mathrm{r}}$ & Exp. ID & $\mathrm{c}_{\mathrm{r}}$ & Exp. ID & $\mathrm{c}_{\mathrm{r}}$ \\
\hline $\mathrm{mcm} 001 \mathrm{t} 07$ & 0.032 & mcm001t19 & 0.030 & $\mathrm{mcm} 001 \mathrm{t} 17$ & 0.032 & ust015t12x & 0.028 \\
\hline mcm001t04 & 0.032 & $\mathrm{mcm} 001 \mathrm{t} 10$ & 0.030 & $\mathrm{mcm} 001 \mathrm{t} 18$ & 0.032 & usi001t12x & 0.028 \\
\hline $\mathrm{mcm} 001 \mathrm{t} 05$ & 0.031 & $\operatorname{mcm} 001 \mathrm{t} 18$ & 0.030 & $\mathrm{mcm} 001 \mathrm{t} 12$ & 0.032 & ust015t11x & 0.028 \\
\hline mcm001t11 & 0.031 & mcm001t12 & 0.030 & umf003t01x & 0.031 & usi001t24x & 0.027 \\
\hline $\operatorname{mcm} 001 \mathrm{t} 17$ & 0.031 & mcm001t15 & 0.029 & mcm001t15 & 0.031 & ust015t01x & 0.027 \\
\hline $\mathrm{mcm} 001 \mathrm{t} 14$ & 0.031 & imf006 & 0.029 & $\mathrm{mcm} 001 \mathrm{t} 13$ & 0.031 & $\mathrm{mmf008t03}$ & 0.019 \\
\hline mem001t19 & 0.031 & imf003 & 0.029 & umf005t02x & 0.031 & imf005 & 0.019 \\
\hline $\mathrm{mcm} 001 \mathrm{t} 10$ & 0.030 & $\mathrm{mcm} 001 \mathrm{t} 13$ & 0.028 & umf002t01x & 0.031 & mmf008t01 & 0.016 \\
\hline $\mathrm{mcm} 001 \mathrm{t} 18$ & 0.030 & $\mathrm{mcm} 001 \mathrm{t} 16$ & 0.027 & umf002t02x & 0.031 & mmf008t06 & 0.015 \\
\hline $\mathrm{mcm} 001 \mathrm{t} 12$ & 0.030 & mmf008t07 & 0.026 & umf005t01x & 0.031 & mmf008t04 & 0.009 \\
\hline mem001t15 & 0.029 & umf002t01x & 0.021 & umf004t01x & 0.030 & mcf001t01 & 0.005 \\
\hline $\mathrm{mcm} 001 \mathrm{t} 13$ & 0.029 & umf002t02x & 0.020 & $\mathrm{mcm} 001 \mathrm{t} 16$ & 0.030 & $\mathrm{mmf008t02}$ & 0.005 \\
\hline $\mathrm{mcm} 001 \mathrm{t} 16$ & 0.027 & mcm001t01 & 0.019 & umf001t00x & 0.030 & mcm001t03 & 0.004 \\
\hline $\mathrm{mcm} 001 \mathrm{t} 01$ & 0.018 & umf005t01x & 0.019 & umf004t02x & 0.030 & $\mathrm{mcm} 001 \mathrm{t} 04$ & 0.004 \\
\hline $\mathrm{mcm} 001 \mathrm{t} 02$ & 0.018 & umf005t02x & 0.019 & $\mathrm{mcm} 001 \mathrm{t} 01$ & 0.024 & $\mathrm{mcm} 001 \mathrm{t} 05$ & 0.004 \\
\hline imf003 & 0.004 & umf006t00x & 0.019 & $\mathrm{mcm} 001 \mathrm{t} 02$ & 0.023 & $\mathrm{mcm} 001 \mathrm{t} 06$ & 0.004 \\
\hline imf004 & 0.004 & $\mathrm{mcm} 001 \mathrm{t} 02$ & 0.019 & $\mathrm{hmt} 025 \mathrm{t} 02$ & 0.012 & mcm001t07 & 0.004 \\
\hline imf006 & 0.004 & umf003t01x & 0.019 & $\mathrm{hmt} 025 \mathrm{t} 01$ & 0.011 & mcm001t08 & 0.004 \\
\hline $\mathrm{hmf030t00}$ & 0.002 & umf003t02x & 0.019 & imf006 & 0.009 & mcm001t09 & 0.004 \\
\hline imf005 & 0.002 & umf001t00x & 0.019 & het010-05 & 0.009 & mcm001t 10 & 0.004 \\
\hline $\mathrm{hmt} 025 \mathrm{t} 02$ & 0.002 & umf004t01x & 0.018 & imf003 & 0.009 & mcm001t11 & 0.004 \\
\hline $\mathrm{hmt} 025 \mathrm{t} 01$ & 0.001 & umf004t02x & 0.018 & imf004 & 0.009 & mcm001t14 & 0.004 \\
\hline $\mathrm{mmf008t07}$ & 0.001 & imf005 & 0.018 & $\mathrm{mmf} 008 \mathrm{t} 01$ & 0.009 & $\mathrm{mcm} 001 \mathrm{t} 17$ & 0.004 \\
\hline $\mathrm{mmf} 008 \mathrm{t} 01$ & 0.000 & $\mathrm{mmf} 008 \mathrm{t} 01$ & 0.016 & $\mathrm{mmf008t06}$ & 0.006 & $\mathrm{mcm} 001 \mathrm{t} 18$ & 0.004 \\
\hline $\mathrm{mmf} 008 \mathrm{t} 03$ & 0.000 & $\mathrm{mmf008t04}$ & 0.008 & $\mathrm{mmf008t04}$ & 0.005 & mcm001t19 & 0.004 \\
\hline $\mathrm{mmf008t05}$ & 0.000 & $\mathrm{mmf} 008 \mathrm{t} 03$ & 0.007 & hmf030t00 & 0.005 & mem001t12 & 0.004 \\
\hline $\mathrm{mmf008t02}$ & -0.001 & $\mathrm{mmf} 008 \mathrm{t} 02$ & 0.003 & imf005 & 0.005 & $\mathrm{mcm} 001 \mathrm{t} 13$ & 0.004 \\
\hline $\mathrm{mmf008t04}$ & -0.001 & mmf008t06 & 0.001 & mcf001t01 & 0.005 & mem001t15 & 0.004 \\
\hline mcf001t01 & -0.002 & $\mathrm{mmf008t05}$ & 0.000 & $\mathrm{mmf} 008 \mathrm{t} 03$ & 0.005 & $\mathrm{mcm} 001 \mathrm{t} 16$ & 0.004 \\
\hline $\mathrm{mmf008t06}$ & -0.013 & mcf001t01 & 0.000 & $\mathrm{mmf008t07}$ & 0.003 & $\mathrm{mcm} 001 \mathrm{t} 01$ & 0.004 \\
\hline $\operatorname{mci005t00}$ & -0.024 & mci005t00 & -0.005 & $\mathrm{mmf008t02}$ & 0.002 & $\mathrm{mcm} 001 \mathrm{t} 02$ & 0.004 \\
\hline hct010-05 & -0.408 & hct010-05 & -0.071 & mmf008t05 & 0.000 & mmf008t05 & 0.001 \\
\hline
\end{tabular}





\section{APPENDIX E}

EXAMPLE USLSTATS INPUT FILE FOR APPLICATION 1, CASE 4 

USLSTATS input file for USL case 4 - EALF trending of experiments with $\mathrm{c}_{\mathrm{r}} \geq 0.95$. Experiment and Monte-Carlo uncertainties are included for each experiment.

\begin{tabular}{|c|c|c|c|}
\hline$\odot .999 \quad 0 . \varsigma$ & $50 \quad 0.950$ & $0 . \odot \quad 0.00 \odot-1$ & 0.02 \\
\hline $2.82 \mathrm{E}-1$ & 1.00928 & $\odot .00304$ & \\
\hline $2.83 E-1$ & 1.00930 & 0.00413 & \\
\hline $2.83 \mathrm{E}-1$ & 1.01064 & 0.00473 & \\
\hline $2.94 \mathrm{E}-1$ & ๑. 99696 & 0.00353 & \\
\hline $2.94 \mathrm{E}-1$ & ๑. 99615 & 0.00354 & \\
\hline $2.95 \mathrm{E}-1$ & 0.99404 & 0.00353 & \\
\hline $2.95 \mathrm{E}-1$ & 0.99513 & 0.00353 & \\
\hline 1. $54 \mathrm{E}-1$ & 1.01114 & 0.00732 & \\
\hline 1. $54 \mathrm{E}-1$ & 1.01196 & $\odot .00702$ & \\
\hline 1. $54 \mathrm{E}-1$ & 1.01202 & 0.00692 & \\
\hline $1.54 \mathrm{E}-1$ & 1.01261 & 0.00732 & \\
\hline 1. $54 \mathrm{E}-1$ & 1.01321 & 0.00672 & \\
\hline $2.86 \mathrm{E}-1$ & 1.00118 & 0.00344 & \\
\hline $2.85 E-1$ & 1.00086 & $\odot .0 \odot 275$ & \\
\hline $2.86 \mathrm{E}-1$ & ๑. 99987 & 0.00344 & \\
\hline $2.86 \mathrm{E}-1$ & $\odot .99956$ & 0.00284 & \\
\hline 1. $47 \mathrm{E}-1$ & 1.01321 & $\odot .00502$ & \\
\hline 1. $47 \mathrm{E}-1$ & 1.01180 & 0.00542 & \\
\hline $1.47 \mathrm{E}-1$ & 1.01370 & $\odot .0 \odot 5 \odot 2$ & \\
\hline 1. $47 \mathrm{E}-1$ & 1.01319 & 0.00453 & \\
\hline 1. $47 \mathrm{E}-1$ & 1.01094 & 0.00542 & \\
\hline 1. $47 \mathrm{E}-1$ & 1.01275 & $\odot .00502$ & \\
\hline $1.47 \mathrm{E}-1$ & 1.00953 & $\odot .00621$ & \\
\hline 1. $47 \mathrm{E}-1$ & 1.01267 & ๑. 00512 & \\
\hline 1. $47 \mathrm{E}-1$ & 1.01419 & 0.00463 & \\
\hline 1. $41 \mathrm{E}-1$ & 1.01368 & 0.00284 & \\
\hline 1. $41 \mathrm{E}-1$ & 1.01477 & 0.00344 & \\
\hline 1. $41 \mathrm{E}-1$ & 1.01417 & 0.00314 & \\
\hline 1. $41 \mathrm{E}-1$ & 1.01378 & 0.00245 & \\
\hline $1.70 \mathrm{E}-1$ & 1.00288 & $\odot .00284$ & \\
\hline 1. $62 \mathrm{E}-1$ & 1.00250 & 0.00255 & \\
\hline 1. $42 \mathrm{E}-1$ & 1. 01016 & 0.00363 & \\
\hline 1. $42 \mathrm{E}-1$ & 1.00916 & 0.00265 & \\
\hline 1. $42 \mathrm{E}-1$ & 1.01155 & $\odot .00275$ & \\
\hline $1.44 \mathrm{E}-1$ & 1.01299 & $\odot .00235$ & \\
\hline $2.98 \mathrm{E}-1$ & 0.99311 & 0.00353 & \\
\hline $2.98 \mathrm{E}-1$ & $\odot .99349$ & 0.00354 & \\
\hline $2.98 \mathrm{E}-1$ & 0.99377 & 0.00353 & \\
\hline 1. $03 \mathrm{E}-1$ & 1.02717 & $\odot .00772$ & \\
\hline $2.86 \mathrm{E}-1$ & 1.01073 & 0.00373 & \\
\hline $2.86 \mathrm{E}-1$ & 1.00536 & 0.00353 & \\
\hline $2.86 \mathrm{E}-1$ & 1.00981 & $\odot .0 \odot 443$ & \\
\hline $2.86 \mathrm{E}-1$ & 1.00998 & ๑. .00363 & \\
\hline 1. $06 \mathrm{E}-1$ & 1.00922 & 0.00353 & \\
\hline 1. $05 \mathrm{E}-1$ & 1.00534 & ๑. .00153 & \\
\hline 1. $43 \mathrm{E}-1$ & $\odot .99973$ & ๑. .0०354 & \\
\hline 1. $43 \mathrm{E}-1$ & 1.01344 & ๑. .0314 & \\
\hline $1.43 \mathrm{E}-1$ & $1.00 \odot 76$ & 0.00363 & \\
\hline 1. $44 \mathrm{E}-1$ & ๑. 99892 & $\odot .0 \odot 284$ & \\
\hline $1.10 \mathrm{E}-1$ & $\odot .99787$ & ๑. .००255 & \\
\hline $8.55 \mathrm{E}-1$ & 1.00149 & ๑.00354 & \\
\hline
\end{tabular}




\begin{tabular}{|c|c|c|}
\hline$E-1$ & 9883 & -4 \\
\hline $7 E-1$ & 0.99700 & 035 \\
\hline $4 \mathrm{E}-1$ & $\odot \odot 179$ & 00354 \\
\hline$E-2$ & & \\
\hline & & \\
\hline$E-1$ & 1.00123 & \\
\hline$E-1$ & 1.00719 & 03 \\
\hline . $02 \mathrm{E}-1$ & 0.98629 & \\
\hline $\mathrm{E}-2$ & 1.00755 & 0712 \\
\hline$E-2$ & 1.0 & \\
\hline$E-1$ & 1.6 & $\odot$ \\
\hline$E-2$ & 1.00585 & 0 \\
\hline$E-2$ & 1.0 & \\
\hline E-2 & 1.00646 & \\
\hline$E-2$ & 1.0 & \\
\hline$E-2$ & 1.0 & $\odot$ \\
\hline$E-2$ & 1.0 & $\odot$ \\
\hline$E-1$ & $\odot .99530$ & 035 \\
\hline$E-1$ & 0.9 & \\
\hline$E-1$ & $0 . \varsigma$ & \\
\hline$E-2$ & 1.0 & \\
\hline$E-2$ & 1.0 & $\odot$. \\
\hline $.12 \mathrm{E}+\Theta$ & 0.99322 & 051 \\
\hline $8.13 E-2$ & 1.00939 & 04 \\
\hline $6.40 \mathrm{E}-1$ & ๑. 99971 & 0.0112 \\
\hline $7.81 \mathrm{E}-1$ & $\odot .99070$ & $\odot .0070$ \\
\hline $7.89 E-2$ & 1.00268 & \\
\hline L. $37 \mathrm{E}-1$ & 1.00008 & $\Theta$. \\
\hline $.71 \mathrm{E}-1$ & 1.00349 & 0 \\
\hline & 0.99262 & \\
\hline & 006 & \\
\hline
\end{tabular}


